\title{
LONELINESS, CONNECTIVITY, AND PLACE IN NEW ZEALAND
}

\author{
by \\ Rebekah Smith
}

\begin{abstract}
A thesis
submitted to the Victoria University of Wellington in partial fulfillment of the requirements for the degree of Masters of Science in Human Geography
\end{abstract}

Victoria University of Wellington

2015 


\section{Abstract}

Loneliness is widespread - 31 percent of New Zealanders reported being lonely a little, some, most, or all of the time in 2012, which equates to approximately 1.3 million New Zealanders. Loneliness is firstly an individual problem associated with corrosive health outcomes such as depression, and suicide. It is also a social problem because of the way social exclusion inhibits community wellbeing.

Loneliness is a reflection of both an objective condition and a subjective condition. The former reflects measures of the number and depth of social contact, and the later captures how people feel and judge their own level of loneliness. Typically, loneliness as a condition is 'being alone and not liking it'.

The majority of research attention, both internationally, as well as in New Zealand, has been paid to loneliness among the old. What my thesis shows is that loneliness is not confined to a particular age group but widespread across all ages, and is in fact highest among the young and declines with age. Therefore, studies of loneliness are most appropriately based on population-wide surveys so that its prevalence across all age and socio-economic groups can be addressed. At the same time, particular attention now needs to be paid to the young. For this reason I apply statistical models of loneliness to two separate data sets: the 2012 New Zealand General Social Survey, and a sample of youth in Wellington, Taranaki and Auckland as provided by the 2006 Youth Connectedness Project.

My analysis of these two samples focuses on the relationship between objective measures of social connection and the subjective expression of loneliness itself. I show that while loneliness decreases with the level of social connection, it is also 
subject to considerable variation across a range of covariates. These include, most importantly, age, gender, socioeconomic status and health.

Connectivity also has a number of geographical properties which render this topic of interest to the human geographer. Among these are proximity - the readily availability of family and friends for regular face-to-face contact, as well as the ability to easily access and contribute to the local community. These are matters of geographic context which is addressed in several ways, including through a GIS analysis.

My primary finding has to do with the cumulative nature of connectedness. Over and above the separate effect of having a partner, local family, and friends, is the importance of their combined and cumulative effect in reducing loneliness, a feature which reinforces the importance of the concept of community.

I find that the young, females, migrants, the poor, and people in poor health are more likely to be lonely, particularly when these attributes combine. In terms of geographical context, residents of main urban areas, and in lower socioeconomic areas show a higher likelihood of being lonely in both datasets. However GIS results for the City of Wellington show that lonely youth show no evidence of spatially clustering in ways that would imply social exclusion in a geographic sense.

My analysis takes place against a backdrop of widespread concern about social connection in general, about the growing role of non-face-to-face communication among the young, about the dislocating effects of marital instability, and the supporting role of families both for the young and the old. None of my results dispel these concerns. What my results suggest is the need for a focused attention on the nature of social connections in particular contexts, and the way they evolve over time. 


\section{Acknowledgements}

I would first like to thank my supervisor, Professor Philip Morrison, for his steadfast confidence in this project, teaching me the art of quantitative analysis, and for affording me the many opportunities that made the Masters process both achievable and enjoyable. I would also like to thank Philip for his assistance in addressing the technical aspects of discrete modelling in Chapter 4 and Appendix 4.

I would also like to give thanks to Dr Jaimee Stuart and Dr Paul Jose for the opportunity to bring a geographical perspective to the 2006 Youth Connectedness Project dataset. I also thank Statistics New Zealand for access to the 2012 New Zealand General Social Survey, which was granted through my supervisor.

I have benefited greatly from the support and feedback given by my mother and father, Nicky, my sisters Alexandra and Kaitlyn, and my brother-in-law Sam. I would like to thank Tamsin Fisher, and also Rachel Riedel, Wellbeing Educator, Counselling Service, Victoria University of Wellington, for their helpful and encouraging feedback.

My sincerest appreciation goes to Matt, whose love, wisdom, and constant conversation about statistics has taught me just how important meaningful social contact really is. 


\section{Table of contents}

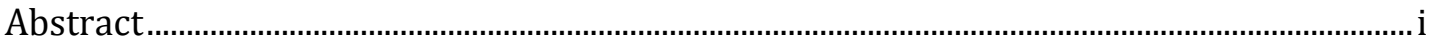

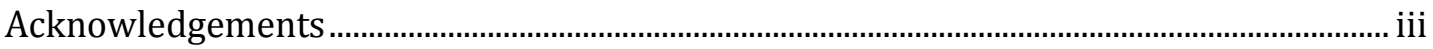

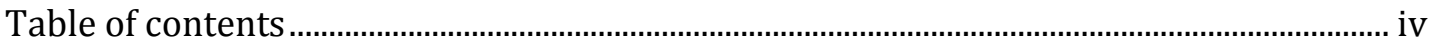

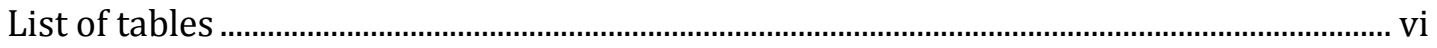

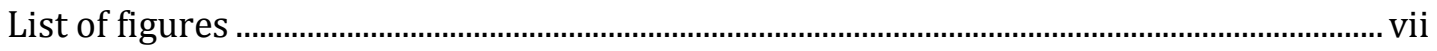

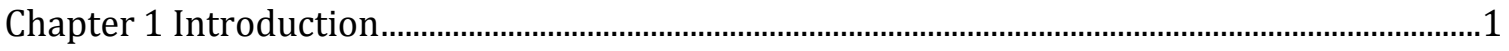

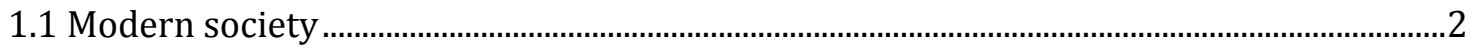

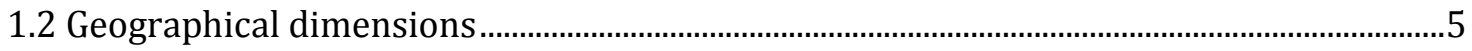

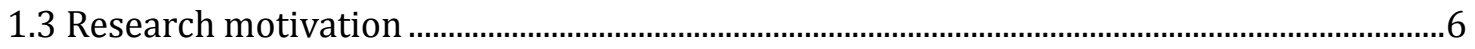

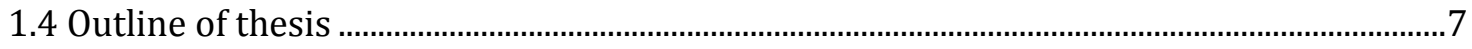

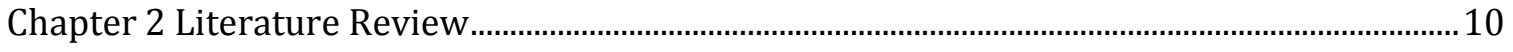

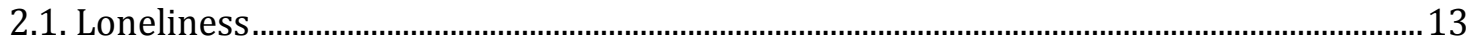

2.2. Loneliness and Youth............................................................................................................ 24

2.3. Place

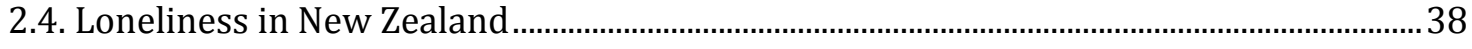

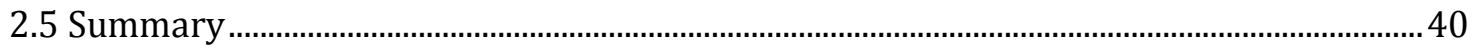

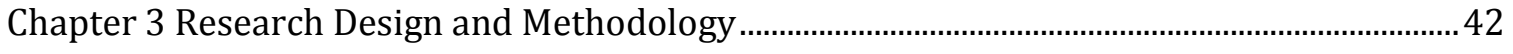

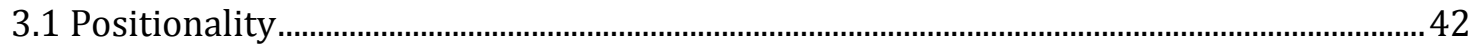

3.2 Epistemology

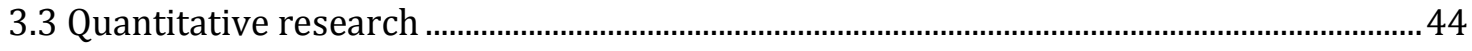

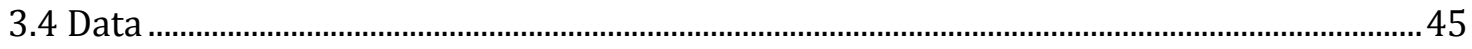

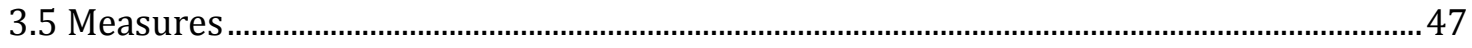

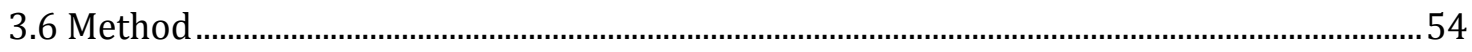




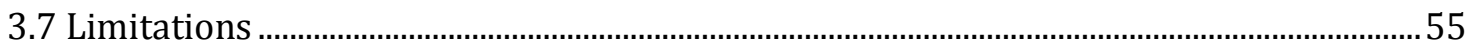

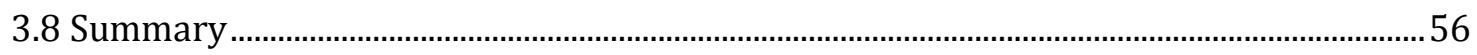

Chapter 4 Adult loneliness in New Zealand...................................................................................... 57

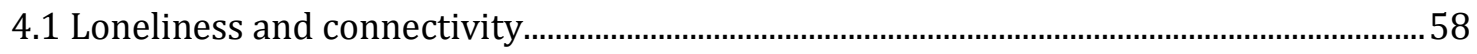

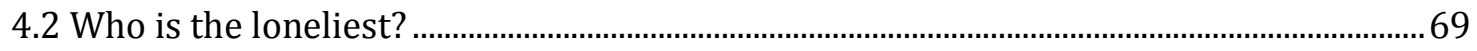

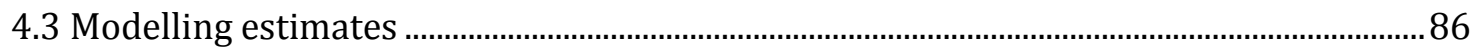

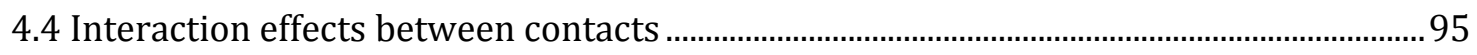

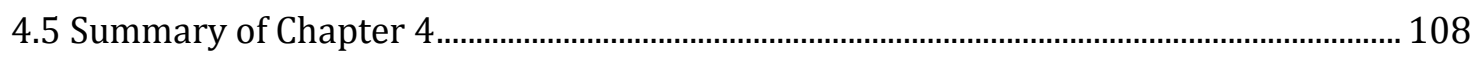

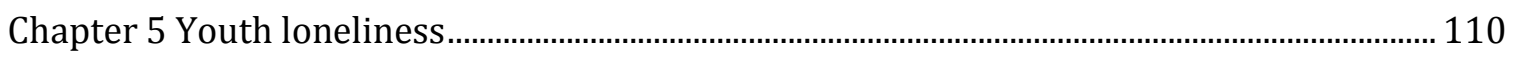

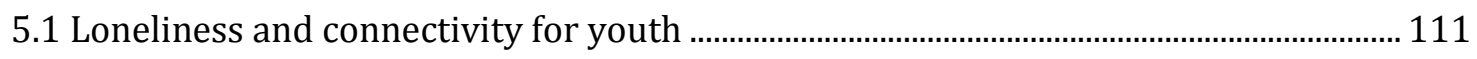

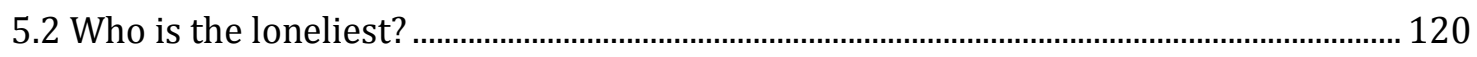

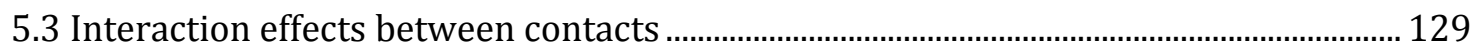

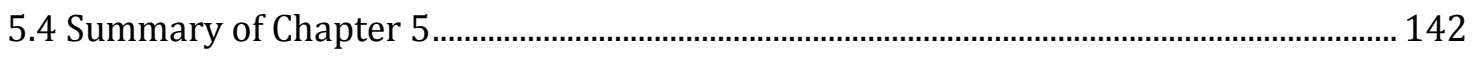

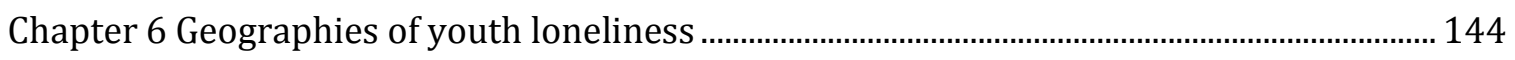

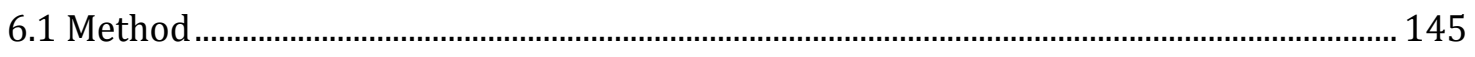

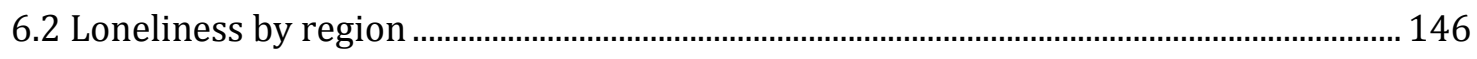

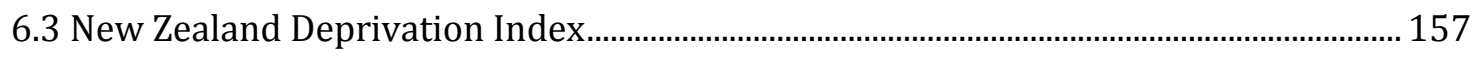

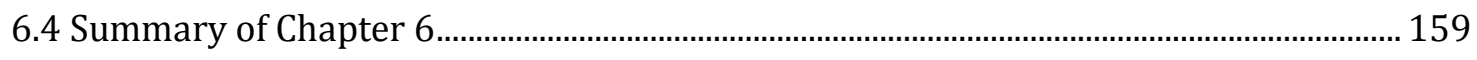

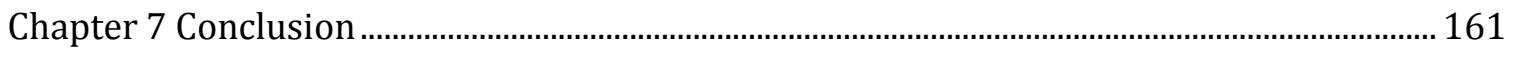

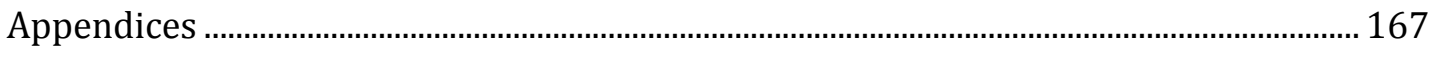

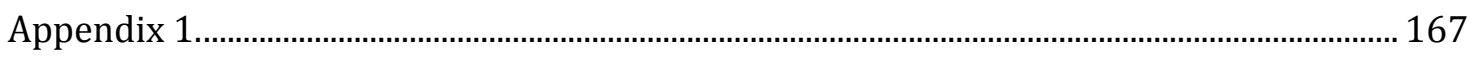

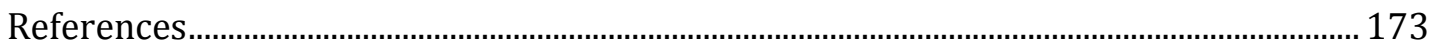




\section{List of tables}

TABLE 4.1: DESCRIPTION OF THE LONELINESS VARIABLE, NEW ZEALAND 2012 ………….........................................59

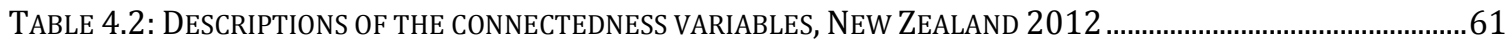

TABLE 4.3: DISTRIBUTION OF RESPONSES TO THE NUMBER OF TYPES OF CONTACT A PERSON HAS, NEW ZEALAND

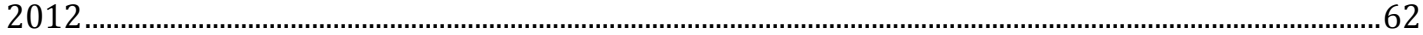

TABLE 4.4: THE ESTIMATED RELATIONSHIP OF LONELINESS TO THE CONNECTIVITY INDEX, NZGSS (2012) ..............65

TABLE 4.5: THE ESTIMATED QUADRATIC RELATIONSHIP BETWEEN LONELINESS AND CONNECTIVITY, NZGSS (2012)

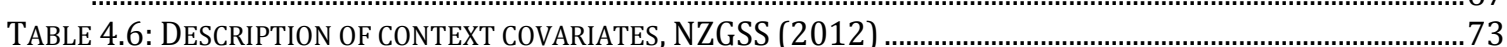

TABLE 4.7: MODEL OF LONELINESS CONTROLLING FOR CONTEXT, NEW ZEALAND 2012 ……………………………....74

TABLE 4.8: DESCRIPTION TABLE OF DEMOGRAPHIC VARIABLES, NZGSS (2012)........................................................76

TABLE 4.9: MODELS OF LONELINESS CONTROLLING FOR CONTEXT, AND DEMOGRAPHICS, NEW ZEALAND 2012 .........77

TABLE 4.10: DESCRIPTION TABLE OF ACHIEVED VARIABLES, NZGSS (2012) ……………………………………...8

TABLE 4.11: MODELS OF LONELINESS, CONTROLLING FOR CONTEXT, DEMOGRAPHICS, AND ACHIEVEMENT VARIABLES,

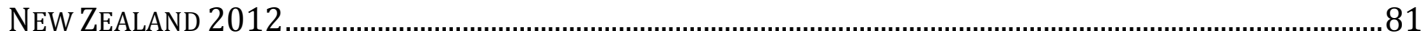

TABLE 4.12: DESCRIPTION TABLE OF DEPRESSION VARIABLE, NZGSS (2012) ............................................................ 84

TABLE 4.13: MODELS OF LONELINESS CONTROLLING FOR CONTEXT, DEMOGRAPHICS, ACHIEVEMENT, AND DEPRESSION,

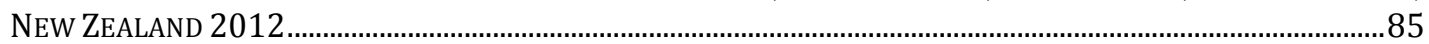

TABLE 4.14: INTERACTION EFFECTS BETWEEN IN PERSON CONTACT AND NON-FACE-TO-FACE CONTACT WITH FRIENDS,

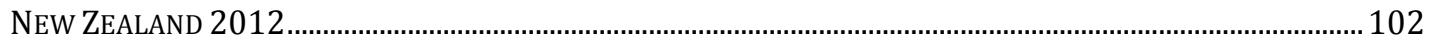

TABLE 4.15: INTERACTION EFFECTS BETWEEN PARTNERSHIP, AND CONTACT WITH FRIENDS AND FAMILY, NEW

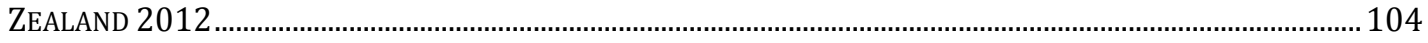

TABLE 4.16: INTERACTION EFFECTS BETWEEN PARTNERSHIP, CONTACT WITH FRIENDS AND FAMILY, AND PARTICIPATION IN GROUPS, NEW ZEALAND 2012 …………..................................................................... 107

TABLE 5.1: DESCRIPTION OF THE LONELINESS VARIABLE, YCP (2006) ……………….........................................112

TABLE 5.2: DESCRIPTION OF THE CONNECTEDNESS VARIABLES, YCP (2006) ......................................................... 114

TABLE 5.3: DISTRIBUTION OF RESPONSES TO THE NUMBER OF TYPES OF CONTACT A YOUNG PERSON HAS, NEW ZEALAND 2006

TABLE 5.4: DESCRIPTION OF CONTEXT COVARIATE, YCP (2006)......................................................................... 121

TABLE 5.5: MODELS OF LONELINESS CONTROLLING FOR CONTEXT, NEW ZEALAND 2006.................................................122

TABLE 5.6: DESCRIPTION TABLE OF DEMOGRAPHIC VARIABLES, NEW ZEALAND 2006 ……..................................123

TABLE 5.7: MODELS OF LONELINESS CONTROLLING FOR CONTEXT, AND DEMOGRAPHICS, NEW ZEALAND 2006 ......124

TABLE 5.8: DESCRIPTION TABLE OF ACHIEVED VARIABLES, NEW ZEALAND 2006 ………….................................... 125

TABLE 5.9: MODELS OF LONELINESS CONTROLLING FOR CONTEXT, DEMOGRAPHICS, AND ACHIEVEMENT VARIABLES,

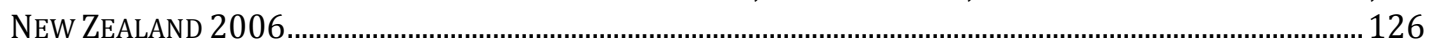

TABLE 5.10: DESCRIPTION TABLE OF SELF-HARMING VARIABLE, NEW ZEALAND 2006 ........................................... 128

TABLE 5.11: MODELS OF LONELINESS CONTROLLING FOR CONTEXT, DEMOGRAPHICS, ACHIEVEMENT, AND SELF HARM,

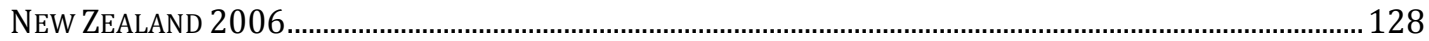

TABLE 5.12: INTERACTION EFFECTS BETWEEN CLOSE FRIENDS AND NET FRIENDS, NEW ZEALAND 2006 ................136

TABLE 5.13: INTERACTION EFFECTS BETWEEN CLOSE FRIENDS, GETTING ALONG WITH CLASSMATES, AND FAMILY COHESION, NEW ZEALAND 2006......................................................................................................... 138

TABLE 5.14: INTERACTION EFFECTS BETWEEN FRIENDS, FAMILY, CLASSMATES AND NEIGHBOURHOOD

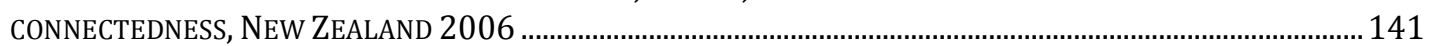

TABLE 6.1: LONELINESS LEVELS BY LEVELS OF DEPRIVATION FOR YOUTH, NEW ZEALAND 2006 ..............................159 


\section{List of figures}

FIGURE 2.1 THE PROGRESSION OF LONELINESS MENTIONS IN LITERATURE 1800-2008 …..........................................12

FIGURE 3.1: THE RESEARCH WHEEL OF POSITIVISM ...................................................................................................

FIGURE 3.2: PREDICTED RELATIONSHIP BETWEEN LONELINESS AND CONNECTIVITY.................................................51

FIGURE 4.1: FREQUENCY DISTRIBUTION OF THE NUMBER OF TYPES OF CONTACT, NEW ZEALAND 2012 ......................63

FIGURE 4.2: HOW LONELINESS FALLS WITH INCREASED TIME SPENT WITH FRIENDS, NEW ZEALAND 2012 .................64

FIGURE 4.3: HOW LONELINESS FALLS WITH INCREASED QUALITY OF FRIENDSHIPS, NEW ZEALAND 2012 ...................65

FIGURE 4.4: THREE POSSIBLE FUNCTIONAL FORMS LINKING LONELINESS AND THE CONNECTIVITY INDEX....................67

FIGURE 4.5: HOW LONELINESS FALLS WITH THE NUMBER OF DIFFERENT TYPES OF CONTACTS, NEW ZEALAND 201268

FIGURE 4.6: HOW THE PROBABILITY OF BEING LONELY FALLS WITH AGE, NEW ZEALAND 2012 .....................................78

FIGURE 4.7: GRAPHICAL REPRESENTATIONS OF HOW MODELS 1-4 CHANGE WITH THE ADDITION OF CONTROLS FROM

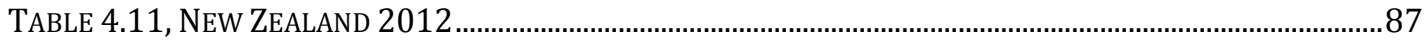

FIGURE 4.8: GRAPHICAL REPRESENTATIONS OF HOW MODELS 5-7 CHANGE WITH THE ADDITION OF CONTROLS FROM

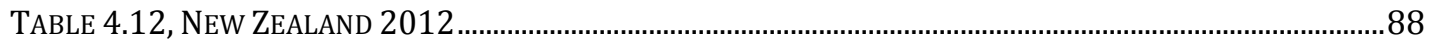

FIGURE 4.9: GRAPHICAL REPRESENTATIONS OF HOW MODELS 8-10 CHANGE WITH THE ADDITION OF CONTROLS FROM

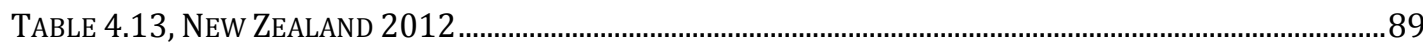

FIGURE 4.10: GRAPHICAL REPRESENTATIONS OF HOW MODELS 11-13 CHANGE WITH THE ADDITION OF CONTROLS

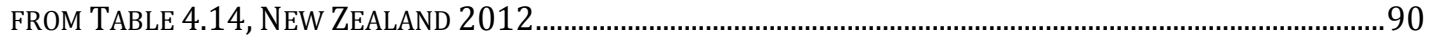

FIGURE 4.11: GRAPHICAL REPRESENTATIONS OF MODEL 13 BROKEN DOWN BY GENDER, NEW ZEALAND 2012 .........92

FIGURE 4.12: GRAPHICAL REPRESENTATIONS OF MODEL 13 BROKEN DOWN BY AGE, NEW ZEALAND 2012 ...............94

FIGURE 4.13: GRAPHICAL REPRESENTATION OF INTERACTION EFFECTS BETWEEN IN PERSON AND NON-FACE-TO-FACE CONTACT WITH FRIENDS, WITH A 95\% CONFIDENCE INTERVAL, NEW ZEALAND 2012 .................................... 103

FIGURE 4.14: GRAPHICAL REPRESENTATION OF INTERACTION EFFECTS BETWEEN PARTNERSHIP, AND CONTACT WITH

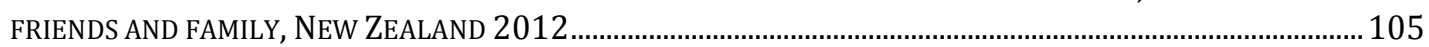

FIGURE 5.1: FREQUENCY DISTRIBUTION OF THE NUMBER OF TYPES OF CONTACT, NEW ZEALAND 2006....................116

FIGURE 5.2: HOW LONELINESS FALLS WITH QUALITY OF CONNECTION, NEW ZEALAND 2006 ...................................117

FIGURE 5.3: HOW LONELINESS FALLS WITH CONNECTIVITY, NEW ZEALAND 2006 .................................................119

FIGURE 5.4: GRAPHICAL REPRESENTATION OF INTERACTIONS BETWEEN CLOSE FRIENDS AND NET FRIENDS, NEW

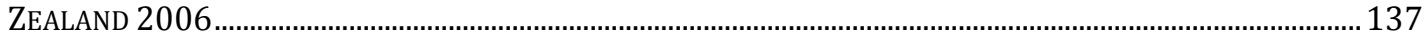

FIGURE 5.5: GRAPHICAL REPRESENTATION OF THE INTERACTION EFFECTS BETWEEN CLOSE FRIENDS, GETTING ALONG

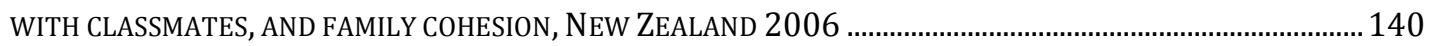

FIGURE 6.1: THE SPATIAL DISTRIBUTION OF RESIDENCES REPORTED BY YOUNG PEOPLE WHO TOOK PART IN THE YCP

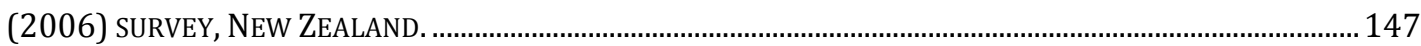

FigURE 6.2: DisTRIBUTION OF LONELINESS OF YOUTH IN THE WELLINGTON REGION, YCP (2006)..........................148

FIGURE 6.3: HOW SPATIALLY CORRELATED YOUTH LONELINESS LEVELS ARE, NEW ZEALAND 2006...........................150

FIGURE 6.4: DISPERSED NATURE OF THE DISTRIBUTION OF LONELINESS, YCP (2006) ...........................................151

FIGURE 6.5: THE DISTRIBUTION OF LONELINESS OF YOUTH ON THE KAPITI COAST, YCP (2006) ............................... 152

FIGURE 6.6: THE DISTRIBUTION OF LONELINESS OF YOUTH IN THE WAIRARAPA, YCP (2006) .................................. 153

FIGURE 6.7: THE DISTRIBUTION OF LONELINESS OF YOUTH IN AUCKLAND, YCP (2006)..........................................154

FIGURE 6.8: THE DISTRIBUTION OF LONELINESS OF YOUTH IN TARANAKI, YCP (2006)............................................ 155

FIGURE 6.9: VISUAL REPRESENTATION OF THE NEW ZEALAND DEPRIVATION INDEX, IN RELATION TO PARTICIPANT'S LONELINESS LEVELS, NEW ZEALAND 2006 ...............................................................................................158 


\title{
Chapter 1 Introduction
}

\author{
"Happiness with other people \\ seems bounded by two kinds of \\ excess: suffocation and loneliness" \\ - Alain de Botton (1995, \\ p.110)
}

Recently, the experience of loneliness has received increased attention internationally, contrasting an opinion held by Ouellette (2001) who suggested loneliness is rarely viewed as a psychological condition worthy of research. It is now widely understood that humans require satisfying connections with other human beings to feel as though they belong. According to Ernst and Cacioppo, loneliness is "a complex set of feelings encompassing reactions to the absence of intimate and social needs" (1999, p. 1).

Writing in a leading geography journal, Geografiska Annaler, Franklin suggests that loneliness has become more widespread in modern society, and that this "trend has important social costs and policy significance, since loneliness has been linked to corrosive impacts on physical and mental health, the functionality of communities and city life, and overall feelings of happiness and satisfaction" (2012, p. 12). In the same view, the Guardian speaks of a loneliness epidemic taking place in the United Kingdom and labels a "silent plague" (Gil, 2014). Others are calling the past decade 'The Age of Loneliness.' For example, The Guardian journalist George Monbiot controversially reported:

"Ebola is unlikely ever to kill as many people as this disease strikes down. Social isolation is as potent a cause of early death as smoking 15 cigarettes a day; loneliness, research suggests, is twice as deadly as obesity. Dementia, high blood pressure, alcoholism and accidents - all these, like depression, paranoia, anxiety and suicide, become more prevalent when connections are cut. We cannot cope alone" (Monbiot, 2014, p. 4). 
Hawkley, Burleson, Berntson, and Cacioppo (2003) found that feelings of loneliness are associated with adverse effects on a person's heart function. These serious consequences of loneliness raise important questions about why this may be occurring.

Research universally tends to show that loneliness is more prevalent among the young (people below the age of 29), and tends to decline with age (Rubenstein, Shaver and Peplau, 1979; Brennan, 1982; Brennan and Auslander, 1979). This finding is becoming widely recognised as being an important issue to address, both nationally and internationally, with many academics outlining their concern for younger generations (Goosby, Bellatorre, Walsemann, and Cheadle, 2013). However, loneliness for youth still constitutes only a small proportion of studies across the wide range of literature regarding loneliness. In their study of the health consequences of loneliness, Goosby et al. wrote that the exclusion of loneliness in the literature on early years of life "somewhat curious" because loneliness is "an eminently social-psychological construct, reflecting how people experience the communal aspects of their social worlds" (2013, p. 505).

\subsection{Modern society}

Many researchers have asked what it is about our current culture that makes so many people vulnerable to loneliness, compared to past generations. Jean Twenge, wrote Generation Me, incorporating the latest research, data, and statistics, to show the individualisation of the modern society. She states that "more than four times as many Americans describe themselves as lonely now than in 1957" (2006, p. 110). In recent times, she notes, "we're malnourished from eating a junk food diet of instant messaging, e-mail and phone calls, rather than the healthy food of live, in-person interaction" (2006, p.110). Twenge (2006) writes about her friend Peter, who moved cities and spent most of his time watching movies. She argues that he is not the only one who spends most of their time by themselves (Twenge, 2006). 
Of particular interest in this thesis is the way high rates of loneliness shine light on the nature of socialisation in the modern era (Franklin, 2012). Dr Andrew McCulloch, chief executive of the UK Mental Health Foundation, interviewed by Barford (2013), a reporter for BBC News Magazine, stated that although there is no hard historical data to show loneliness has been getting worse over time, there is some sociological evidence. As an example, Twenge (2006) points to the fact that people's social networks, a structure of social actors (such as individuals and organisations), have become smaller, and families are not providing the same level of social context they may have done 50 years ago. This is problematic because social relationships are "at the core of human life" (Russell, Peplau and Cutrona, 1980). Twenge reported that almost half of 'GenMe' (those under the age of 35 in 2006) has seen their parents' divorce, or have never known their father at all. She states that children of divorce are more likely to be anxious, and depressed as it can cause a lifetime of pain, cynicism, uncertainty, and greater loneliness. Sociologist Zygmunt Bauman views social connections as becoming increasingly "liquid", that is, more flexible and constantly changing, with people logging in and out as needed (2003). Others interpret what appears to be increasingly individual lives as the breakdown of old forms of social connection but not as evidence of greater isolation or disconnection, but rather of a transition to a new form of relating that includes many temporary connections (Baker, 2012).

In Bowling Alone (2001), Robert Putnam documents the steep decline in all kinds of social connections: in the USA he found people were less likely to belong to clubs and community organisations, less likely to have friends over for dinner, and less likely to visit their neighbours. Political scientist Robert Lane also observes, "a kind of famine of warm interpersonal relations, of easy-to-reach neighbours, of inclusive memberships, and of solid family life" (as cited in Twenge, 2006, p. 110). This move away from prioritising social contact has been linked to mental health conditions, such as depression, self-harm, and suicide. Twenge feels as though "many of us are 
one break-up or move away from depression - our roots are not deep enough, our support systems are too shallow" (2006, p. 115).

Other factors are also contributing to the increase in loneliness rates. Young people nowadays are single for longer, and there has been a rise in single person households. Additionally, Twenge (2006) states that more than a quarter of people aged 25 to 29 moved city or country in the USA between 2002 and 2003. Transient people are unlikely to maintain the same degree of social contact compared with those who have lived in the same place. Indeed McCulloch (as cited in Barford, 2013) states that fifty years ago, people tended to live closer to their parents, but travel and work opportunities have led more people to move away from their family homes or cities, often internationally. The $9 \mathrm{am}$ to $5 \mathrm{pm}$ working week has expanded to evenings and weekends as well, which means that people have less time to spend with their families, and socialise with their friends.

Another significant contributing factor to loneliness levels is the technological advances of the twenty-first century such as the internet, cellphones, social networking sites, and online gaming. People are opting to make friends or keep up existing friendships in the virtual rather than the real world. The Internet has changed the dynamics of how people interact and share information and some believe this is a contributing cause of high contemporary levels of loneliness. A partial focus on this new age form of connecting with others, as opposed to a sole focus on in-person contact, has become increasingly important given that "39 percent of Americans spend more time socializing online than they do with friends in the real world" (Badoo, 2012, p. 1). This is the likely case for most of the 'developed' world and can be seen locally in New Zealand. Ninety percent of New Zealanders aged between 15 and 34 used social networking in 2012, and this age group are the largest users of social media (Diesing, 2013). 
There is a growing realisation of the need to focus more specifically on loneliness among the young. In an interview this year conducted by The Telegraph reporter John Bingham (2014), Esther Rantzen, founder of ChildLine (a youth online counselling service), described how she believes that this generation of children are facing a plague of self-harm and online bullying. She noted a 50 percent increase in self-harm among those aged 12 in the last year alone. Rantzen explains that the growth of the Internet and online communication is partly to blame, as well as major changes in family life, including family breakdowns and the inability of parents to spend enough time with their children because of long working hours (Bingham, 2014). Rantzen attributes the trend of increased self-harm and online bullying to this growing loneliness (Bingham, 2014). Children are now facing an epidemic of loneliness in a different way to older generations, and the internet is attempting to fill "a 'vacuum' in children's lives left by the disappearance of traditional structures such as the village, the neighbours, the extended family and parental attention" (Bingham, 2014, p. 11).

\subsection{Geographical dimensions}

Lack of friendships and other forms of social relations that underpin loneliness have important geographical dimensions. Friendship is a means through which people across the world maintain intimate social relationships that are both proximate and distant (Bunnell, Yea, Peake, Skelton, and Smith, 2012). Technological developments in communication however have meant that friendships and family connections can be both formed and maintained at a distance. Given the close association between social contact and the experience of loneliness, some researchers have endeavoured to examine the role played by geography in the experience of loneliness (Willgerodt, Miller, \& McElmurry, 2002; Schmitz, Jacobus, Stakeman, Valenzuela, \& Sprankel, 2003; Burholt and Scharf, 2014).

Two dimensions of geography are relevant - location and dislocation. A location is the place where a particular point or object lives (National Geographic, 2015), and 
can refer to the contextual relevance of place as measured, for example, by population density. The second refers to the leaving of familiar places and engagement in a new place, which is an integral feature of migration. When it comes to the influence of place there are several possible factors at work: the potential for contact (implicit in population density), those features of place that affect the frequency of contact (accessibility of people to each other), and the quality of contact (whether people are surrounded by those they feel empathy with).

It has been widely concluded that loneliness is prevalent in lower socioeconomic areas (Scharf and de Jong Gierveld, 2008; Scharf, Phillipson and Smith, 2004), communities which are fragmented (Griffin, 2010; Twenge, 2006; Middleton, 2004), and for those who have recently migrated (Hossen, 2012; Griffin, 2010). There is conflicting evidence as to whether loneliness is more common in urban areas or rural areas (Hunt, 2013; Chlipala, 2008; Burholt and Scharf, 2014). As such, human geography brings a valuable perspective to the study of loneliness because of its focus on the contextual role of place.

\subsection{Research motivation}

I am particularly interested in the way geography can influence well-being and mental health conditions for young people. I was initially drawn to investigating the relationship between online communication, well-being, and geography. I have experienced the growth of the online world, and been warned about the dangers of online communication by my peers and elders (who had not been exposed to the benefits of social media for communicating with others). However, I have also experienced the undeniable benefits of online communication for young people. In particular, I am reminded of my partner's experience when he was younger. He moved to New Zealand when he was 14 from South Africa, and was out of school for a few months. Given that he did not know anyone in New Zealand, and that he was not in school, he opted to make international friends through online gaming, while also maintaining contact with his friends from back home. This social contact meant 
that he felt satisfied with his social relations, and therefore had little-to-no feelings of loneliness and depression. My partner's story prompted me to wonder whether online communication is really as detrimental as most people suspect. My original focus of online connectedness was extended to encompass a wide range of social connections, including contact with family and friends, non-face-to-face contact, partnership, and community connectedness. This led to my interest in the role of place as a context for social connection. Place of residence has been associated with people's well-being (Jokela, Bleidorn, Lamb, Gosling and Rentfrow, 2014). In particular, I am interested in what role geography has in the experience of loneliness. Are there similar associations between place and being lonely for the young and old?

I have also witnessed growing demand for mental health services for youth during my part-time work in a health and counselling service within a university environment. This experience together with my interest in the effects of online communication, and my own experiences with feelings of loneliness, shyness, and anxiety, prompted me to focus on loneliness as a contemporary social phenomenon. From personal experience, I believe that disconnectedness and unsatisfactory social relations can exacerbate loneliness.

\subsection{Outline of thesis}

My thesis centres primarily around three key questions: why more people are lonely in the contemporary world, who are the loneliest, and where do these lonely people live (and what role does that geographical context play)? A large proportion of the literature focuses on why people are lonely, and who are the loneliest, however there is little current research which considers how geographical context and location may be a key factor in understanding the experience of loneliness. In particular, New Zealand wellbeing literature largely overlooks the subject of loneliness, and so there is scope to conduct a current original research piece. 
To answer these key questions I explore connections between the distribution of loneliness across the New Zealand population and various forms of social connectivity. I do so by modelling loneliness levels that New Zealanders report, as a function of their level of social connection, for example their connectedness via partnership, family, and friends, their geographical context, demographic attributes, and achieved characteristics (for example education). I draw on measurements of social isolation for adults, from the 2012 New Zealand General Social Survey (NZGSS), and reported levels of loneliness among young people from the 2006 wave of the Youth Connectedness Project (2006), each of which allows the experience of individuals to be embedded within a local geography.

My thesis is presented in seven chapters. The first chapter has introduced the growing international concern for loneliness and highlighted some possible contributing factors. I have also introduced my personal motivation for writing about loneliness. Chapter Two, to follow, reviews the literature on loneliness, and documents how the connection between loneliness, connectedness, and geography has been treated. A review of some of the key well-being surveys based in New Zealand is also included. Chapter Three outlines my research design and positionality as a researcher. I introduce the available measures of loneliness, connectivity, and geography from the NZGSS 2012 and the YCP 2006, as well as outlining the methods to analyse the data.

Chapter Four uses responses from the NZGSS 2012 to address the differences in the experience of loneliness based on a person's personal attributes, their place, and characteristics. In doing so I show loneliness levels are highest amongst the young. In Chapter Five I draw on the YCP in order to focus on the experience of loneliness among young people aged nine to sixteen. This analysis is extended in Chapter Six where I employ spatial statistics to test the geographical patterning of loneliness among youth. The thesis concludes in Chapter Seven by reviewing the contribution of my study to the wider literature on loneliness and, more generally, social 
geography. I also draw attention to some of the limitations of the above analysis and suggest extensions for further research. 


\title{
Chapter 2 Literature Review
}

\author{
"[M]an is by nature a social \\ animal; an individual who is \\ unsocial naturally, and not \\ accidentally, is either beneath our \\ notice or more than human." \\ - Aristotle (n.d., p.1)
}

Loneliness kills. This is the conclusion that many researchers are drawing attention to in the attempt to highlight what some are calling the next public health issue. Loneliness has been recognised for both its psychological and social significance. It can have harmful effects on a person's mental health and wellbeing, for example heart disease, depression and suicide, and also is a social problem for community functioning and social exclusion. If our relationships can have such an effect on our overall mental and physical health, why do 31.46 percent of New Zealanders not prioritise spending time with the people they are surrounded by? How can a physical environment and a community play a role in fostering connectivity and social inclusion?

Loneliness has been described as "a complex set of feelings encompassing reactions to the absence of intimate and social needs" (Ernst and Cacioppo, 1999, p. 1). Heinrich and Gullone (2006) consider that loneliness is the state a person can be in if there is an incongruity between the social relationships they wish to have, and those that they currently have. They believe that this shows "loneliness is clearly distinguishable from the objective state of solitude, social isolation, or being alone" (2006, p. 699). For the same reason, West, Kellner and Moore-West (1986) note that 
physical isolation is not the same as loneliness, and people have to perceive themselves as being lonely in order for loneliness to occur. There is, in other words, a strong subjective dimension to loneliness. It is not just being alone, physically, but feeling alone, emotionally.

Over time loneliness has gained increased attention in the published literature. Figure 2.1 shows the relative occurrence of loneliness in published literature as shown by the 'Google Books Ngram Viewer', which is a tool used to track occurrences of words over time. The proportion of times 'loneliness' was mentioned (y-axis) peaked in the early 1980s. The rise throughout the 1960s and 1970s reflects Franklin's points that the post-war economic restructuring generated the first concerns for loneliness, with the breakdown of established industrial communities and their reorganisation into "largely experimental forms of architecture and urban/residential design" (2012, p.13). This reorganisation raised concerns firstly for people scattered in new towns and suburbs, and secondly the people left behind in the city centres, who were both "forced to spend long periods of their life apart from their formerly vibrant social worlds" (Franklin, 2012, p.13). A reduction in the appearance of loneliness literature can be witnessed from the mid1980 s to 2000, but in recent years interest in loneliness has become more evident, given the increase from 2003. This is consistent with the extent to which loneliness features in newspaper articles that draw attention to the 'epidemic' facing many of us today. 
Figure 2.1 The progression of loneliness mentions in literature 1800-2008

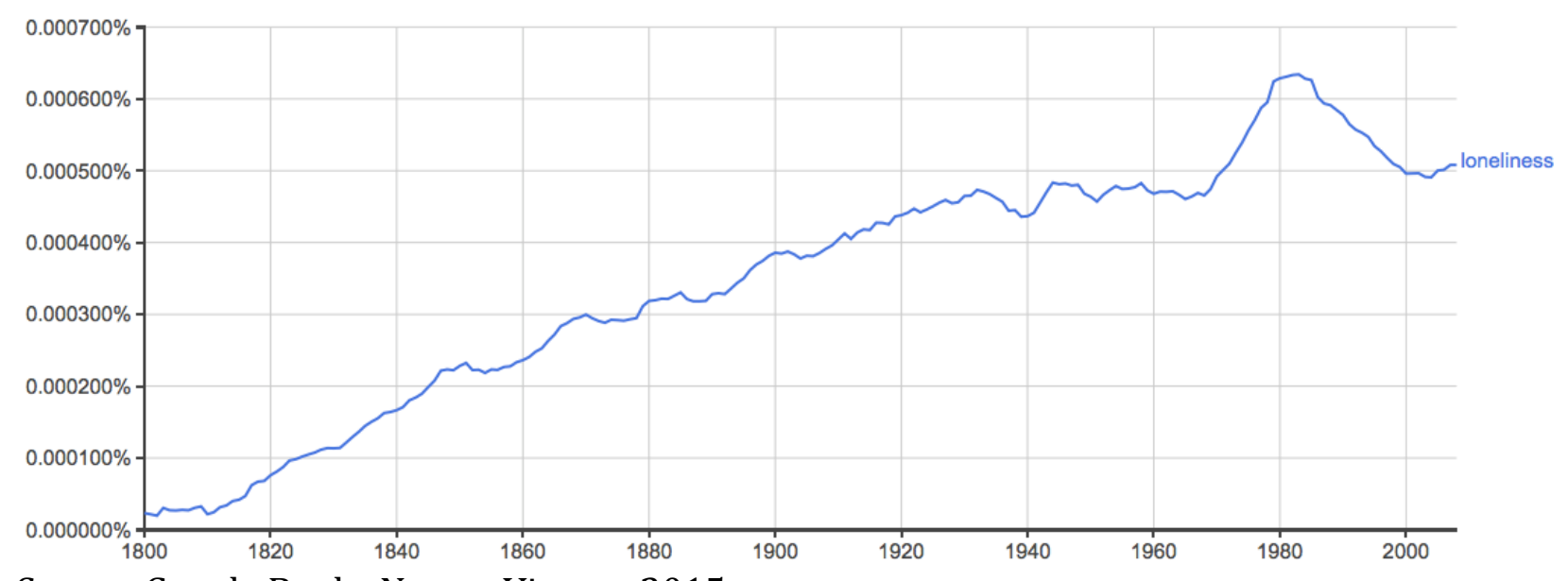

Source: Google Books Ngram Viewer, 2015

There are two phases of literature in loneliness. Early studies of loneliness focus on small case studies (1900-1980), whereas later studies involve cross sectional data on large surveys of sub-populations (1980 onwards). Many of the insights from the early literature (for example Durkheim's social integration theory, Erikson's psychosocial stages of development, and Bowlby's attachment theory) have been drawn on, developed, and tested in the more survey based literature. This loneliness literature centres primarily around three key questions: why more people are lonely in the contemporary world, who are the loneliest, and more recently and to a lesser degree, where do these lonely people live (and what role does that geographical context play)?

This chapter will introduce what we currently know about loneliness, how it contributes to connectedness, and how social capital, community and place fit in. The review will investigate the gaps in research regarding the link between loneliness, connectedness, and the role of place. The chapter is divided into five parts. Section one will discuss the concept of loneliness, the relationship it has with connectivity, people's demographics, achieved characteristics, and psychological predisposition. In section two I will consider the present and historical definitions of youth and will look more closely at the literature on young people (anticipating chapters five and six). Section three introduces the dimension of place and its 
relationship to loneliness. I draw on current research on the state of loneliness in New Zealand in section four. I summarize the main points in section five. For more information on the literature I review here, see Appendix 1.

\subsection{Loneliness}

In this classic study in the late 1950s, Fromm-Reichmann wrote, "the longing for interpersonal intimacy stays with every human being from infancy throughout life; and there is no human being who is not threatened by its loss... the human being is born with the need for contact and tenderness" (1959, p. 3). In other words, humans

are social by nature; they have a need to belong, and a need to have satisfying connections with other human beings (Heinrich and Gullone, 2006). The need to belong also involves a need to create and maintain long-term positive relationships through quality communication (Baumeister and Leary, 1995). As a result, those people who find it difficult to establish and maintain positive relationships with other people, and thus do not feel as though they belong, are likely to experience a sense of loneliness, anger, depression, and anxiety (Baumeister and Leary, 1995; Cacioppo and Hawkley, 2000).

\subsubsection{Loneliness and connectivity}

A range of definitions of loneliness have been established by researchers, with most drawing a connection between loneliness and connectedness. According to Ernst and Cacioppo, for example, loneliness is "a complex set of feelings encompassing reactions to the absence of intimate and social needs" (1999, p. 1). Similarly, Heinrich and Gullone (2006) treat loneliness as the state a person can be in if there is a discrepancy between the relationships they wish to have, and those that they currently have. The term 'relationship' embodies both quantity and quality. Fischer and Phillips (1982) state for example that it is not necessarily the number of friends that makes a person lonely, but the quality of the relationships. Parker and Seal (1996) support this idea stating that a child with one friend is no lonelier than a child with many friends, but is less lonely than a child without any friends. A study 
by Hawkley, Burleson, Berntson and Cacioppo (2003) illustrate that the daily activities of lonely and non-lonely people do not differ, nor does the time they spend alone. Heinrich and Gullone believe that this shows "loneliness is clearly distinguishable from the objective state of solitude, social isolation, or being alone" (2006, p. 699). Therefore physical isolation is not the same as loneliness, for people have to perceive themselves as being lonely in order for loneliness to occur (West, Kellner and Moore-West, 1986).

Many researchers believe that loneliness is a natural part of life and that most people will feel lonely at some point in their lives (Hymel, Tarulli, Hayden Thomson, and Terrell-Deutsch, 1999; McWhirter, 1990; Medora and Woodward, 1986). Loneliness can be felt for short periods or for more extensive periods of time, and there are generally multiple causes of feeling lonely. The experience of loneliness can also vary in intensity given the wide ranges of circumstances that lead to people suffering. For example, Heinrich and Gullone state that, "the loneliness of a child who has lost their mother is experienced differently to the loneliness of a child who has no playmates" (2006, p. 699).

Although people can feel loneliness differently, Perlman and Peplau (1998) state it is possible to understand the mitigating factors that influence loneliness, highlighting the incongruity between a person's social relations and what they wish their social relationships were like. A person may feel, for example, as though their social relations are not being fulfilled because of a loss of a loved one, or the disruption of relationships through moving jobs, schools, or location.

The range of definitions reviewed above indicate that the state of loneliness is inextricably linked with both the quality and quantity, of a person's social relationships. Being alone and reporting oneself as lonely are not always synonymous for one can be lonely in a crowd of people. Therefore, our social 
connections, more specifically the quality and quantity of our social connections, play an important role in loneliness levels.

\subsubsection{Early studies of loneliness}

The importance of treating loneliness and connectedness separately in analysis is particularly evident in early studies of loneliness. While Cacioppo and Hawkley (2000) state that the scientific study of loneliness has a short history, loneliness, as a conditional experience sparked by the desire for strong social relations, can be dated back as far as the prehistoric era. Indeed, as Perlman and Peplau (1998) explain, Greek mythology and drama often referred to feelings of being alone. This culture influenced Aristotle's observation that:

"man is by nature a social animal; an individual who is unsocial naturally and not accidentally is either beneath our notice or more than human. Society is something that precedes the individual. Anyone who either cannot lead the common life or is so selfsufficient as not to need to, and therefore does not partake of society, is either a beast or a god" (The Hindu, 2012, p. 2).

Aristotle argues here that human beings are social by nature and it is unusual for someone to not need to socialise with other human beings.

T.L. Stoddard's 1932 text Lonely America, and Gregory Zilboorg's article (1938) which linked loneliness with narcissism, megalomania and hostility, are two of the earliest social science examinations of loneliness. Following these studies, FrommReichmann (1959) examined the idea of loneliness in her seminal article Loneliness, in which she asserted that loneliness is inextricably tied to mental disorders, physical well-being and psychosocial issues. She also proposed a social needs approach to loneliness, whereby loneliness is caused by the absence of a needed relationship. Clark Moustakas, an American psychologist, also wrote about loneliness in his book Loneliness (1961), which was published two years later. He believed that loneliness is a widespread issue in society and needed to be 
understood and accepted in order to prevent it from being a damaging force on social networks for example on society. Conversely, Carl Rogers, a key historic figure in psychology, gives an existential view on loneliness in A Way of Being (1961), a book published in the same year as Moustakas'. He describes loneliness as a fatal division between sensing one meaning in an experience but clinging to another, for example being in an unfulfilling or undesired partnership.

Research on loneliness is also connected to Erikson's (1963) psychosocial theory of development, which highlights the importance of social relationships for human development. Erikson (1963) believed that human development consists of eight stages. The fourth, fifth and sixth stages of Erikson's psychosocial theory of development focus on a range of contacts: the school environment (5-12 years), social relationships (13-19 years) and partnership (20-39 years). These phases are important times in a person's life in order to develop deep and meaningful relationships with others (Heinrich and Gullone, 2006).

In his book, Loneliness: The Experience of Emotional and Social Isolation, Robert Weiss (1973) argued that there are two types of loneliness: emotional and social. Weiss identified loneliness as the experience of, "being without some definite needed relationship or set of relationships" (1973, p. 17). He believes that those people who experience emotional loneliness are lacking close, emotional relationships with one other person. Weiss interviewed people who had lost a spouse to death, and inferred that this type of loneliness does not disappear even if they are surrounding by other family and friends. This type of loneliness could only heal when a new relationship is formed (I show this later in Chapter Three, how loneliness decreases when adding a partner, even with friends and family contact in place). On the other hand, social loneliness is the lack of integration into a social network and can be felt even while in a loving relationship. Weiss studied several couples who moved and found that the wives felt homesick despite having support from their husbands (a point I also make when observing higher rates of loneliness 
among migrants). He, therefore, believes that people not only need to be in a stable loving relationship, but they also need to feel as though they are part of a wider social group. Moreover, stable loving relationships are often seen as a base for a wider social group.

John Bowlby developed the Attachment Theory in 1951, and it has had a long developmental history, as it was influenced directly by Sigmund Freud and other psychoanalytic thinkers (Bretherton, 1992). While Bowlby formulated the basic principles of the theory, Mary Ainsworth produced a methodology that was able to test some of Bowlby's ideas. The theory explains the links between the behaviour of caregivers and infants, and how this impacted the behaviour of children later in life. Bowlby's attachment theory proposes that children form attachment bonds with their parents while in infancy: "the infant and young child should experience a warm, intimate, and continuous relationship with his mother (or permanent mother substitute) in which both find satisfaction and enjoyment (1951, p. 13). He made the observation that young orphans in hospitals would become distressed when they were separated from their caregiver and the child and would try everything at their disposal to find that person (Seepersad, 2010). Miller (1993) believes that attachment helps children bond with their caregiver and with other people later in life. These attachment bonds secure the capability of the child to grow up with good mental health (Bretherton, 1992). Bettmann (2006) states that anxiety and depression are symptoms of disruptions to personal bonds, and so understanding a person's attachment history can be crucial in understanding their current mental health struggles. Recently, the attachment theory has also been linked to adults (Kerns, 1994; Bettmann, 2006), which shows the attachment theory lens can be used in the treatment of mental illnesses at all ages (Bettmann, 2006).

Attachment Theory has also been adopted by academics to examine the feelings of loneliness for adolescents. The need for a child to have contact with someone who can provide them with love and safety is closely linked with the idea that loneliness 
appears if the person is not getting satisfaction from their social relations (Seepersad, 2010). Weiss (1973) was one of the first researchers to connect loneliness and attachment theory together, when he linked loneliness with the loss of a romantic partner. Seepersad (2010) concluded that adolescents are going through a transition period where they no longer want to have the same level of attachment with their parents, and are searching for connection and intimacy in a partner. If a person is unable to find a partner, or is 'between partners', they are likely to be dissatisfied with their social relations and therefore may feel lonely (Seepersad, 2010).

An early study by Spitz and Wolf (1946) documented how a number of infants, who lived in orphanages, died because the institutions were poor quality and staff rarely interacted with them despite adequate feeding and physical care. Spitz and Wolf (1946) concluded that this was because the children did not receive cuddling or holding. These early studies therefore focus directly on the relationship loneliness has with social connectivity, independent of any measurement of their personal characteristics.

In summary there are three main findings from this early literature: social contact is generally related to lower levels of loneliness, various levels and forms of social contact can have different effects on a person's experience of loneliness, and social and emotional connectedness effect a person's experience of loneliness very differently.

\subsubsection{Cross-sectional studies on loneliness}

In recent times, a number of cross-sectional studies have been conducted to investigate whom within the wider society is most affected by loneliness. Crosssectional studies rely on data collected from a population at a point in time in order to examine the association between an outcome (loneliness) and a set of variables theorised as accounting for variations in that outcome (for example age). These 
arguments or independent variables typically include demographics, achieved characteristics, contextual descriptors and, in some cases, psychological wellbeing. Together they show that loneliness "does not respect the boundaries of age, gender, race, marital status, socioeconomic status, or health status" (Heinrich and Gullone, 2006, p. 699). The following sub-section details what these studies have revealed about the way loneliness is related to variables, such as age, gender, relationship status, ethnicity, socio-economic position, employment, psychological state, and physical health. I address place separately later in this chapter.

\section{Age}

There are conflicting reports on how loneliness affects people from different age groups. Rubenstein, Shaver and Peplau (1979), Brennan (1982), Brennan and Auslander (1979) all reported that their expectation that the young would exhibit higher rates of loneliness was correct empirically. Schultz and Moore (1988) studied high school students, university students, and retirees in the US (given reports that these age groups show a higher likelihood of being lonely), and reported that loneliness was highest for high school students, at intermediate levels for college students, and non significant for retirees. On the other hand, West, Kellner and Moore-West (1986) argue that older populations show the strongest disposition to being lonely. They suggest that this is because of physical incapacity, decreased financial funds and decreased transportation. Interestingly, Yang and Victor (2011) tested the loneliness levels of 47,099 Europeans and found that there is a U-shaped distribution across the age range, in that the young and old experience higher rates of loneliness than the middle aged.

\section{Gender}

Studies on loneliness have found considerable gender based differences, some in favour of men and others of women. In their studies of university students, Borys and Perlman (1985) and Cramer and Neyedly (1998) observed that females are more likely to report feeling lonely than males. Borys and Perlman (1985) and 
Cramer and Neyedly (1998) believe that females were more likely to self-report loneliness because the negative social consequences of admitting loneliness was greater among men. Borys and Perlman argued men "elicit a more negative response for manifesting their loneliness than do women" (1985, p. 71). Men are portrayed as less interpersonally sensitive and less emotionally expressive, and thus "may be less aware of the target's loneliness and less willing than women to chastise the target for it" (Borys and Perlman, 1985, p. 71).

Conversely, some studies have found that men actually report being lonelier than women (Wiseman, Guttfreund and Lurie, 1995). UK's Institute for Social and Economic Research (2005) questioned about 1142 people from all ages and found that females reported lower levels of loneliness compared to males. This was also the case in studies that focused on young people, as reported by Priyadarshini and Mishra (2013) and Wiseman, Guttfreund and Lurie (1995). A Belgium study conducted by Heylen (2010) also found that in the over 55 age group, men were the loneliest gender. Baker (2013) and Flood (2005) both used the Household, Income and Labour Dynamics in Australia (HILDA) Survey for their studies on loneliness in Australia and found that males reported the highest levels of loneliness. The HILDA survey collected information from about 20,000 Australian's, regarding economic and subjective well-being, labour markt dynamics, and family dynamics (The Melbourne Institute, 2015).

\section{Relationship status}

There is an almost universal agreement that partnered individuals report lower levels of loneliness. Correspondingly, Wood (1978) found that loneliness rates were the highest for non-married individuals, especially single women, and consistently Russell (1982) also found that loneliness scores were lower for those college students who were married or in a stable relationship. In Rubenstein and Shaver's (1982) US study, 44 percent of participants highlighted that the reason why they felt lonely was because they were not in a relationship. Perlman, Gerson and Spiunner 
(1978) concluded that widowed men feel lonelier than married men, but there was no indicated difference between widowed and married women.

The quality of partnerships/relationships is also a crucial consideration for it is possible to be quite lonely within a relationship. Perlman, Gerson, and Spinner (1978) measured loneliness for older Canadians and found that low marital satisfaction was associated with higher levels of loneliness. Similarly, Knoke, Burau and Roehrle (2010) similarly found that emotional forms of loneliness are associated with marital dissatisfaction in a sample of 126 German couples.

\section{Ethnicity}

A number of studies have also linked loneliness rates with ethnicity (Neto and Barros, 2000; Victor, Burholt and Martin, 2012; Mullins, Elston and Gutkowski, 1996). Victor et al. (2012) studied loneliness rates among ethnic minorities in Britain, because their loneliness rates tended to be higher than the general population. They studied 300 people 65 years and older who originated from the key minority groups in Britain, and confirmed their higher levels of loneliness.

\section{Socio-economic status}

One of the most significant and telling correlates of loneliness is standard of living. This is also among the most important because it is amenable to public policy initiatives that address poverty. Several studies have showed the link between personal employment/income factors and loneliness. Access Research Knowledge (2012) for example investigated adolescents in Northern Ireland and found that perceiving one's family as not being well off was associated with increased scores on the UCLA loneliness measure (discussed in Chapter Three). Demakakos, Nunn and Nazroo (2006) found that wealth and loneliness were highly positively correlated for those over 50 years old in the UK, with the poorest respondents reporting double or greater rates of loneliness than the richest people. Kearns, Whitley, Tannahill and Ellaway (2013) suggests that this is the case because of "low incomes, 
poor or disjointed services, and fear of crime" (2013, p. 3). The association between loneliness and the average income of the geographic area in which someone lives will be discussed later on in this literature within a wider discussion of place. There is an important distinction to make here between poor people, and poor places. Independent of place, poor people will still be lonelier, and so there is a separate explanation for the role of neighbourhood deprivation later in the chapter.

\section{Employment}

Creed and Reynolds (2001) studied the loneliness rates of 148 Australian young people, in comparison to their employment status. Interestingly, they found that those who were unemployed, with access to regular paid work, were the least lonely, whereas those young unemployed people with no paid work experienced the highest rates of loneliness. Rokach (2013) also reported that it has been widely recognised that being employed is strongly correlated with lower levels of loneliness. As a result, Creed and Reynolds (2001) recommend that despite the strong link between loneliness and various negative psychological health outcomes, the issue of employment must be considered as well. While employment is usually essential in order to generate an income, employment offers more than the wages needed to combat loneliness. It involves regular social contact, status, and often gives deeper meaning to life. Therefore, employment needs to be addressed as a variable in its own right in relationship to loneliness.

\section{Physical health}

Loneliness can also be influenced by a person's physical health. Loneliness itself can also induce certain physical changes so the causation can potentially work both ways. West et al. (1986) state that some studies have concluded that loneliness has negatively impacted on physical health through immunologic impairment and neuroendocrine changes. In addition, Hawkley et al. (2003) researched 135 undergraduates in the US, and found that loneliness affects the cardio-vascular 
system and predicted higher total peripheral resistance and lower cardiac output. In other words, being lonely has adverse consequences on a person's heart functioning. Goosby, Bellatorre, Walsemann and Cheadle (2013) found, by using data from 132 schools in the US, loneliness during adolescence is associated with diagnosed depression, poorer adult self-rated health, and metabolic risk factors related to cardiovascular disease.

Research also suggests people in poor health are more likely to report being lonely because of a physical incapacity to socialize. Rokach (2013) states that deteriorating senses, such as loss of hearing or vision, can result in increased levels of loneliness because it impacts on the ability to communicate effectively and easily with others. In addition, physical health problems may be related to difficulties with mobility, and therefore a person's ability to socialise with other people in different locations becomes more difficult, leading a person with poor health to feel more isolated and lonely (Rokach, 2013).

\section{Psychological wellbeing}

To a considerable extent the variables considered up to this point can be treated as exogenous as far as loneliness is concerned. As such they could exert an influence on loneliness. When it comes to psychological wellbeing however there is considerable scope for endogeneity. In other words, loneliness is to some degree both a measure of, and a reflection of, mental illness - which is why loneliness and depression are often linked. While I cover psychological factors here I am quite grounded in my subsequent treatment of them as 'independent' variables in my model of loneliness.

Research linking a person's psychological wellbeing and loneliness has highlighted the intimate connection between the two. Eisemann (1984) for example studied 110 depressed patients in Norway and found the depressed felt lonelier and suffered more from their loneliness than those in the control group. The study also found that loneliness was more negatively correlated with the number of regular contacts 
with family members in the case of all depressed patients. As depression is strongly linked with suicide, Wenz (1977) studied the seasonal impact on suicide attempts and loneliness. He found that loneliness peaked during spring and winter, which coincided with the timing of suicide attempts. These studies demonstrate the importance of psychological controls for studies, because it is clear that loneliness is interconnected with mental health conditions.

This review of cross-sectional studies has shown that there are clear associations between a person's loneliness levels and their demography, achieved characteristics and physiological and psychological wellbeing. From these findings I have formed a number of hypotheses in which I will analyse in Chapters 4, 5 and 6 of this thesis, very generally I expect that people will report higher levels of loneliness if they are young, female, single, an ethnic minority, poorer, unemployed, and have poor physical and mental health. Geographical context covariates will be covered later in this chapter in a section on place.

\subsection{Loneliness and Youth}

In this study 'youth' is a general term referring to young people between the ages nine and sixteen in the YCP. Other studies may include younger and/or older people within the label 'youth'. Pierre Bourdieu (1978) considers 'youth' as an evolving concept that reflects current moral, political and social concerns. For example, Liebau and Chisholm (1993) have indicated that youth in Europe are non-existent because young people in the various countries and cultures of Europe have very different socio-political circumstances than others. Indeed, Bourdieu (1978) argues that intergenerational power relations will be the key to understanding 'youth,' because the concept has been socially constructed out of the relationship between

young and old. While the Oxford English Dictionary (1983) defines 'youth' as the period between childhood and adulthood, the United Nation's currently describe it as a transitional phase between dependence and independence. 
Regardless of where the concept of youth originated and what ages it includes, researching youth is useful and important simply because youth is a critical stage in constructing the self-concept. The 'transition period' that many researchers refer to is a time of change whereby risky behaviour, exceeding boundaries set by caregivers and causing permanent harm to oneself is common (Office of the Prime Minister's Science Advisory Committee, 2011). In order to reduce the occurrences of this risky behaviour, researchers aim to investigate what exactly is causing it. This suggestion reflects the focus on this research which is to determine the risks associated with feeling lonely, both social (the shift in how young people communicate) and geographically (differences between place of residence).

Given that youth are reporting higher rates of loneliness than ever before, some

academics have endeavoured to establish why this is the case (Valkenburg and Peter, 2007; Wolak, Mitchell and Finkelhor, 2003). Only a small proportion of loneliness literature focuses on youth. In their study of the health consequences of loneliness, Goosby et al. stated that the exclusion of loneliness in early life literature is "somewhat curious" because loneliness is "an eminently social-psychological construct, reflecting how people experience the communal aspects of their social worlds" (2013, p. 505). There are a number of reasons why academics such as those discussed here believe that a research focus on loneliness for young people is critical, as I will consider below.

\subsubsection{Transition period}

Youth are traversing through a transitional period whereby a switch in their main social agents, from their parents to their friends occurs (Crosnoe, 2000). Brennan (1982) believes that the need for belonging and to be socially accepted is particularly pertinent for adolescents given this developmental phase of becoming more dependent on social friendships. Moreover, Roscoe and Skomski (1989) also believe that loneliness manifests in youth while they separate themselves from their families and create their own identities. Despite this desire for independence, 
adolescents are still likely to need someone to depend on. Erikson's psychosocial theory of development "proposes that during the period of late adolescence and early adulthood, there is a crisis of intimacy versus isolation" (Roscoe and Skomski, 1989, p. 948). More specifically, young people are, on the one hand, in conflict with themselves as they demand independence and solitude, but on the other, crave support and love to feel socially satisfied and needed. During this time of change and confusion, adolescents would therefore continue to benefit from having support and love from their family (Marcoen and Brumagne, 1985).

Goosby et al. (2013) and Brennan (1982) also believe that the transitional period can also lead to instability and higher rates of loneliness because young people reach pubertal onset where they are physically and emotionally transitioning from childhood to adulthood, and are moving from primary to secondary school - where youth are challenged in new ways and often need to form new social circles. Lester states that the transition between primary and secondary school "provides both challenges and opportunities as many adolescents undergo transition while experiencing environmental, physiological, cognitive and social changes as part of the adolescent development process" (2012, p. 1). She also notes that adolescents have a high risk of being bullied in their school life, which can lead to high levels of social loneliness. Indeed, Berguno, Leruos, McAinsh and Sahikh (2004) studied 42 children aged between 8 and 10, and found that lonely children were more likely to be victimized by their peers.

\subsubsection{Attachment}

The classical studies of loneliness provide an important basis for discussion regarding why loneliness research should focus on all age ranges. Parental warmth, both maternal and paternal, can be associated with lower levels of loneliness (Goosby et al., 2013). As stipulated earlier, the attachment theory postulates "people form internal working models of themselves and of others in close relationships based on their experiences with childhood caregivers" (Wiseman, Mayseless and 
Sharabany, 2005, p. 238). Shaver and Mikulincer (2002) believe that people who have secure attachments with their caregivers, where warmth, respect for autonomy and trust are prevalent, are less lonely than others. Cognitive-emotional schemas that young adults carry, which stem from early relationships with parents, are partly responsible for feelings of loneliness, and therefore it is important to ensure early relationships are healthy and nurturing (Shaver and Mikulincer, 2002). Moreover, Marcoen and Brumagne (1985) examine how this early relationship between parents and children does not lose its importance when a child enters high school. Adolescents, they argue, still need "attention, assistance, encouragement, activation and confirmation" (1985, p. 1025). Hill (1980) believes that there are often many conflicts between parents and adolescents at this stage because parents sometimes do not succeed in adjusting their parenting practices to suit the growing autonomy of the youth (as cited in Marcoen and Brumagne, 1985). It is this conflict that can leave a young person feeling disconnected, unloved, misunderstood and alone, which are all triggers for becoming lonely.

\subsubsection{Perception of friendships}

Goosby et al. (2013) state that loneliness is also a significant part of the lives of young people because of how they perceive the quality of their relationships. Goosby et al. (2013) found that connectedness to school is protective against loneliness, and those who are well liked by their peers are less likely to report being lonely. A young person's relationship with their friends changes, however, when he or she enters adolescence. According to Marcoen and Brumagne, this is due to the fact that from the age of nine a young person begins to have an objective view on friendships, where "their cooperation now envisions the benefit of both [people], although the friendship remains exclusive and possessive" (1984, p. 1026). From the age of 12 onwards, friendships start to become less exclusive, and friends become more tolerant of each other. Alongside this, there is likely to be an increase in tension, uncertainty, conflict and non-fulfilment within friendship groups (Marcoen and Brumagne, 1985). 


\subsubsection{Defining users of the internet}

In the last decade, the internet has changed the way humans live, communicate, and seek information (Wang and Wang, 2011). Thurlow, Lengel and Tomic (2004) states that offline and online experiences are increasingly becoming intertwined, and nowadays it is becoming more difficult to imagine life without the internet. Indeed, they believe that the difference between 'real life' and 'life online,' which some would argue is an artificial distinction, is becoming difficult to tease apart as online communication is seen as an extension of everyday in-person communication.

Youth are the defining users of the internet as they spend more time online than adults and they use online social technologies, such as instant messaging websites, more frequently (Valkenburg and Peter, 2007). Wang and Wang believe that adolescents are "more apt to online communication because of their developmental stage" (2011, p. 359). Although, the majority of adolescents use the internet to maintain social relations with existing friends, some are also using it to form relationships with strangers (Valkenburg and Peter, 2007; Wolak, Mitchell and Finkelhor, 2003). This formation of friendships with strangers has been the topic of academic debate, but there has been no clear consensus about whether online engagement is harmful, hurtful, or has no influence on a person's well-being. However, a consistent conclusion has not been drawn.

Several researchers including Wang and Wang (2011) and Valkenburg and Peter (2007) believe there are at least two theoretical perspectives to acknowledge when investigating the effects of online communication on users' well-being: the augmentation/complement hypothesis and the displacement/substitution hypothesis. The augmentation hypothesis argues that some types of communication can facilitate the use of others, and having online friendships strengthens offline relations (Katz and Rice, 2002; Wang and Wang, 2011; Valkenburg and Peter, 2007). Adherents of this hypothesis suggest that recent online communication tools, such 
as instant messaging, encourage people to communicate with existing friends. Wang and Wang (2011) argue that adolescents often use online communication to meet strangers at first but most users communicate with existing friends, which will stimulate their subjective well-being.

Meanwhile, the displacement hypothesis claims that those who communicate online are spending time online rather than with their 'real' life friends (Wang and Wang, 2011; Nie, Hillygus and Erbring, 2008). Many researchers have argued that people will have lower levels of well-being and poorer social outcomes if they spend large amount of time on the Internet. Kraut, Patterson, Lundmark, Kiesler, Mukopadhyay and Scherlis (1998) argue that the adherents of the displacement hypothesis suspect that these adolescents are forming superficial online relationships rather than strengthening friendships in the 'real' world. The online 'friends' are thought to reduce the quality of adolescents' existing friendships and their well-being (Kraut et al., 1998) by enabling social isolation and limiting genuine relationships (Mazalin and Moore, 2004). Nie (2001) argues that internet use takes time away from face-toface relationships, which could reduce social capital. He reports that "eye contact, body language, facial expressions, vocalization, hugs, pats on the back, cries, embraces, kisses and giggles are the fundamentals of our evolutionary socioemotional well-being" (2001, p. 432). Bauman (2000) offers the most radical reappraisal of contemporary forms of loneliness, arguing that contemporary social bonds are emotionally looser, weaker, and less satisfying. Bauman asserts that online communication is a doomed substitute of in-person relations.

\subsubsection{Summary}

In summary, this section on loneliness and youth has described potential reasons as to why youth are reporting higher levels of loneliness than older people. It is also interesting to conduct my own analysis based on this literature which points to a potentially important relationship between three forms of social contact in reducing loneliness for young people: attachments to family, friends and classmates. I have 
also formulated a hypothesis of which to test in my own analysis, in that there is an augmenting effect between face-to-face and non-face-to-face contact in reducing loneliness for both adults (NZGSS 2012) and youth (YCP 2006).

\subsection{Place}

One of the aims of this thesis is to explore and emphasise the role geography can have on loneliness. The concept of place in Human Geography consists of three key meanings, as a point on the surface of the earth, as the centre of individual or group identity and as the scale of individual's daily actions and interactions. In the wake of globalisation and the increasing interconnectedness of people and places across the earth, the concept of place had to be rethought due to the need to analyse both place differences and interdependence (Castree, 2003). Hagerstrand wrote:

"A life biography...is made up of both internal mental experiences and events related to the inter-play between body and environmental phenomena. We must assume that inner experiences and outer events are joined in many intricate ways. The most indispensable connection lies in the sequential correspondence between what happens in the two realms (1975, p. 10).

Here, Hagerstrand is arguing that a person and the environment around them are intertwined and therefore to understand wellbeing issues, like loneliness, we must consider the environment as well. Jones has argued that work by geographers would be beneficial to mental health research and policy sector because of their "broadness of knowledge about the world in which we live, as well as their expertise in 'thinking geographically' about research problems" (2001, p. 223). Indeed, Jones (2001) states that geographical information is important for policy makers who are interested in examining mental health services and their locations.

There are a number of research projects that have interweaved research on wellbeing/mental health and geography. Holley (1998) states that the geography of well-being can be traced back to the Victorian era when Hack Tuke (1892) 
published his Dictionary of Psychological Medicine. Tuke's study sparked the interest in the geography of suicide by finding "a 29-fold difference in the incidence of suicide across 19 countries" (Holley, 1998, p. 536). This provided the premise for further analyses of geographic variation in Europe and the US. Durkheim's study of suicide (1897) formed the empirical basis for both psychiatric epidemiology and quantitative sociology and as such, resulted in important theories that are still referred to and relevant today, by finding that the degree to which people are integrated into their social surroundings has an effect on suicide levels.

Morrison (2013) believes the role that place plays in the lives of people is of interest but there is little research conducted regarding well-being and the regional context. He considers that there are a number of ways regional science and well-being can work together - mapping and interpreting distributions of well-being within and between regions, how well-being varies by population density (urban versus rural), and how contexts (the features which make places different) are associated with higher or lower well-being. In their article, Gray, Lobao and Martin (2012) argue that a number of studies have illustrated that local characteristics and context shape local residents' well-being. Moreover, they state that "many of the attributes and features that influence well-being are likely to be locality-specific and hence spatially variable" (Gray et al., 2012, p. 9). An example of this is the way that many rural and ex-urban areas are thought to have cleaner and greener environments, less crime, less road congestion, but will have less access to public services and cultural facilities.

Given the strong influence place has on people, the following discussion will consider how geographers have investigated the distribution of loneliness rates across places, including rural and urban differences, deprivation studies, social fragmentation, and mobility. Chlipala (2008) and Burholt and Scharf (2014) believe most studies are limited because important differences in loneliness levels for people in rural and urban areas are not often considered. Chlipala suggests that 
rural and urban differences are vital to take into consideration because of "factors such as population density, proximity to neighbours, availability of public transportation, access to cultural and recreational services, and various degrees of neighbourhood security and urban stress" (2008, p. 32). This research gap will be addressed in this thesis by investigating the associations between loneliness and a number of geographical variables, such as levels of neighbourhood deprivation, settlement type, region, and migration.

\subsubsection{Rural and urban differences}

Geographers often attempt to establish whether or not settlement type has an effect on a person's wellbeing. There are several theories associated with this approach, including the thought that urban centres could be lacking strong social bonds because "the closer people live to one another, the more they tend to emotionally isolate from one another," while rural "communities have a much greater sense of community than urban areas" (Hunt, 2013, p. 41). This theory suggests that people who live in rural communities are less likely to experience feelings of loneliness because they are able to create and maintain strong social networks. On the other hand, it can also be argued that people from rural areas might suffer from mental health conditions more when there is a lack in employment opportunities (Morrell, Taylor and Slater, 1999) and/or because of geographic isolation. Moreover, urban spaces can often provide more opportunities for people to connect due to a large population base, and as a consequence people are likely to be less lonely in rural communities than in urban areas.

Burholt (2011) researched loneliness levels for older people in the UK. The study found that sparsity in rural areas, alongside a decrease in the functionality of the sample, led to a reduced ability to maintain social relationships. Burholt (2011) believes that this suggests that loneliness levels might be exacerbated in rural areas. Moreover, the Commission for Rural Communities (2005) reports that rural areas have a unique set of circumstances that can exacerbate the social isolation of older 
residents, leading to poor health, loss of independence, lower quality of life and increased loneliness. Burholt and Naylor suggest that "communities are not merely settings - they play a significant role in self-identity and are a vital source of emotional and experiential meaning for the inhabitant" (2005, p. 109), and as a result the role of the community on a person's well-being should be examined and detailed.

Although some researchers have established that those people who live in rural areas are more prone to feelings of loneliness, it is also common for people to think that urban residents will be lonelier, especially for older people (Age UK, 2011). This has become a growing issue, with urbanisation being blamed for a breakdown in communication because people do not have the same opportunities to participate in communities as they would in a rural area (Griffin, 2010). It has also been suggested that the character of an urban environment may make the person living there feel either alienated or integrated into the community. For example, Victor, Scambler, Bowling and Bond (2005) believe that rural areas have low levels of loneliness because there are more opportunities for social interaction in these settings than in urban areas because the community is connected and more sociable. Hunt's (2013) research, moreover, argued that the closer people are geographically, the more they tend to isolate themselves from each other. Urban residents may not feel as though they need to make the effort because they are constantly surrounded by others. This is an interesting point, as it shows that a person can feel lonely in a crowd because urban areas are often perceived as more 'impersonal', with fewer possibilities for social relationships (Havens, Hall, Sylvestre and Jivan, 2004).

\subsubsection{Socio-economic differences among places}

A number of recent studies have investigated the impact of socio-economic levels and social exclusion on the loneliness experience, with growing evidence that socioeconomic status is a developing 'risk factor' in the rise of loneliness (Scharf and de Jong Gierveld, 2008; Scharf, Phillipson and Smith, 2004; Victor, Scambler, Shah, 
Cook, Harris, Rink and de Wilde, 2002). Deprivation indices have been created to capture differences socioeconomic inequalities between places, and have been widely utilized in health research to examine the social dimensions of ill health (Carstairs and Morris, 1991).

It is understood that in general, people in deprived areas are more likely to have shorter lives and suffer from health conditions (Secretary of State for Health in the UK, 2010). It is suggested that inequality is the underlying driving force and cause of poor health and well-being. Age Concern/Help the Aged (2009) estimates that around 1 in 10 older people in the UK experience chronic loneliness, with people living in deprived areas experiencing much higher rates. Indeed, London's Local Government Association's 'Campaign to end Loneliness' (2012) found that neighbourhood socioeconomic deprivation is a key risk factor in understanding loneliness. They reported that neighbourhoods are vital in understanding loneliness, as they can either protect people from it (encourage social contact) or exacerbate it (ignore the importance of social contact). As an outcome of this finding, London's Local Government Association considers that working with individuals and creating friendlier and more interactive communities will result in a reduction of the amount of people feeling lonely.

Livingston, Bailey and Kearns (2010) suggest a possible reason for loneliness levels being high in poorer communities is that deprived areas are transient places, so it can be harder to maintain strong social networks and attachments to place. It is also reported by Kearns et al. that any form of neighbourly contact, "even casual and fleeting" could be beneficial for reducing loneliness (2013, p. 10). In the case of deprived areas, Kearns et al. believe that "these possibilities for contact can be affected by such things as the structure of buildings and streets, the provision of local amenities, territorial boundaries, residential turnover and area reputations" (2013, p. 10). These issues are often found in lower socio-economic 
neighbourhoods. In other words, the context of a neighbourhood can create conditions where loneliness can be exacerbated through a lack of social contact.

\subsubsection{Social fragmentation}

In an age where technological developments have meant that it has become easier to contact others, research suggests that more people are losing strong ties to their physical community and neighbourhood. According to Griffin, the notion of what makes a community has become fluid, because "communities that were tied to localities are declining, but communities based on common interests, such as environmentalism, are thriving" (2010, p. 10). These fluid communities, while supported by new technologies, have resulted in a drop in interpersonal contact (Griffin, 2010). For example, a survey by Dorling, Vickers, Thomas, Pritchard and Ballas at the University of Sheffield in 2008 tracked 'anomie,' which is a sense of not belonging to a community. This study reached the conclusion that a sense of community had weakened in almost every area of the UK over the past 30 years (Dorling et al., 2008).

There are several theories that investigate social relationships and their influence on health, including Emile Durkheim's social integration theory. It may be that contemporary youth are more vulnerable to loneliness than those older in the population, because they are less integrated within a 'physical society' than in the past and more integrated into a 'virtual community' (Twenge, 2006). Dorling et al. (2008) believe that there has been a social segregation and polarisation over the past forty years and suspects that these factors could lead to more frequent and powerful feelings of loneliness and isolation because people are less inclined to socialise with others.

Durkheim's theory of social integration proposes that social integration and cohesion influence mortality, and remains relevant in today's world (Berkman, Glass, Brissette and Seeman, 2000). Despite the fact that his studies are focused on 
the prevalence of suicide, according to Berkman et al. (2000), the theory can be used to consider other human conditions and experiences, such as loneliness. Suffering from extreme and chronic loneliness can be a contributing factor in the choice toward taking one's own life (Ponizovsky and Ritsner, 2004). Berkman et al. (2000) states that Durkheim theorised that the underlying reason why people commit suicide is because of the level of social integration into a group.

Putnam in his book Bowling Alone (2000) documented the diminishing nature of community and social relationships, stating that low community involvement is the reason. Indeed, Flood (2005) used a national survey data from Australia and found that:

“[p]eople are more likely to report that personal support and friendship are available to them if they participate in paid employment, contribute some of their time each week to voluntary and charity work, are parents looking after other people's children, or actively participate in sporting, hobby or community-based associations" (Flood, 2005, p. 38).

What this suggests is that those people who participate in society are less likely to be lonely because they have a wider base of social networks. Social networks can come from a range of activities, not solely spending time with friends and family, as demonstrated in Flood's above quote.

\subsubsection{Mobility}

Migration, similar to urbanisation, has become a worldwide phenomenon in the age of globalisation (Hossen, 2012). This effect of changing place of residence has also been linked to increased loneliness rates. Griffin (2010) states that moving to a new town can result in acute loneliness. People who were driven to migrate predominately by pull factors were most likely to experience feelings of loneliness compared to those who were driven by push factors. Vance Packard (1972) wrote 
about how people need to be aware that mobility is potentially harmful to families and communities and can lead to higher levels of loneliness.

Durkheim' social integration theory is supported by empirical studies that have found an association between migration and higher rates of loneliness. In particular, it is thought that when people migrate to a new area or country, they are often disconnected from their familiar way of life, resources and family relations (Hossen, 2012; Willgerodt, Miller, and McElmurry, 2002; Schmitz, Jacobus, Stakeman, Valenzuela, and Sprankel, 2003; Rashid, 2011). This is often exacerbated by cultural, religious and language differences, and a lack of financial resources and community networks, which can also increases a person's sense of alienation and isolation. Immigrants access to health care could be affected by language and cultural barriers, making them more vulnerable to the negative health outcomes associated with loneliness (Shik, 2003).

Ponizovsky and Ritsner (2004) studied 400 adult Russian born Jewish immigrants living in Ashkelon and Jerusalem. Their researched indicated that the immigrants as a whole exhibit a higher level of experienced loneliness, than those who have not immigrated. Ponizovsky and Ritsner believe that the people who were connected to their feelings were able to "rely on one's own abilities in a self-sufficient and autonomic manner" (2004, p. 412). This suggests that those people who are more resilient with a strong sense of self are less likely to be lonely. In a study by Shik (2003), Hong Kong Chinese immigrant youth were more susceptible to experience loneliness during the first three to six months of arriving in Canada. Further to this, Shik discovered that adolescents were inclined "to use passive coping strategies during this period, which not only deters the adaptation process, but may also lead to negative health outcomes" (2003, p. 161).

The review on migration and loneliness has shown that those who have moved recently are more likely to be lonely. Migrants are less likely to be integrated into 
the community when they arrive, and over time migrants might become more connected to the community and their neighbours, and as a consequence feel less lonely. From this review of loneliness and migration, I have formulated a hypothesis of which to test in my own analysis of the NZGSS (2012) and the YCP (2006).

\subsubsection{Summary}

Overall, the review on the geographical dimensions of loneliness has shown that there are clear associations between a person's loneliness levels and their place of residence. From these findings I have formed a number of hypotheses in which I will analyse in Chapters 4, 5 and 6 of this thesis, more specifically that higher levels of loneliness will be reported by people who: live in urban areas, live in lower socioeconomic areas, are disconnected from their community, and have migrated to New Zealand.

\subsection{Loneliness in New Zealand}

There has been limited attention placed on loneliness in New Zealand policy and research, despite social isolation being a feature within New Zealand literature, such as John Mulgan's novel Man Alone, in which identity was explored through ideas of isolation. La Grow, Neville, Alpass and Rodgers (2012) conducted a cross-sectional study on 332 people aged 65 years and older using the de Jong Gierveld Loneliness Scale, and found that $52 \%$ of their 332 New Zealand participants reported themselves as lonely. Similarly, the Auckland Council (2012) researched loneliness levels in the city for people aged 50 and over and found that over half of their participants labelled themselves as being lonely. However, both of these studies focus on older populations - 50 years old and above - and excluded any focus on younger populations. More significantly, Statistics New Zealand and the Ministry of Social Development both have written comprehensive reports on wellbeing, including loneliness, the results of which will be detailed below. 
The Social Report (2010), prepared and written by the Ministry of Social Development, concludes that social contact is fundamental to the well-being of people due to the fact that humans are social creatures. The report notes that in 2008 sixteen percent of New Zealanders reported feeling lonely during the previous twelve months. Fifteen percent of people said that they felt lonely sometimes and less than two percent of people said that they were lonely most of the time or all of the time. In 2008, females were more likely than males to have reported being lonely. Interestingly, the report found that loneliness is most prevalent among young females. The Social Report (2010) also described how ethnic differences, such as Europeans (15\%) were found to be less lonely in the past year than Maori (18\%), Pacifica (23\%) and Asian peoples (24\%). Controlling for age, Maori and Pacifica have younger populations, so this could be explained by the fact that younger people are more likely to be lonely than older people.

The report argues that feelings of loneliness are strongly linked with self-rated health and overall life satisfaction. Those people who rated their health as 'excellent' or 'very good' were less likely to have felt lonely in the past 12 months than those people who classed their health as 'poor'. People who lived in couple-only households were found to be lonelier in comparison to those who live alone or with families, which seems, on a surface level, counter-intuitive. It was found that people living in Rodney were the least lonely, and those who live in Manukau, Hamilton, Tauranga, Auckland, and Waitakere had the highest levels of loneliness, however other attributes are not controlled for. The report also states that loneliness tends to decline as personal incomes rise.

Statistics New Zealand (2013) states that one in three adult New Zealanders (aged over 15 years old) felt lonely to some degree in the last four weeks in 2010. This is estimated to equate to about 1.02 million people, a result that was similar in the 2008 NZ General Social Survey. The report also shows that women are more likely to feel lonely than men, holding other variables constant. The chance of a person 
feeling lonely, based on these results, decreases as people get older (when holding all other factors constant), although, older people living in economic hardship were more likely than younger age groups living in similar levels of hardship to feel lonely. The report also shows that those people who had not had face-to-face contact with their family and friends in the last week were more likely to feel lonely in comparison to those who had contact.

I expect findings from my analysis of the 2012 NZGSS will be predominately in line with these previous studies of loneliness in New Zealand, however, my analysis will go beyond these studies by bringing in a geographical analysis to loneliness.

\subsection{Summary}

Loneliness is an important research topic given its association with other mental health conditions and its potential to exacerbate social exclusion and undermine community functioning. Given the potential for loneliness to lead to higher levels of social exclusion and a range of mental health conditions, it is imperative to undertake loneliness research in New Zealand to better understand its correlates and the ways loneliness might be avoided or reversed.

Loneliness literature largely centres around three key questions: why are more people lonely in the contemporary world, who are the loneliest, and more recently and to a lesser degree, where do these lonely people live, and does place have a role in raising or lowering the rate of loneliness? Literature reviewed in this chapter provides reasonably consistent findings to these questions, suggesting that certain people are more prone to loneliness. There is a noticeable gap in the New Zealand literature on the role of place in the study of loneliness. As a result, there is scope to conduct a current, original piece of research that explores whether the geographic context a person lives in has a positive or negative effect on their experience of loneliness in New Zealand. I have formed a number of hypotheses to test in the following analysis chapters based on findings to these questions. 
At the same time, I employ an approach to analysis that departs from most of this research. While much of the research reviewed here focuses on the statistical relationship between loneliness and a person's demographic, achieved characteristic, psychological wellbeing, and to a lesser degree, place, the central relationship between loneliness and connectivity is often overlooked. I argue that there is a strong case for separating the loneliness and connectedness factors to avoid a conflation of loneliness levels. It is also important to establish at what level of connectedness loneliness becomes most apparent, and also what types of connectedness are associated with different levels of loneliness. The following three chapters provide initial answers to the three central questions. 


\title{
Chapter 3 Research Design and Methodology
}

\author{
"If you're lonely when \\ you're alone, you're in \\ bad company." \\ - Jean-Paul Sartre
}

In Chapter 2, I reviewed the literature on loneliness as well as documented how loneliness is related to connectedness, a person's characteristics and their geography. I drew attention to how both loneliness and connectedness have been measured in a number of different ways in studies, and in fact are often merged into one entity. I detailed how loneliness can vary based on a person's attributes and characteristics, and how it has been widely suggested that younger people are more prone to reporting loneliness. I also explored the fields of mental health and wellbeing and concluded that there is scope and an opportunity for further research into the role of place in the study of loneliness.

For the purpose of my own research as reported in this thesis, I am defining loneliness as the aversive state experienced when a discrepancy exists between the interpersonal relationships one wishes to have and those that one perceives they currently have (Peplau and Perlman, 1982). In other words, loneliness is the difference between simply being alone and not liking being alone - the difference between an objective condition (lack of social connection) and how one feels about it. In this chapter I will firstly outline my positionality and then address the key steps involved in adopting the positive approach to the study of loneliness.

\subsection{Positionality}

When conducting research in the social sciences it is important to be clear about one's positionality (Metcalf 2008; Rose 1997). In my case I am a young, New Zealand 
European, educated female, and I come from a stable family background, albeit a 'broken/divorced' one. I have experienced, like most others, periods of loneliness, anxiety and experienced many ups and downs in my social environments. I was also about the same age as the Youth Connectedness Project (YCP) survey respondents when they participated in 2006. However, I was not a part of the data collection process for either of the 2012 New Zealand General Social Survey (NZGSS) or the YCP surveys I analyse below. Therefore, my positionality will not have affected the responses given for either of the surveys. I do want to acknowledge however, that I am aware of my positionality in the analysis to follow, in that I take a balanced nonbias approach to analysing the results that are produced out of the models I have developed out of the literature reviewed in Chapter Two.

\subsection{Epistemology}

I adopt the positivist approach standard in the multidisciplinary literature reviewed on loneliness. Positivism forms the basis for the majority of health research today (Broom and Willis, 2007; Saks and Allsop, 2012) including the allied field of health geography (Saks and Allsop, 2012). I employ positivism for its pragmatic and appropriate approach towards quantitative analysis (see Figure 3.1). Figure 3.1 shows the key features of the scientific method namely collecting data, looking for patterns and developing a theory, forming a hypothesis to test the theory, testing the hypothesis and supporting the theory (Mukherji and Albon, 2009). This view of positivism is a suitable way of analysing and interpreting the data gathered from participants in this research. 


\section{Figure 3.1: The research wheel of positivism}

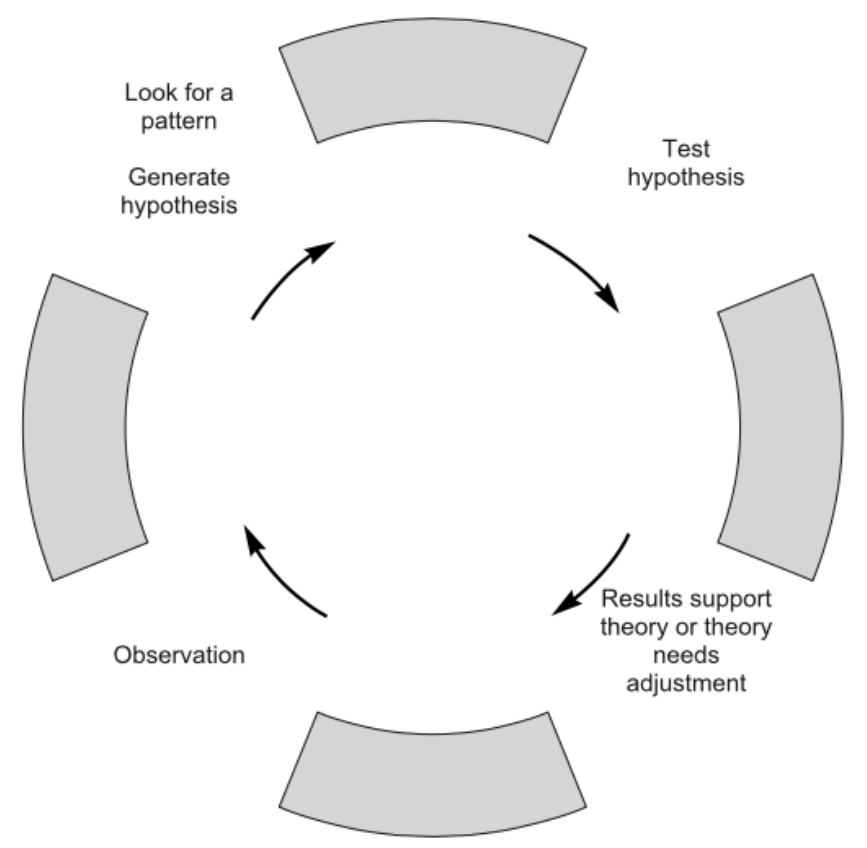

Source: Mukherji and Albon, 2009

There are some strong advantages to using a positivist framework, for example, quantitative methodology and statistical analysis has been valuable for large cohort studies (Mukherji and Albon, 2009). However, there are also some limitations for using a positivist framework, for example controlling for a number of variables in a model of loneliness can lead to a significant reduction in the sample size, as witnessed in the analysis of the YCP in Chapter 5. Methods such as questionnaires may or may not lead to superficial results and in some cases methods that delve deeper, such as interviews, would add additional information.

\subsection{Quantitative research}

The positivist paradigm lends itself to the use of quantitative methodology (Katsirikou and Skiadas, 2010). Researchers using quantitative methodology aim to form hypotheses, collect numerical data, and test the hypotheses (Tuli, 2010). Quantitative research "aims to measure, quantify or find the extent of a phenomenon, as opposed to qualitative methodology, which is usually more 
concerned with describing experiences, emphasising meaning and exploring the nature of an issue" (Mukherji and Albon, 2009, p. 14). Most quantitative geographers today have moved well past the idea that quantitative techniques lead to objective research, and I too recognise that knowledge is situated and that there is an important place for reflexivity (Marshall, 2006).

A significant part of quantitative research is the use of statistical analysis. Stata13 software was used to conduct statistical analysis. Stata13 is an integrated statistical software package, which provides the user with tools for data analysis, management and graphics. Stata13 provides commands to conduct statistical tests including cross-sectional and cohort analysis. In this thesis, Stata13 is used for basic statistics, cross tabulations, ordinary least squares (OLS) regression, logistic regression, hierarchical regression analysis, and probability analysis.

It must be noted that a longitudinal analysis was planned for the YCP survey, which has four waves of data, however, the fourth wave of data had just been collected and was unusable as it was being cleaned and prepared for analysis. Geocoded information was only available for the first wave (2006) of the project. As a result, it was decided that the analysis should be confined to this wave, in order to fulfil my role in bringing a geographical perspective to psychological data.

\subsection{Data}

I use two data sets for analysis, the 2012 NZGSS and the 2006 YCP, and details will be discussed here.

\subsubsection{NZGSS}

Statistics New Zealand's NZGSS provides detail on the well-being of New Zealanders aged 15 and above. It is a national random household survey of 8,000 households and is administered every two years by Statistics New Zealand (Smith, 2010). The NZGSS 2012 is the third survey in the series, with the first survey being carried out 
in 2008, and the second in 2010. It gathers a wide range of social and economic variables to demonstrate how New Zealanders are coping. The survey demonstrates a view of how well-being outcomes are distributed across different groups within the New Zealand population. Households were selected at random using a multistage sample design. Smith (2010) states that information was gathered through face-to-face computer-assisted interviews of one respondent from each household. The achieved response rate (calculated by dividing the weighted percentage of eligible individuals who responded by the estimated number of eligible individuals) for 2012 was 78 percent. Statistics New Zealand used donor imputation to fill in responses to questions (like age, personal income, and labour force status) when they were not given, to maintain the quality of the data.

\subsubsection{YCP}

The YCP is one of the biggest youth studies in New Zealand. The project was launched in 2004 and is organised and run by the Roy McKenzie Centre for the Study of Families, the New Zealand Council for Educational Research and the Foundation for Research, Science and Technology. Researchers collected data from New Zealand adolescents annually for four years $(2006,2007,2008,2013)$ to assess their connectedness to family, school, peer group and community as well as other indicators of adolescent functioning (Jose \& Pryor, 2010). Questionnaires were administered to 1866 participants individually each year at the same time during data collection sessions through laptops, so answers could not be seen by others. Teachers and research assistants were able to answer any questions the students had about concepts or definitions. New Zealand ethical guidelines were followed, and all participants obtained parental consent for their involvement as well as agreeing to the procedure themselves. A full description of the study was provided to parents and potential participants.

A number of research papers have been produced out the YCP, however only one on loneliness to date (Jose and Lim, 2014). This study had a particular focus on the 
protective factor of social connectedness on two constructs - loneliness and depression, and finds that social connectedness in 2006 predicted lower loneliness levels in 2007 which in turn lead to lower depression in 2008 (Jose and Lim, 2014).

The YCP sample is relatively small in comparison to those reviewed, as most studies covered in the literature review for this research drew on samples over 2000 participants, with a few wide scale surveys of over 10,000 participants. The YCP is also under a quarter of the size of the NZGSS, and so it is contextually important to keep in mind that this sample may be less representative as the youth population as a whole. Further to the sample size, YCP participants were chosen from three main areas of New Zealand: Wellington, Auckland, and the Taranaki because of the time and resource constraints of the data collection. Participants in other areas of New Zealand are not represented in the study, and this undercoverage resulted in selection bias. It is therefore important to understand that the results can be applied to youth in these three areas of New Zealand, but not necessarily to other parts of the country, even though the broad demographic characteristics of the sample mirror those of the country as a whole (Jose and Lim, 2014).

\subsection{Measures}

\subsubsection{Measuring loneliness}

Two main loneliness scales have been used in the majority of research projects on loneliness (Pinquart and Sörensen, 2001). The first is the University of California Loneliness Scale (Russell, Peplau, and Cutrona 1980), consisting of 20 items for scaling, and its shorter version, the 3-item UCLA Loneliness Scale (Hughes Waite, Hawkley and Cacioppo, 2004). The UCLA scale was published by Daniel Russell and his colleagues at the University of California in 1978 and contains twenty questions about one's social relations (Peplau and Perlman, 1982). Participants are asked to rate the extent to which the statements describe their experiences on a Likert scale from one (not at all) to four (very much). Russell, Peplau, and Cutrona (1980) later, however, developed a revised version of the UCLA scale, to include positively 
worded items. The new scale incorporated items that both reflected satisfaction and also dissatisfaction with social relationships.

The second prominent loneliness scale was developed by De Jong Gierveld and colleagues (De Jong Gierveld and Kamphuis 1985; De Jong Gierveld and Van Tilburg 1999). The De Jong Gierveld Loneliness Scale was developed at the beginning of the 1980s and involves 11 items for scaling, with a distinction between social and emotional loneliness. This could be helpful in determining the risk factors and consequences associated with social or emotional loneliness alone. Other studies use loneliness scales that are less common and vary between measuring loneliness in the past day (Weeks, 2013), week (Fokkema, De Jong Gierveld and Dykstra, 2012), month (Parker and Seal, 1996), year (Page and Cole, 1991), and even 10 years (Victor, Burholt and Martin, 2012) prior to the interview/questionnaire. Some studies do not even include a time frame. Loneliness is typically measured using between 1 and 24 items.

In summary it is clear that loneliness can be measured in a number of different ways. However, I am critical of adopting a loneliness scale, like the UCLA scale, because they do not differentiate loneliness and connectedness as separate entities. Hughes et al. state that "feelings of loneliness are not synonymous with being alone, but instead involve feelings of isolation, feelings of disconnectedness, and feelings of not belonging" (2004, p. 657). Accordingly, they studied the difference between subjective (loneliness) and objective (social contact) social isolation, and found that the two are related, but are individual concepts and should be treated as such. Thus, although I understand the drawbacks of using a one-item measure (for example issues with validity and reliability), this thesis will treat loneliness and social contact as separate concepts, in individual item measures.

The individual measure of loneliness in the NZGSS (2012) is a measure of 'isolation' from others. The question asked was 'in the last four weeks, how often have you felt 
isolated from others? Participants answered the item by selecting a point on a 5point Likert scale (none, a little, some, most, all of the time). The term 'loneliness' was avoided in the questionnaires because of stigma effect associated with the term. However, Statistics New Zealand (2013) uses the terms 'social isolation' and 'loneliness' interchangeably in their analysis, and therefore I adopt their practice. I discuss the responses to this question in Chapter 4 to follow.

Loneliness is also captured through a single item question in the YCP (2006). It is asked as follows: "Please tell us on how many days have you felt these ways in the last week: I felt lonely". Participants answered the item by selecting a point on a 4-point Likert scale (less than one day, one to two days, three to four days, five to seven days). There is no indication of how feeling 'lonely' was defined to the participants in the data dictionary, or the survey itself. Participants were allowed to ask for clarification from the teacher and research assistant, but records of this were not available to me. This means that participants may have interpreted the question differently, and there responses could reflect this. In the YCP survey, loneliness is measured across a week, whereas the NZGSS (2012) measured loneliness across a month. I recognise the difference in time frame of the two questions and will consider this fact when analysing the results. The results of the YCP question are presented in Chapter 5.

\subsubsection{Measuring connectedness}

There are many challenges in the study of connectedness and definitions of social connectedness have ranged widely in the literature. The origins of the connectedness concept can be found in a number of areas of research, including sociology and developmental psychology (Barber \& Schluterman, 2008). One of the challenges in the study of connectedness is the process that connectedness is thought to measure. Research projects have diverse directions on this point with researchers believing that connectedness represents any one or more of the following: "a measure of quality of a relationship, the degree of liking an 
environment or relationship, the quality of performance in an environment or relationship, the possession of feelings or attitudes states, and a combination of states and the behaviours that antecede them" (Barber \& Schluterman, 2008, p. 210). Despite these challenges and differing definitions, most studies conclude that connectedness is positively related to a variety of health and development indices, and ultimately to loneliness.

There is a range of different social connections that can be considered when researching loneliness including presence, frequency and quality of contact. The studies reviewed in the literature for this research use a variety of different measures of social connectivity - but predominately contact with family and friends. Some studies also focus on contact with classmates (youth studies), and wider community connectedness. Most studies have a focus on both the quality and quantity of social contact. I aim to test the effects of an array of different types of connectivity on loneliness.

For the NZGSS, I have created an overall connectedness index which is the sum of seven different types of contact - partnership, contact with family and friends, nonface-to-face contact with friends, voluntary work, participation in activity, and giving help to others. Details of these variables are present in Chapter 4.

I also created an overall measure of connectedness for the YCP sample which is the sum of five types of connectedness - family, presence of close friends, boy/girlfriend, ability to get on with classmates, and whether the young person believes that their neighbourhood is a good place (net friendships were originally included however the large number of missing values in this variable significantly reduced the size of this contact measure so it was omitted). Details of these variables are present in Chapter 5. 


\subsubsection{Expectations}

One would expect loneliness to decline with increased connectivity and there is clear evidence in the literature suggesting just that (Baumeister \& Leary, 1995; Cacioppo and Hawkley, 2000; Ernst and Cacioppo, 1999; Heinrich and Gullone, 2006). The more connected a person feels, the lower their feelings of loneliness are likely to be. I express this hypothesis graphically in Figure 3.2. The negative relationship shows that as connectivity (C) increases, loneliness (L) is reduced.

\section{Figure 3.2: Predicted relationship between loneliness and connectivity.}

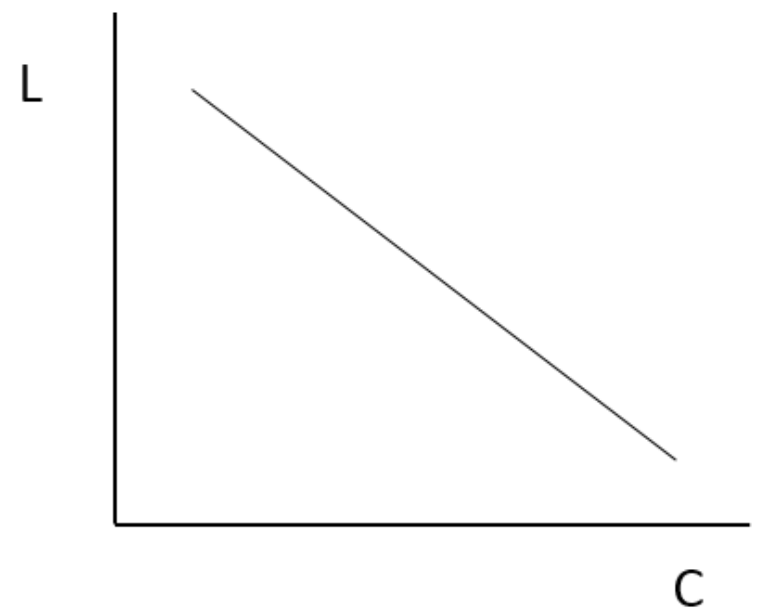

\subsubsection{Testing the relationship}

In chapters 4 and 5 I will estimate several equations to answer a range of hypotheses (including the depicted expectation above through equation (1)), all of which are detailed below.

\section{Linear model}

The expected negative relationship between connectivity and loneliness can be tested empirically by applying equation (1).

$$
L_{i}=a+\beta C_{i}+\varepsilon_{i}
$$


where $\mathrm{L}$ is a measure of loneliness as reported by the $\mathrm{i}^{\text {th }}$ respondent, $\mathrm{C}$ is a measure of contact (to be defined explicitly in chapters 4 and 5) for the $i^{\text {th }}$ respondent, $a$ and $\beta$ are parameters to be estimated, and $\varepsilon$ is the error term.

\section{Quadratic model}

I also explore the functional form and estimate the magnitude of the relationships between loneliness and connectedness in chapters 4 and 5. In order to test these hypotheses I use equation (2), in which $\mathrm{L}_{\mathrm{i}}$ is the measure of loneliness, $\mathrm{C}_{\mathrm{i}}$ is the measure of contact, $\mathrm{Ci}^{2}$ is the squared centred value of contact, $a$ and $\beta$ are parameters to be estimated, and $\varepsilon$ is the error term.

$$
L_{i}=a+\beta_{1} C_{i}+\beta_{2} C_{i}^{2}+\varepsilon_{i}
$$

\section{Linear-with-covariates model}

As a methodological next step I then consider the role of covariates, which are variables such as gender, age and employment status, which can alter both loneliness and connectedness and the relationship between them. For example, I will be interested in Chapter 4 in the way being young or old alters the level of loneliness and how loneliness in the two age groups is affected by the connections the young and old have. In other words, I add to equation (1) to form equation (3) as follows:

$$
L_{i}=\alpha+\beta_{1} C_{i}+\beta_{2} V_{i}, \ldots, \beta_{n} V_{i}+\varepsilon_{i}
$$

where $\mathrm{Li}_{\mathrm{i}}$ is a binary form of loneliness, $\mathrm{C}_{\mathrm{i}}$ is the measure of contact, $\mathrm{V}_{\mathrm{i}}$ is a typical covariate (such as age, and later place). The parameters $\beta_{2}$ through to $\beta_{n}$ indicate the influence the covariate has on the degree of loneliness. 


\section{Individual connectedness linear model}

I then examine the effect individual types of contact have on loneliness, without any added covariates, as shown in equation (4).

$$
L_{i}=a+\beta_{1} C_{i}^{k}+\varepsilon_{i}
$$

where $\mathrm{Li}_{\mathrm{i}}$ is the binary lonely variable, $\mathrm{C}^{\mathrm{k}}$ is a range of types of contact (to be defined in chapters 4 and 5), $a$ and $\beta$ are parameters to be estimated, and $\varepsilon$ is the error term.

\section{Interaction linear model}

Interaction terms are also introduced in chapters 4 and 5, and I will use equation (5) to estimate the interaction effects.

$$
L_{i}=a+\beta_{1} C_{i}^{1}+\beta_{2} C_{i}^{2}+\beta_{3} C_{i}^{3} \cdot C_{i}^{4}+\sum \beta X+\varepsilon_{i}
$$

where $\mathrm{L}$ is defined as loneliness, $\beta_{1} C^{1}$ is the first contact of interest, $\beta_{2} C^{2}$ is the second contact of interest, $\beta_{3} C^{1}, C^{2}$ is the interaction effect between the contact types, and $\Sigma \beta X$ is the sum of covariates.

\subsubsection{Covariates}

I have identified a number of covariates to include in equation (3), and equation (5) to answer two questions. The first is the effect on the level of loneliness, and the second is an interaction with a given measure of connectivity. Among other things, I will estimate how context (place) affects loneliness, and then later, how the characteristics of the people themselves correlate with loneliness. Three forms of geographical context are used as covariates in this analysis of loneliness, in both the NZGSS and the YCP. I test the relative effect of region, settlement type and level of neighbourhood deprivation on the relationship between loneliness and the contact index. 
I also test the influence of a person's age, gender and ethnicity, followed by their household structure, employment status, standard of living, and physical health, for both samples. In addition, I test level of income, highest qualification and migrant status for those in the 2012 NZGSS sample. Self-harming thoughts (YCP) and depression (NZGSS) are also used, however because of the endogeneity with loneliness, I cannot treat these variables as being independent.

\subsection{Method}

Literature reviewed in Chapter 2 employed a number of different methods to test hypotheses about loneliness levels, ranging from basic tabulations, ordinary least squares (OLS) regression, logistic regression, multivariate analysis, hierarchical and step-wise regression analysis. With two large samples at hand, I have used both OLS regression and logistic regression to estimate the direction and shape of the relationship between loneliness and connectivity. A series of hierarchical logistic regressions were used to include covariates and to control for context, demographics, achieved characteristics, and psychological wellbeing conditions.

My analysis of the 2012 NZGSS tests propositions about geography by identifying place using a set of dummy variables. Confidentiality restrictions do not allow Statistics New Zealand to release individual addresses. However, the 2006 YCP data set was assembled without such constraints in which case geocoding was possible from the questionnaire records. The dataset was not spatially coded, and Dr Mairead de Roiste, Senior Lecturer, School of Geography, Environment and Earth Sciences, Victoria University of Wellington, therefore undertook that step. Once most of the addresses of the YCP were geocoded, GIS software allowed me to create a map of individual addresses that could then be merged with other geocoded data (Brown, 2013, p. 2). A spatial statistics tool (Anselin Local Morans I) was then used to map and test whether loneliness, connectedness, and a number of personality factors have a clustered, random, or dispersed pattern across the Wellington, Auckland, and Taranaki regions, as reflected in Chapter 6. 


\subsection{Limitations}

The study of loneliness has a number of issues for researchers to consider, including the interpretation of survey questions. I recognise that the topic of loneliness is subjective, and how a person responds to the question will depend severely on their background and who they are as a person. As stated above, a number of controls will be considered to capture many of these factors. However, no statistical model can account for other unobserved factors, such as a participant misinterpreting the question, making up answers, and also just having a different view on what loneliness or social isolation means.

The majority of loneliness studies I reviewed above use loneliness scales, rather than one loneliness question. The use of scales means that the researcher can get a better idea about the extent of loneliness, and whether it extends from emotional, social or other reasons. Both the 2012 NZGSS and the 2006 YCP measure loneliness through a single question. The results, as I will show in the chapters to follow, are quite consistent with the wider literature.

It is also important to recognise the way in which the questions are phrased, in what context they are asked, and how this may influence results. In particular, when discussing matters involving feelings, like loneliness, it may be that a male participant would be more likely to respond truthfully to an anonymous survey. Additionally, the question asked by Statistics New Zealand was framed as 'social isolation' rather than loneliness, which could result in more truthful answers because of the stigma effect of loneliness. The YCP has the participant responding on a computer to pre-programmed questions, whereas the NZGSS is a face-to-face interview. The presence of the two different methods adds robustness to the overall studies. 


\subsection{Summary}

This chapter covered the research design and methodology used in the analysis of the NZGSS and YCP surveys reported in the next three chapters. My positionality, epistemology and methodology will inform the examination of these datasets where I will begin by applying equation (1) and (2) above. The results will allow the testing of most of the major propositions in the literature and beyond. The result is perhaps the most thorough study of loneliness yet undertaken in New Zealand. 


\section{Chapter 4 Adult loneliness in New Zealand}

"The most terrible poverty is loneliness and the feeling of being unloved." - Mother Teresa.

The experience of loneliness is intimately tied to the quantity and quality of a person's social relationships, with loneliness itself being that "complex set of feelings encompassing reactions to the absence of intimate and social needs" (Ernst and Cacioppo, 1999, p. 1). It is for this reason that my approach to loneliness set out in Chapter 3 is centred on the relationship between these two variables: loneliness and connectedness. While social contact is vital for a person's wellbeing, we all have different levels of need for social contact and also a desire for different sorts of connectivity. What has yet to receive any more than passing attention in New Zealand research is the different way the number and type of connectedness, and their frequency and quality, are associated with loneliness, and how the relationship between loneliness and connectedness along these four dimensions varies across the adult population of New Zealand.

This chapter will draw on the 2012 New Zealand General Social Survey (NZGSS) in order to address the association between loneliness and a number of types of connectivity, in populations defined by their demographic, ascribed and achieved characteristics, and geographic context. Of particular interest throughout is the geographic context as defined by the contexts of proximity of friends and family (ability to see them in-person), the level of deprivation in the neighbourhood, the size of the city, and the location of the region. 
The chapter is broken into five parts. The first examines the overall association between loneliness and connectivity in the population as a whole. Part two examines how loneliness differs across subpopulations as defined by covariates. Part three asks how the association between loneliness and connectivity differs by these covariates. Part four explores how loneliness is affected by different types of contact and the interaction effects between various combinations of types of contact. Part five presents a summary of the chapter as a whole.

\subsection{Loneliness and connectivity}

Loneliness has been considered as the state a person can be in if there is a discrepancy between the relationships they wish to have, and those that they currently have (Heinrich and Gullone, 2006). While there is a general agreement that loneliness declines with social connectedness we know little about just how responsive loneliness is to different levels of contact. In order to explore this relationship empirically it is necessary to define both loneliness and connectivity explicitly. I address each in turn.

\subsubsection{Loneliness}

Table 4.1 introduces four measures of loneliness based on the single NZGSS question introduced in Chapter 3. The table has fourteen columns. Column one refers to the number I have given the variable. For example the first row refers to the first definition of loneliness. Column two shows the question number in the NZGSS survey asking about loneliness (or isolation in this case). Column three shows the variable name I use, and the shortened version when necessary. Column four presents the specific question that was asked in the NZGSS, and column five shows the number of response categories offered for that question. Column six gives the label associated with each response category. Columns seven through twelve show the distribution of responses over the different response categories, and their associated percentages. The last column (14) is the total number of responses. The 
grey shaded column (13) gives the number of responses which were either "don't know", or that were not answered. These will be omitted from analysis.

Table 4.1: Description of the loneliness variable, New Zealand 2012

\begin{tabular}{|c|c|c|c|c|c|c|c|c|c|c|c|c|c|}
\hline \multirow[b]{2}{*}{$\begin{array}{c}\operatorname{Ref} \\
\text {. }\end{array}$} & \multirow[b]{2}{*}{$\begin{array}{c}\text { Question } \\
\text { Number }\end{array}$} & \multirow[b]{2}{*}{$\begin{array}{c}\text { Variable/ } \\
\text { Shortened } \\
\text { version }\end{array}$} & \multirow[b]{2}{*}{ Question } & \multirow[b]{2}{*}{$\begin{array}{c}\text { Num. of } \\
\text { groups }\end{array}$} & \multirow[b]{2}{*}{ Labels } & \multicolumn{8}{|c|}{ Number (percentage) } \\
\hline & & & & & & 0 & 1 & 2 & 3 & 4 & 5 & \begin{tabular}{|c|} 
Don't \\
know/ \\
missing \\
(DKM)
\end{tabular} & Total \\
\hline 1 & SOCQ11 & $\begin{array}{l}\text { Loneliness/ } \\
\text { Lonely }\end{array}$ & $\begin{array}{l}\text { In the last } \\
\text { four } \\
\text { weeks, } \\
\text { how often } \\
\text { have you } \\
\text { felt } \\
\text { isolated } \\
\text { from } \\
\text { others? }\end{array}$ & 5 & $\begin{array}{l}\text { (1) None of the } \\
\text { time, (2) A little } \\
\text { of the time, (3) } \\
\text { Some of the } \\
\text { time, (4) Most } \\
\text { of the time, (5) } \\
\text { All of the time }\end{array}$ & & $\begin{array}{c}5415 \\
(68.25)\end{array}$ & $\begin{array}{c}1202 \\
(15.15)\end{array}$ & $\begin{array}{c}963 \\
(12.14)\end{array}$ & $\begin{array}{c}258 \\
(3.25)\end{array}$ & $\begin{array}{c}73 \\
(0.92)\end{array}$ & $\begin{array}{c}23 \\
(0.29)\end{array}$ & $\begin{array}{l}7934 \\
(100)\end{array}$ \\
\hline 2 & $\begin{array}{l}\text { SOCQ11 } \\
\text { (derived) }\end{array}$ & $\begin{array}{l}\text { Lonely all or } \\
\text { most of the } \\
\text { time/ } \\
\text { Lonely_MA }\end{array}$ & & 2 & $\begin{array}{l}(1,2,3) \text { Some/a } \\
\text { little/none of } \\
\text { time, }(4,5) \\
\text { Most/all of time }\end{array}$ & $\begin{array}{c}7580 \\
(95.53)\end{array}$ & & & & $\begin{array}{c}258 \\
(3.25)\end{array}$ & $\begin{array}{c}73 \\
(0.92)\end{array}$ & $\begin{array}{c}23 \\
(0.29)\end{array}$ & $\begin{array}{l}7934 \\
(100)\end{array}$ \\
\hline 3 & $\begin{array}{l}\text { SOCQ11 } \\
\text { (derived) }\end{array}$ & $\begin{array}{l}\text { Lonely all, } \\
\text { most or some } \\
\text { of the time/ } \\
\text { Lonely_SMA }\end{array}$ & & 2 & $\begin{array}{l}(1,2) \mathrm{A} \\
\text { little/none of } \\
\text { time, }(3,4,5) \\
\text { Some/most/all } \\
\text { of time }\end{array}$ & $\begin{array}{c}6617 \\
(83.4)\end{array}$ & & & $\begin{array}{c}963 \\
(12.14)\end{array}$ & $\begin{array}{c}258 \\
(3.25)\end{array}$ & $\begin{array}{c}73 \\
(0.92)\end{array}$ & $\begin{array}{c}23 \\
(0.29)\end{array}$ & $\begin{array}{l}7934 \\
(100)\end{array}$ \\
\hline 4 & $\begin{array}{l}\text { SOCQ11 } \\
\text { (derived) }\end{array}$ & \begin{tabular}{|l|} 
Lonely all, \\
most, some, \\
or a little of \\
the time/ \\
Lonely_LSMA
\end{tabular} & & 2 & $\begin{array}{l}\text { (1) None of } \\
\text { time, }(2,3,4,5) \\
\text { A little /some } \\
\text { /most /all of } \\
\text { time }\end{array}$ & $\begin{array}{c}5415 \\
(68.25)\end{array}$ & & $\begin{array}{c}1202 \\
(15.15)\end{array}$ & $\begin{array}{c}963 \\
(12.14)\end{array}$ & \begin{tabular}{|c|}
258 \\
$(3.25)$
\end{tabular} & $\begin{array}{c}73 \\
(0.92)\end{array}$ & $\begin{array}{c}23 \\
(0.29)\end{array}$ & $\begin{array}{l}7934 \\
(100)\end{array}$ \\
\hline
\end{tabular}

Source: NZGSS (2012)

As stated in Chapter 3, the measure of loneliness in the NZGSS is 'isolation' from others, the question being 'In the last four weeks, how often have you felt isolated from others?'. Row one of the above table shows the distribution of respondents' levels of loneliness. The majority (68.25\%) reported that they did not feel lonely and less than one percent of respondents reported that they were lonely all of the time. 
Row two shows that $4.17 \%$ of respondents said that they felt lonely most or all of the time (MA), row three tells us that $16.31 \%$ said that they felt lonely some, most or all of the time (SMA), and row four reveals $31.46 \%$ reported being lonely at least a little of the time (LSMA) in the month before the survey was taken.

\subsubsection{Connectedness}

The layout of the columns in Table 4.2 is the same as Table 4.1, but for NZGSS questions on connectedness. Row one shows that $54.16 \%$ of the sample were partnered, row two shows that $84.64 \%$ of participants saw their family in the last month, and row three tells us that $92.03 \%$ of respondents saw their friends in the last month. A similar number of people had non-face-to-face contact with friends in the last month (91.33\%), 37.1\% of people had participated in activities (row five), $30.02 \%$ did voluntary work (row six) and $61.94 \%$ had helped others out in the last month (row seven). Response rates to each of these questions were quite high, as shown in column nine. 
Table 4.2: Descriptions of the connectedness variables, New Zealand 2012

\begin{tabular}{|c|c|c|c|c|c|c|c|c|c|}
\hline 1 & 2 & 3 & 4 & 5 & 6 & 7 & 8 & 9 & 10 \\
\hline & & & & & & \multicolumn{4}{|c|}{ Number (percentage) } \\
\hline Ref & $\begin{array}{c}\text { Qu. } \\
\text { Number }\end{array}$ & $\begin{array}{l}\text { Variable/ } \\
\text { Shortened } \\
\text { version }\end{array}$ & Question & $\begin{array}{l}\text { Num. of } \\
\text { group }\end{array}$ & Labels & 0 & 1 & $\begin{array}{l}\text { Don't } \\
\text { know/ } \\
\text { missing }\end{array}$ & Total \\
\hline 1 & CORDV1 & Partner & Social marital status & 2 & $\begin{array}{l}(0) \text { Non- } \\
\text { partnered, (1) } \\
\text { Partnered }\end{array}$ & $\begin{array}{c}3637 \\
(45.84)\end{array}$ & $\begin{array}{c}4297 \\
(54.16)\end{array}$ & & $\begin{array}{l}7934 \\
(100)\end{array}$ \\
\hline 2 & SOCQ01 & $\begin{array}{l}\text { Contact with } \\
\text { family/ Family }\end{array}$ & $\begin{array}{l}\text { In the last four weeks, } \\
\text { have you seen family or } \\
\text { relatives who don't live } \\
\text { with you? }\end{array}$ & 2 & (0) No, (1) Yes & $\begin{array}{c}1206 \\
(15.2)\end{array}$ & $\begin{array}{c}6715 \\
(84.64)\end{array}$ & $\begin{array}{c}13 \\
(0.16)\end{array}$ & $\begin{array}{l}7934 \\
(100)\end{array}$ \\
\hline 3 & SOCQ06 & $\begin{array}{l}\text { Contact with } \\
\text { friends/ Friends }\end{array}$ & $\begin{array}{l}\text { In the last four weeks, } \\
\text { have you seen friends } \\
\text { who don't live with you? }\end{array}$ & 2 & (0) No, (1) Yes & $\begin{array}{c}616 \\
(7.76)\end{array}$ & $\begin{array}{c}7302 \\
(92.03)\end{array}$ & $\begin{array}{c}16 \\
(0.21)\end{array}$ & $\begin{array}{l}7934 \\
(100)\end{array}$ \\
\hline 4 & SOCQ08 & $\begin{array}{l}\text { Non-face-to- } \\
\text { face contact } \\
\text { with friends/ } \\
\text { NF2Ffriends }\end{array}$ & $\begin{array}{l}\text { In the last four weeks, } \\
\text { have you had non-face- } \\
\text { to-face contact with } \\
\text { friends who don't live } \\
\text { with you? }\end{array}$ & 2 & (0) No, (1) Yes & $\begin{array}{c}672 \\
(8.47)\end{array}$ & $\begin{array}{c}7246 \\
(91.33)\end{array}$ & $\begin{array}{c}16 \\
(0.20)\end{array}$ & $\begin{array}{l}7934 \\
(100)\end{array}$ \\
\hline 5 & SOCQ018 & $\begin{array}{l}\text { Activities/ } \\
\text { Active }\end{array}$ & $\begin{array}{l}\text { In the last four weeks, } \\
\text { did you take part in any } \\
\text { activity (not including } \\
\text { volunteer work)? }\end{array}$ & 2 & (0) No, (1) Yes & $\begin{array}{c}4972 \\
(62.66)\end{array}$ & $\begin{array}{l}2943 \\
(37.1)\end{array}$ & $\begin{array}{c}19 \\
(0.24)\end{array}$ & $\begin{array}{l}7934 \\
(100)\end{array}$ \\
\hline 6 & SOCQ015 & $\begin{array}{l}\text { Volunteer } \\
\text { work/Volwork }\end{array}$ & $\begin{array}{l}\text { In the last four weeks, } \\
\text { did you do any voluntary } \\
\text { work for a group or } \\
\text { organisation? }\end{array}$ & 2 & (0) No, (1) Yes & $\begin{array}{c}5535 \\
(69.76)\end{array}$ & $\begin{array}{c}2382 \\
(30.02)\end{array}$ & $\begin{array}{c}17 \\
(0.22)\end{array}$ & $\begin{array}{l}7934 \\
(100)\end{array}$ \\
\hline 7 & SOCQ20 & $\begin{array}{l}\text { Help others/ } \\
\text { helpothers }\end{array}$ & $\begin{array}{l}\text { In the last four weeks, } \\
\text { did you give any help } \\
\text { that you did not get paid } \\
\text { for? }\end{array}$ & 2 & (0) No, (1) Yes & $\begin{array}{c}3002 \\
(37.84)\end{array}$ & $\begin{array}{c}4915 \\
(61.94)\end{array}$ & $\begin{array}{c}17 \\
(0.22)\end{array}$ & $\begin{array}{l}7934 \\
(100)\end{array}$ \\
\hline
\end{tabular}

Source: NZGSS (2012)

These seven types of contact are likely to have an effect on the degree of loneliness reported by respondents. However, initially I will explore the influence of the number of these different types of contact. 


\subsubsection{An index of connectedness}

To test the relationship between loneliness and number of types of contact, an overall index of connectedness was constructed which I call 'connect'. This index is the sum of the presence of partnership, contact with one or more family members, contact with one or more friends, non-face-to-face contact with friends, and participation in community work (activity, help others and volunteer work) - seven categories in all.

Table 4.3 presents the distribution of respondents over this connectivity index, from a minimum of zero contacts to a maximum of all seven types of contacts. It shows that 23 people responded 'no' to all of the possible contacts, from which I infer isolation and a considerable potential for loneliness. The majority of participants, however (27.06\%), responded 'yes' to six of the types of possible contacts. Just over seven percent (7.22\%) of the sample responded 'yes' to experiencing all of the types of contact, suggesting these people feel widely connected. My expectation is that they are likely to express a low level of loneliness as a result.

Table 4.3: Distribution of responses to the number of types of contact a person has, New Zealand 2012

\begin{tabular}{|c|c|c|c|}
\hline connect I & Freq. & Percent & Cum. \\
\hline 01 & 23 & 0.29 & 0.29 \\
\hline 11 & 138 & 1.74 & 2.04 \\
\hline 21 & 410 & 5.18 & 7.22 \\
\hline 31 & 1,207 & 15.26 & 22.48 \\
\hline 41 & 2,019 & 25.52 & 48.00 \\
\hline 51 & 2,141 & 27.06 & 75.06 \\
\hline 61 & 1,402 & 17.72 & 92.78 \\
\hline 71 & 571 & 7.22 & 100.00 \\
\hline Total | & 7,911 & 100.00 & \\
\hline
\end{tabular}

Source: NZGSS (2012) 
Figure 4.1 shows the same distributions graphically, and that the number of responses rise successively until after 5 types of contact, where the number of respondents starts to lower.

Figure 4.1: Frequency distribution of the number of types of contact, New Zealand 2012

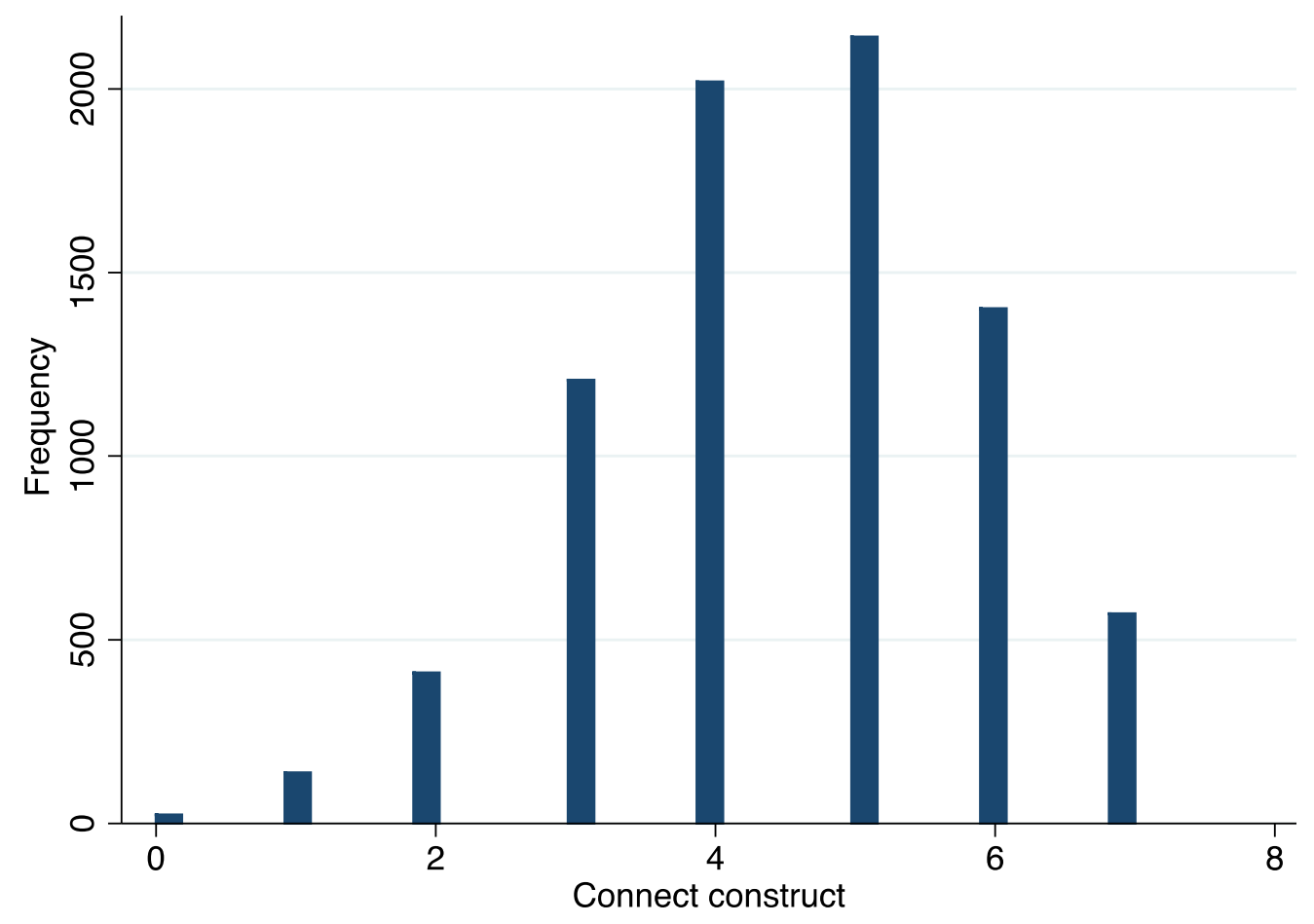

Source: NZGSS (2012)

I recognise that this contact index is missing detail on the frequency and quality of contact - which have both been documented as important factors to consider when researching loneliness. There was only one question available in the NZGSS (2012) about the quality of one's social contact, and therefore it was not possible to properly assess this. Variables that involved the frequency of contact, had a lot of missing values, which significantly reduced the sample size. Accordingly these variables were excluded from analysis. However I have produced figures 4.2 and 4.3 to simply show how both higher quality and higher frequencies of social 
relationships are associated with lower levels of loneliness (most significantly the quality of one's relationships).

Figure 4.2: How loneliness falls with increased time spent with friends, New Zealand 2012

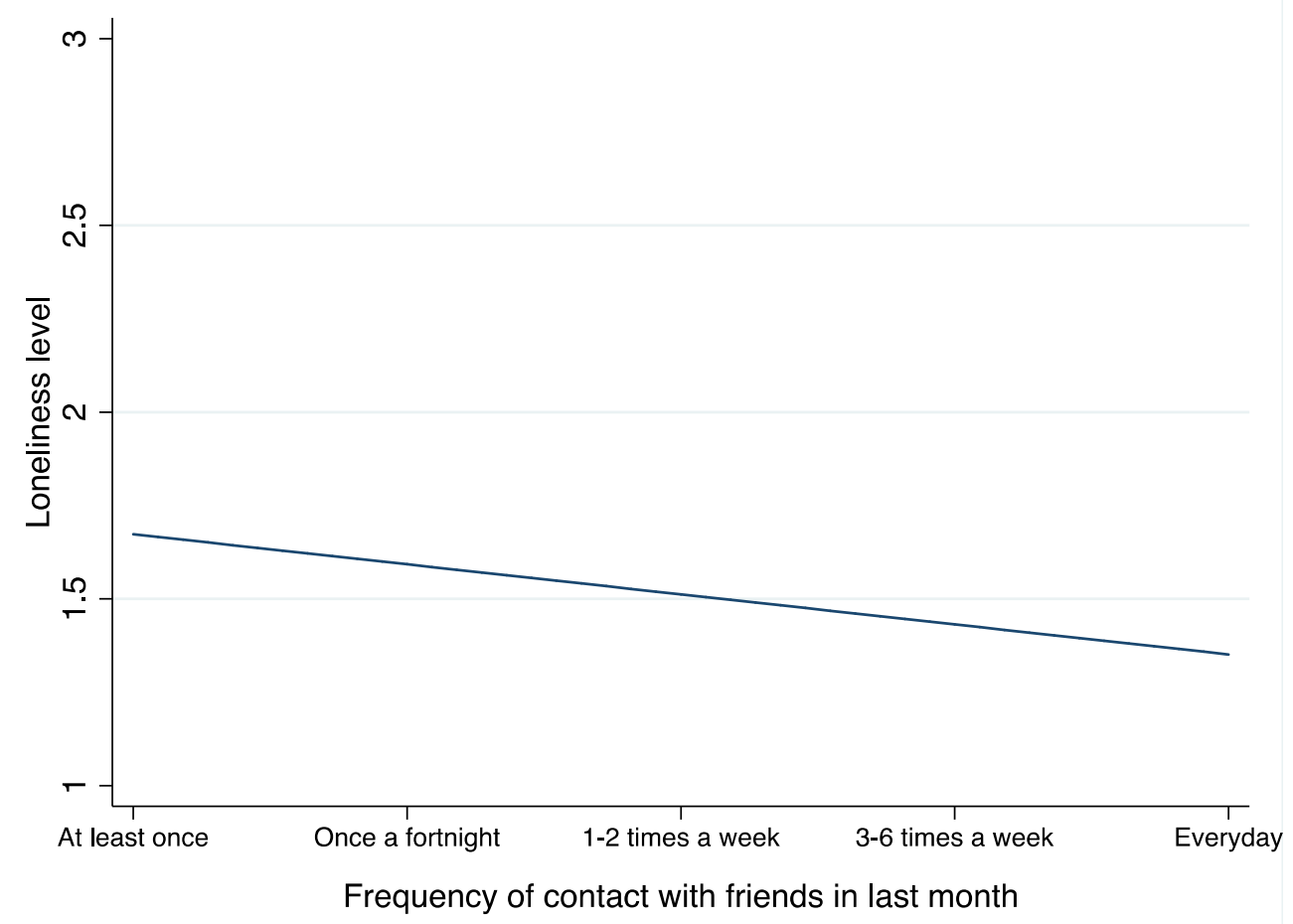

Source: NZGSS (2012) 
Figure 4.3: How loneliness falls with increased quality of friendships, New

Zealand 2012

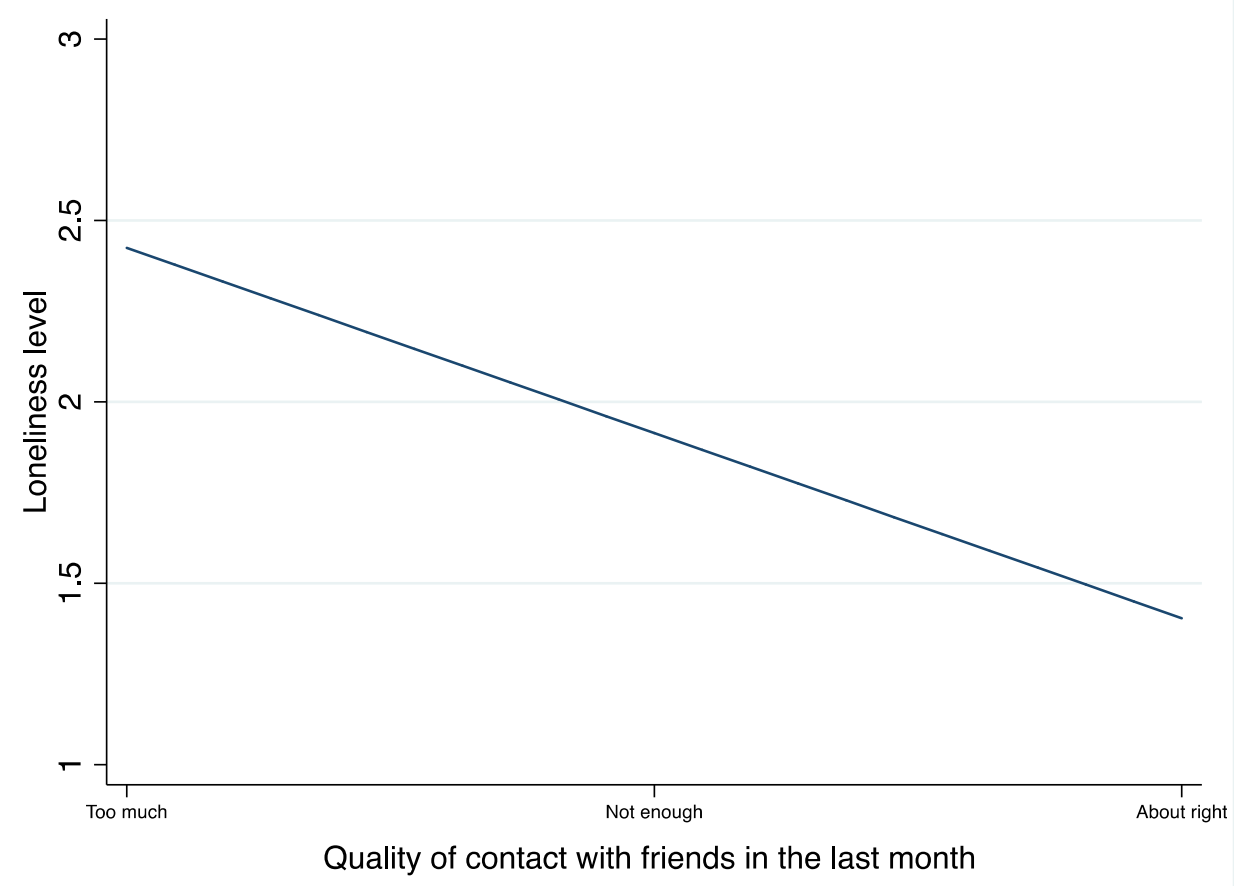

Source: NZGSS (2012)

\subsubsection{Testing the relationship}

To test the hypothesis that higher levels of connectedness are associated with lower levels of loneliness, an Ordinary Least Squares (OLS) linear regression, as in equation (1) in Chapter 3, was estimated, and the results are displayed in Table 4.4.

Table 4.4: The estimated relationship of loneliness to the connectivity index, NZGSS (2012)

\begin{tabular}{|c|c|c|c|c|c|c|c|}
\hline Source I & SS & $d f$ & \multicolumn{2}{|c|}{ MS } & & $\begin{array}{l}\text { Number of obs } \\
F(1,7901)\end{array}$ & 7903 \\
\hline Mode1 & 130.288697 & 1 & 130 & 288697 & & Prob $>\mathrm{F}$ & $=0.0000$ \\
\hline Residual | & 6184.32398 & 7901 & .78 & 726741 & & R-squared & $=0.0206$ \\
\hline & & & & & & Adj $\mathrm{R}$-squared & 0.0205 \\
\hline Total | & 6314.61268 & 7902 & .79 & 115753 & & Root MSE & .88472 \\
\hline 1onely & Coef. & std. & Err. & $\mathrm{t}$ & $P>|t|$ & [95\% Conf. & Interva \\
\hline $\begin{array}{r}\text { connect } \\
\text { _cons }\end{array}$ & $\begin{array}{r}-.0926936 \\
1.949255\end{array}$ & $\begin{array}{l}.0071 \\
.0335\end{array}$ & $\begin{array}{l}346 \\
319\end{array}$ & $\begin{array}{r}-12.90 \\
57.36\end{array}$ & $\begin{array}{l}0.000 \\
0.000\end{array}$ & $\begin{array}{r}-.1067773 \\
1.882642\end{array}$ & $\begin{array}{r}-.0786099 \\
2.015869\end{array}$ \\
\hline
\end{tabular}

Source: NZGSS (2012) 
The results confirm the hypothesis that the more connected a person is, the less likely they are to be lonely. The equation may be written succinctly as:

$$
L_{i}=1.95-0.093 C_{i}
$$

The coefficient of -0.093 means that for every additional type of connectedness in the last month, the level of loneliness (on a one to five scale) decreases by 0.0993 of a unit. This result is statistically significant, as reflected by the z-score $(-12.90)$ and the $\mathrm{p}$-value $(0.000)$. The $\mathrm{R}^{2}$ value of 0.02 however implies that much else is going on.

Given the clear negative relationship between loneliness and connectivity I now want to pay attention to other possible functional forms of this relationship. There are three relationships of interest as illustrated in Figure 4.4. The first is the linear relationship just estimated (solid line labelled 2) which suggests that each additional contact has the same (marginal) effect in reducing loneliness. The second is the concave dashed line (line 3), sitting above the diagonal suggesting that loneliness levels remain high until a certain level of connectedness is reached, after which loneliness levels fall. This model implies that people need a certain social mix before loneliness levels drop. 
Figure 4.4: Three possible functional forms linking loneliness and the connectivity index.

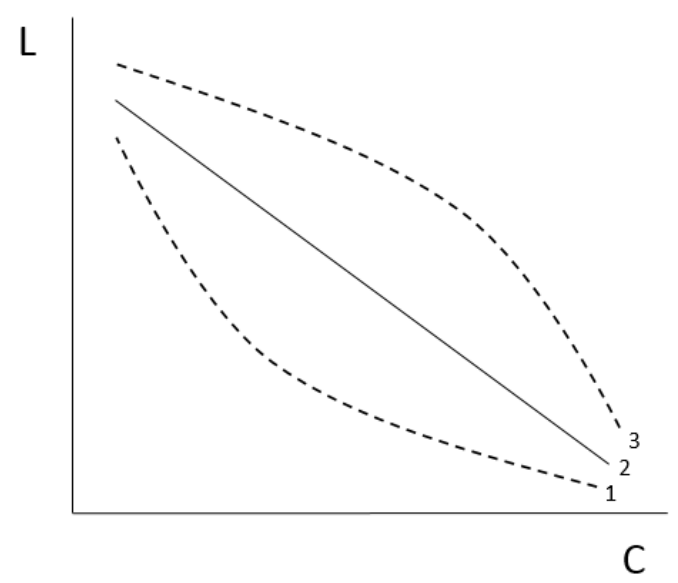

The third possible form is represented by the convex dotted line (line 1) sitting below the diagonal. This suggests that loneliness levels fall most quickly after the first one or two connections, and that additional connections have successively less impact. According to this hypothesis, an average person with no connectivity will have a high level of loneliness, but their loneliness levels will lower quickly once they become connected (regardless of type at this stage). In order to test these hypotheses an OLS regression on the quadratic model in equation (2) in Chapter 3 was estimated, and the results are displayed in Table 4.5.

Table 4.5: The estimated quadratic relationship between loneliness and connectivity, NZGSS (2012)

\begin{tabular}{|c|c|c|c|c|c|c|c|}
\hline Source I & SS & $d f$ & \multicolumn{2}{|r|}{ MS } & & $\begin{array}{l}\text { Number of obs }= \\
F(2,7900)\end{array}$ & $\begin{array}{r}7903 \\
88.14\end{array}$ \\
\hline \begin{tabular}{r|} 
Mode1 \\
Residual
\end{tabular} & $\begin{array}{l}137.826113 \\
6176.78657\end{array}$ & $\begin{array}{r}2 \\
7900\end{array}$ & $\begin{array}{l}68 \\
.78\end{array}$ & $\begin{array}{l}130564 \\
871717\end{array}$ & & $\begin{array}{l}\text { Prob > F } \\
\text { R-squared }\end{array}$ & $\begin{array}{l}=0.0000 \\
=0.0218\end{array}$ \\
\hline & & & & & & Adj $\mathrm{R}$-squared & 0.0216 \\
\hline Total | & 6314.61268 & 7902 & .79 & 115753 & & Root MSE & .88424 \\
\hline 1one1y I & Coef. & std. & Err. & $t$ & $P>|t|$ & [95\% Conf. & Interva1] \\
\hline connectc & -.0880926 & .007 & 332 & -12.01 & 0.000 & -.1024652 & -.07372 \\
\hline connectc2 & .0121801 & .0035 & 229 & 3.10 & 0.002 & .0044902 & .01987 \\
\hline _cons | & 1.506773 & .012 & 745 & 120.79 & 0.000 & 1.482319 & 1.531226 \\
\hline
\end{tabular}

Source: NZGSS (2012) 
The estimated equation now reads:

$$
L_{i}=1.51-0.088 C_{i}+0.012 C_{i}^{2}
$$

which says that connectedness remains negatively associated with loneliness $\left(\beta_{1}=-\right.$ 0.088), and starts to increase slightly $\left(\beta_{2}=0.012\right)$ at higher levels of contact. In order words, the relationship is convex.

I demonstrate the convexity by plotting the average predicted value (point on the 15 scale) of loneliness at successive levels of contact (Figure 4.5). Therefore loneliness levels are highest for those who have none or little social contact, and these loneliness levels drop at a decreasing rate as number of types of contact increase.

Figure 4.5: How loneliness falls with the number of different types of contacts, New Zealand 2012

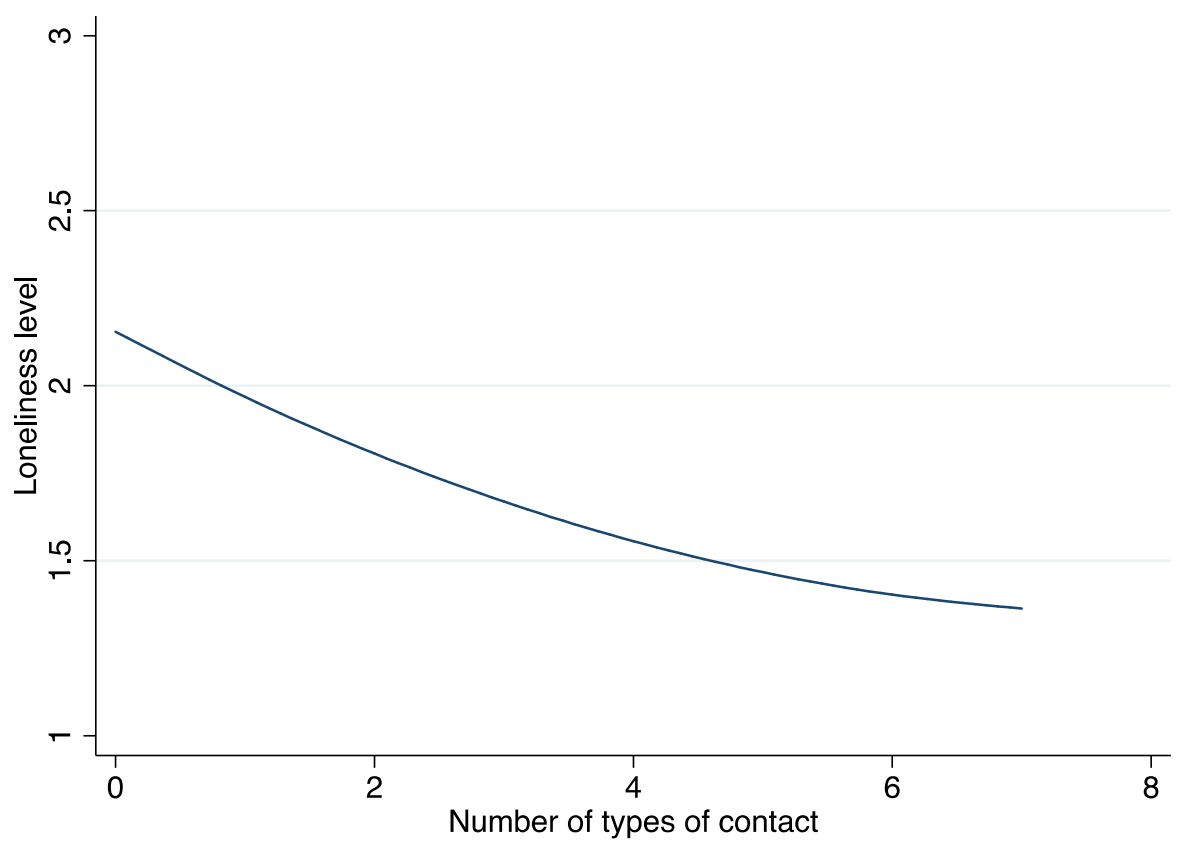

Source: NZGSS (2012) 
In summary, it is apparent from these initial results that loneliness is "an embedded social structure feature of contemporary" society (Franklin, 2012, p. 11). I have shown that loneliness is associated with lower levels of connectivity so that each additional type of contact reduces loneliness but to a lesser degree.

\subsection{Who is the loneliest?}

So far I have only used the 'lonely' variable introduced in Table 4.1. This has allowed me to demonstrate the way the average level of loneliness declines with connectivity. However in much of the discussion below I am not as interested in the average level of loneliness, on a 1-5 scale, as I am in the proportion of people who are lonely according to a given criterion. I suggest it is often more interesting conceptually, and more useful practically, to know whether a particular change in context (or intervention) raises or lowers the proportion of the population who say they are lonely than knowing whether the average level of loneliness rises or falls.

In Table 4.1 I provided three possible threshold measures of loneliness; those who say they are lonely MA, SMA, or LSMA of the time. However, as shown in Table 4.1, there are relatively few people who fall within the MA category (less than five percent), and the LSMA variable includes a higher proportion of people than most studies reviewed in Chapter 2 would deem as 'lonely'. Therefore I have chosen as my threshold level of loneliness the middle ground, which is being lonely SMA of the time, which includes $16.31 \%$ of the population.

Unlike 'lonely' which approximated a continuous variable, albeit from 1-5 only, this new threshold measure, LonelySMA, is a binary variable because the respondent is either in this particular loneliness category or not. This change in level of measurement from continuous to binary however has implications for the way we model loneliness. It is no longer appropriate to use OLS regression since there is no continuity in the dependent variable. For well documented reasons, I will use 
logistic regression in order to estimate the log-odds of someone being LonelySMA. From these log-odds I can easily calculate the odds and, even more usefully, the estimated probability of being lonely SMA.

Moving from a continuous to a binary variable not only has implications for how I estimate being lonely but for how I model (and interpret) the effect of other variables, most particularly their interaction with each other. In particular, it matters a great deal which metric I model the event in, the log-odds of being lonely, the odds of being lonely, or the probability of being lonely. ${ }^{1}$

There is a well-defined mathematical relationship between the log-odds of being lonely, the odds of being lonely, and the probability of being lonely. Although these are standard results, it is helpful for me and the reader to repeat the relationships between them here. ${ }^{1}$

Let $\mathrm{p}$ be the proportion of the population who fall above the category l've defined as lonelySMA. Then the odds of being lonely (SMA) is just the ratio of the probability of being lonely (p) and not being lonely (1-p). Hence

\section{(1) Odds $=p /(1-p)$}

Since it is simpler to model relationships as if they were linear it is conventional to take the natural log of these odds, known as the logit, as the dependent variable in the linear logistic regression model.

(1) $\log$ odds $=\operatorname{logit}=\log (\mathrm{p} / 1-\mathrm{p})$

An important concept in the modelling of binary variables is the odds ratio. These are just the ratio of ratios as follows. In the following, $\mathrm{p} 1$ is the probability of

${ }^{1}$ Logistic regression was introduced to geography most comprehensively by Neil Wrigley in the mid1980s (Wrigley, 1985). 
someone being lonely and $\mathrm{p} 2$ is the probability of them not being lonely (SMA in this case).

(2) Odds ratio $=$ odds1/odds2 $=\mathrm{p} 1-(1-\mathrm{p} 1) / \mathrm{p} 2(1-\mathrm{p} 2)$

It is straight forward to calculate this odds-ratio as it simply involves exponentiating the estimated coefficients of the logistic regression (the regression of lonelySMA on 'connect' for example).

(3) Odds_ratio $=\exp (b)=e^{b}$

Following this step it is then possible to compute the probability that someone will be lonely directly from the regression coefficients for the formula

(4) Probability $=\exp (\mathrm{Xb}) /\left(1+\exp (\mathrm{Xb})\right.$ or $\mathrm{e}^{\mathrm{Xb}} /\left(1+\mathrm{e}^{\mathrm{Xb}}\right)$

where $\mathrm{Xb}$ is the linear predictor from the regression model in equation 1 in chapter 3 , when we use lonelySMA rather than lonely.

Fortunately the statistical package I am using here, Stata13, has a built in flexible estimation routine, 'margins', which automates these calculations. The above relationships are especially important when it comes to formulating and interpreting interaction effects, for example the way age might relate to the level of connectivity (connect) in altering the predicted level of loneliness. As the UCLA notes emphasise, logistic interactions are a complex concept because researchers need to decide on how to conceptualise the interaction - whether in terms of log odds (logits), odds ratios or probabilities. The decision as to what metric to use can make a big difference because an interaction that is significant in log odds for example, may not be significant in terms of the probabilities. As I discuss later in the chapter, interaction involves exploring differences in differences because if differences are not different there is no interaction. But the metric used can mean 
that the difference in differences that are statistically different in one metric may not be in another.

The logistic regression fits a maximum likelihood logit model. It is only linear in the $\log$ of the odds ratio (or logit) metric. Probabilities in turn are a nonlinear transformation of the log odds results. This last step is important because, unlike in linear regression of a continuous variable on arguments $\mathrm{X}$, it is not possible simply to read off the likely average level of loneliness from any given value of $\mathrm{X}$ as one would in linear regression. For this reason, when it comes to estimating the probabilities of being lonelySMA from a fitted logistic model, at any given age for example, it is necessary to both specify a particular age and also specify the specific values of all the other variables in the logistic regression model (or their means).

In summary, I began this chapter by treating loneliness as if it were a continuous variable (even though in fact it is truncated to lie between 1 and 5). This yielded 'average' levels of loneliness. However, I have argued that it is often more useful to know whether people are lonely or not according to some threshold of loneliness. The one I've selected here from the options given in the NZGSS is 'being lonely some/most/all of the time' (LonelySMA), a degree of loneliness experienced between $16.31 \%$ of the 2012 New Zealand population.

I now wish explore the influence a range of covariates might have on loneliness over and above the influence of types of contact. For the following application I estimate the linear-with-covariates model, as in equation (3) in Chapter 3.

\subsubsection{Context}

A general suggestion about the geography of loneliness is that loneliness will be higher in the larger centres because rural residents have a stronger sense of community than urban residents, and that urban residents are more likely to be socially avoidant and withdrawn (Hunt, 2013). There are also suggestions that 
loneliness is higher in lower socio-economic areas because deprived areas are often transient places and lack local amenities that encourage interaction with others.

I will now test the association between being lonely SMA, connectivity, and a number of context variables - those being region, settlement type, and neighbourhood deprivation (estimated by the New Zealand Deprivation Index 2006 (NZDep2006)). These are shown in Table 4.6. Given the geographical focus of this thesis, I placed context variables above all other covariates in order to see how they were affected by adding control variables.

Table 4.6: Description of context covariates, NZGSS (2012)

\begin{tabular}{|c|c|c|c|c|c|c|c|c|c|c|c|c|c|}
\hline \multirow[b]{2}{*}{ Ref. } & \multirow[b]{2}{*}{$\begin{array}{c}\text { Qu. } \\
\text { Number }\end{array}$} & \multirow{2}{*}{$\begin{array}{l}\text { Variable/ } \\
\text { shortene } \\
\text { d version }\end{array}$} & \multirow[b]{2}{*}{ Qu. } & \multirow{2}{*}{$\begin{array}{c}\text { Number } \\
\text { of } \\
\text { groups }\end{array}$} & \multirow[b]{2}{*}{ Labels } & \multicolumn{8}{|c|}{ Number (percentage) } \\
\hline & & & & & & 1 & 2 & 3 & 4 & 5 & 6 & DKM & Total \\
\hline 1 & REGDV1 & Region & Region & 6 & $\begin{array}{l}\text { (1) Auckland, } \\
\text { (2) } \\
\text { Wellington, } \\
\text { (3) } \\
\text { Northland, } \\
\text { BoP, } \\
\text { Gisborne, (4) } \\
\text { Rest of North } \\
\text { Island, (5) } \\
\text { Canterbury, } \\
\text { (6) Rest of } \\
\text { South Island }\end{array}$ & $\begin{array}{c}1832 \\
(23.09)\end{array}$ & $\begin{array}{c}1033 \\
(13.02)\end{array}$ & $\begin{array}{c}1179 \\
(14.86)\end{array}$ & $\begin{array}{c}1571 \\
(19.80)\end{array}$ & $\begin{array}{c}1198 \\
(15.10)\end{array}$ & $\begin{array}{c}1121 \\
(14.13)\end{array}$ & & $\begin{array}{l}7934 \\
(100)\end{array}$ \\
\hline 2 & ua & Area & Urban area & 4 & \begin{tabular}{|l|} 
(1) Main \\
urban, (2) \\
secondary \\
urban, (3) \\
minor urban, \\
(4) rural
\end{tabular} & $\begin{array}{c}5750 \\
(72.47)\end{array}$ & $\begin{array}{c}685 \\
(8.63)\end{array}$ & $\begin{array}{c}799 \\
(10.07)\end{array}$ & $\begin{array}{c}682 \\
(8.60)\end{array}$ & & & $\begin{array}{c}18 \\
(0.23)\end{array}$ & $\begin{array}{l}7934 \\
(100)\end{array}$ \\
\hline 3 & NZDep & $\begin{array}{l}\text { NZDep20 } \\
06\end{array}$ & $\begin{array}{l}\text { Socio- } \\
\text { economic } \\
\text { Deprivation } \\
\text { in New } \\
\text { Zealand }\end{array}$ & 10 & $\begin{array}{l}\text { (1) most } \\
\text { deprived - (5) } \\
\text { least } \\
\text { deprived }\end{array}$ & $\begin{array}{c}1333 \\
(16.80)\end{array}$ & $\begin{array}{c}1386 \\
(17.47)\end{array}$ & $\begin{array}{c}1439 \\
(18.14)\end{array}$ & $\begin{array}{c}1974 \\
(24.88)\end{array}$ & $\begin{array}{c}1802 \\
(22.71)\end{array}$ & & & $\begin{array}{l}7934 \\
(100)\end{array}$ \\
\hline
\end{tabular}

Source: NZGSS (2012) 
Table 4.7 shows that geography appears to be an important factor in the study of loneliness, with the influence becoming stronger as we move from the broad (regional) to the local (neighbourhood). Model 2 in Table 4.7 shows that the odds of someone being lonely SMA are 1.22 times higher in Wellington than in the rest of New Zealand. This result is supported by findings in Model 3, which show the odds of someone reporting being lonely SMA is 1.17 times higher in main urban areas (such as Wellington or Auckland), than those who live outside of main centres. These findings are consistent with some studies reviewed in the literature review for this thesis, which also suggest that loneliness levels are higher in areas that are denser in population (Age UK, 2011; Hunt, 2013). Hunt (2013) suggests that a reason for this could be that residents of highly dense areas are less likely to make the effort to socialise and more likely to isolate themselves from others because they are complacent given that they are surrounded by hundreds of thousands of people.

Table 4.7: Model of loneliness controlling for context, New Zealand 2012

\begin{tabular}{|c|c|c|c|}
\hline Variable | & Mode12 & Mode 13 & Mode 14 \\
\hline connect | & $.762 * * *$ & $.763 * * *$ & $.78 * * *$ \\
\hline We11ingtonR | & $1.22 *$ & $1.19 *$ & $1.22 *$ \\
\hline Main_urban | & & 1.17 & $1.22 *$ \\
\hline Rural | & & .987 & 1.14 \\
\hline NZdep3_4 | & & & 1.09 \\
\hline NZdep5_6 | & & & $1.29 \%$ \\
\hline NZdep7_8 | & & & $1.58 * * *$ \\
\hline NZdep9_10 | & & & $1.73 * * *$ \\
\hline _cons | & $.621 * * *$ & $.551 * * *$ & $.349 * * *$ \\
\hline r2_p | & .0228 & .0235 & .0296 \\
\hline df_m | & 2 & 4 & 8 \\
\hline N I & 7903 & 7903 & 7903 \\
\hline
\end{tabular}

Source: NZGSS (2012) 
Table 4.7 also shows that the odds of loneliness rises successively with higher levels of neighbourhood deprivation, even after controlling for regional and urban area effects. People who live in areas of NZDep 9-10 (highly deprived) show the highest odds of being lonely (1.73), in comparison to those who live in the least deprived areas (the base). The literature reviewed for this thesis also clearly suggests that loneliness is more prevalent in lower socioeconomic areas (Kearns, Whitley, Tannahill and Ellaway, 2013; Scharf and de Jong Gierveld, 2008). Kearns et al believe that possible reasons for this finding is that the likelihood of social contact "can be affected by... residential turnover and area reputations" (2013, p. 10). These factors are often found in lower socio-economic neighbourhoods. In other words, the context of a neighbourhood can create conditions that inhibit contact.

\subsubsection{Demographics}

Although the literature is inconsistent when it comes to age and gendered differences in loneliness levels, findings from New Zealand studies, such as The Social Report (2010), state that young and females are more likely to report being lonely. The general hypothesis when it comes to ethnicity is that ethnic minorities show stronger tendencies to report themselves as being lonely, and this was also found in the Social Report (2010). As a result, it is important to control for such factors in the model, alongside context. These variables are shown in Table 4.8. 
Table 4.8: Description table of demographic variables, NZGSS (2012)

\begin{tabular}{|c|c|c|c|c|c|c|c|c|c|c|}
\hline \multirow[b]{2}{*}{ Ref } & \multirow[b]{2}{*}{ Variable } & \multirow[b]{2}{*}{$\begin{array}{l}\text { Short } \\
\text { version }\end{array}$} & \multirow[b]{2}{*}{ Qu. } & \multirow[b]{2}{*}{$\begin{array}{l}\text { Num. } \\
\text { of cat. }\end{array}$} & \multirow[b]{2}{*}{ Labels } & \multicolumn{5}{|c|}{ Number (percentage) } \\
\hline & & & & & & 0 & 1 & 2 & 3 & Total \\
\hline 1 & Age & Age & Age & 3 & $\begin{array}{l}\text { (1) Age_Young (15- } \\
29 \text { years), (2) } \\
\text { Age_Middle (30 - } \\
64 \text { years), (3) } \\
\text { Age_Old (65 - 85+ } \\
\text { years) }\end{array}$ & & $\begin{array}{c}1417 \\
(17.86)\end{array}$ & $\begin{array}{c}4703 \\
(59.28)\end{array}$ & $\begin{array}{c}1814 \\
(22.86)\end{array}$ & $\begin{array}{l}7934 \\
(100)\end{array}$ \\
\hline 2 & Gender & Gender & Gender & 2 & $\begin{array}{l}\text { (0) Female, (1) } \\
\text { Male }\end{array}$ & \begin{tabular}{|c|}
4456 \\
$(56.16)$
\end{tabular} & $\begin{array}{c}3478 \\
(43.84)\end{array}$ & & & $\begin{array}{l}7934 \\
(100)\end{array}$ \\
\hline 3 & Asian & Asian & $\begin{array}{l}\text { Asian } \\
\text { ethnic } \\
\text { groups }\end{array}$ & 2 & (0) no, (1) yes & $\begin{array}{c}7328 \\
(92.36)\end{array}$ & $\begin{array}{c}606 \\
(7.64)\end{array}$ & & & $\begin{array}{l}7934 \\
(100)\end{array}$ \\
\hline
\end{tabular}

Source: NZGSS (2012)

Table 4.9 is the continuation of the series of regressions between loneliness, contact, and context, with the addition of age, gender and ethnicity. 
Table 4.9: Models of loneliness controlling for context, and demographics, New Zealand 2012

\begin{tabular}{|c|c|c|c|}
\hline Variable | & Mode15 & Mode16 & Mode17 \\
\hline connect | & $.771 * * *$ & $.767 * * *$ & $.77 * * *$ \\
\hline We11ingtonR | & $1.22 *$ & $1.22 *$ & $1.23 \%$ \\
\hline Main_urban | & 1.17 & $1.18 *$ & 1.16 \\
\hline Rural | & 1.1 & 1.12 & 1.12 \\
\hline NZdep3_4 | & 1.08 & 1.08 & 1.08 \\
\hline NZdep5_6 | & $1.29 *$ & $1.28 *$ & $1.28 \%$ \\
\hline NZdep7_8 | & $1.57 * * *$ & $1.57 * * *$ & $1.56 * * *$ \\
\hline NZdep9_10 | & $1.7 * * *$ & $1.69 * * *$ & $1.69 * * *$ \\
\hline Age_Young | & $1.74 * * *$ & $1.77 * * *$ & $1.72 * * *$ \\
\hline Age_Middle | & $1.57 * * *$ & $1.58 * * *$ & $1.55 * * *$ \\
\hline Female I & & $1.3 * * *$ & $1.31 * * *$ \\
\hline Asian | & & & 1.23 \\
\hline _cons I & $.262 * * *$ & $.226 * * *$ & $.224 * * *$ \\
\hline r2_p | & .0351 & .0377 & .0382 \\
\hline df_m | & 10 & 11 & 12 \\
\hline $\mathrm{N}$ । & 7903 & 7903 & 7903 \\
\hline
\end{tabular}

legend: * $\mathrm{p}<0.05 ; * * \mathrm{p}<0.01 ; * * * \mathrm{p}<0.001$

Source: NZGSS (2012)

Model 5 demonstrates that the odds of reporting higher levels of loneliness decreases with age, in that the young (15-29 years) exhibit the highest levels of loneliness (1.74). This finding has been supported in the literature. Valkenburg and Peter (2007) and Wolak, Mitchell and Finkelhor (2003) have suggested that loneliness for young people is not only on the rise, but also is becoming a serious issue. Indications as to why the young are showing higher levels of loneliness, which were discussed in the literature review, include the effects of early attachments (Goosby, Bellatorre, Walsemann and Cheadle, 2013), the transitional period young people are embarking on (Brennan, 1982; Roscoe and Skomski, 1989), and also how modern day society has led to an increase in smaller families, greater distance between friends and family, and an increase in impersonal relationships, such as online friendships (Twenge, 2006). 
Due to the fact that the correlation between loneliness and age is an important component of this thesis I estimated an equation showing how loneliness varies by age, shown here:

$$
\begin{aligned}
& L_{i}=0.333+0.989 \text { Age } \quad \mathrm{R}^{2}=0.0064, N=7911 \\
& (\mathrm{z}=-6.68)
\end{aligned}
$$

Figure 4.7 shows this relationship visually in terms of probabilities of being lonely SMA and the associated 95\% confidence intervals (as shown by the vertical lines at each point). It is clear that the probability of reporting loneliness SMA falls with age and people who are aged 17.5 are the least likely to be lonely, as opposed to people aged 87.5. The chance of being lonely falls by $10 \%$ over 70 years - about 0.14 per annum.

Figure 4.6: How the probability of being lonely falls with age, New Zealand 2012

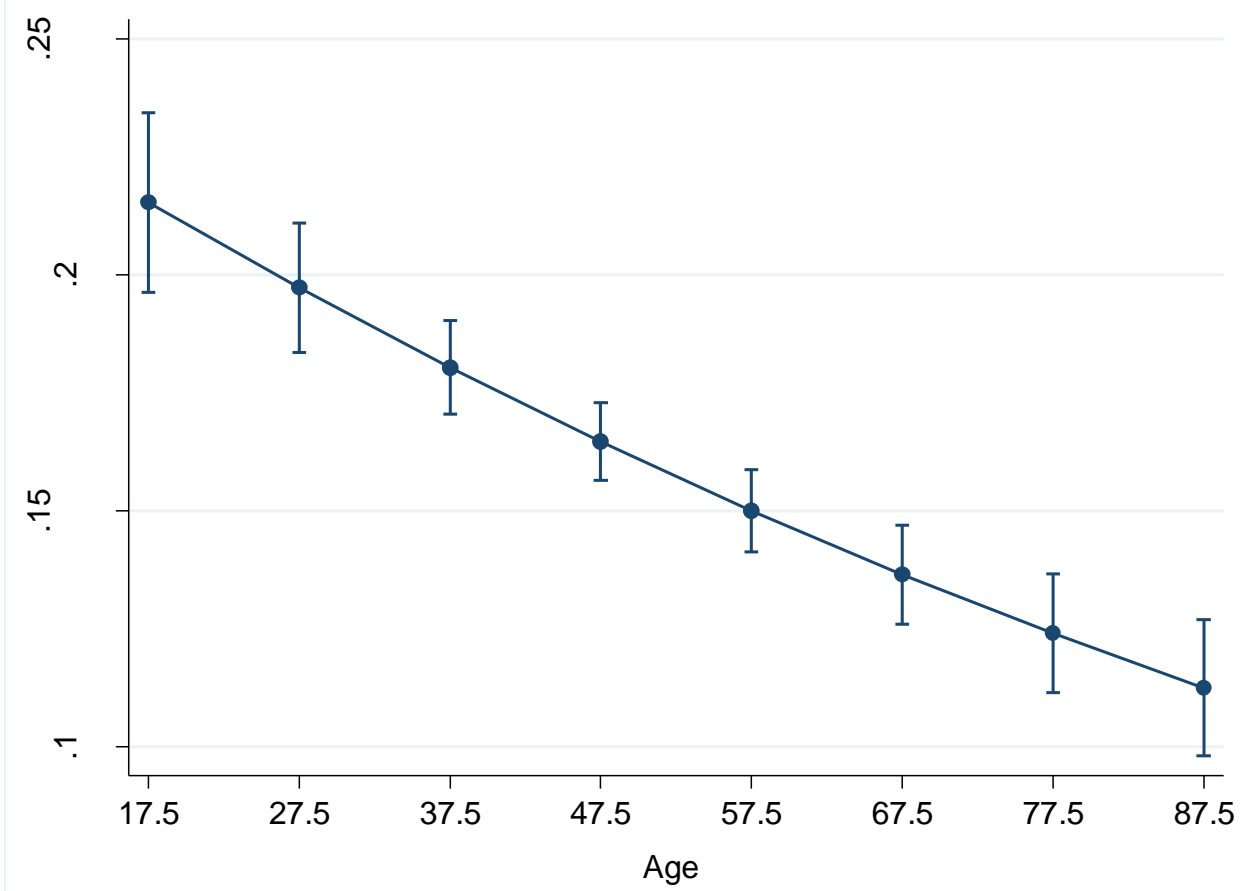

Source: NZGSS (2012) 
Table 4.9 also shows that females show higher odds of reporting loneliness, as shown in Model 6 by odds ratio of 1.3. This finding is strongly evidenced by the literature, as reviewed in Chapter 2 (for example Cramer and Neyedly, 1998). This is explained by the propositions that females are more inclined to need a larger social network and support from families (Franklin, 2012; Weeks, 2013), and when this level is not achieved, there is a higher likelihood of feeling lonely. It has also been suggested that females are more likely to acknowledge their feelings of loneliness (Borys and Perlman, 1985). This may particularly be the case for responses to the NZGSS as participants took part in a face-to-face computer questionnaire where males may have been more reluctant to admit their perceived 'weaknesses' to the researchers (despite how the question was framed around social isolation instead of 'loneliness'). Borys and Perlman (1985) also discussed how the social forces on men and women appear different, which could result in more women reporting themselves as being lonely. Men "elicit a more negative response for manifesting their loneliness than do women [and] may be less aware of the target's loneliness and less willing than women to chastise the target for it" (Borys and Perlman, 1985, p. 71).

\subsubsection{Achievement variables}

Also of interest is a person's achieved characteristics, for example a person's employment status in accounting for variations in loneliness. Table 4.10 introduces such variables associated with achieved rather than ascribed personal characteristics. They allow for a continuation of this model of loneliness, by adding household structure, employment, economic standard of living, education, immigrant status, and physical health. These variables are introduced in Table 4.10. 
Table 4.10: Description table of achieved variables, NZGSS (2012)

\begin{tabular}{|c|c|c|c|c|c|c|c|c|c|c|c|c|c|}
\hline \multirow[b]{2}{*}{ Ref } & \multirow[b]{2}{*}{ Variable } & \multirow[b]{2}{*}{ Question } & \multirow[b]{2}{*}{$\begin{array}{c}\text { Num. of } \\
\text { categories }\end{array}$} & \multirow[b]{2}{*}{ Labels } & \multicolumn{9}{|c|}{ Number (percentage) } \\
\hline & & & & & 0 & 1 & 2 & 3 & 4 & 5 & 6 & DKM & Total \\
\hline 1 & $\begin{array}{l}\text { Household } \\
\text { structure }\end{array}$ & $\begin{array}{l}\text { Family type } \\
\text { by child } \\
\text { dependency } \\
\text { status }\end{array}$ & 6 & $\begin{array}{l}\text { (1) Couple with no } \\
\text { children, (2) Couple } \\
\text { dependent children, } \\
\text { (3) Couple adult } \\
\text { children, (4) Single } \\
\text { parent dependent } \\
\text { child, (5) Single } \\
\text { parent adult child, (6) } \\
\text { No nucleus }\end{array}$ & & $\begin{array}{c}2268 \\
(28.63)\end{array}$ & $\begin{array}{l}1980 \\
(25)\end{array}$ & $\begin{array}{c}368 \\
(4.65)\end{array}$ & $\begin{array}{c}674 \\
(8.51)\end{array}$ & $\begin{array}{c}234 \\
(2.95)\end{array}$ & $\begin{array}{c}2397 \\
(30.26)\end{array}$ & & $\begin{array}{l}7934 \\
(100)\end{array}$ \\
\hline 2 & Employment & $\begin{array}{l}\text { Labour force } \\
\text { status }\end{array}$ & 3 & $\begin{array}{l}\text { (1) Employed } \\
\text { fulltime, (2) } \\
\text { Employed part-time, } \\
\text { (3) Not-employed }\end{array}$ & & $\begin{array}{c}4825 \\
(60.81)\end{array}$ & $\begin{array}{c}315 \\
(3.97)\end{array}$ & $\begin{array}{c}2790 \\
(35.17)\end{array}$ & & & & $\begin{array}{c}4 \\
(0.05)\end{array}$ & $\begin{array}{l}7934 \\
(100)\end{array}$ \\
\hline 3 & ELSI & $\begin{array}{l}\text { Economic } \\
\text { living } \\
\text { standard } \\
\text { derived } \\
\text { variable. }\end{array}$ & 31 & $\begin{array}{l}0=\text { poor ELSI } 30= \\
\text { high ELSI }\end{array}$ & & & & & & & & & \\
\hline 4 & $\begin{array}{l}\text { Highest } \\
\text { qualification }\end{array}$ & $\begin{array}{l}\text { Highest } \\
\text { qualification }\end{array}$ & 5 & $\begin{array}{l}\text { (0) None, (1) High } \\
\text { School, (2) Other } \\
\text { post-school, (3) } \\
\text { Graduate degree, (4) } \\
\text { Post-grad degree }\end{array}$ & $\begin{array}{c}1785 \\
(22.5)\end{array}$ & $\begin{array}{c}3452 \\
(43.51)\end{array}$ & $\begin{array}{c}1013 \\
(12.77)\end{array}$ & $\begin{array}{c}783 \\
(9.87)\end{array}$ & $\begin{array}{c}901 \\
(11.36)\end{array}$ & & & & $\begin{array}{l}7934 \\
(100)\end{array}$ \\
\hline 5 & Born in NZ & $\begin{array}{l}\text { Were you } \\
\text { born in New } \\
\text { Zealand? }\end{array}$ & 2 & (0) no, (1) yes & $\begin{array}{c}1876 \\
(23.65)\end{array}$ & $\begin{array}{c}6056 \\
(76.34)\end{array}$ & & & & & & $\begin{array}{c}1 \\
(0.01)\end{array}$ & $\begin{array}{l}7934 \\
(100)\end{array}$ \\
\hline 6 & $\begin{array}{l}\text { Physical } \\
\text { Health }\end{array}$ & $\begin{array}{l}\text { In general, } \\
\text { would you } \\
\text { say your } \\
\text { health is } \\
\text { excellent, } \\
\text { very good, } \\
\text { good, fair or } \\
\text { poor? }\end{array}$ & 5 & $\begin{array}{l}\text { (1) Excellent health, } \\
\text { (2) Very good health, } \\
\text { (3) Good health, (4) } \\
\text { Fair health, (5) Poor } \\
\text { health }\end{array}$ & & $\begin{array}{c}1668 \\
(21.02)\end{array}$ & $\begin{array}{c}2823 \\
(35.58)\end{array}$ & $\begin{array}{c}2188 \\
(27.58)\end{array}$ & $\begin{array}{c}935 \\
(11.78)\end{array}$ & $\begin{array}{c}315 \\
(3.97)\end{array}$ & & $\begin{array}{c}5 \\
(0.06)\end{array}$ & $\begin{array}{l}7934 \\
(100)\end{array}$ \\
\hline
\end{tabular}

Source: NZGSS (2012)

The hypothesis when it comes to these achieved characteristics and loneliness is that single parents, the unemployed, people with poor standards of living or lower education, immigrants, and those in poor health all show stronger tendencies to report themselves as being lonely. These associations are tested in Table 4.11. 
Table 4.11: Models of loneliness, controlling for context, demographics, and achievement variables, New Zealand 2012

\begin{tabular}{|c|c|c|c|c|c|c|}
\hline Variable | & Mode18 & Mode 19 & Mode 110 & Mode 111 & Mode 112 & Mode 113 \\
\hline connect | & $.791 * * *$ & $.802 * * *$ & $.831 \% * *$ & $.829 \% * *$ & $.837 \% * *$ & $.847 * * *$ \\
\hline WellingtonR | & $1.24 *$ & $1.25 \%$ & $1.27 * *$ & $1.26 *$ & $1.26 *$ & $1.28 * *$ \\
\hline Main_urban | & 1.16 & 1.18 & $1.22 \%$ & $1.21 *$ & 1.18 & 1.16 \\
\hline Rural I & 1.16 & 1.19 & 1.17 & 1.17 & 1.17 & 1.18 \\
\hline NZdep3_4 | & 1.06 & 1.06 & .919 & .924 & .926 & .946 \\
\hline NZdep5_6 | & 1.25 & 1.23 & .963 & .97 & .96 & .964 \\
\hline NZdep7_8 | & $1.51 * * *$ & $1.49 * * *$ & 1.13 & 1.14 & 1.13 & 1.12 \\
\hline NZdep9_10 | & $1.6 * * *$ & $1.51 * * *$ & 1.01 & 1.03 & 1.01 & .992 \\
\hline Age_Young | & $1.6 * *$ & $1.9 * * *$ & $1.44 * *$ & $1.44 * *$ & $1.5 * *$ & $1.72 * * *$ \\
\hline Age_Middle | & $1.48 * * *$ & $1.87 * * *$ & 1.2 & 1.18 & 1.22 & $1.29 \%$ \\
\hline Female | & $1.24 * * *$ & $1.19 * *$ & 1.1 & 1.09 & 1.1 & 1.13 \\
\hline Asian | & $1.31 *$ & $1.3^{*}$ & $1.39 * *$ & $1.33 *$ & 1.08 & 1.08 \\
\hline CoupleNoCh n | & $.811 \%$ & $.826 \%$ & .91 & .911 & .89 & .884 \\
\hline CoupleDepe n | & .963 & .948 & .947 & .943 & .908 & .964 \\
\hline CoupleAdu1 n | & $.554 \% *$ & $.564 * *$ & $.615 *$ & $.621 \%$ & $.606 * *$ & $.591 * *$ \\
\hline OneParentD n | & $1.31 *$ & 1.2 & .904 & .909 & .908 & .997 \\
\hline OneParentA n | & 1.14 & 1.09 & 1.05 & 1.06 & 1.07 & 1.07 \\
\hline EmployedPa e | & & $1.55 \% *$ & 1.04 & 1.05 & 1.03 & 1.02 \\
\hline NotInLabou e | & & $1.5 * * *$ & $1.21 \%$ & $1.22 \%$ & $1.21 \%$ & 1.09 \\
\hline ELSI | & & & $.917 * * *$ & $.916 * * *$ & $.917 * * *$ & $.929 * * *$ \\
\hline Highschool n | & & & & 1 & .982 & 1.02 \\
\hline OtherPosts n | & & & & 1.06 & 1.01 & 1.07 \\
\hline GraduateDe e | & & & & 1.13 & 1.04 & 1.14 \\
\hline PostGradua e | & & & & 1.18 & 1.03 & 1.1 \\
\hline NotBornNZ | & & & & & $1.41 * * *$ & $1.45 * * *$ \\
\hline ExcellentP h & & & & & & $.381 * * *$ \\
\hline VeryGoodPh h | & & & & & & $.497 * * *$ \\
\hline GoodPhysic h | & & & & & & $.663 \% *$ \\
\hline Fairphysic h | & & & & & & 1.02 \\
\hline _cons I & $.232 * * *$ & $.161 * * *$ & $1.76 *$ & $1.78 *$ & $1.64 *$ & $1.81 \%$ \\
\hline r2_p & .0422 & .0469 & .0927 & .0931 & .0954 & .108 \\
\hline df_m | & 17 & 19 & 20 & 24 & 25 & 29 \\
\hline $\mathrm{N}$ । & 7890 & 7886 & 7633 & 7633 & 7632 & 7628 \\
\hline
\end{tabular}

legend: $* p<0.05 ; * * p<0.01 ; * * * p<0.001$

Source: NZGSS (2012)

Model 8 demonstrates that people who live in 'couple' households show the lowest odds of being lonely SMA, in comparison to the base variable (no nucleus households). People who live in one-parent households with dependent children show the highest odds of reporting loneliness (1.31) among the household groups. This was also established by Baker (2012). It has been suggested that single parents have to "produce income, care for children, keep on top of the family's schedule, 
respond to emergencies, and manage the household alone", and therefore may not have sufficient time to create and maintain social networks, and so they can develop feelings of loneliness (Anderson, 1998, p. 140). Twenge (2006) argues that children of divorce are more likely to suffer from mental health issues, for example loneliness because they may feel abandoned by their 'missing' parent and lonely with just one parent to depend on.

In addition, Model 9 in Table 4.11 shows that the odds of someone being lonely is highest for those who are unemployed (0.196), than those who are employed part time (0.171), compared to those who are employed full time (the base). Creed and Reynolds (2001) and Middleton (2004) also found that those who have no paid work are the loneliest. Employment allows for increased opportunity to interact and spend time with other people, as opposed to being unemployed and spending time alone at home. Consequently, those who are employed may have a wider social network, and therefore would have lower levels of loneliness.

Model 10 shows that each increase in a person's economic standard of living2 (ELSI) is associated with a decrease in the odds of loneliness by 0.917 . These findings correspond with the literature suggesting that higher levels of income are associated with lower levels and frequency of loneliness (Baker, 2012; Franklin and Tranter, 2008). High earners may have increased capabilities and opportunities to meet social contacts because they can afford transport to see their friends and relatives abroad, to take holidays from work and to spend money on activities to share with family and friends. Also its likely there is some unobserved variable bias in here in that those who are successful and earn higher incomes have better personal skills, networks, and indeed know the importance of maintaining friendships. Moreover, people enjoy making friends with those who have money - it

\footnotetext{
${ }^{2}$ The ELSI is a measure of people's economic standard of living by the Ministry of Social Development, for more information see https://www.msd.govt.nz/about-msd-and-our-work/publicationsresources/monitoring/living-standards/elsi-short-form.html
} 
is well documented that people lose friends when they 'fall from grace' (Newman, 1988).

Model 12 demonstrates how immigrants show higher odds of being lonely SMA (1.41) compared to people who are New Zealand born. This is supported by literature including how Durkheim believed that migration would lead to lower levels of social integration which could in turn lead to feelings of loneliness and depression (Hassan, 1995). This theory is supported by empirical studies that have found an association between migration and higher rates of loneliness. In particular, it is thought that when people migrate to a new area or country, they are often disconnected from their familiar way of life, resources, and family relations, and as a result experience higher levels of loneliness (Hossen, 2012; Willgerodt, Miller, \& McElmurry, 2002; Schmitz, Jacobus, Stakeman, Valenzuela, \& Sprankel, 2003; Rashid, 2011).

The odds of loneliness rises successively with poorer health, as shown in Model 13. Those in excellent health show the lowest odds of being lonely (0.381) compared to those in very good (0.497), good (0.663), and poor health (the base). I am reminded of Monibot's claim that "social isolation is as potent a cause of early death as smoking 15 cigarettes a day... is twice as deadly as obesity. We cannot cope alone" (2014: 4). Poor health can be disabling and reduce a person's capacity to socialise and participate in activities where new friendships could be formed and original friendships could be maintained. People with poor health could also feel socially isolated and feel as though no one else understands their situation or condition.

\subsubsection{Psychological wellbeing}

People with poor mental health tend to show stronger propensities to report themselves as being lonely (Cacioppo and Hawkley, 2000). Table 4.12 is also a continuation of this estimates table of loneliness, with the addition of a variable showing how often a person is feeling downhearted or depressed. The following 
depression variable was entered separately to the other covariates because of its endogeneity. Loneliness can be both a cause and consequence of depression. In other words, depression and loneliness are highly interconnected and often come hand in hand (Eisemann, 1984; Wenz, 1977).

Table 4.12: Description table of depression variable, NZGSS (2012)

\begin{tabular}{|c|c|c|c|c|c|c|c|c|c|c|c|c|}
\hline \multirow[b]{2}{*}{ Ref } & \multirow[b]{2}{*}{ Variable } & \multirow[b]{2}{*}{ Question } & \multirow{2}{*}{$\begin{array}{c}\text { Number } \\
\text { of } \\
\text { categori } \\
\text { es }\end{array}$} & \multirow[b]{2}{*}{ Labels } & \multicolumn{8}{|c|}{ Number (percentage) } \\
\hline & & & & & 0 & 1 & 2 & 3 & 4 & 5 & DKM & Total \\
\hline 1 & $\begin{array}{l}\text { Depressi } \\
\text { on }\end{array}$ & $\begin{array}{l}\text { How much of } \\
\text { the time } \\
\text { during the } \\
\text { past four } \\
\text { weeks have } \\
\text { you felt } \\
\text { downhearted } \\
\text { and } \\
\text { depressed? }\end{array}$ & 5 & $\begin{array}{l}\text { (1) All the } \\
\text { time, (2) } \\
\text { Most of the } \\
\text { time, (3) } \\
\text { Some of the } \\
\text { time, (4) A } \\
\text { little of the } \\
\text { time, (5) } \\
\text { None of the } \\
\text { time }\end{array}$ & & $\begin{array}{c}74 \\
(0.93)\end{array}$ & $\begin{array}{c}264 \\
(3.33)\end{array}$ & $\begin{array}{c}1038 \\
(13.08)\end{array}$ & $\begin{array}{c}1882 \\
(23.72)\end{array}$ & $\begin{array}{c}4662 \\
(58.76)\end{array}$ & $\begin{array}{c}14 \\
(0.18)\end{array}$ & $\begin{array}{l}7934 \\
(100)\end{array}$ \\
\hline
\end{tabular}

Source: NZGSS (2012)

A number of different variables pertaining to the amount of time a person feels downhearted or depressed have been entered into the series of regressions in Table 4.13 
Table 4.13: Models of loneliness controlling for context, demographics, achievement, and depression, New Zealand 2012

\begin{tabular}{|c|c|}
\hline Variable | & Mode 114 \\
\hline connect | & $.844 * * *$ \\
\hline WellingtonR | & $1.27 *$ \\
\hline Main_urban | & 1.13 \\
\hline Rural | & 1.24 \\
\hline NZdep3_4 | & 1 \\
\hline NZdep5_6 | & 1.03 \\
\hline NZdep7_8 | & 1.16 \\
\hline NZdep9_10 | & 1.04 \\
\hline Age_Young | & $1.62 * * *$ \\
\hline Age_Middle | & 1.1 \\
\hline Fema1e I & 1.05 \\
\hline Asian | & 1.11 \\
\hline CoupleNoCh n | & .9 \\
\hline CoupleDepe n | & 1.08 \\
\hline Coup1eAdu1 n | & $.623 *$ \\
\hline OneParentD n | & 1.08 \\
\hline OneParentA n | & 1.09 \\
\hline EmployedPa e | & .97 \\
\hline NotInLabou e | & 1.01 \\
\hline ELSI | & $.947 * * *$ \\
\hline Highschool n | & 1.04 \\
\hline OtherPosts n | & 1.04 \\
\hline GraduateDe e | & 1.15 \\
\hline PostGradua e | & 1.06 \\
\hline NotBornNZ | & $1.46 * * *$ \\
\hline Exce11entP h | & $.671^{*}$ \\
\hline VeryGoodPh h | & .791 \\
\hline GoodPhysic h | & .932 \\
\hline FairPhysic h | & 1.18 \\
\hline Depres ttime | & 1.19 \\
\hline Depres ftime | & .896 \\
\hline Depressed 7e | & $.45 * *$ \\
\hline Depressed_ r | & $.194 * * *$ \\
\hline _cons | & $2.5 *$ \\
\hline r2_p | & .158 \\
\hline df_m | & 33 \\
\hline$N \mid$ & 7624 \\
\hline
\end{tabular}

legend: * $\mathrm{p}<0.05 ; * * \mathrm{p}<0.01 ; * * * \mathrm{p}<0.001$

Source: NZGSS (2012) 
The odds of someone reporting loneliness SMA is lower for those who are depressed none of the time compared to those who reported feeling depressed all of the time, as shown by the small odds ratio of 0.194 . This small odds ratio is evidence of the endogeniety of the relationship between depression and loneliness, and hence why it will be left out of further analysis. The addition of depression has wiped out the statistical significance of all geography variables, except for the Wellington region. This may suggest that depressed people who live in Wellington are more likely to be lonely than depressed people in other areas, or that there is no correlation between depression and loneliness in Wellington. Depression is often a symptom of loneliness, and vice versa (Twenge, 2006; Cacioppo and Hawkley, 2000; Wenz, 1977). Those who feel depressed and/or lonely often feel that way because they believe they do not have strong social networks to support them (Kraut, Patterson, Lundmark, Kiesler, Mukopadhyay and Scherlis, 1998). Similarly those who are lonely might be that way because depression can get in the way of socialising.

\subsubsection{Summary}

In summary, this section has shown that women, young people, single parents, the unemployed, those with low ELSI, people in poor health, those who live in Wellington, people who live in main urban centres or lower socioeconomic areas show a higher odds of being lonely. This shows that there is a tendency for the 'disadvantaged' to be lonelier. These results are similar to that of Statistics New Zealand's (2013) report 'Loneliness in New Zealand: Findings from the 2010 NZ General Social Survey', however they did not include any focus on geography which is where my thesis departs from literature.

\subsection{Modelling estimates}

Figures 4.8 to 4.11 are a visualisation of the above models (1-13), through which we can see how the effect of these covariates on the 'connect' variable changes when they are controlled for. The black line at zero shows a zero odds of being lonely SMA, 
points that fall to the left show lower odds of being lonely SMA, and points to the left show higher likelihood of being lonely SMA.

Figure 4.8 shows that once people who live in Wellington, main urban, and rural areas are controlled for the 'connect' coefficient barely changes. However, once those who live in higher socio-economic areas are controlled for social connection exerts slightly more influence on loneliness implying that higher socioeconomic resident's connectedness levels are more strongly related to loneliness.

Figure 4.7: Graphical representations of how models 1-4 change with the addition of controls from Table 4.11, New Zealand 2012

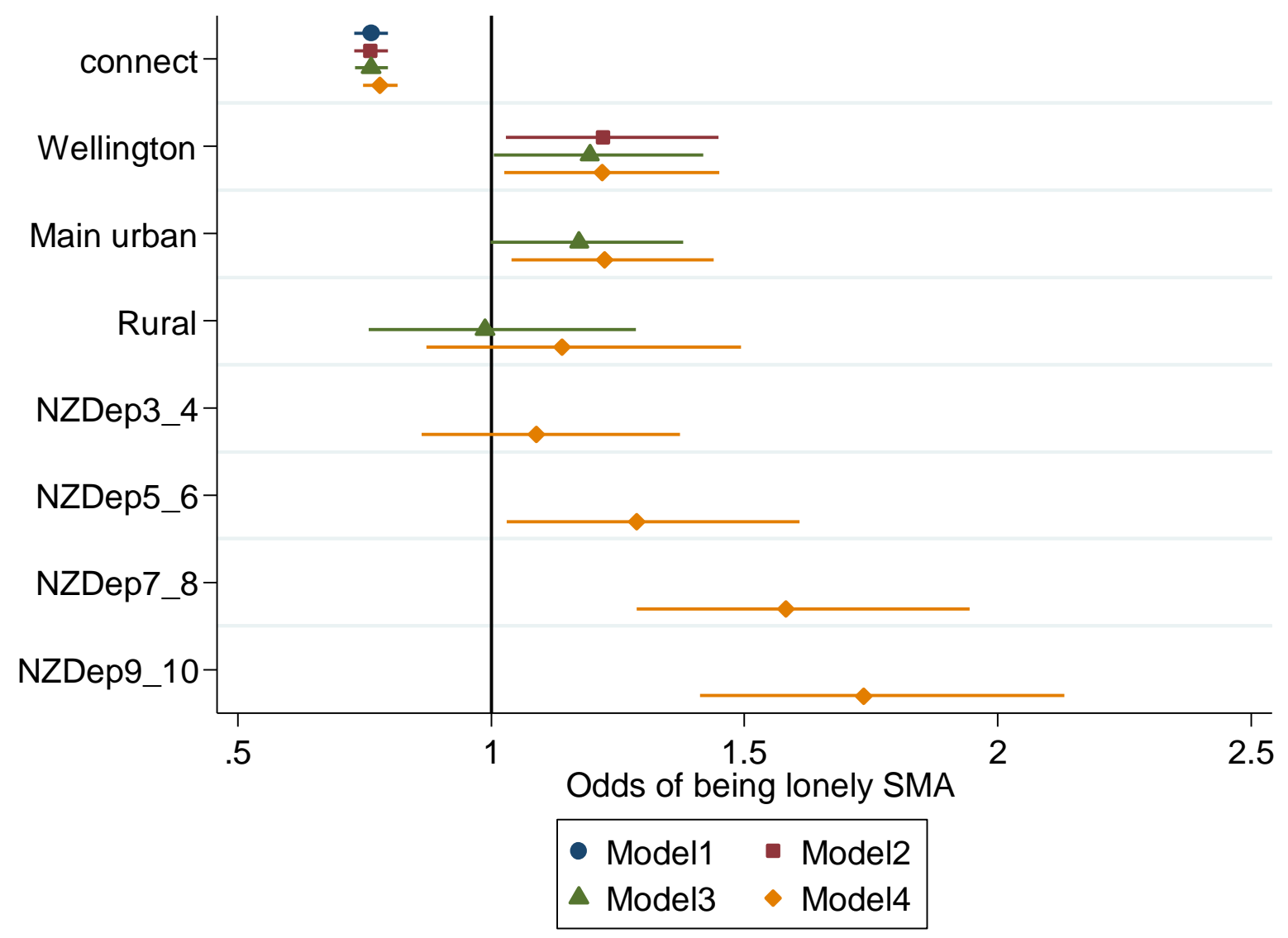

Source: NZGSS (2012) 
Figure 4.9 shows that the addition of demographic controls has little effect on the degree to which 'connect' reduces loneliness.

Figure 4.8: Graphical representations of how models 5-7 change with the addition of controls from Table 4.12, New Zealand 2012

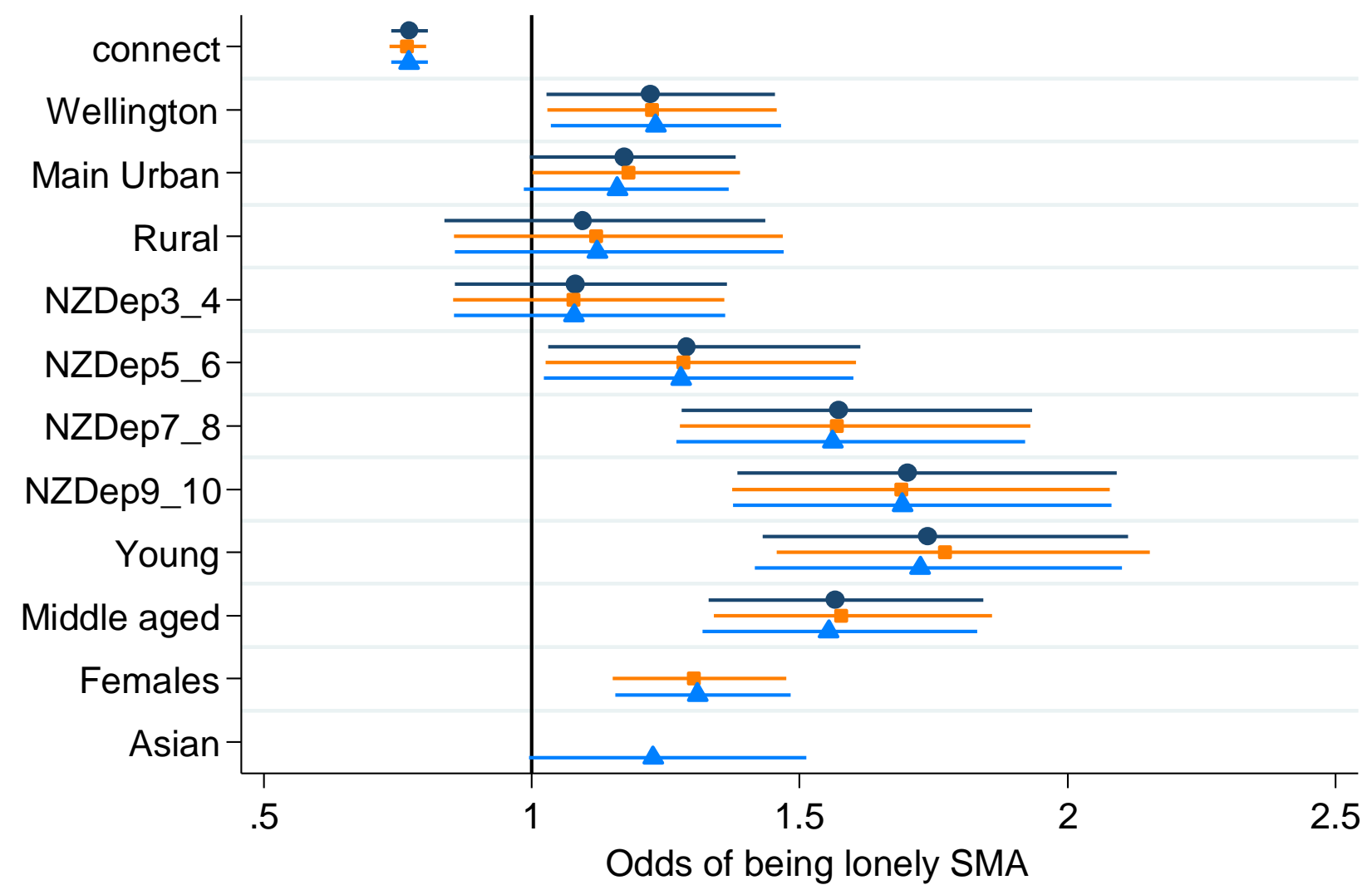

- Model5 - Model6

- Model7

Source: NZGSS (2012)

Figure 4.10 shows that the addition of various achieved characteristic covariates have little effect on the coefficient of 'connect', with the exception of ELSI. The addition of ELSI makes the 'connect' variable slightly less negative. People with higher standards of living have a 
large number of social connections, and as such ELSI is carrying some of the influence of connections.

Figure 4.9: Graphical representations of how models 8-10 change with the addition of controls from Table 4.13, New Zealand 2012

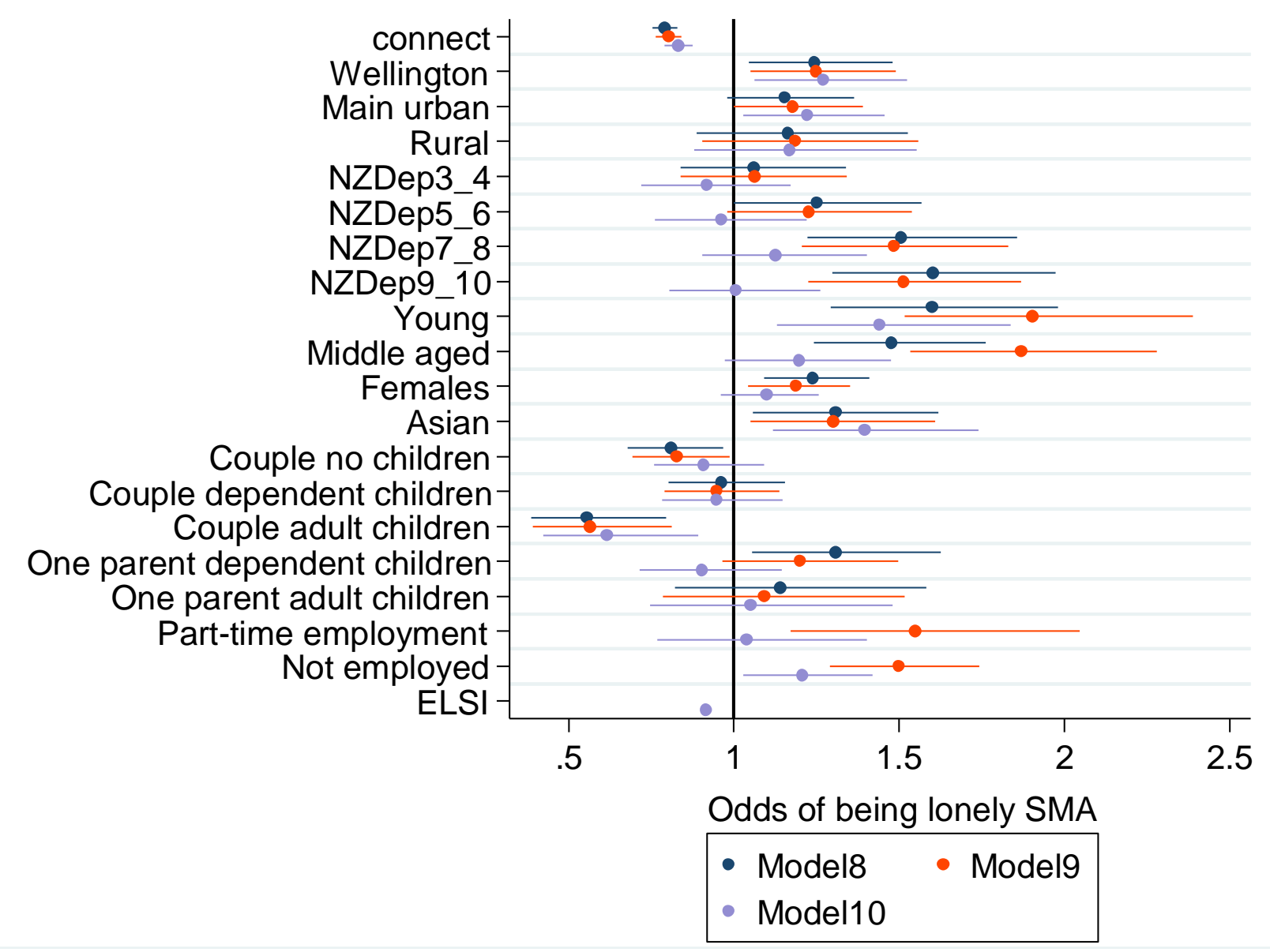

Source: NZGSS (2012)

Figure 4.11 shows that the addition of achieved characteristic covariates again have little effect on the coefficient of connect, and all make the 'connect' variable slightly less negative. 
Figure 4.10: Graphical representations of how models 11-13 change with the addition of controls from Table 4.14, New Zealand 2012

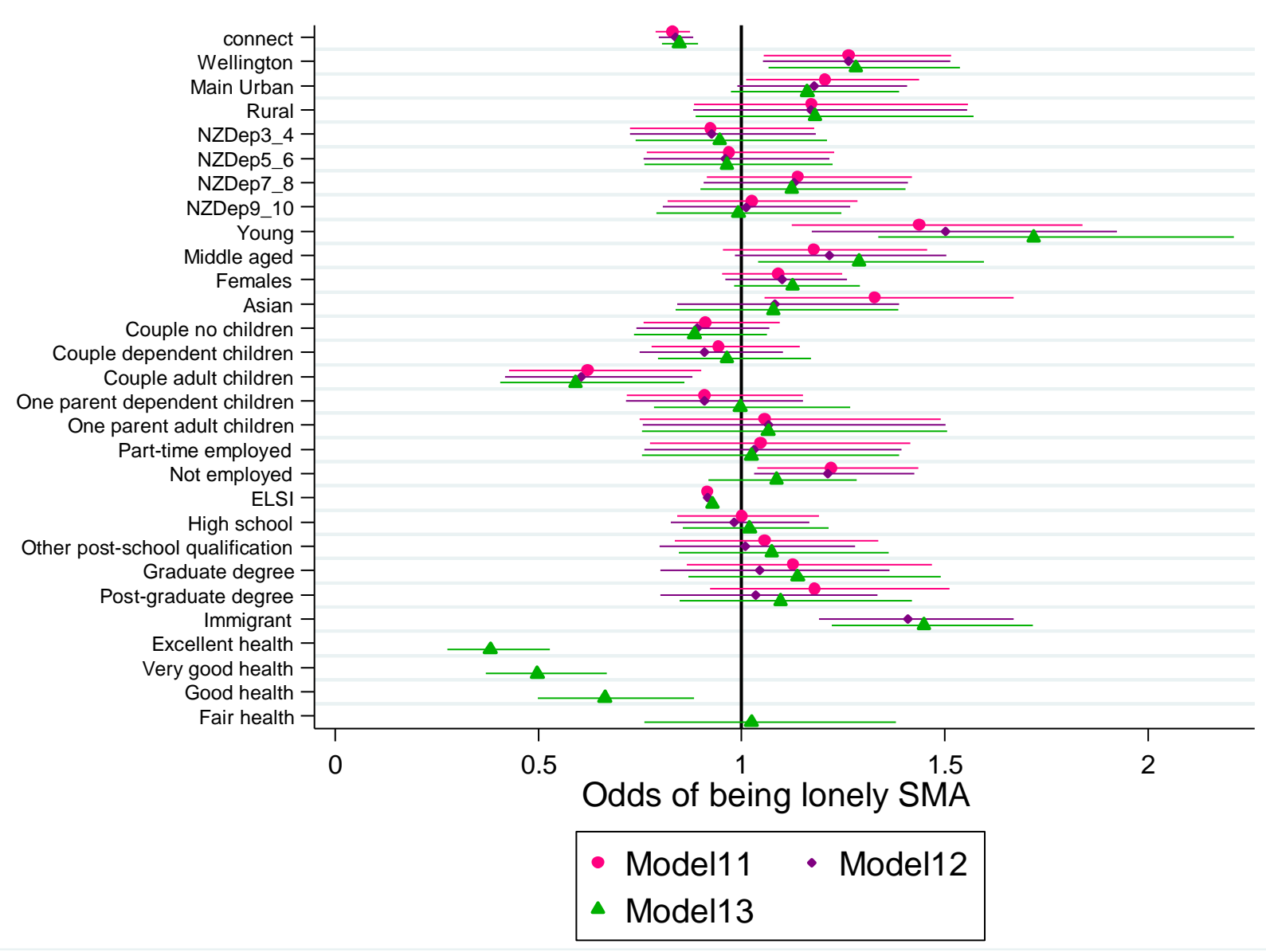

Source: NZGSS (2012)

\subsubsection{Loneliness by gender}

Figure 4.12 shows the breakdown of Model 13 (once all covariates are controlled for), by gender. The graphs show that the effect of 'connect' on reducing loneliness is slightly smaller for males. Males are more likely to report being lonely if they live in Wellington, as opposed to females. This is also the case (to a larger extent) for urban areas in general. Males and females report similar levels of loneliness in rural areas. Living in lesser-deprived areas has stronger reducing effects on loneliness for males. 
Young females show a stronger association with higher levels of loneliness than young males do. On the other hand, middle-aged females show a weaker association with higher levels of loneliness than middle-aged males. Asian females are associated with lower levels of loneliness, whereas Asian males are associated with higher levels of loneliness.

Females in all types of household structures show higher levels of loneliness, in particular there is a large discrepancy between loneliness levels of males and females who live in one parent or adult children households. Males who are employed part-time show lower levels of loneliness, in comparison to females, but males who are not employed show higher levels than females. There is little difference in loneliness levels of males and females based on their economic standard of living. Females who have done postgraduate work are less likely to be lonely than their male counterparts, but this is not the case for graduates. Female immigrants are associated with higher levels of loneliness, compared to male immigrants. Females show lower likelihoods of being lonely than males based on different stages of physical health. 
Figure 4.11: Graphical representations of model 13 broken down by gender, New Zealand 2012

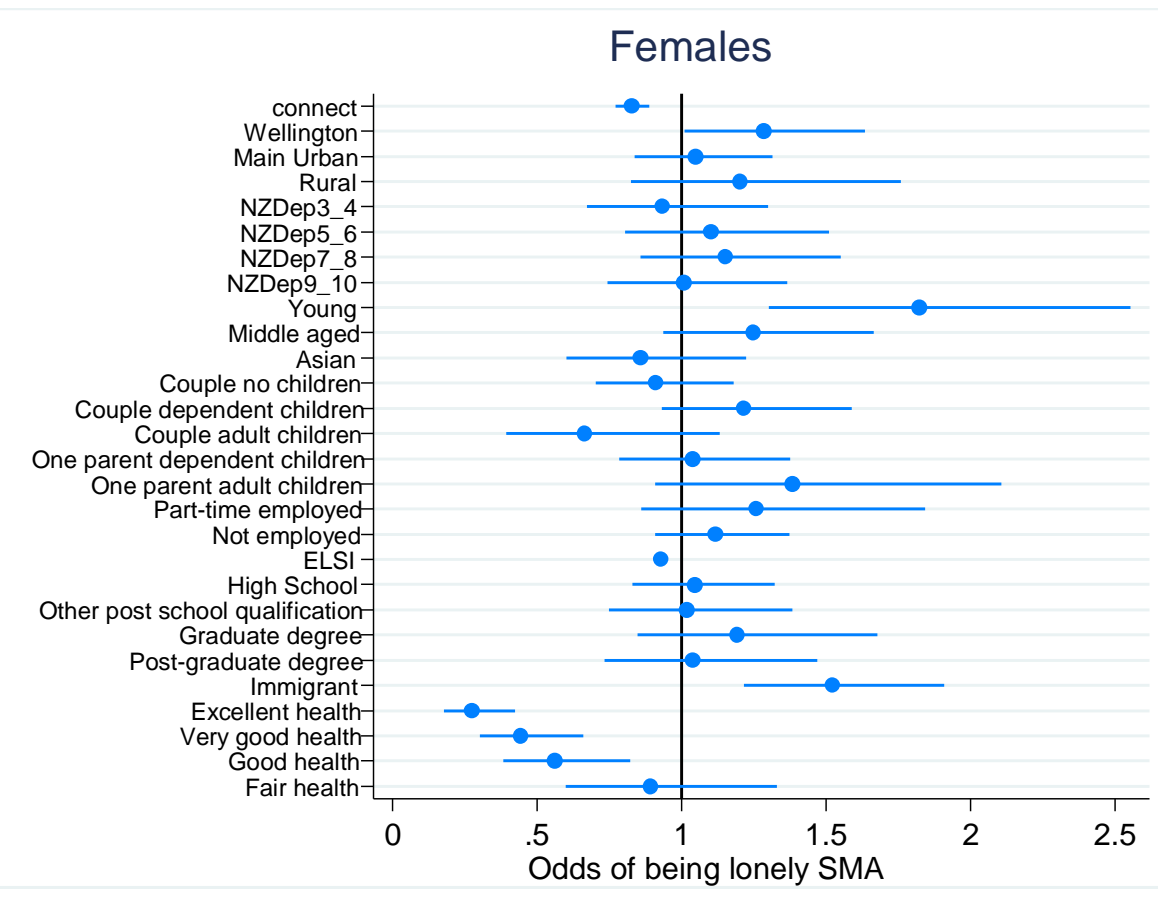

Source: NZGSS (2012)

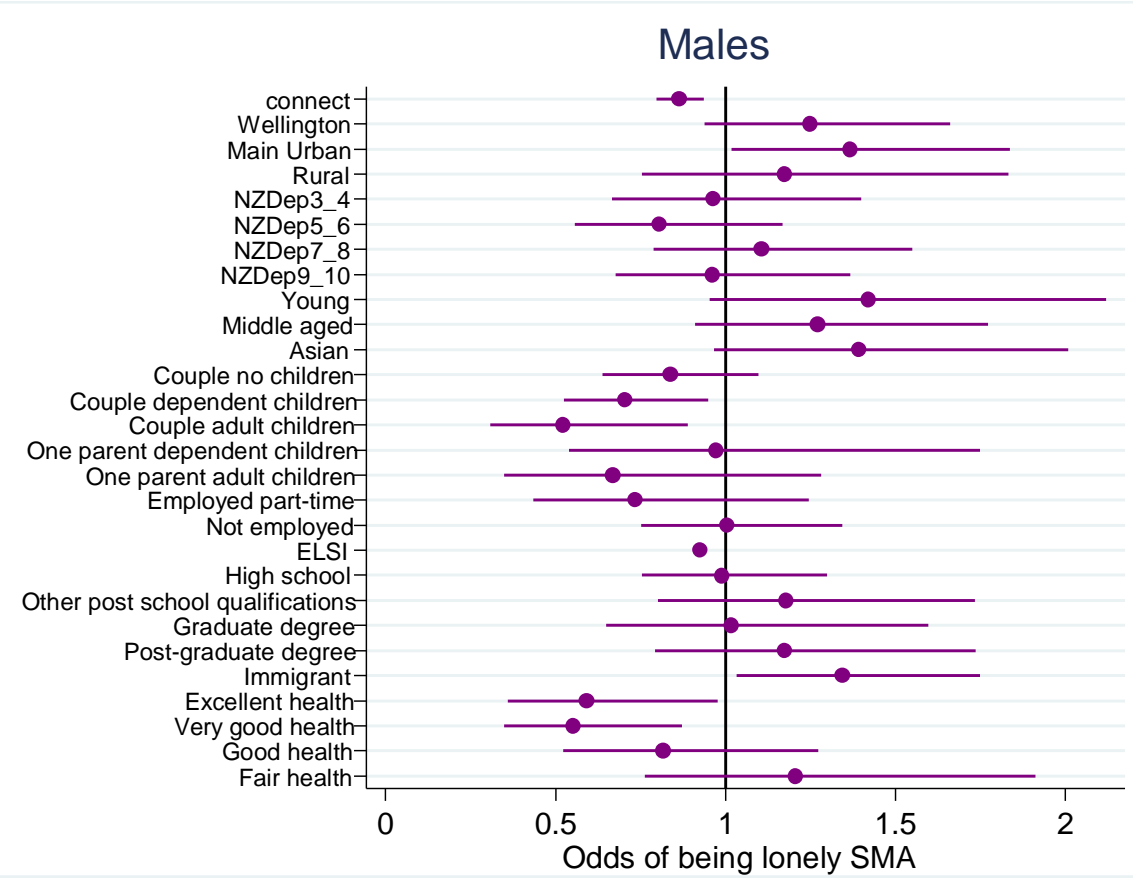

Source: NZGSS (2012) 


\subsubsection{Loneliness by age}

Figure 4.13 shows the breakdown of Model 13 (once all covariates are entered), by age - young (15-29 years), middle (30-64 years) and old (65-90+). Young people who are connected show a higher likelihood of being lonely, compared to the middle aged and the old. Young Wellingtonians show higher odds of being lonely than other areas. It is the middle aged and older people who are less likely to be lonely if they live in Wellington/urban areas. Wellington is a political and business focused city, and this finding could suggest that the city is not fostering the development and strengthening of the social worlds of young people. Figure 4.13 also shows that older people are more likely to be lonely if they live in rural areas, possibly because of being isolated physically from other people and services, such as a wide range of community groups. Figure 4.13 also shows that young people are much less likely to be lonely if they live in less deprived areas, than older people. Therefore, geographic effects on loneliness are heavily dependent on age.

As stated above, young females show a higher likelihood of being lonely, whereas there is little difference in loneliness levels between middle-aged and old people based on gender. Older people who identify as Asian show a lower likelihood of being lonely, as opposed to the young and middle-aged (where there is little difference).

Older people in a couple household with no children are much more likely to be lonely compared to those who are younger. This is also the case for couples with dependent children, single parents with dependent children, and single parents with adult children households. Older people who are employed part-time are much more likely to be lonely, whereas younger people who are not employed at all show a higher likelihood. There is little difference in the association between the likelihood of loneliness and ELSI, based on age. Young people with high school qualifications are more likely to be lonely than older people with the same 
qualification. The middle-aged show a higher likelihood of loneliness for all other levels of education, compared to the young and old. Younger and older immigrants show a higher likelihood of loneliness, in comparison to the middle-aged, but the difference is quite minimal. Being in good health seems to reduce loneliness more for the young, followed by the middle aged, and then older people.

\section{Figure 4.12: Graphical representations of model 13 broken down by age, New}

\section{Zealand 2012}

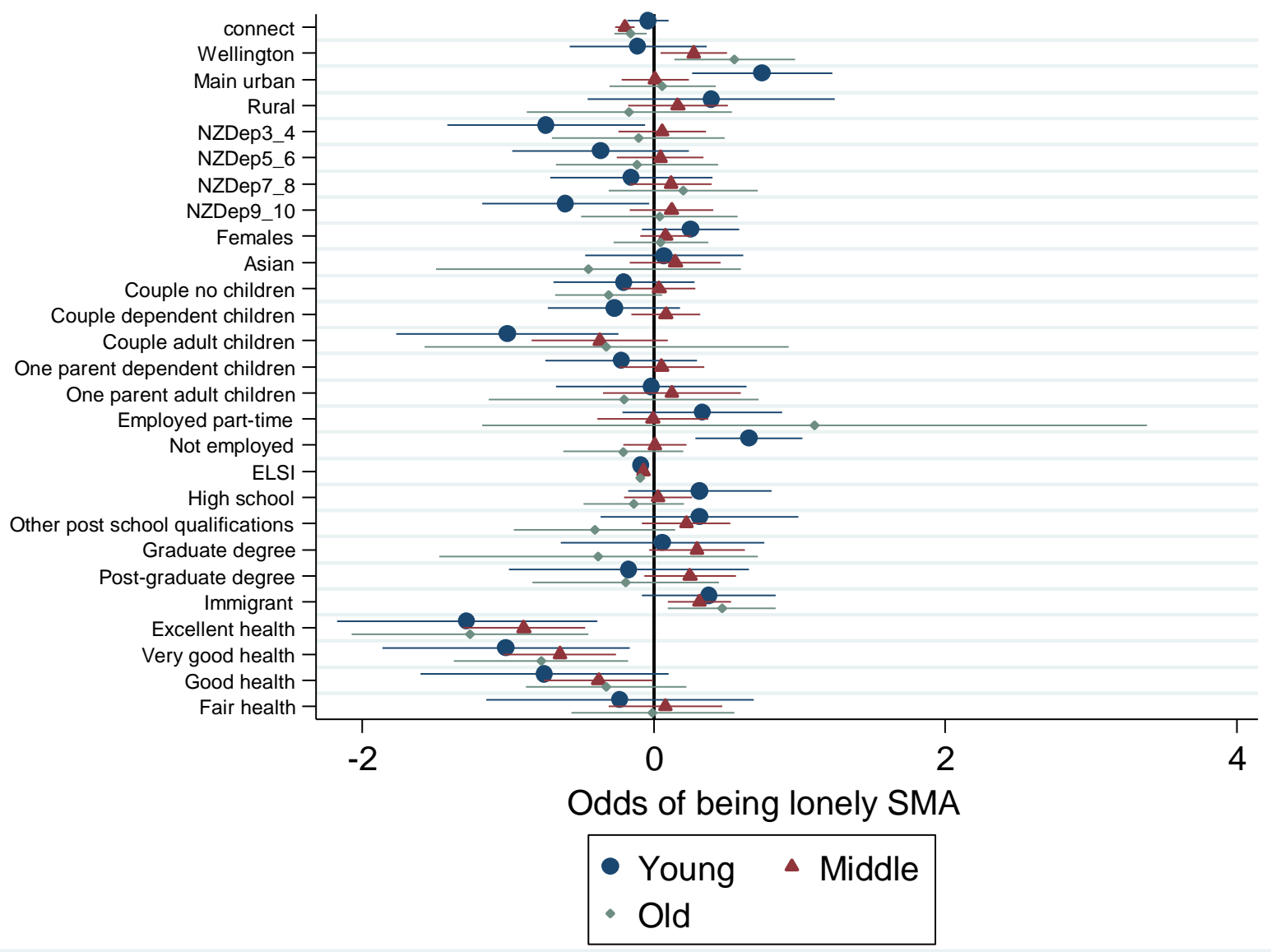

Source: NZGSS (2012)

\subsubsection{Summary}

This section has shown that the seven forms of contact seem to be reasonably independent of one another, suggesting that a person is likely to need all forms of 
social contact to see a significant reduction in loneliness. Additionally, it is clear that there is significant variation in loneliness levels based on covariates broken down by age and gender.

\subsection{Interaction effects between contacts}

This section will look at the effect of individual connectivity measures, and also different combinations of them together, on loneliness levels. In the following section I adopt specific connectivity measures, and focus primarily on those who are lonely SMA. A series of logistic regressions were applied to the discrete measures of connectedness, and the relationship they exhibit with being lonely SMA.

\subsubsection{Partnership}

As detailed in the literature review, Weiss (1973) argued that there are two types of loneliness: emotional and social. Weiss identified loneliness as the experience of "being without some definite needed relationship or set of relationships" (1973, p. 17). He believed that those people who experience emotional loneliness are lacking close, emotional relationships with one other person, in most occurrences a partner. This was also determined by Seepersad (2010) who found that if a person is unable to find a partner, chooses not to be in a relationship, or is 'between partners', they are likely to be dissatisfied with their social relations and therefore may feel lonely.

The following logit regression tests the association between having a partner in the last month and loneliness through the individual connectedness linear model, as in equation (4) in Chapter 3, where $\mathrm{L}$ is the LonelySMA variable, and $\mathrm{C}^{\mathrm{k}}$ is partnership ( 0 = single, 1 = partnered). It is expected that loneliness levels will be higher for those who are single.

The results confirm the hypothesis that partnership is negatively associated with being lonely SMA. The odds ratio tells us that the odds of being lonely are $38 \%$ less 
for those who are partnered $(1-0.62=0.38)$. This result is statistically significant ( $\mathrm{z}$ $=-7.70$ ).

$$
\begin{gathered}
L_{i}=0.248+0.624 \text { Partner } \quad \mathrm{R}^{2}=0.0085, N=7911 \\
(\mathrm{z}=-7.70)
\end{gathered}
$$

\subsubsection{Family}

Family connectedness is also important to consider when researching loneliness. Burke, Woszidlo and Segrin (2012) state that loneliness can occur in family environments for a number of reasons, including how a family environment can exacerbate loneliness because "it is an arena in which family members are exposed to various communication processes and behaviours that might be associated with their feelings of loneliness" (Burke et al., 2012, p. 76). For example, a detached, uncommunicative family environment may lead to increased feelings of loneliness, as opposed to a supportive and friendly family. It has also been suggested that loneliness can be genetic, and therefore investigating family members' loneliness can be beneficial (Burke et al, 2012). However, the dataset used for this research does not enable the testing of genetic effects.

The following logit regression tests the association between seeing family in the last month and loneliness through the individual connectedness linear model, as in equation (4) in Chapter 3, where $\mathrm{L}$ is the LonelySMA variable, and $\mathrm{C}$ is family $(0=$ have not seen family, 1 = seen family). It is expected that loneliness levels will be higher for those who have not seen their family in the last month.

The results confirm this expectation, in that seeing family is negatively associated with being lonely SMA. The odds ratio indicates the odds of loneliness are $42 \%$ less for those who have seen their family in the last month and the result is statistically significant $(z=-7.05)$. 


$$
\begin{gathered}
L_{i}=0.304+0.584 \text { Family } \quad \mathrm{R}^{2}=0.0066, N=7911 \\
(\mathrm{z}=-7.05)
\end{gathered}
$$

\subsubsection{Friends}

A common part of a person's social network also includes friends, and having friends has been strongly linked to lower levels of loneliness. Weiss (1973) has described social loneliness as the lack of integration into a social network and can be felt even while in a loving relationship. In other words, social loneliness can stem from a lack of connection with friends. I expect that seeing friends will significantly reduce the probability of loneliness.

The following logit regression tests the association between seeing friends in the last month and loneliness through the individual connectedness linear model, as in equation (4) in Chapter 3, where $\mathrm{L}$ is the LonelySMA variable, and $\mathrm{C}$ is friends $(0=$ have not seen friends, 1 = seen friends).

The following estimated equation shows that seeing friends is in fact negatively associated with being lonely SMA of the time. The odds ratio shows that the odds of reporting loneliness are $65 \%$ less for those who have seen their friends in the last month. This result is statistically significant $(\mathrm{z}=-11.35)$.

$$
\begin{gathered}
L_{i}=0.497+0.352 \text { Friends } \quad \mathrm{R}^{2}=0.0164, N=7910 \\
(\mathrm{z}=-11.35)
\end{gathered}
$$

Contact is not restricted to face-to-face interaction - with the boom of information and communication technology, it is also crucial to understand the relationships between loneliness and non-face-to-face connectivity. We have established that seeing friends and family that do not live with the participant, is associated with lower levels of loneliness, but what about non-face-to-face interaction such as texting, talking on the phone, or communicating via the internet? Although there are 
mixed findings in the literature regarding the effect having non-face-to-face contact has on loneliness (Wang \& Wang, 2011; Carden \& Rettew, 2006; Mazalin \& Moore, 2004), it is expected that, similar to other forms of contact, there will be a negative relationship for the NZGSS sample.

The following logit regression tests the association between having non-face-to-face contact with friends in the last month and loneliness through the individual connectedness linear model, as in equation (4) in Chapter 3 , where $L$ is the LonelySMA variable, and $\mathrm{C}$ is non-face-to-face contact ( 0 = have not, $1=$ have).

Results show that the amount of time contacting friends non-face-to-face is negatively associated with being lonely SMA of the time. The coefficient tells us that having non-face-to-face contact reduces the log odds of loneliness by $37 \%$. This result is statistically significant $(\mathrm{z}=-4.60)$.

$$
\begin{gathered}
L_{i}=0.293+0.638 \text { NF2Ffriends } \quad \mathrm{R}^{2}=0.0028, N=7910 \\
(\mathrm{z}=-4.60)
\end{gathered}
$$

No consistent conclusion was found as to whether non-face-to-face contact has harming or positive effects on a person's loneliness in the literature I reviewed (Wang \& Wang, 2011; Carden \& Rettew, 2006). However, the odds ratio result from the estimated equation above indicates that increased amount of time contacting friends via a phone or the Internet seems to be beneficial in reducing loneliness - by $37 \%$.

\subsubsection{Community involvement}

In an age where technological developments make contact with others easier, research suggests that more people are losing strong ties to their community and neighbourhood. Putnam in his book Bowling Alone (2000) documented the diminishing nature of community and social relationships, stating that low 
community involvement is the reason. Sum, Mathews, Pourghasem and Hughes (2009) believe that loneliness is inversely related to a person's sense of community, meaning that connectedness to a community is vital to understand in order reduce rates of loneliness. I will test the relationships between loneliness and three community variables: participation in activities, helping out others, and volunteer work. It is expected that these forms of community connectedness will be associated with lower odds of being lonely. The following results are all statistically significant.

Results from estimating the individual connectedness linear model, as in equation (4) in Chapter 3, show that participating in community activities is negatively associated with being lonely SMA. The coefficient tells us that being involved in activities reduces the log odds of loneliness by $34 \%$.

$$
\begin{gathered}
L_{i}=0.224+0.665 \text { Active } \quad \mathrm{R}^{2}=0.0056, N=7907 \\
(\mathrm{z}=-6.18)
\end{gathered}
$$

Similarly, helping others in the community for no financial gain is negatively associated with being lonely SMA. The coefficient tells us that helping others reduces the log odds of loneliness by around $17 \%$.

$$
\begin{gathered}
L_{i}=0.218+0.833 \text { helpothers } \quad \mathrm{R}^{2}=0.0012, N=7909 \\
(\mathrm{z}=-6.18)
\end{gathered}
$$

Moreover, community work is negatively associated with being lonely SMA. The coefficient tells us that volunteering reduces the log odds of loneliness by just under $30 \%$.

$$
\begin{gathered}
L_{i}=0.213+0.726 \text { volwork } \quad \mathrm{R}^{2}=0.0031, N=7909 \\
(\mathrm{z}=-4.59)
\end{gathered}
$$


These community involvement results indicate that community connectedness is important to consider when researching how different forms of connectivity reduces loneliness. This is supported in the literature, as Baker (2012) also found that Australians who are disconnected from their community are more likely to be lonely. What this suggests is that those people who participate in society are less likely to be lonely because they have a wider base of social networks. Social networks can come from a range of activities, not solely spending time with friends and family.

\subsubsection{Summary}

What is clear from the above logit models is that there are a range of different types of social connectivity, such as within the household, outside the household, and within the community, that should be considered when researching loneliness. It is clear that seeing friends has the largest influence on reducing the effects of loneliness, followed by family and partnership. Non-face-to-face contact with friends has a smaller reducing effect on loneliness compared to in-person interaction. Community involvement seems to have smaller effects on reducing loneliness, but is still beneficial given the reductions in loneliness by about $30 \%$.

\subsubsection{Interaction effects}

I am also interested in knowing how the effect of these contact types change based on different combinations of types of contact. More specifically, this section focuses on the slope of the line, or how quickly or slowly loneliness falls based on what type of contact/ combination of a person has, and their demographics, context, and achieved characteristics. The interaction effects on loneliness can be tested empirically by applying the interaction linear model, as in equation (5) in Chapter 3.

\subsubsection{In person and non-face-to-face contact with friends}

A topic of interest is the growing body of research that focuses on the effect having non-face-to-face contact has on loneliness. Several researchers including Wang and 
Wang (2011) believe there are at least two theoretical perspectives to acknowledge when investigating the effects of online communication on users' well-being: the augmentation hypothesis and the displacement hypothesis. The displacement hypothesis suggests that having solely non-face-to-face contact will adversely affect a person's wellbeing. The augmentation hypothesis argues that some types of communication can facilitate the use of others, and having non-face-to-face friendships can strengthen in-person relationships (Katz \& Rice, 2002; Wang \& Wang, 2011). I expect that when it comes to accounting for loneliness there is an augmenting effect between face-to-face and non-face-to-face contact with friends.

Table 4.14 shows the predicted probabilities of being lonely SMA based on the combination of these connections, where 0 refers to 'no' and 1 refers to 'yes'. The results support this hypothesis, by showing that when someone has no friends and no non-face-to-face contact $(0,0)$ they report high levels of loneliness, $p=0.33$. This probability more than halves when both non-face-to-face contact and in-person contact with friends are in place $(1,1)$ to $\mathrm{p}=0.14$. 
Table 4.14: Interaction effects between in person contact and non-face-to-face contact with friends, New Zealand 2012

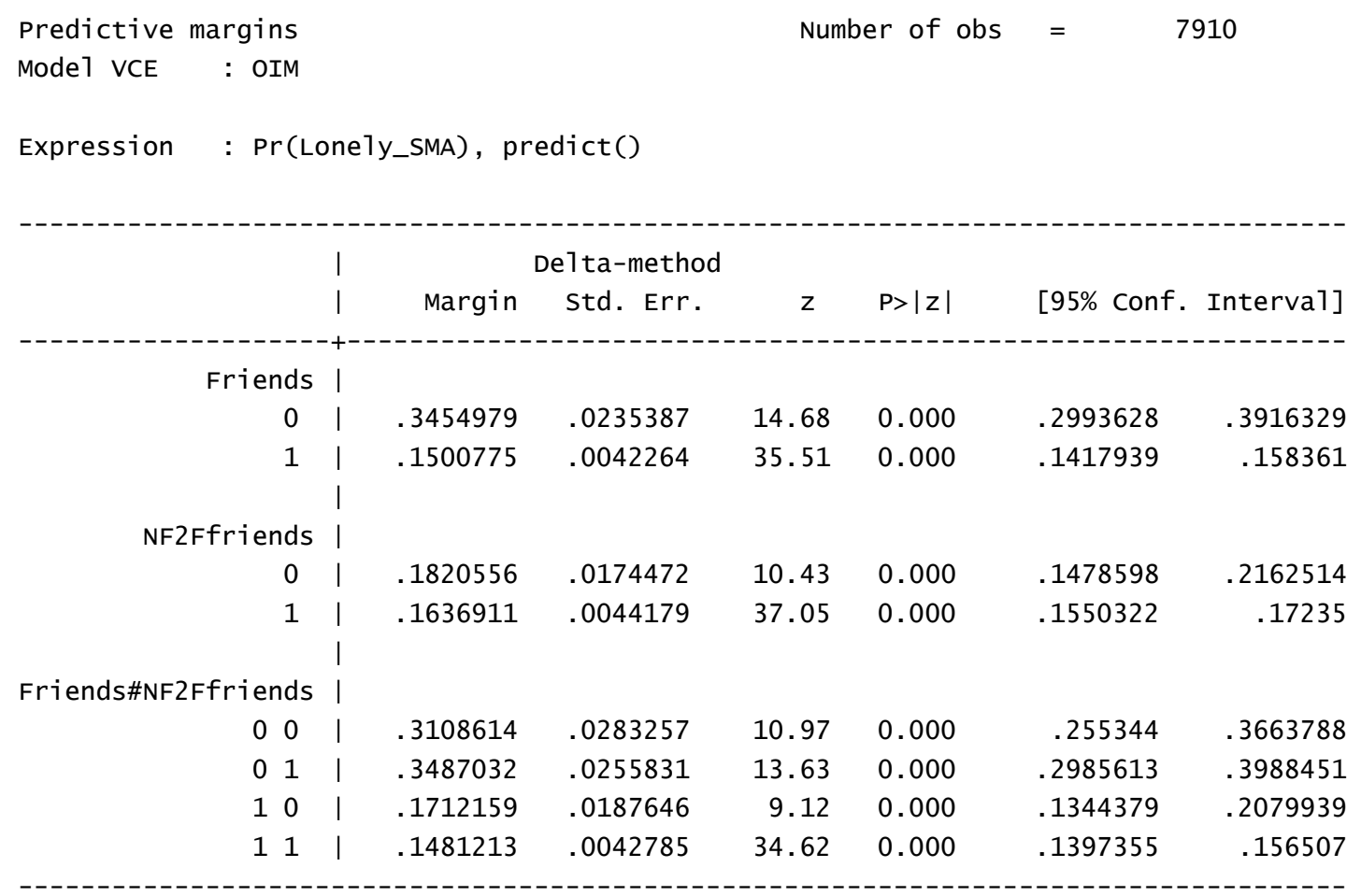

Source: NZGSS (2012)

Graphically (Figure 4.14), friends reduce loneliness (downward slope), and the simultaneous presence of non-face-to-face contact is associated with lower loneliness (orange line). 
Figure 4.13: Graphical representation of interaction effects between in person and non-face-to-face contact with friends, with a $95 \%$ confidence interval,

New Zealand 2012

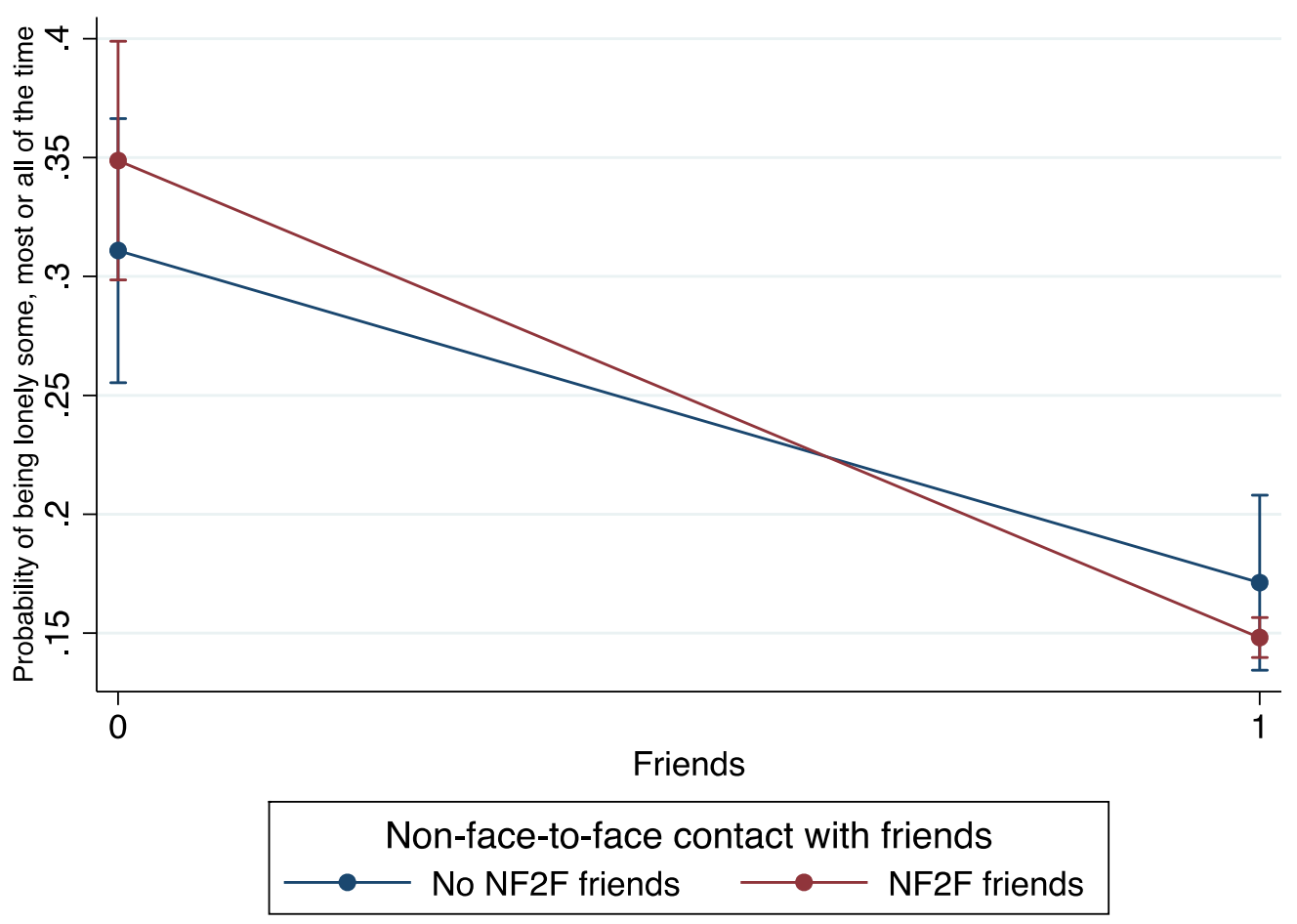

Source: NZGSS (2012)

This suggests that having both forms of contact are augmenting, and is helpful in reducing loneliness; therefore the hypothesis of an augmentation effect can be supported. The interaction effect is not statistically significant, although the signs are in the expected direction.

\subsubsection{Emotional and social connectedness}

The second hypothesis that I want to test is the interaction effects between emotional and social connectedness. As stated above, being in a relationship (emotional), and having contact with friends and family (social) have the greatest reducing effects on loneliness. It is for this reason that I expect there is a strong interaction effect between having a partner (emotional connectedness) and seeing family and friends (social connectedness). 
Table 4.15 shows people who answered 'no' $(0,0,0)$ to all of the contact questions show the highest probability of being lonely SMA (0.478). If one form of contact is added this probability reduces (most considerably for contact with friends).

If partnership and family connections are in place $(1,1,0)$ then the chance of loneliness drops further to 0.265 , however if just contact with friends is in place $(0,0,1)$ the probability of loneliness is lower, at 0.246 . This supports what I have already established - that friendship has the strongest reducing effect on loneliness, and this also suggests that it has a stronger reducing effect than having both contact with family, and a partner. If family and friend connections are in place $(0,1,1)$ then the chance of loneliness drops to 0.170 . Moreover, if I take out family, and have partnership and friend connections in place (without family $(1,0,1)$ ) then the chance of loneliness drops further to 0.169 .

Table 4.15: Interaction effects between partnership, and contact with friends and family, New Zealand 2012

\begin{tabular}{|c|c|c|c|c|c|c|c|c|}
\hline \multicolumn{6}{|c|}{ Adjusted predictions } & \multicolumn{2}{|c|}{ Number of obs } & \multirow[t]{2}{*}{7910} \\
\hline Model VCE & : & OIM & & & & & & \\
\hline \multirow[t]{3}{*}{ Expression } & \multicolumn{5}{|c|}{$: \operatorname{Pr}($ Lonely_SMA), predict() } & & & \\
\hline & & I & & elta-methoc & & & & \\
\hline & & I & Margin & Std. Err. & z & $\mathrm{P}>|z|$ & {$[95 \%$ conf. } & Interva1] \\
\hline \multicolumn{9}{|c|}{ Partner\#Fami1y\#| } \\
\hline \multicolumn{9}{|c|}{ Friends | } \\
\hline 0 & 00 & 1 & .3593745 & .0599771 & 5.99 & 0.000 & .2418215 & .4769275 \\
\hline 0 & 01 & 1 & .2424779 & .0180306 & 13.45 & 0.000 & .2071386 & .2778171 \\
\hline 0 & 10 & 1 & .3913042 & .0339213 & 11.54 & 0.000 & .3248197 & .4577887 \\
\hline 0 & 11 & 1 & .1716954 & .0071473 & 24.02 & 0.000 & .157687 & .1857038 \\
\hline 1 & 00 & 1 & .3749996 & .0570544 & 6.57 & 0.000 & .263175 & .4868243 \\
\hline 1 & 01 & -1 & .1868787 & .017381 & 10.75 & 0.000 & .1528127 & .2209448 \\
\hline 1 & 10 & 1 & .2693726 & .0269488 & 10.00 & 0.000 & .2165539 & .3221914 \\
\hline 1 & 11 & 1 & .1106272 & .0053449 & 20.70 & 0.000 & .1001513 & .121103 \\
\hline
\end{tabular}

Source: NZGSS (2012) 
Those who have all three forms of contact $(1,1,1)$ show the lowest probability (0.114) of being lonely SMA. This is also reflected in Figure 4.15 which indicates that there is a strong interaction effect between all three forms of contact, meaning that they complement each other in reducing loneliness.

\section{Figure 4.14: Graphical representation of interaction effects between partnership, and contact with friends and family, New Zealand 2012}

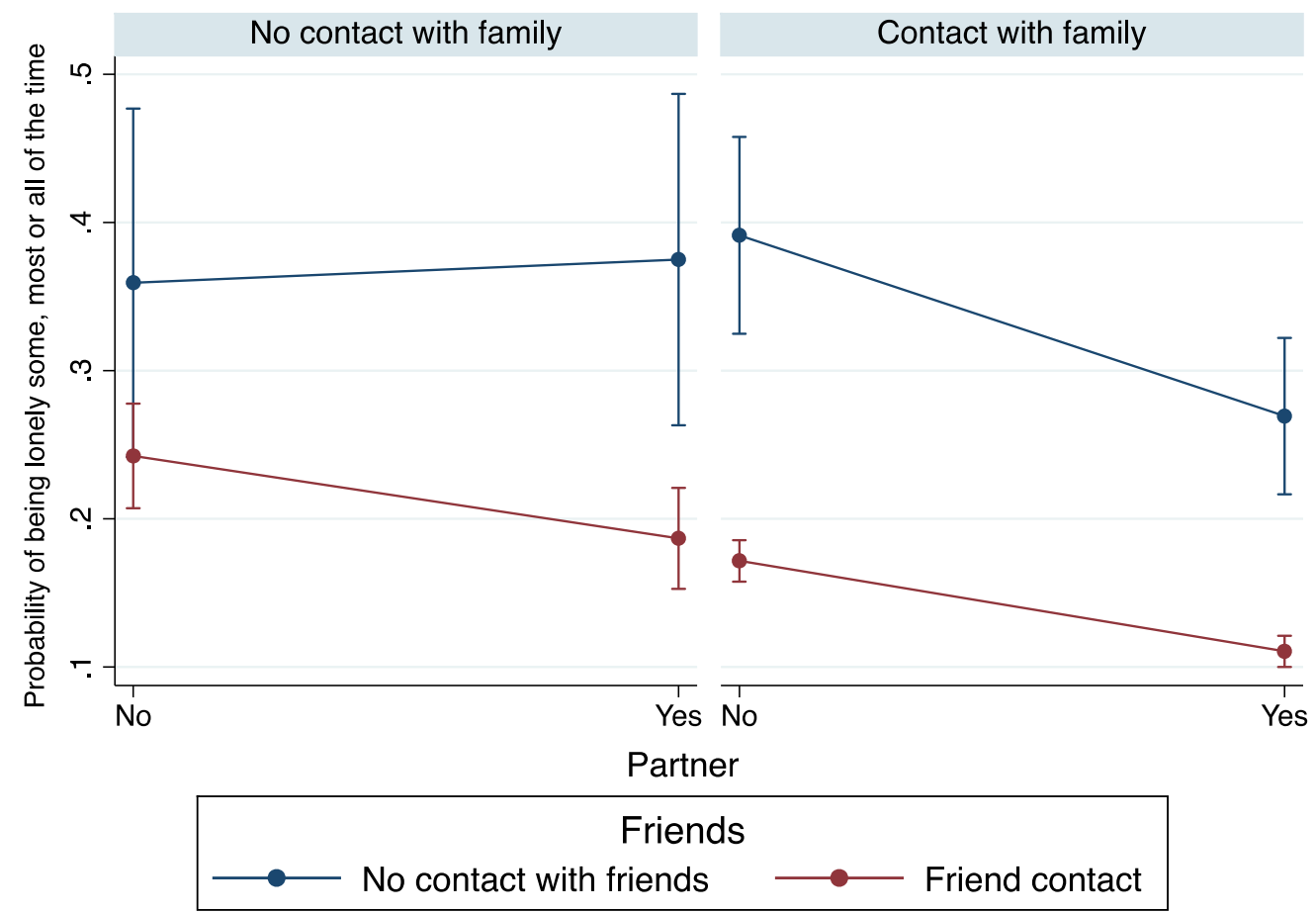

Source: NZGSS (2012)

As above, the interaction effect is not statistically significant, although the signs are in the expected direction.

\subsubsection{The added effect of community connectedness}

I also want to see what effects the addition of community connectedness has on the interaction between contact with friends, family, and partnership. I chose to add 
activity in community groups because of the stronger relative effect in reducing loneliness than other community connections, as described earlier. I expect that community connectedness further reduces the interaction effect between family, friends, and partnership.

Table 4.16 shows people who answered 'no' to all of the contact questions $(0,0,0)$ show the highest probability of being lonely SMA (0.485). If one form of contact is added this probability reduces. Once all contacts are present $(1,1,1)$, the probability of loneliness drops even further to 0.097 . This coefficient is lower than that of just family, friends, and partnership, which suggests that the cumulative nature of connectedness still stands. 
Table 4.16: Interaction effects between partnership, contact with friends and family, and participation in groups, New Zealand 2012

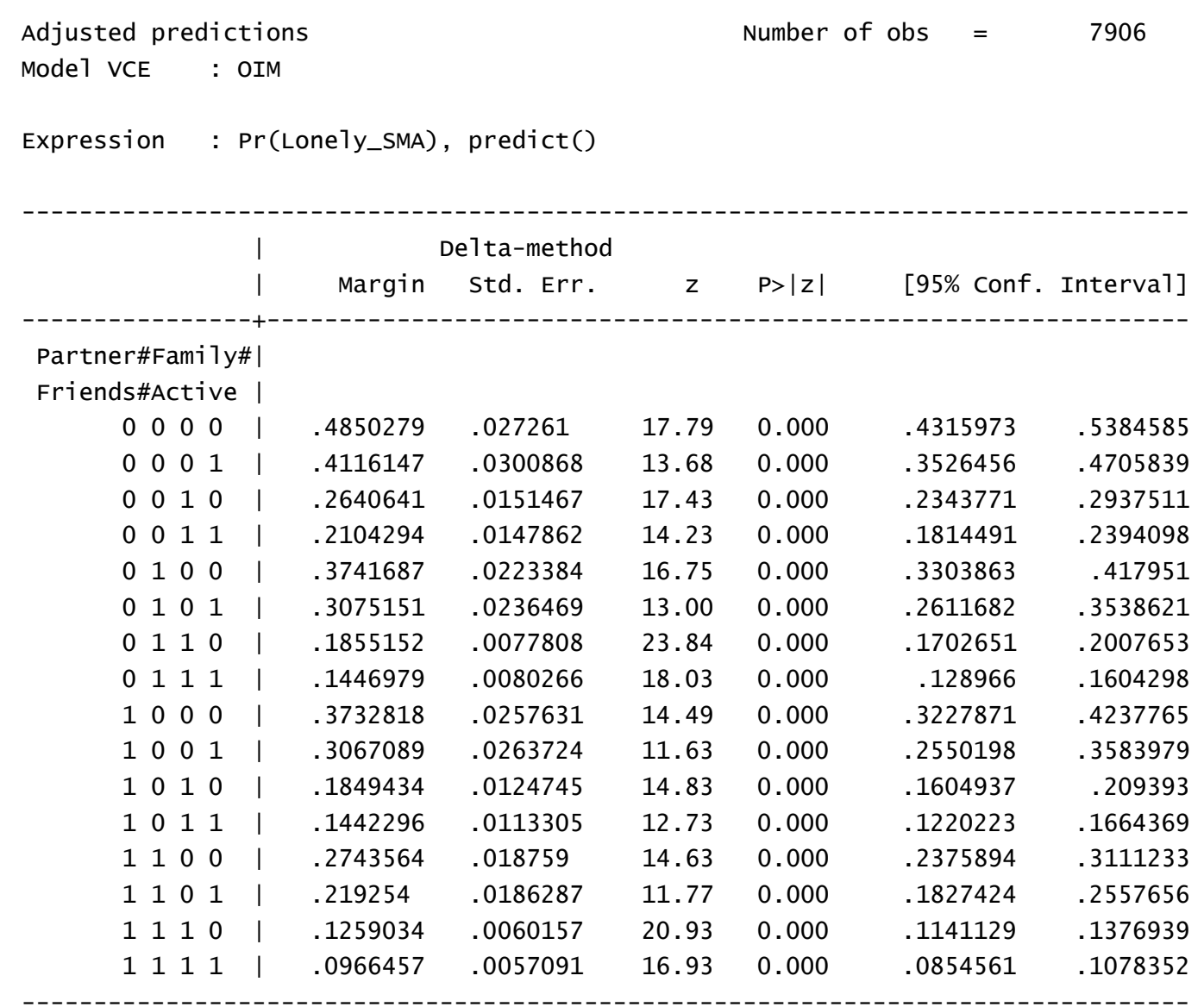

Source: NZGSS (2012)

The interaction effect is not statistically significant, although the signs are in the expected direction.

\subsubsection{Summary}

We have seen the impact that interactions between different types of connectedness can have on the probability of being lonely some/most/all of the time. People who have both in-person and non-face-to-face contact with friends are less likely to be lonely, than those who have just one form, suggesting that the hypothesis of an augmentation effect can be supported. It appears that interaction between 
partnership and contact with both friends and family reduces the probability of being lonely, and this reduces further when variables such as participation in community groups are added. The interaction effects are not statistically significant, although the signs are in the expected direction, which reinforces the notion of a balanced community, in which both emotional and social relationships are fostered through family, friends, partnerships, and community.

\subsection{Summary of Chapter 4}

This chapter has explored the relationship between loneliness and connectivity, for a representative sample of adult New Zealanders through the 2012 sample of the NZGSS. There is a clear association between reporting loneliness and being connected, but this is dependent on the level of contact, the type of contact, geographic context, and demographic and personal characteristics. Lower levels of loneliness are associated with increased types of connectedness. There are significant associations between loneliness levels and a person's demography and achieved characteristics, in that there seems to be an association between feeling lonely and being disadvantaged - for example the young, females, a single parent, those in poor health.

We have seen the impact that interactions between different types of connectedness can have on the probability of being lonely SMA. There is a clear augmenting interaction effect to having non-face-to-face contact and in person contact with friends, in that having both types of contact is more beneficial in reducing loneliness than having one or another. It appears that interaction between partnership and contact with both friends and family reduces the probability of being lonely, and this reduces further when variables such as participation in community groups are added. These interaction effects highlight the potential benefits in living in a balanced community since a range of relationships are clearly important. 
Imperative to the motivation of this thesis, this chapter highlighted how younger people (15-29 years) report higher rates of loneliness than older people in the New Zealand population. This finding provides a strong basis for an examination of the experience of loneliness for youth in New Zealand, through the 2006 Youth Connectedness Project sample in the following chapter, where I examine and analyse data to consider the validity of this finding. 


\title{
Chapter 5 Youth loneliness
}

\author{
"Solitude is fine but \\ you need someone to \\ tell that solitude is \\ fine." \\ - Honoré de Balzac
}

The analysis of the 2012 New Zealand General Social Survey (NZGSS) in Chapter 4 validates the internationally recognised tendency for loneliness to decline with age. This loneliness 'epidemic' among younger people has become a pertinent topic among many researchers, although most New Zealand research has focused primarily on loneliness among the old. However, the NZGSS (2012) only includes data from people aged 15 years and over, and this precludes a population wide study on loneliness levels among 'youth'. Therefore this chapter will focus on the 2006 Youth Connectedness Project (YCP) sample which focuses solely on young people aged 9 to 16. The YCP dataset, introduced in the methodology in Chapter 3, will be used to explore the relationship between connectedness and loneliness of youth.

Young people go through various transitions, adjustments, and challenges in the process of searching for their own identity and individuality. Perceptions that youth crave independence and tend to withdraw themselves from their family during this journey may make them feel isolated and lonely. Adolescence is also a turbulent time for creating and continuing friendships, as this period can involve shifting schools and developing personalities and interests, which may not be in line with that of their friends. Hence, the primary focus of this chapter is on the relationship between loneliness and connectivity for young people aged 9 to 16 in primary, intermediate, and early years of secondary school. 
As a reminder, the YCP is one of the biggest youth studies in New Zealand. The project was launched in 2004 and is organised and run by the Roy McKenzie Centre for the Study of Families, the New Zealand Council for Educational Research, and the Foundation for Research, Science and Technology. Researchers collected data from New Zealand adolescents annually for four years $(2006,2007,2008,2013)$ to assess their connectedness to family, school, peer group and, community as well as other indicators of adolescent functioning (Jose and Pryor, 2010).

This chapter is presented in four parts. The first part examines the overall association between loneliness and connectivity for youth. Part two examines how loneliness for youth differs across subpopulations as defined by covariates. Part three explores how loneliness is affected by different types of contact and the interaction effects between various combinations of types of contact. Part four presents a summary of the chapter as a whole.

\subsection{Loneliness and connectivity for youth}

As discovered for a wide range of the New Zealand population in Chapter 4, loneliness and connectivity are inextricably linked in that the lower the level of connectedness, the greater the chance of reporting loneliness. This chapter will reexamine this relationship using a sample of the youth population of New Zealand. This separate analysis is important as determinants of loneliness are likely to be different for youth than for adults, and in particular youth are likely to need different levels and types of contact. In order to explore this relationship empirically for young people it is necessary to define both loneliness and connectivity explicitly.

\subsubsection{Loneliness}

Table 1 has fourteen columns. Column one refers to the variable number in the table, for example the first row refers to question/variable one. Column two shows the question number in the YCP survey. Column three shows the variable name I use, and the shortened version when necessary. Column four presents the specific question that was asked in the YCP, and column five shows the number of response 
categories that are associated with the question. Column six gives the label names to the response categories, and columns seven through thirteen show the distribution of responses based on the different response categories. The last column is a sum of the count of responses and also the associated percentages. The grey shaded column labelled 'don't know/missing' refers to the number of responses which were either 'don't know' or that were not answered. These will be omitted from analysis, however it is important to highlight their existence given how they may affect the total number of participants.

Table 5.1: Description of the loneliness variable, YCP (2006)

\begin{tabular}{|c|c|c|c|c|c|c|c|c|c|c|c|c|}
\hline 1 & 2 & 3 & 4 & 5 & 6 & 7 & 8 & 9 & 10 & 11 & 12 & 13 \\
\hline & & & & & & \multicolumn{7}{|c|}{ Number (percentage) } \\
\hline Ref. & Qu. Num. & $\begin{array}{c}\text { Variable/ } \\
\text { Shortened } \\
\text { version }\end{array}$ & Qu. & $\begin{array}{c}\text { Num. } \\
\text { of } \\
\text { groups }\end{array}$ & Labels & 0 & 1 & 2 & 3 & 4 & DKM & Total \\
\hline 1 & 32 & $\begin{array}{l}\text { Loneliness/ } \\
\text { Lonely }\end{array}$ & I felt lonely & 4 & $\begin{array}{l}\text { (1) less than } \\
1 \text { day } \\
\text { (2) } 1-2 \text { days } \\
\text { (3) } 3-4 \text { days } \\
\text { (4) } 5-7 \text { days }\end{array}$ & & $\begin{array}{c}1105 \\
(59.22)\end{array}$ & $\begin{array}{c}334 \\
(17.9)\end{array}$ & $\begin{array}{c}132 \\
(7.07)\end{array}$ & $\begin{array}{c}130 \\
(6.97)\end{array}$ & $\begin{array}{c}165 \\
(8.84)\end{array}$ & $\begin{array}{l}1866 \\
(100)\end{array}$ \\
\hline 2 & (derived) & $\begin{array}{l}\text { Lonely } 1 \text { to } \\
7 \text { days of } \\
\text { the week/ } \\
\text { Lonely1to7 }\end{array}$ & I felt lonely & 2 & $\begin{array}{l}\text { (0) not } \\
\text { lonely, (1) } \\
\text { lonely }\end{array}$ & $\begin{array}{c}1105 \\
(59.22)\end{array}$ & $\begin{array}{c}596 \\
(31.94)\end{array}$ & & & & $\begin{array}{c}165 \\
(8.84)\end{array}$ & $\begin{array}{l}1866 \\
(100)\end{array}$ \\
\hline 3 & (derived) & $\begin{array}{l}\text { Lonely } 3 \text { to } \\
7 \text { days of } \\
\text { the week/ } \\
\text { Lonely3to7 }\end{array}$ & I felt lonely & 2 & $\begin{array}{l}(0) \text { not } \\
\text { lonely, (1) } \\
\text { lonely }\end{array}$ & $\begin{array}{c}1439 \\
(77.11)\end{array}$ & $\begin{array}{c}262 \\
(14.04)\end{array}$ & & & & $\begin{array}{c}165 \\
(8.84)\end{array}$ & $\begin{array}{l}1866 \\
(100)\end{array}$ \\
\hline 4 & (derived) & $\begin{array}{l}\text { Lonely } 5 \text { to } \\
7 \text { days of } \\
\text { the week/ } \\
\text { Lonely5to7 }\end{array}$ & I felt lonely & 2 & $\begin{array}{l}\text { (0) not } \\
\text { lonely, (1) } \\
\text { lonely }\end{array}$ & $\begin{array}{c}1571 \\
(84.19)\end{array}$ & $\begin{array}{c}130 \\
(6.97)\end{array}$ & & & & $\begin{array}{c}165 \\
(8.84)\end{array}$ & $\begin{array}{l}1866 \\
(100)\end{array}$ \\
\hline
\end{tabular}

Source: YCP (2006)

As stated in the methodology chapter, participants in the YCP were asked to respond to the statement 'I felt lonely'. Participants answered the item by selecting an interval on a 4-point Likert scale, including the options "less than 1 day", "1-2 
days", "3-4 days" and "5-7 days". Row one of Table 1 shows the distribution of loneliness across the sample, and shows that the majority of respondents said that they were lonely less than one day (59.22\%), whereas, 130 participants said that they were lonely 5 to 7 days of the week. Table 1 rows two to four shows the derived binary versions of loneliness, named Lonely1to7days, Lonely3to7days and Lonely5to7days.

The 'lonely' variable is in contrast to the NZGSS where loneliness is defined by the level of social isolation, and is measured across a month as opposed to a week.

\subsubsection{Connectedness}

Table 2 has ten columns. The layout of the columns are the same as described for Table 1. The table shows the distribution of answers to a number of different forms of connectivity. These questions differ from those asked in the NZGSS, but still involve questions on family and friends. The main focus of connectedness asked in the YCP are family, friends, classmates, net friends, partnership, and neighbourhood satisfaction.

This shows that $91.21 \%$ of participants get on with their classmates, $84.94 \%$ have close friends, $86.23 \%$ come from a family that believes that spending time together is important, $36.26 \%$ have net friends, $24.38 \%$ are in a relationship, and $84.24 \%$ believe that their neighbourhood is a good place to grow up in. I must draw attention to the higher non-response rate than for the NZGSS, as reflected in shaded column nine. 
Table 5.2: Description of the connectedness variables, YCP (2006)

\begin{tabular}{|c|c|c|c|c|c|c|c|c|c|}
\hline 1 & 2 & 3 & 4 & 5 & 6 & 7 & 8 & 9 & 10 \\
\hline \multirow[b]{2}{*}{ Ref } & \multirow[b]{2}{*}{ Qu. } & \multirow[b]{2}{*}{ Variable } & \multirow[b]{2}{*}{ Question } & \multirow{2}{*}{$\begin{array}{c}\text { Num. of } \\
\text { groups }\end{array}$} & \multirow[b]{2}{*}{ Labels } & \multicolumn{4}{|c|}{ Number (percentage) } \\
\hline & & & & & & 0 & 1 & DKM & Total \\
\hline 1 & 178 & Classmates & $\begin{array}{l}\text { Do you get on } \\
\text { with } \\
\text { classmates? }\end{array}$ & 2 & $\begin{array}{l}0=\text { no } \\
1 \text { = yes. }\end{array}$ & $\begin{array}{c}41 \\
(2.19)\end{array}$ & $\begin{array}{c}1702 \\
(91.21)\end{array}$ & $\begin{array}{c}123 \\
(6.59)\end{array}$ & $\begin{array}{l}1866 \\
(100)\end{array}$ \\
\hline 2 & 197 & $\begin{array}{l}\text { Close } \\
\text { friends }\end{array}$ & $\begin{array}{l}\text { Is there } \\
\text { anyone who } \\
\text { you see as a } \\
\text { close friend? }\end{array}$ & 2 & $\begin{array}{l}0=\text { no } \\
1=\text { yes. }\end{array}$ & $\begin{array}{c}104 \\
(5.57)\end{array}$ & $\begin{array}{c}1585 \\
(84.94)\end{array}$ & $\begin{array}{c}177 \\
(9.49)\end{array}$ & $\begin{array}{l}1866 \\
(100)\end{array}$ \\
\hline 3 & 128 & $\begin{array}{l}\text { Family } \\
\text { cohesion }\end{array}$ & $\begin{array}{l}\text { For my family, } \\
\text { spending time } \\
\text { together is } \\
\text { important }\end{array}$ & 2 & $\begin{array}{l}0=\text { no } \\
1 \text { = yes. }\end{array}$ & $\begin{array}{c}159 \\
(8.52)\end{array}$ & $\begin{array}{c}1609 \\
(86.23)\end{array}$ & $\begin{array}{c}95 \\
(5.25)\end{array}$ & $\begin{array}{l}1866 \\
(100)\end{array}$ \\
\hline 4 & 243 & Net friends & $\begin{array}{l}\text { Do you have } \\
\text { internet } \\
\text { friends, that } \\
\text { you have } \\
\text { never met face- } \\
\text { to-face }\end{array}$ & 2 & $\begin{array}{l}0=\text { no } \\
1 \text { = yes. }\end{array}$ & $\begin{array}{c}812 \\
(63.74)\end{array}$ & $\begin{array}{c}462 \\
(36.26)\end{array}$ & $\begin{array}{c}592 \\
(31.73)\end{array}$ & $\begin{array}{l}1866 \\
(100)\end{array}$ \\
\hline 5 & 207 & Partner & $\begin{array}{l}\text { Do you have a } \\
\text { boyfriend or a } \\
\text { girlfriend? }\end{array}$ & 2 & $\begin{array}{l}0=\text { no } \\
1 \text { = yes. }\end{array}$ & $\begin{array}{c}1233 \\
(66.08)\end{array}$ & $\begin{array}{c}455 \\
(24.38)\end{array}$ & $\begin{array}{c}178 \\
(9.54)\end{array}$ & $\begin{array}{l}1866 \\
(100)\end{array}$ \\
\hline 6 & 277 & $\begin{array}{l}\text { Neighbourh } \\
\text { ood }\end{array}$ & $\begin{array}{l}\text { My } \\
\text { neighbourhoo } \\
\text { d is a good } \\
\text { place to grow } \\
\text { up in }\end{array}$ & 2 & $\begin{array}{l}0=\text { no } \\
1=\text { yes }\end{array}$ & $\begin{array}{c}184 \\
(9.86)\end{array}$ & $\begin{array}{c}1572 \\
(84.24)\end{array}$ & $\begin{array}{c}110 \\
(5.89)\end{array}$ & $\begin{array}{l}1866 \\
(100)\end{array}$ \\
\hline
\end{tabular}

Source: YCP (2006) 


\subsubsection{An index of connectedness}

To test the relationship between loneliness and total contact, an overall index of connectedness was constructed and named 'connect', as in Chapter 4 but with this different set of contacts. This index is the sum of the presence of a relationship, family time, close friends, net friends (never met face-to-face), getting on with classmates, and believing that your neighbourhood is a good place - six categories in all. However, because of a large number of missing values (as seen in Table 2 in grey) the size of this index dropped by nearly 800 participants (this is largely due to the net friends variable). As a result, I have decided to omit the net friends variable for part of this analysis (I will introduce it back in part 3 of this chapter) and I have renamed the updated variable, without net friends, as 'connects'.

Table 5.3 presents a frequency distribution of this connectivity index, from one contact to all five contacts. It shows that five people responded 'yes' to only one of the possible contacts, suggesting that these people are not very connected. By comparison, the majority of participants (1036) responded 'yes' to four out of the five possible types of contact, and 325 participants responded 'yes' to all of the questions, suggesting that these people are widely connected.

\section{Table 5.3: Distribution of responses to the number of types of contact a young} person has, New Zealand 2006

\begin{tabular}{r|rrr} 
connects | & Freq. & Percent & Cum. \\
\hline 1 & 5 & 0.30 & 0.30 \\
2 & 44 & 2.68 & 2.99 \\
3 & 231 & 14.08 & 17.06 \\
4 & 1,036 & 63.13 & 80.20 \\
5 & 325 & 19.80 & 100.00 \\
- Tota1 & 1,641 & 100.00 &
\end{tabular}

Source: YCP (2006) 
Figure 5.1 shows this detail graphically, where we can see that the number of responses rises successively, with a large jump from three to four contacts, and then lowers considerably from four to five contacts.

Figure 5.1: Frequency distribution of the number of types of contact, New Zealand 2006

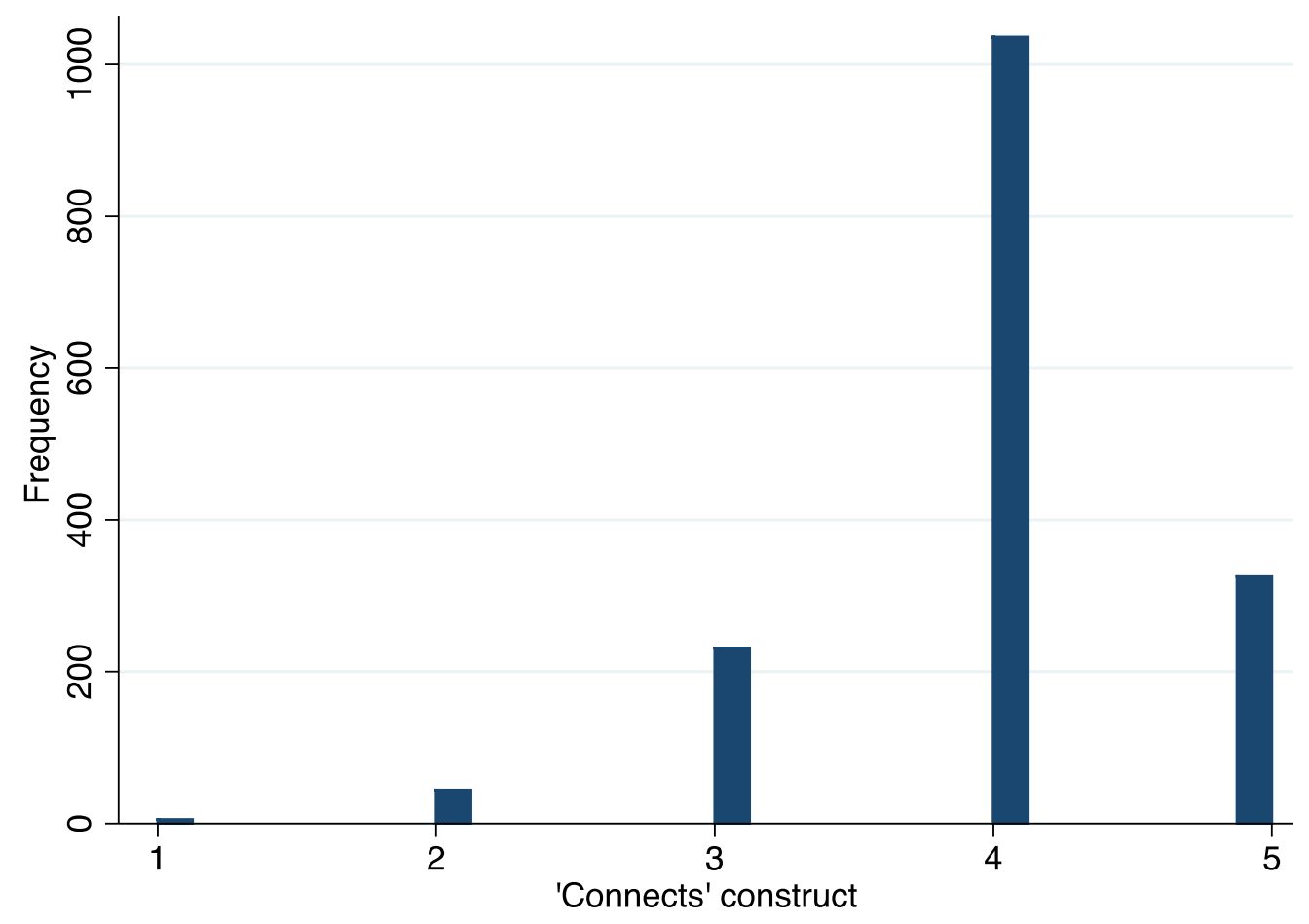

Source: YCP (2006)

I recognise here that this contact index is missing detail on the frequency and quality of contact. Figure 5.2 below shows how loneliness falls with increased quality/satisfaction of relationships with close friends. This is also the case (to a lesser degree) with increased frequency of contact with friends (not shown graphically). 
Figure 5.2: How loneliness falls with quality of connection, New Zealand 2006

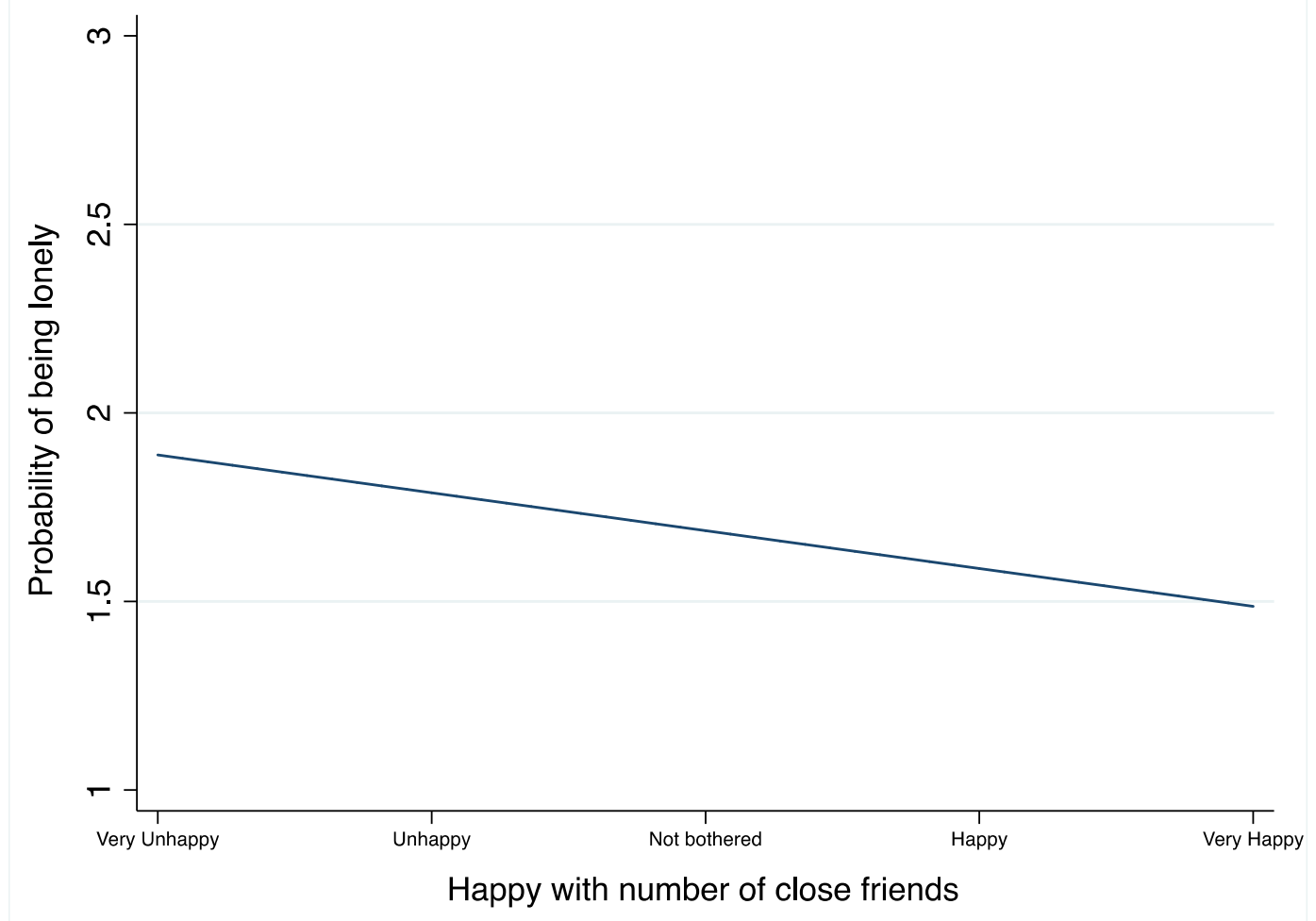

Source: YCP (2006)

Frequency and quality contact variables had larger numbers of missing values (in comparison to presence of contact), and so more reliable and useful results are expected from this 'connects' variable. Consequently, frequency and quality are omitted from the rest of this analysis.

\subsubsection{Results from the $Y C P$}

The analysis of the NZGSS (2012) in Chapter 4, and findings from literature (Baumeister and Leary, 1995; Cacioppo and Hawkley, 2000; Ernst and Cacioppo, 1999; Heinrich and Gullone, 2006), suggest that low levels of connectedness are linked to high levels of loneliness. I expect this to also apply to youth, so that the more connected a young person is, the lower their feelings of loneliness. The same approach introduced in Chapter 3, to test the hypothesis that lower levels of 
loneliness and higher levels of connectedness are related for youth, will be adopted here using the linear model, as in equation (1).

The results of the regression are displayed in the following equation. It confirms the hypothesis that the more connected a person is, the less likely they are to be lonely, as reflected by the coefficient of -0.199 . The coefficient means that for every one unit increase in connectedness in the last month, the average on the loneliness scale decreases by 0.199 . The result is statistically significant, as reflected by the $t$ score ($6.06)$ and $p$ value $(0.000)$. The statistical significance means that there is less than one percent chance the result is due to random chance.

$$
L_{i}=2.35-0.199 C_{i} \quad R^{2}=0.022 N=1576
$$

Given the central importance of the relationship between loneliness and connectivity it is also worth paying attention to the functional form of this association. The same three relationships are of interest, as in the NZGSS: convex, linear, and concave.

The results of estimating the quadratic model, as in equation (2) of Chapter 3, are shown below in which connectedness remains negatively associated with loneliness $\left(\beta_{1}=-0.142\right)$ and starts to increase slightly $\left(\beta_{2}=0.112\right)$, as it did in the NZGSS case. The slight increase shows what happens to the curve and this positive coefficient means that the line starts to curve up in a convex manner. The results are statistically significant, as shown by the $\mathrm{z}$ scores for each of the coefficients. Therefore the hypothesis (that the line would be convex) is also supported by these YCP findings.

YCP:

$$
\begin{gathered}
L_{i}=1.5-0.142 C_{i}+0.112 C^{2} \quad R^{2}=0.03 \\
(\mathrm{z}=-0.402) \quad(\mathrm{z}=-4.11)
\end{gathered}
$$


NZGSS:

$$
L_{i}=1.5-0.09 C_{i}+0.12 C^{2}
$$

$R^{2}=0.02$

These two estimated equations (NZGSS and the YCP) are very similar except for the greater sensitivity of youth to their connections. This may suggest that youth and the adult populations respond to loneliness in reasonably similar ways.

This convex relationship between loneliness and contact is shown in Figure 5.3 which shows us, as with the adult population, that connectedness decreases loneliness but with diminshing returns.

Figure 5.3: How loneliness falls with connectivity, New Zealand 2006

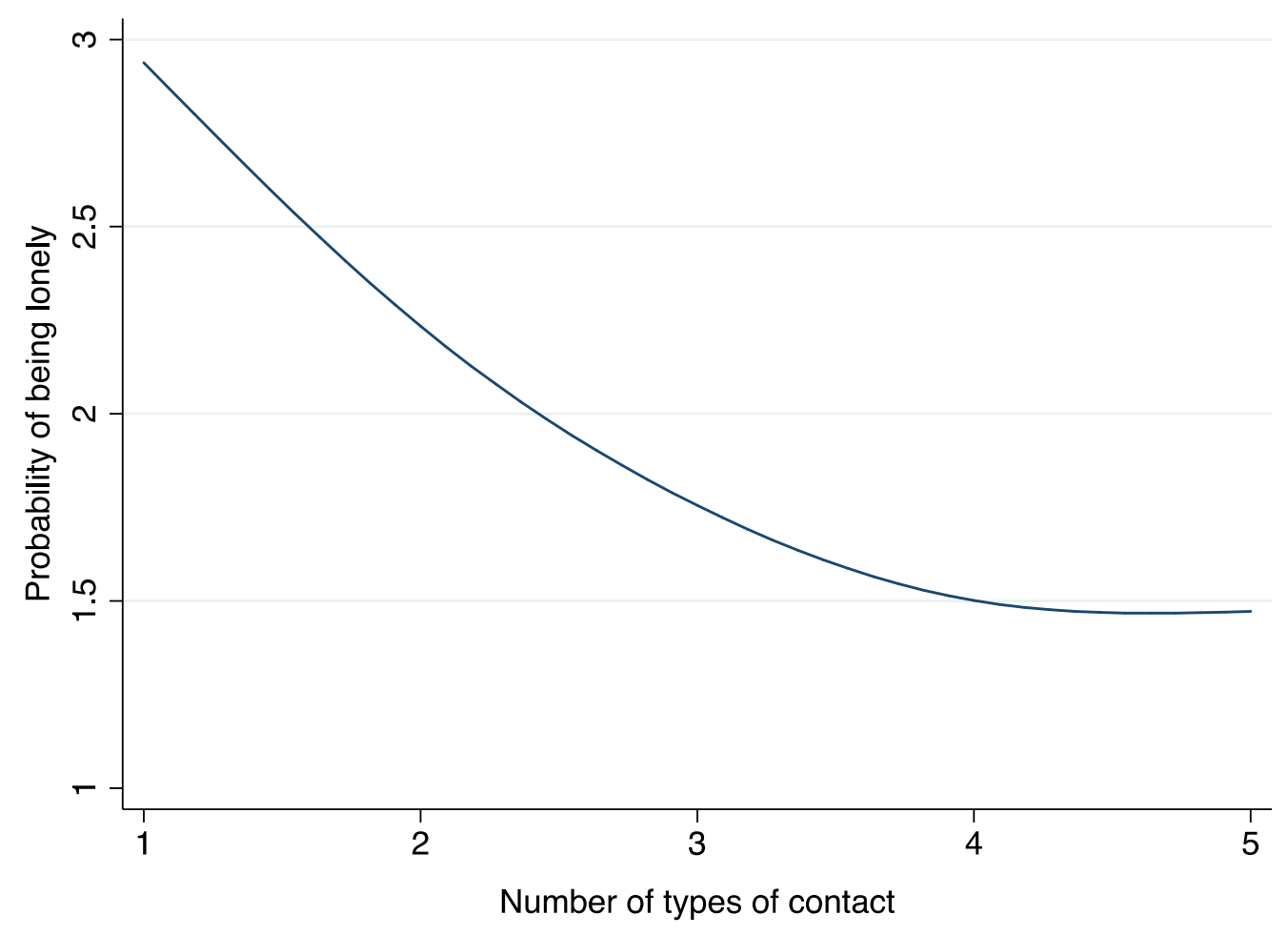

Source: YCP (2006) 


\subsubsection{Summary}

In summary, the negative relationship between loneliness and connectedness reported in Chapter 4, as well as the literature in general, has been confirmed here. This relationship between loneliness and the overall connectivity measure is convex in shape for the youth of New Zealand, suggesting diminishing returns to additional types of contact. In other words as a person becomes more connected the experience of loneliness reduces at a decreasing rate.

\subsection{Who is the loneliest?}

Given that loneliness is negatively associated with connectedness for youth, it is now of interest to learn how loneliness varies based on the addition of several covariates. So far I have only used the 'Lonely' variable introduced in Table 5.1. This has allowed me to demonstrate the way the average level of loneliness declines with connectivity. However, in much of the discussion below I am not as interested in the average level of loneliness on a 1-4 scale as I am in the proportion of people who are lonely according to a given criterion - lonely three to seven days of the week. For the following application I estimate the linear-with-covariates model, as in equation (3) in Chapter 3.

\subsubsection{Context}

I will now see how loneliness, connect, and geographic context relate to each other, where context refers to settlement type (main urban, secondary urban, minor urban and rural areas). These geographic context variables are shown in Table 5.4. The majority of respondents to the YCP survey (59.75\%) live in main urban areas, 14.47\% live in secondary urban areas, 20.42 live in minor urban areas, and 5.31\% reside in rural areas. 
Table 5.4: Description of context covariate, YCP (2006)

\begin{tabular}{|c|c|c|c|c|c|c|c|c|c|c|c|c|}
\hline 1 & 2 & 3 & 4 & 5 & 6 & 7 & 8 & 9 & 10 & 11 & 12 & 13 \\
\hline & & & & Num. & & \multicolumn{7}{|c|}{ Number (percentage) } \\
\hline Ref & Qu. & Variable & Question & $\begin{array}{c}\text { of } \\
\text { groups }\end{array}$ & Labels & 0 & 1 & 2 & 3 & 4 & DKM & Total \\
\hline 1 & . & $\begin{array}{l}\text { Settlement } \\
\text { type }\end{array}$ & $\begin{array}{l}\text { Settlement } \\
\text { type }\end{array}$ & 4 & $\begin{array}{l}\text { (1) Main } \\
\text { urban, (2) } \\
\text { Secondary } \\
\text { urban, (3) } \\
\text { Minor } \\
\text { urban, (4) } \\
\text { Rural }\end{array}$ & & $\begin{array}{c}1115 \\
(59.75)\end{array}$ & $\begin{array}{c}270 \\
(14.47)\end{array}$ & $\begin{array}{c}381 \\
(20.42)\end{array}$ & $\begin{array}{c}99 \\
(5.31)\end{array}$ & $\begin{array}{c}1 \\
(0.05)\end{array}$ & $\begin{array}{l}1866 \\
(100)\end{array}$ \\
\hline
\end{tabular}

Source: YCP (2006)

As in the NZGSS (2012) analysis in Chapter 4, I have placed context variables above all other covariates in order to see how they were affected by adding control variables. The general hypothesis around the geography of loneliness is that loneliness will be higher in the larger centres because "the closer people live to one another, the more they tend to emotionally isolate from one another, [while rural] communities have a much greater sense of community than urban areas" (Hunt, 2013, p. 41). The analysis of the NZGSS (2012) in Chapter 4 found that people who live in main urban areas showed a higher odds of being lonely some/most/all of the time than all other settlement types (and especially if they lived in Wellington). I expect that this urban effect will also be the case for youth involved in the YCP. In order to test this hypothesis my lonely variable has been regressed on three settlement dummy variables: main urban, secondary urban, and minor urban, using rural areas as the base category for comparison. 


\section{Table 5.5: Models of loneliness controlling for context, New Zealand 2006}

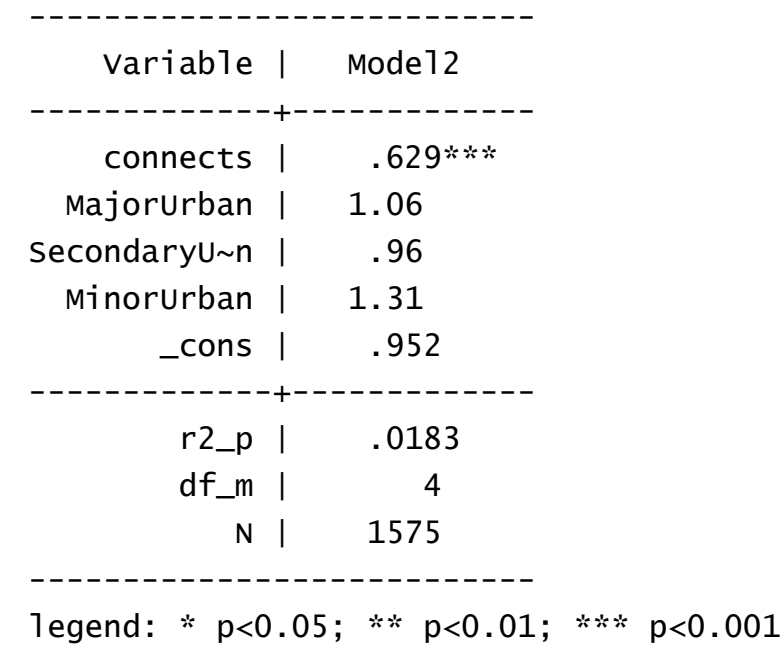

Source: YCP (2006)

Model two suggests that the hypothesis that youth in main urban areas are more likely to be lonely is correct, however the results are not statistically significant meaning that there is a high chance that that the association is a result of random chance. In fact, most of the estimated odds ratios discussed in this section are not statistically significant. Larger sample sizes increase the chance of finding statistical difference, and it could be that the YCP dataset is too small (1866 youth), in comparison to the NZGSS (about 8000 participants). The limitations of sample size are exacerbated by the numbers of missing values across the covariates - some variables are missing over 100 answers.

Another reason for statistical insignificance may be due to the sample itself. Young people are less diverse than adults - it may be that there is little difference in loneliness levels because young people are entering a phase of individuality and difference but their differences have yet to become apparent. In addition, young people do not have the agency to decide where to live, where to go to school, and in some cases, who to be friends with, preventing location working as a selection mechanism as it may do in the adult case. In addition, youth may be less affected by their location because the school environment encourages social relationships and 
or social contact, in comparison to adults who can more easily isolate themselves from others.

\subsubsection{Demographics}

Although findings from the literature are inconsistent when it comes to age and gendered differences in loneliness levels, findings from New Zealand studies, such as The Social Report (2010), and the analysis of the NZGSS (2012) in Chapter 4 found that the young and women are more likely to be lonely than older adults and men, respectively. When it comes to ethnicity, the hypothesis is that ethnic minorities will show stronger tendencies to report themselves as being lonely, which was also found in the Social Report (2010), and the analysis of the NZGSS (2012) in Chapter 4. Table 5.7 continues the previous summary table by adding age, gender and ethnicity. These variables are shown in Table 5.6.

Table 5.6: Description table of demographic variables, New Zealand 2006

\begin{tabular}{|c|c|c|c|c|c|c|c|c|c|c|c|c|c|c|c|}
\hline 1 & 2 & 3 & 4 & 5 & 6 & 7 & 8 & 9 & 10 & 11 & 12 & 13 & 14 & 15 & 16 \\
\hline & & & & Num. & & \multicolumn{10}{|c|}{ Number (percentage) } \\
\hline Ref & Qu. & Variable & Qu. & $\begin{array}{c}\text { of } \\
\text { groups }\end{array}$ & Labels & 0 & 1 & 2 & 3 & 4 & 5 & 6 & 7 & DKM & Total \\
\hline 1 & 2 & Age & Age & 8 & $\begin{array}{l}\text { (0) } 9 \\
\text { (1) } 10 \\
\text { (2) } 11 \\
\text { (3) } 12 \\
\text { (4) } 13 \\
\text { (5) } 14 \\
\text { (6) } 15 \\
\text { (7) } 16\end{array}$ & $\begin{array}{c}13 \\
(0.70)\end{array}$ & $\begin{array}{c}462 \\
(24.76)\end{array}$ & $\begin{array}{c}216 \\
(11.58)\end{array}$ & $\begin{array}{c}379 \\
(20.31)\end{array}$ & $\begin{array}{c}186 \\
(9.97)\end{array}$ & $\begin{array}{c}336 \\
(18.01)\end{array}$ & $\begin{array}{c}180 \\
(9.65)\end{array}$ & $\begin{array}{c}1 \\
(0.05)\end{array}$ & $\begin{array}{c}93 \\
(4.98)\end{array}$ & $\begin{array}{l}1866 \\
(100)\end{array}$ \\
\hline 2 & 1 & Gender & Gender & 2 & $\begin{array}{l}(0) \\
\text { females } \\
(1) \\
\text { males }\end{array}$ & $\begin{array}{c}919 \\
(49.25 \\
1\end{array}$ & $\begin{array}{c}854 \\
(45.77)\end{array}$ & & & & & & & $\begin{array}{c}93 \\
(4.98)\end{array}$ & $\begin{array}{l}1866 \\
(100)\end{array}$ \\
\hline 3 & 252 & Ethnicity & Ethnicity & 3 & \begin{tabular}{|l}
$(1)$ \\
Europea \\
$n$, \\
$(2)$ \\
Maori, \\
$(3)$ \\
Other
\end{tabular} & & $\begin{array}{c}1024 \\
(54.88)\end{array}$ & $\begin{array}{c}476 \\
(25.51)\end{array}$ & $\begin{array}{c}271 \\
(14.52)\end{array}$ & & & & & $\begin{array}{c}95 \\
(5.09)\end{array}$ & $\begin{array}{l}1866 \\
(100)\end{array}$ \\
\hline
\end{tabular}

Source: YCP (2006) 
I have entered females, age (as a continuous variable) and Maori into the series of regressions the Table 5.7. Again, as above, these demographic covariates are not statistically significant in their relationship to loneliness, however the signs are in the expected direction until the last covariates are entered. Therefore, there is no justification to further analyse these results as they may be a result of random chance.

Table 5.7: Models of loneliness controlling for context, and demographics, New Zealand 2006

\begin{tabular}{|c|c|c|c|}
\hline Variable & Mode13 & Mode 14 & Mode15 \\
\hline $\begin{array}{r}\text { connects } \\
\text { Majorurban } \\
\text { SecondaryU n } \\
\text { Minorurban } \\
\text { Age } \\
\text { Females } \\
\text { NZEuropean } \\
\text { Maori } \\
\text { _cons }\end{array}$ & $\begin{array}{l}.592 * * * \\
1.31 \\
1.2 \\
1.33 \\
1.06\end{array}$ & $\begin{array}{l}.591 * * * \\
1.31 \\
1.19 \\
1.3 \\
1.05 \\
1.28\end{array}$ & $\begin{array}{l}.596 * * * \\
1.28 \\
1.15 \\
1.23 \\
1.06 \\
1.24 \\
1.05 \\
1.42 \\
.362\end{array}$ \\
\hline $\begin{array}{l}\mathrm{r} 2{ }_{\mathrm{p}}^{\mathrm{p}} \\
\mathrm{df}{ }_{\mathrm{m}}\end{array}$ & $\begin{array}{c}.0227 \\
5 \\
1184\end{array}$ & $\begin{array}{c}.0249 \\
6 \\
1184\end{array}$ & $\begin{array}{c}.0277 \\
8 \\
1184\end{array}$ \\
\hline
\end{tabular}

Source: YCP (2006)

\subsubsection{Achievement variables}

Also of interest are the students achieved characteristics, for example a young person's religion. Table 5.8 introduces additional variables associated with achievement characteristics. They allow for a continuation of this estimates table of loneliness, in the adding of religion, employment status, household structure, bullying, and physical health. 
Table 5.8: Description table of achieved variables, New Zealand 2006

\begin{tabular}{|c|c|c|c|c|c|c|c|c|c|c|c|c|c|}
\hline 1 & 2 & 3 & 4 & 5 & 6 & 7 & 8 & 9 & 10 & 11 & 12 & 13 & 14 \\
\hline \multirow{2}{*}{ Ref } & \multirow{2}{*}{ Qu. } & \multirow{2}{*}{ Variable } & \multirow{2}{*}{ Question } & \multirow{2}{*}{$\begin{array}{l}\text { Num. of } \\
\text { groups }\end{array}$} & \multirow{2}{*}{ Labels } & \multicolumn{8}{|c|}{ Number (percentage) } \\
\hline & & & & & & 0 & 1 & 2 & 3 & 4 & 5 & DKM & Total \\
\hline 1 & 210 & Religion & \begin{tabular}{|l} 
Do you \\
believe in \\
a higher \\
power?
\end{tabular} & 2 & $\begin{array}{l}(0) \text { no, (1) } \\
\text { yes. }\end{array}$ & $\begin{array}{c}686 \\
(36.76)\end{array}$ & $\begin{array}{c}1041 \\
(55.79)\end{array}$ & & & & & $\begin{array}{c}139 \\
(7.45)\end{array}$ & $\begin{array}{l}1866 \\
(100)\end{array}$ \\
\hline 2 & 87 & Parents & $\begin{array}{l}\text { Who is in } \\
\text { your } \\
\text { family? }\end{array}$ & 2 & $\begin{array}{l}(0) \text { no, (1) } \\
\text { yes. }\end{array}$ & $\begin{array}{c}1781 \\
(95.44)\end{array}$ & $\begin{array}{c}85 \\
(4.56)\end{array}$ & & & & & & $\begin{array}{l}1866 \\
(100)\end{array}$ \\
\hline 3 & 87 & Siblings & $\begin{array}{l}\text { Who is in } \\
\text { your } \\
\text { family? }\end{array}$ & 2 & $\begin{array}{l}(0) \text { no, (1) } \\
\text { yes. }\end{array}$ & $\begin{array}{c}1777 \\
(95.23)\end{array}$ & $\begin{array}{c}89 \\
(4.77)\end{array}$ & & & & & & $\begin{array}{l}1866 \\
(100)\end{array}$ \\
\hline 4 & 152 & Bullying & $\begin{array}{l}\text { How often } \\
\text { have you } \\
\text { bullied } \\
\text { other } \\
\text { students? }\end{array}$ & 5 & \begin{tabular}{|l|} 
(1) never \\
bullied, (2) 1- \\
3 days, (3) 4- \\
6 days, (4) 7+ \\
days, (5) Daily
\end{tabular} & & $\begin{array}{c}1202 \\
(64.58)\end{array}$ & $\begin{array}{c}417 \\
(22.35)\end{array}$ & $\begin{array}{c}75 \\
(4.02)\end{array}$ & $\begin{array}{c}36 \\
(1.93)\end{array}$ & $\begin{array}{c}21 \\
(1.13)\end{array}$ & $\begin{array}{c}112 \\
(6)\end{array}$ & $\begin{array}{l}1866 \\
(100)\end{array}$ \\
\hline 5 & 36 & Health & $\begin{array}{l}\text { How } \\
\text { healthy } \\
\text { are you? }\end{array}$ & 3 & $\begin{array}{l}\text { (1) poor } \\
\text { health, (2) } \\
\text { average } \\
\text { health, (3) } \\
\text { good health }\end{array}$ & & $\begin{array}{c}78 \\
(4.18)\end{array}$ & $\begin{array}{c}458 \\
(24.54)\end{array}$ & $\begin{array}{c}1221 \\
(65.43)\end{array}$ & & & $\begin{array}{c}109 \\
(5.84)\end{array}$ & $\begin{array}{l}1866 \\
(100)\end{array}$ \\
\hline
\end{tabular}

Source: YCP (2006)

The general expectation when it comes to these achieved characteristics and loneliness is that non-religious youth without parents and siblings, who are bullied and are in poor health would show stronger tendencies to report themselves as being lonely. These hypotheses are tested in Table 5.9. 
Table 5.9: Models of loneliness controlling for context, demographics, and achievement variables, New Zealand 2006

\begin{tabular}{|c|c|c|c|c|c|}
\hline Variable & Mode16 & Mode17 & Mode18 & Mode19 & Mode110 \\
\hline 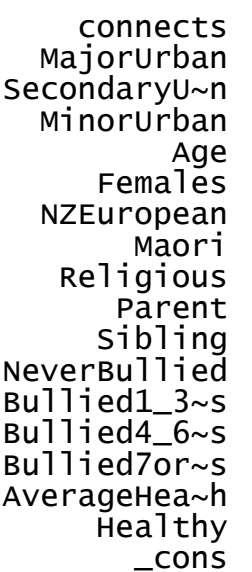 & $\begin{array}{l}.581 * * * \\
1.41 \\
1.23 \\
1.35 \\
1.06 \\
1.18 \\
1.25 \\
1.6 \\
1.6 *\end{array}$ & $\begin{array}{l}.582 * * * \\
1.42 \\
1.24 \\
1.35 \\
1.07 \\
1.18 \\
1.25 \\
1.61 \\
1.59 * \\
.878\end{array}$ & $\begin{array}{l}.581 * * * \\
1.45 \\
1.28 \\
1.4 \\
1.07 \\
1.16 \\
1.27 \\
1.61 \\
1.6 * \\
.733 \\
1.84\end{array}$ & $\begin{array}{l}.573 * * * \\
1.48 \\
1.28 \\
1.42 \\
1.04 \\
1.22 \\
1.28 \\
1.54 \\
1.6 \% \\
.753 \\
1.73 \\
.187 * * \\
.235 * \\
.218^{*} \\
.394\end{array}$ & $\begin{array}{l}.592 * * * \\
1.48 \\
1.3 \\
1.44 \\
1.05 \\
1.19 \\
1.33 \\
1.56 \\
1.57 * \\
.702 \\
1.52 \\
.164 * * \\
.205 * * \\
.189 * \\
.347 \\
.781 \\
.646 \\
1.76\end{array}$ \\
\hline $\begin{array}{l}\mathrm{r} 2 \_p \\
\mathrm{df}{ }_{\mathrm{N}}\end{array}$ & $\begin{array}{c}.0362 \\
9 \\
1158\end{array}$ & $\begin{array}{c}.0363 \\
10 \\
1158\end{array}$ & $\begin{array}{c}.039 \\
11 \\
1158\end{array}$ & $\begin{array}{c}.0502 \\
15 \\
1152\end{array}$ & $\begin{array}{c}.0517 \\
17 \\
1144\end{array}$ \\
\hline
\end{tabular}

Source: YCP (2006)

As with the context and demographic covariates, very few of these results end up having any statistical significance, which again could be attributed to the sample size, or the limited diversity in loneliness across the range of participants. The results which are statistically significant, namely religion and bullying are worth discussing here.

Religious youth show higher odds of being lonely than non-religious youth, as shown by the positive coefficient (1.6) in Model 6. This finding has also been recognized in the literature, in that religious children may feel like outsiders and may be subject to bullying because of their beliefs (Lester, 2012). On the other hand, lonely people can also exclude themselves from situations by withdrawing (Jones, 1990), and this may be the case with youth from religious families as they may be prohibited from participating in some activities, or being connected with certain groups of people because of their beliefs. 
Model 10 demonstrates how being a 'bully' or participating in bullying another person is associated with higher levels of loneliness for youth. Those who never bully others demonstrate the smallest odds of being lonely (0.164), and the odds of reporting loneliness increases as frequency of bullying increases. Although a significant majority of literature focuses on the association between being bullied and feeling lonely, some academics allude to how being a bully can often stem from social issues and loneliness. Macintyre (2012) suggests that bullying can often be a result of anxiety, loneliness, underachieving in school, and experiences from home. She points out how many bullies learn their behavior from home and project their feelings onto their peers, through bullying, because of the negative social environment at home. A harsh family environment can be related to the Attachment Theory (1951), which was discussed in the literature review. The Attachment Theory proposes that a young person forms attachment bonds with their parents while in infancy, and arguably all throughout childhood (Kerns, 1994). If these bonds are not warm, intimate, and continuous it is likely that these children will go on to struggle to form connections with others - which may be the case for why some children bully.

\subsubsection{Psychological wellbeing}

People with poor mental health tend to show stronger propensities to report themselves as being lonely, as found by Cacioppo and Hawkley (2000) and the NZGSS (2012) data in Chapter 4. Table 5.10 introduces a self-harm variable. I decided to enter the self-harm variable separately to the other covariates, like the depression variable in Chapter 4, because it is likely to be endogenous. In other

words, self-harming/being depressed and loneliness are highly interconnected and often come hand in hand (Eisemann, 1984; Wenz, 1977). Loneliness can be both a cause and consequence of depression. 
Table 5.10: Description table of self-harming variable, New Zealand 2006

\begin{tabular}{|c|c|c|c|c|c|c|c|c|c|c|c|}
\hline 1 & 2 & 3 & 4 & 5 & 6 & 7 & 8 & 9 & 10 & 11 & 12 \\
\hline \multirow[b]{2}{*}{ Ref } & \multirow[b]{2}{*}{ Qu. } & \multirow[b]{2}{*}{$\begin{array}{c}\text { Variabl } \\
\text { e }\end{array}$} & \multirow[b]{2}{*}{ Qu. } & \multirow{2}{*}{$\begin{array}{c}\text { Num. } \\
\text { of } \\
\text { group } \\
s\end{array}$} & \multirow[b]{2}{*}{ Labels } & \multicolumn{6}{|c|}{ Number (percentage) } \\
\hline & & & & & & 0 & 1 & 2 & 3 & DKM & Total \\
\hline 1 & 46 & $\begin{array}{l}\text { Self- } \\
\text { harm }\end{array}$ & $\begin{array}{l}\text { Physically hurt or } \\
\text { tried to hurt } \\
\text { youself on } \\
\text { purpose in last } \\
\text { month }\end{array}$ & 3 & $\begin{array}{l}\text { (1) never, } \\
\text { (2) 1-5 days, } \\
\text { (3) 6-10+ } \\
\text { days }\end{array}$ & & $\begin{array}{c}1605 \\
(86.01)\end{array}$ & $\begin{array}{c}133 \\
(7.13)\end{array}$ & $\begin{array}{c}19 \\
(1.02)\end{array}$ & $\begin{array}{c}109 \\
(5.84)\end{array}$ & $\begin{array}{l}1866 \\
(100)\end{array}$ \\
\hline
\end{tabular}

Source: YCP (2006)

Table 5.11 is also a continuation of this estimates table of loneliness, with the addition of a variable showing whether a young person self-harms (and to what degree) or not.

Table 5.11: Models of loneliness controlling for context, demographics, achievement, and self harm, New Zealand 2006

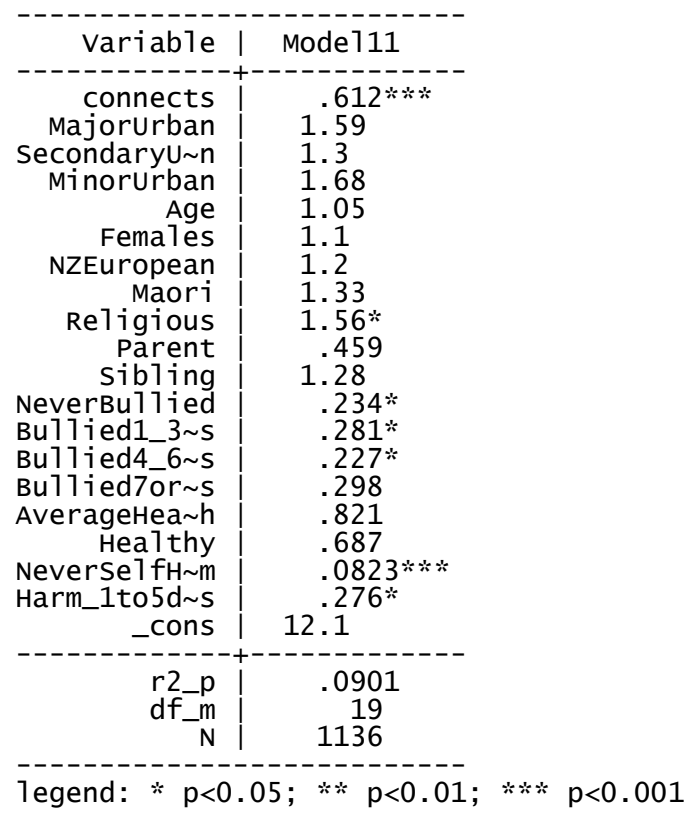

Source: YCP (2006) 
This estimates table shows that those who never self-harm have a much smaller odds of being lonely than those who do (0.0823), and this result is statistically significant. There is a cumulative effect of self-harming - the more a young person self-harms, the more likely they are to report being lonely. Depression and loneliness are highly associated with one another, and self-harming is often an extension of depression (Cacioppo, Hughes, Waite, Hawkley and Thisted, 2006). Youth who feel depressed and/or lonely often feel that way because they believe they do not have strong social networks to support them (Cacioppo et al., 2006). Similarly those who are lonely might be that way because depression/self-harming can get in the way of socialising.

\subsubsection{Summary}

This section has shown that covariates are mostly statistically insignificant, and therefore it seems that the limited variation in people's demography and related characteristics do not exert a marked effect on loneliness within this narrow age range. It is likely the insignificant results are a result of the small sample size (the effect of which is exacerbated by missing values), the fact that youth have less agency to make many decisions for themselves, and that youth are arguably less diverse than adults. Religion, bullying and self-harm are the only exceptions.

\subsection{Interaction effects between contacts}

The aim of the rest of this chapter is to consider the effect of individual connectivity measures, and their joint presence, on loneliness levels. In the following section I have not only adopted specific connectivity measures, but I focus primarily on those who are lonely to different degrees three to seven days out of the week (Lonely3to7days), discussed in Table 5.1. A series of logistic regressions were applied to the discrete measure of loneliness and the discrete measures of connectedness: contact within the household (family), outside of the household (contact with friends and classmates), and within the community (neighbourhood 
satisfaction). Contact with net friends is also a variable of special interest in this section.

\subsubsection{Family cohesion}

I want to begin by testing the way loneliness is associated with a young person's connectedness with their family. Perceptions of the importance of family time is important to consider as it could signal a disconnect with family, and therefore a potential for higher levels of loneliness (Rokach, 2013). Cohesion with family members is one of the basic functions of the family, and this can be indicated by whether a family believes that spending time together is important. Families teach individuals how to relate to and treat one another (Barnes and Olson, 1985; Gulerce, 1996). Furthermore, it is expected that families provide an appropriate setting for nurturing, growth and education (Demirli and Demir, 2014).

It is expected that loneliness for youth will be negatively associated with family cohesion (see Table 2) for the YCP sample, as spending time with family was in the NZGSS analysis. The following results are estimated using the individual connectedness linear model, as in equation (4) in Chapter 3, where C refers to family cohesion.

The estimated equation below confirms the hypothesis that family cohesion is negatively associated with being lonely three plus days of the week. The odds ratios tells us that the odds of loneliness are $65 \%$ less for those who come from a family who believe that family time is important. This result is statistically significant $(\mathrm{z}=-$ $5.40)$.

$$
\begin{gathered}
L_{i}=0.451+0.357 \text { Family } \quad \mathrm{R}^{2}=0.0179, N=1697 \\
(\mathrm{z}=-5.40)
\end{gathered}
$$




\subsubsection{Close friends}

Youth are traversing a transitional period in their lives where they are craving more independence from their families and spending more time with their friends (Roscoe and Skomski, 1989; Brennan, 1982). Having no friends at this vulnerable stage in life can be detrimental to a young person's psychological wellbeing and adjustment (Margalit, 2010). Not surprisingly, children without friends tend to report higher levels of loneliness compared to those with friends (Margalit, 2010). It is expected that results from this study will be in line with these findings, and results from Chapter 4, in that youth who have close friends (see Table 2) will show a lower odds of loneliness by the YCP sample. The following results are estimated using the individual connectedness linear model, as in equation (4) in Chapter 3, where $\mathrm{C}$ refers to close friends.

The estimated equation below confirms the hypothesis that close friends and loneliness are associated. The estimated odds ratio tells us that the odds of loneliness are reduced by over half (51\%) when these respondents have close friends. This result is statistically significant $(\mathrm{z}=-2.90)$.

$$
\begin{gathered}
L_{i}=0.337+0.494 \text { CloseFriends } \quad \mathrm{R}^{2}=0.055, N=1622 \\
(\mathrm{z}=-2.90)
\end{gathered}
$$

Although contact with friends is an important part of a young person's social network, how they get along with their classmates is also a crucial factor to consider.

\subsubsection{Classmates}

The ability to get on with fellow students is an important factor to consider when studying youth's experiences of loneliness (Rotenberg and Hymel, 1999). Recent studies of young people in school settings show that youth who are not accepted by their classmates show a higher level of loneliness, compared to those who are 
accepted (Campfield, 2006). This can be exacerbated by bullying, which is often common in schools. Peer victimization may increase vulnerability to loneliness because victims of bullying can become socially anxious and socially avoidant (Campfield, 2006). It is expected that these results will be confirmed, in that youth who get on with their classmates (see Table 2) will show lower odds of loneliness by the YCP sample. The following results are estimated using the individual connectedness linear model, as in equation (4) in Chapter 3, where C refers to classmates.

The estimated equation below confirms the hypothesis that getting on with classmates and loneliness are associated. The estimated odds ratio tells us that the odds of loneliness are reduced by $74 \%$ for youth who get on with their classmates. This result is statistically significant $(\mathrm{z}=-4.09)$.

$$
\begin{gathered}
L_{i}=0.639+0.261 \text { Classmates } \quad \mathrm{R}^{2}=0.0103, N=1672 \\
(\mathrm{z}=-4.09)
\end{gathered}
$$

Another form of contact within a young person's social network worth considering is their relationship status.

\subsubsection{Relationship status}

Partnership is negatively associated with loneliness for those aged 15 and over (as shown by the NZGSS results), but what of youth? Research has indicated that being in a relationship as a youth could be detrimental to wellbeing and be positively associated with loneliness because spending more time with your partner may exclude you from spending time with a wider social network (Laursen and Hartl, 2013). On the other hand, being in a relationship can make a young person feel "totally accepted, esteemed, supported, and cared for" (Chen, 2003, p. 21). These two hypotheses are tested here, with the expectation that youth who are in a relationship (see Table 2) will show a lower odds of loneliness by the YCP sample, similar to that of the adult population in Chapter 4. The following results are 
estimated using the individual connectedness linear model, as in equation (4) in Chapter 3, where C refers to partnership.

The estimated equation below rejects the hypothesis that having a partner and loneliness are negatively associated. The estimated odds ratio tells us that the odds of loneliness are 1.35 times higher for youth who are in a relationship. This result is statistically significant $(\mathrm{z}=1.99)$.

$$
\begin{gathered}
L_{i}=0.159+1.35 \text { Partner } \quad \mathrm{R}^{2}=0.0029, N=1619 \\
(\mathrm{z}=1.99)
\end{gathered}
$$

The analysis of the NZGSS (2012) in Chapter Four showed that being in a relationship is associated with lower levels of loneliness, however for youth this is not the case. This suggests that there is a change in the importance of emotional connections as we age, and social loneliness may be more important to consider for younger people, while emotional loneliness may be more prevalent in older people.

Given the changing dynamics of social connectivity, it is also of interest to examine the association between loneliness and having internet friends.

\subsubsection{Internet friends}

More youth are choosing to make friends with others over the internet as they do not have to be concerned with self-presentation or physical distance, and the internet can bring together a group of people with shared interests and passion easily (Bargh and McKenna, 2004). Some research has indicated that the growing interest in the internet and online communication has led to high levels of loneliness for the youth of today (Nie, 2001; Hillygus, and Erbring, 2002). However, it has also been suggested that having internet friends is better than having no friends at all when it comes to loneliness (Parks and Floyd, 1995; Mazalin and Moore, 2004). I expect that youth who have internet friends (see Table 5.2) will show a lower odds 
of loneliness by the YCP sample. The following results are estimated using the individual connectedness linear model, as in equation (4) in Chapter 3, where C refers to internet friendships. The estimated equation below confirms the hypothesis that having internet friends and loneliness are positively associated. The estimated odds ratio tells us that the odds of loneliness are 1.35 times higher for youth who have internet friends. This result is not statistically significant, but it is close $(\mathrm{z}=1.89)$.

$$
\begin{gathered}
L_{i}=0.165+1.35 \text { NetFriends } \quad \mathrm{R}^{2}=0.0033, N=1229 \\
(\mathrm{z}=1.89)
\end{gathered}
$$

\subsubsection{Neighbourhood connectedness}

In an age where technological developments make contact with others easier, as discussed above, research suggests that more people are losing strong ties to their community and neighbourhood. Putnam in his book Bowling Alone (2000) documented the diminishing nature of community and social relationships, stating that low community involvement is the reason. Sum, Mathews, Pourghasem and Hughes (2009) believe that loneliness is inversely related to a person's sense of community, which means that connectedness to a community is vital to understand in order to reduce rates of loneliness. I expect that neighbourhood connectedness will be negatively associated with loneliness levels, in that youth who believe their neighbourhood is a good place (see Table 2) will show a lower odds of loneliness by the YCP sample. The following results are estimated using the individual connectedness linear model, as in equation (4) in Chapter 3, where C refers to neighbourhood.

The estimated equation below confirms the hypothesis that being connected to a community and loneliness are negatively associated. The estimated odds ratio tells us that the odds of loneliness are 54\% lower for youth who are connected to their community. This result is statistically significant $(\mathrm{z}=-4.13)$. 


$$
L_{i}=\underset{(\mathrm{z}=-4.13)}{0.353+0.465 \text { Neighbourhood }} \quad \mathrm{R}^{2}=0.0107, N=1687
$$

\subsubsection{Summary}

What is clear from the above logit models is that there are a range of different types of social connectivity, ranging from within the household, outside the household, and within the community, that should be considered when researching loneliness for youth and with the population as a whole (as shown in Chapter 4). It is clear that getting along with classmates has the largest influence on reducing the effects of loneliness, followed by family, the neighbourhood, and close friends. Having net friends and a partner in fact increases the odds of loneliness.

\subsubsection{Interaction effects}

I now want to test how the probability of young people being lonely is affected by different combinations of types of contact. For example, is someone less lonely if they have seen their friends and also their family, and how does the addition of partnership alter this? Also of interest is how these interaction effects influence loneliness levels with the presence of covariates discussed earlier. The interaction effects on loneliness can be tested empirically by applying the interaction linear model, as in equation (5) in Chapter 3. I proceed in the following way: the interaction between in-person and non-face-to-face contact, emotional and social connectedness, and the added effect of community connectedness, where 0 refers to 'no contact' and 1 refers to 'yes contact'.

\subsubsection{In person and non-face-to-face contact with friends}

A topic which is attracting a growing body of research is the effect increasing nonface-to-face contact has on loneliness. Several researchers including Wang and Wang (2011) and Valkenburg and Peter (2007) believe there are at least two theoretical perspectives to acknowledge when investigating the effects of online communication on users' well-being and these were discussed in Chapter 2: the augmentation/complement hypothesis and the displacement/substitution 
hypothesis. As a reminder, the displacement hypothesis suggests that having solely non-face-to-face contact will adversely affect a person's wellbeing. The augmentation hypothesis argues that some types of communication can facilitate the use of others, and having non-face-to-face friendships strengthens in person relations (Katz and Rice, 2002; Wang and Wang, 2011). I hypothesise, based on this literature, and earlier findings, that the probability of being lonely is lower for a person who has both in-person and online friends.

The results in Table 5.12 reject this hypothesis, and suggest that when a young person has only online friends they are at their most lonely, $\mathrm{p}=0.25$, and that this probability is lower for youth who have had neither contact, $\mathrm{p}=19$. This makes sense, as it was shown earlier that net friends are associated with higher levels of loneliness. When both close friends and net friends are part of the youth's network $(1,1)$, the probability of being lonely reduces to $p=0.17$, and this reduces further when only close friends are in place $(1,0), p=0.13$. These results suggest that there is a 'displacement' effect of net friends on loneliness, in that a young person benefits more from just having close friends, and having net friends lowers the reducing effect on loneliness. Moreover, the lonely could be driven to forming online friends as a result of having no/few close face-to-face friends.

\section{Table 5.12: Interaction effects between close friends and net friends, New}

\section{Zealand 2006}

\begin{tabular}{|c|c|c|c|c|c|c|c|c|}
\hline \multicolumn{5}{|c|}{ Adjusted predictions } & \multirow{2}{*}{\multicolumn{2}{|c|}{ Number of obs }} & \multirow{2}{*}{\multicolumn{2}{|c|}{1181}} \\
\hline Mode1 VCE & : OIM & & & & & & & \\
\hline \multirow[t]{3}{*}{ Expression } & : $\operatorname{Pr}$ (Lone1 & $\operatorname{ly} 3 t$ & 7days), pr & $\operatorname{dict}()$ & & & & \\
\hline & & I & \multicolumn{3}{|c|}{ Delta-method } & & \multirow[b]{2}{*}{$95 \%$} & \\
\hline & & 1 & Margin & Std. Err. & z & $P>|z|$ & & Interva1] \\
\hline \multicolumn{9}{|c|}{ CloseFriends\#NetFriends } \\
\hline & 00 & । & .1836735 & .0553168 & 3.32 & 0.001 & .0752545 & .2920924 \\
\hline & 01 & । & .2941176 & .1105102 & 2.66 & 0.008 & .0775217 & .5107136 \\
\hline & 10 & 1 & .1328571 & .0128289 & 10.36 & 0.000 & .107713 & .1580013 \\
\hline & 11 & 1 & .1710843 & .0184857 & 9.25 & 0.000 & .134853 & 2073157 \\
\hline
\end{tabular}

Source: YCP (2006) 
Graphically, close friends reduce loneliness, but the simultaneous presence of net friends is associated with higher loneliness.

Figure 5.4: Graphical representation of interactions between close friends and net friends, New Zealand 2006

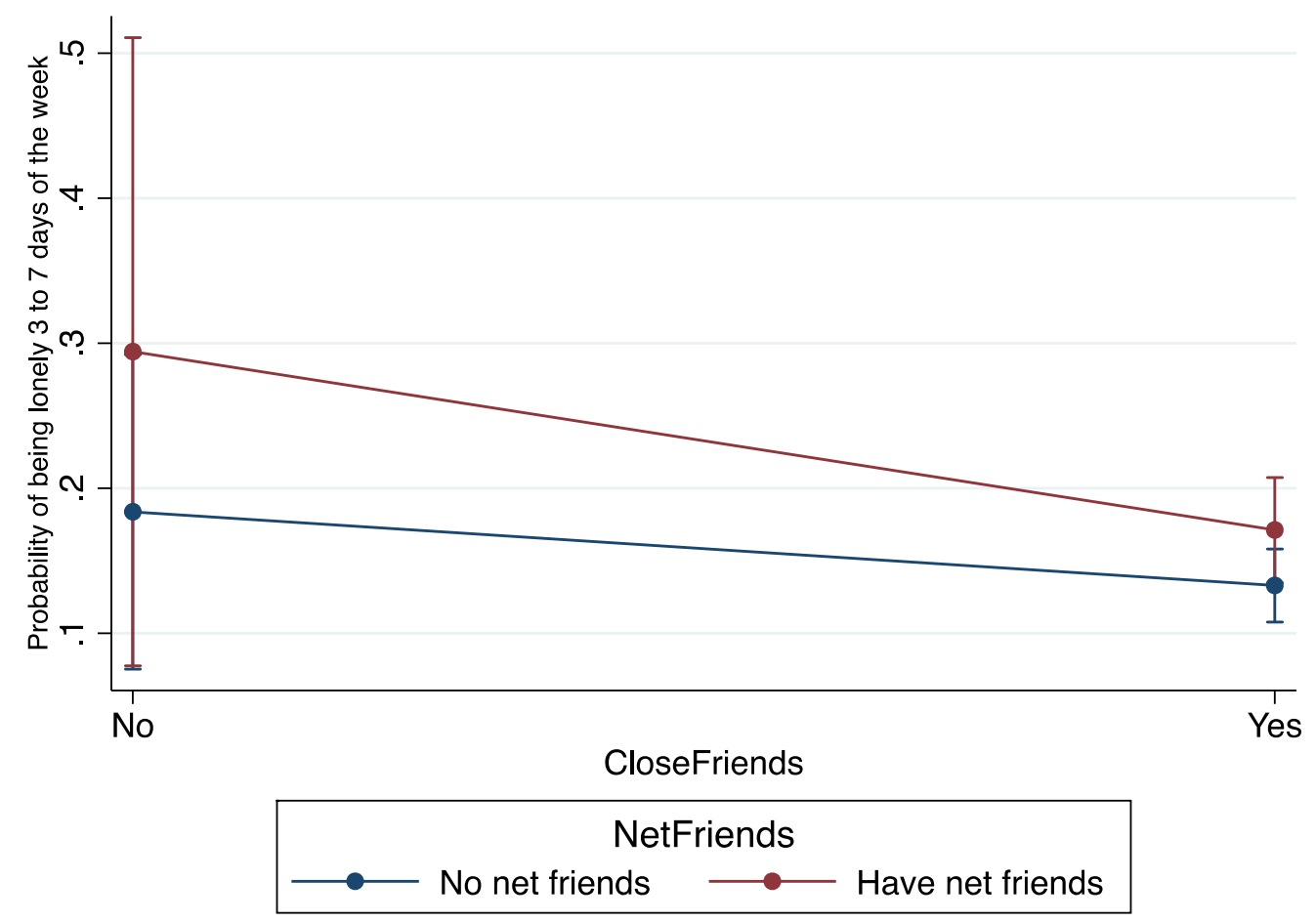

Source: YCP (2006)

These results differ from the NZGSS, however it must be noted that there is a clear difference between a person having supplementary non-face-to-face contact with friends (NZGSS), and a person having friends that they have never met face-to-face. The interaction effects for both samples are not statistically significant, although the signs are in the expected direction. 


\subsubsection{Emotional and social connectedness}

The second hypothesis that I want to test is the interaction between different forms of social connectedness. As stated above, as far as the YCP survey is concerned believing that family time is important, getting along with classmates, and having close friends is likely to have the greatest reducing effects on loneliness. I now want to test the hypothesis that there is a strong interaction effect between believing that family time is important, getting along with classmates, and having close friends.

Table 5.13 shows the predicted probabilities of being lonely based on a number of different combinations of these connections. Those people who answered 'no' to all of the contact questions $(0,0,0)$ show the highest probability of being lonely $(0.706)$. If one form of contact is added this probability reduces (most considerably for close friends).

\section{Table 5.13: Interaction effects between close friends, getting along with classmates, and family cohesion, New Zealand 2006}

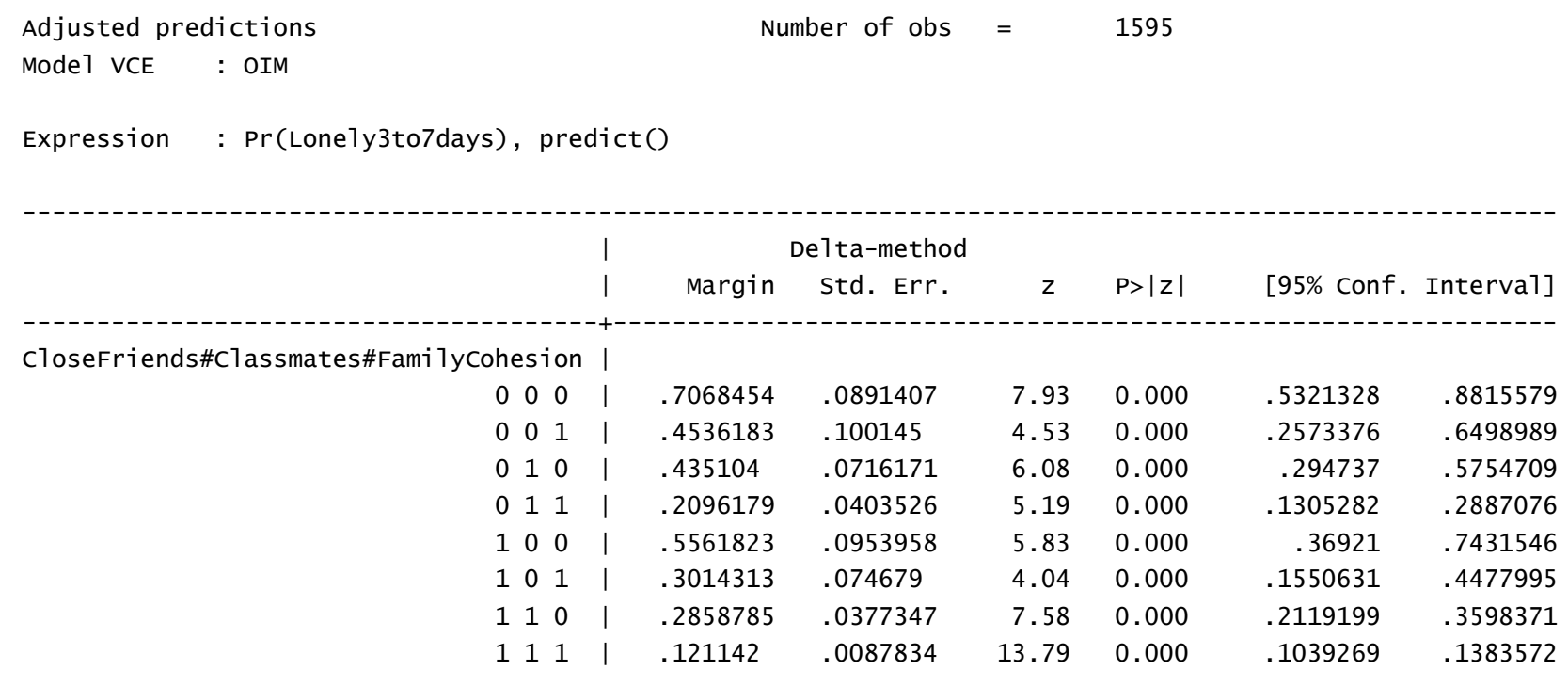

Source: YCP (2006) 
If close friends and family cohesion are in place $(1,0,1)$ then the chance of loneliness drops further to 0.301 . If close friends and classmates are in place $(1,1,0)$ then the chance of loneliness drops slightly further to 0.285 . In addition, if family cohesion and classmates are in place $(0,1,1)$ then the probability reduces further to 0.209 . The lowest probability of loneliness is observed when all types of contact are in place, $\mathrm{p}=0.121(1,1,1)$. These results suggest that there is a strong interaction effect between all three forms of contact, meaning that they complement each other in reducing loneliness. This would suggest that social relationships among young people are fostered through family, friends, as well as classmates in a combined way.

Figure 5.5 shows these interaction effects between close friends, getting along with classmates, and family visually. This figure shows how the probability of being lonely is much higher for youth who have none of these contacts, compared to youth who have all of the contacts. 
Figure 5.5: Graphical representation of the interaction effects between close friends, getting along with classmates, and family cohesion, New Zealand 2006

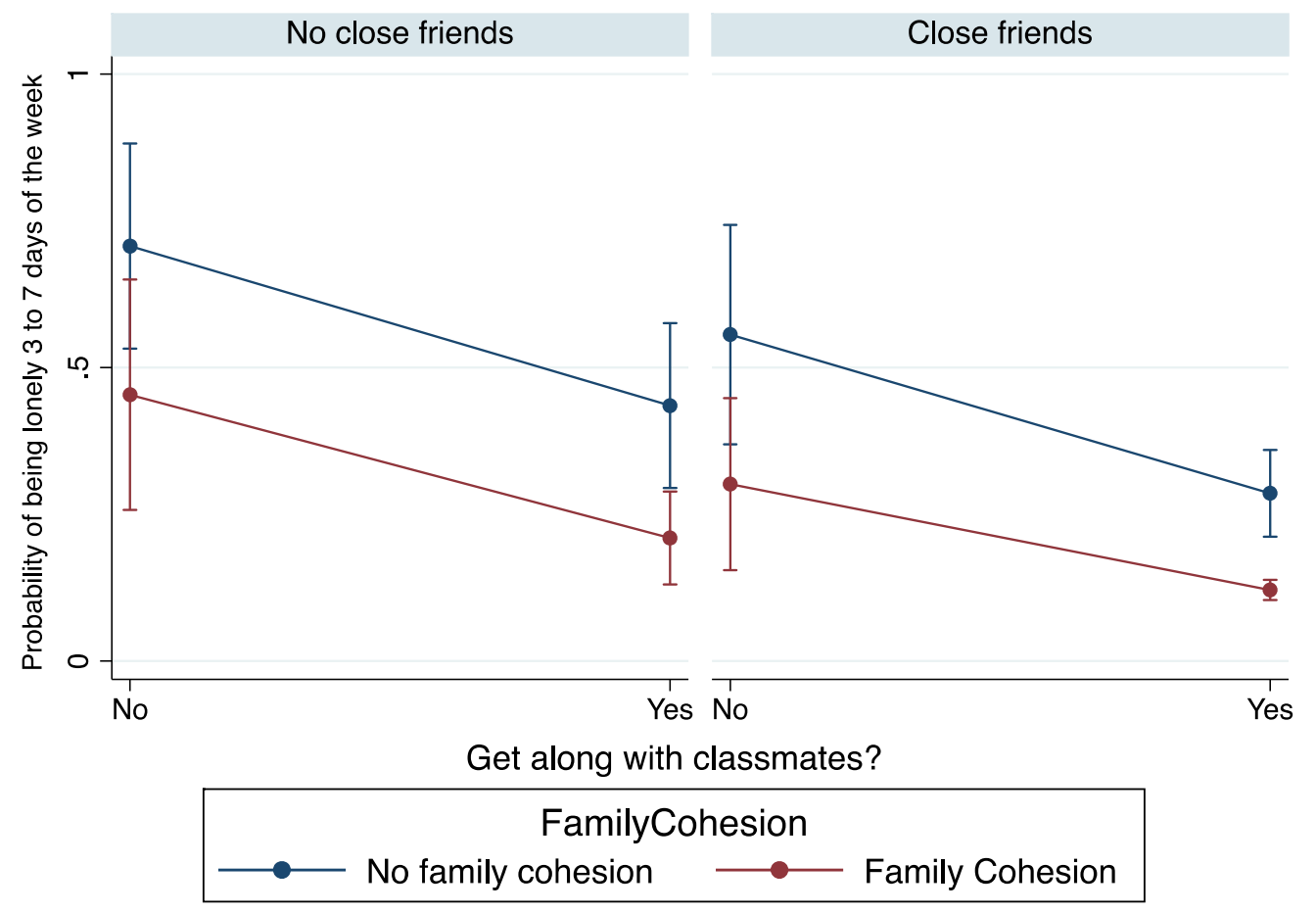

Source: YCP (2006)

The interaction effect is not statistically significant, although the signs are in the expected direction, and are in line with findings from the interactions between family, friends and partnership in Chapter 4.

\subsubsection{The added effect of community connectedness}

I also want to see what effects the addition of community connectedness has on the interaction between contact with friends, family and classmates for youth. My prior expectation is as follows: community connectedness further reduces the joint reducing effect between family, friends and classmates on loneliness.

Table 5.14 shows the predicted probabilities of being lonely based on a number of different combinations of these connections, where 0 refers to 'no' and 1 refers to 'yes'. Those people who answered 'no' to all of the contact questions show the 
highest (0.757) probability of being lonely (note this is much higher than adults in the NZGSS). If one form of contact is added this probability reduces. Once all contacts are present $(1,1,1,1)$, the probability of being lonely drops even further to 0.116. This coefficient is lower than that of just family, friends and classmates, which suggests that the cumulative nature of connectedness still stands, and may actually have more effect on youth.

Table 5.14: Interaction effects between friends, family, classmates and neighbourhood connectedness, New Zealand 2006

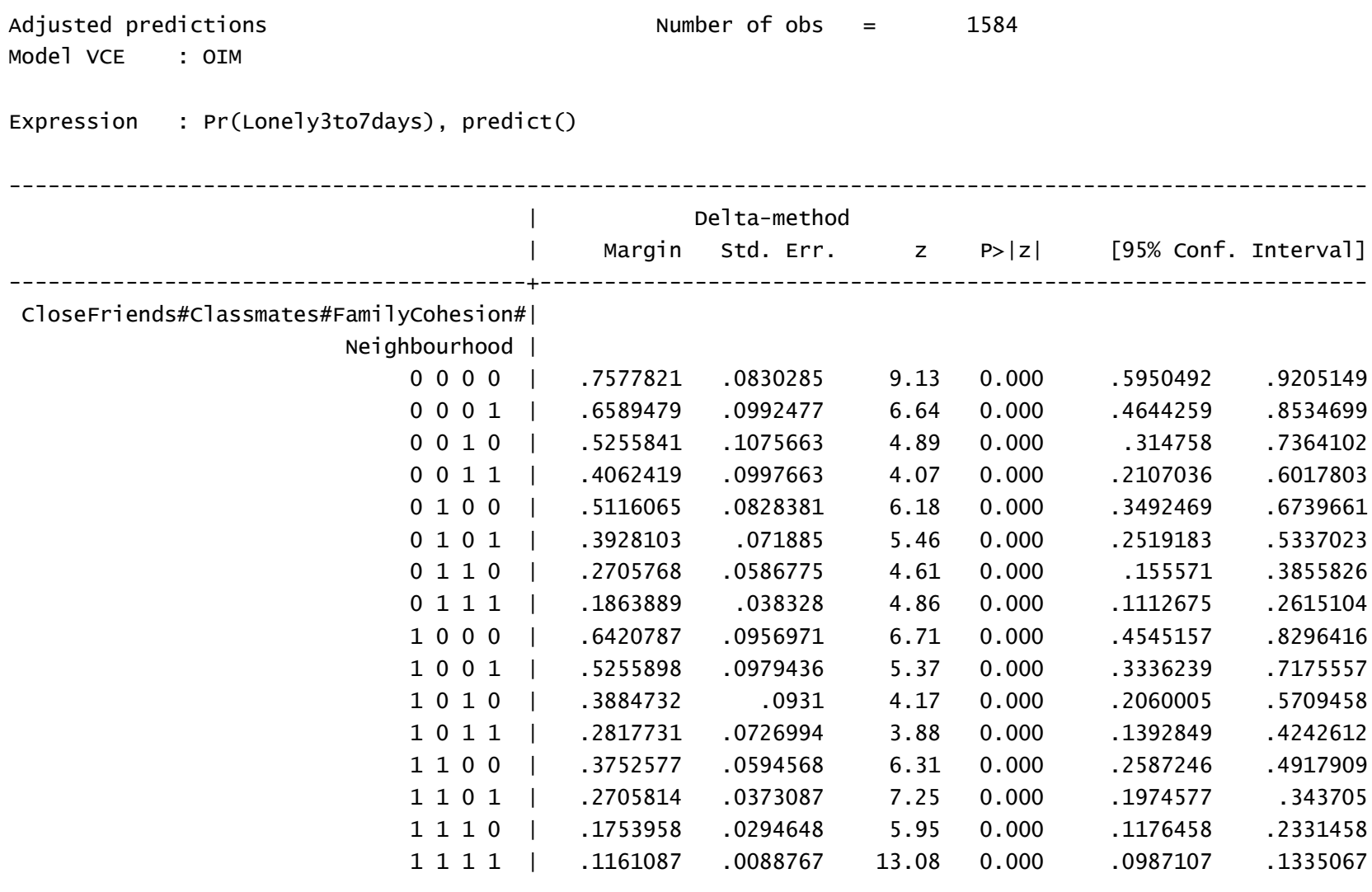

Source: YCP (2006)

We have seen the impact that interactions between different types of connectedness can have on the probability of being lonely for young people. It appears that interactions between friends, family, and classmates reduce the probability of being 
lonely, and this reduces further when variables such as neighbourhood satisfaction are added.

As above, the interaction effect is not statistically significant, although the signs are in the expected direction, and are in line with findings from the NZGSS analysis in Chapter 4 which showed that community connectedness reduced loneliness further.

\subsubsection{Summary}

We have seen the impact that interactions between different types of connectedness can have on the probability of being lonely. A young person who has just close friends (as opposed to having net friends also) are less likely to be lonely, suggesting that the hypothesis of a displacement effect can be supported. It appears that interactions between family, friends, and classmates reduces the probability of being lonely, and this reduces further when variables such as neighbourhood satisfaction are added. This reinforces the notion of a balanced community, in which both emotional and social relationships are fostered through contact with family, friends, classmates, and the neighbourhood.

\subsection{Summary of Chapter 5}

This chapter has explored the relationship between loneliness and connectivity, using the 2006 sample of the YCP. Findings are similar to the analysis of the NZGSS (2012), in that there is a clear association between reporting loneliness and being connected, but in both cases this is dependent on the type of contact. Overall, lower levels of loneliness are associated with higher levels of connectedness, and the consistency between the two samples confirms generalisations made in both the academic and popular literature, namely that social isolation has harmful consequences for a person's wellbeing.

Most covariates, however, were not statistically significant in reducing or increasing loneliness levels for the young - with the exceptions of bullying, religion, and self- 
harming. This is likely due to the small sample size, that youth are arguably less diverse than adults, and that they do not have the agency to make most of their decisions.

We have seen the impact that interactions between different types of connectedness can have on the probability of youth being lonely. Of special interest is the role of online friends. The results suggest that having close friends reduces the probability of a young person being lonely, more than having both forms of contact, or just net friends. It appears that interactions between family, friends, and classmates have a cumulative effect on reducing loneliness and this effect is stronger when neighbourhood satisfaction is added. These findings highlight the potential benefits of living in a balanced community as identified in Chapter 4 for adults. A range of forms of relationships are clearly important.

This chapter has shown that geographic context, more specifically settlement type, does not play a statistically significant role when researching young people's loneliness in New Zealand. The availability of geocodes of the 2006 YCP participant's locations has allowed further geographical analysis to be performed in Chapter 6, through the employment of spatial statistics. In particular, the association between regions, neighbourhood deprivation, and loneliness are covered. These forms of geographic context were found to be strongly associated with loneliness for the adult population of New Zealand in Chapter 4, and hence it is of interest to see whether this is the case for the young. 


\section{Chapter 6 Geographies of youth loneliness}

"All the lonely people, where do they all come from? All the lonely people, where do they all belong?"

- The Beatles

In the previous two chapters I have found that geography is associated with the experience of loneliness for the New Zealand population. Settlement type, region and neighbourhood deprivation all showed statistically significant associations with loneliness in the 2012 New Zealand General Social Survey (NZGSS) sample covered in Chapter 4. However, in Chapter 5 settlement type was found to be statistically insignificant for the YCP sample. This chapter employs the use of spatial statistics to examine the geographical patterns of loneliness of the YCP more carefully, focusing on five main regions - Wellington, Kapiti Coast, Wairarapa, Taranaki, and Auckland.

The vast majority of research concerning geographic variations in wellbeing has been focused across countries. However, increasingly researchers are undertaking regional and also neighbourhood level analysis (Rentfrow, Gosling and Potter, 2008). It has been widely suggested, for example, that a person's well-being and satisfaction depends on the interactions between the disposition of individuals and neighbourhood characteristics (Jokela, Bleidom, Lamb, Gosling and Rentfrow, 2014). Contemporary research projects in the geography of well-being have shown geographic variations in a range of mental health conditions, and hence the psychological significance of spatial clustering motivates this chapter. It is yet to be established whether the characteristics of a person's settlement geography are related to the level of loneliness they experience. 
The aim of this chapter is to firstly identify whether there is a tendency for lonely people to cluster geographically. In other words, whether lonely youth live close to other lonely youth. There is no indication of whether this is the case in the literature reviewed, but I suspect that loneliness is not clustered because it is not a contagious condition, and that lonely people who live near each other are likely to make contact with each other.

The second aim is to relate the distribution of loneliness to the level of neighbourhood deprivation. I expect that loneliness and neighbourhood deprivation are related because of the large body of research which suggests that loneliness is higher in areas of lower deprivation, and also the results in Chapter 4 which show this relationship.

\subsection{Method}

In this chapter I will use Geographical Information Systems (GIS) technology to see how a young person's loneliness is related to region and neighbourhood deprivation. GIS "are a special class of information systems that keep track not only of events, activities, and things, but also of where these events, activities, and things happen or exist" (Longley, Goodchild, Maguire and Rhind, 2005, p. 4). More practically, Damien Cassin, ESRI Australia's GIS in Health specialist said "by using GIS technology to identify where people are suffering with mental health problems we can then start to investigate why this is occurring and determine the actions required to address the situation" (Pro Bono Australia, 2013, p. 5).

To do this, I am utilising the YCP dataset wherein the sample was built around school populations. The names of such schools will not be divulged because no agreement was discussed for release. Questionnaires were administered to 1866 participants individually each year $(2006,2007,2008,2013)$ at the same time during data collection sessions through laptops, so answers could not be seen by others. Teachers and research assistants were available to answer any questions the 
students had about concepts or definitions. Only the 2006 sample will be used in this chapter for analysis as geocodes were not available for the subsequent years.

\subsection{Loneliness by region}

Figure 6.1 shows the locations of the 2006 YCP participants (over the North Island of New Zealand). There are large clusters of respondents who live in the Wellington Region (in green), Kapiti Coast (purple), Wairarapa (blue), Taranaki (yellow) and in Auckland (pink) - the location of the schools where the surveys took place. There are a number of addresses that are outside of these regions that may be a home address (as some youth may be boarding), another relative's address, or perhaps entirely fabricated. The geocodes outside of these main regions are therefore misleading and I have little option but to omit these from the geographical analysis that follows in order to have a clear regional focus. 
Figure 6.1: The spatial distribution of residences reported by young people who took part in the YCP (2006) survey, New Zealand.

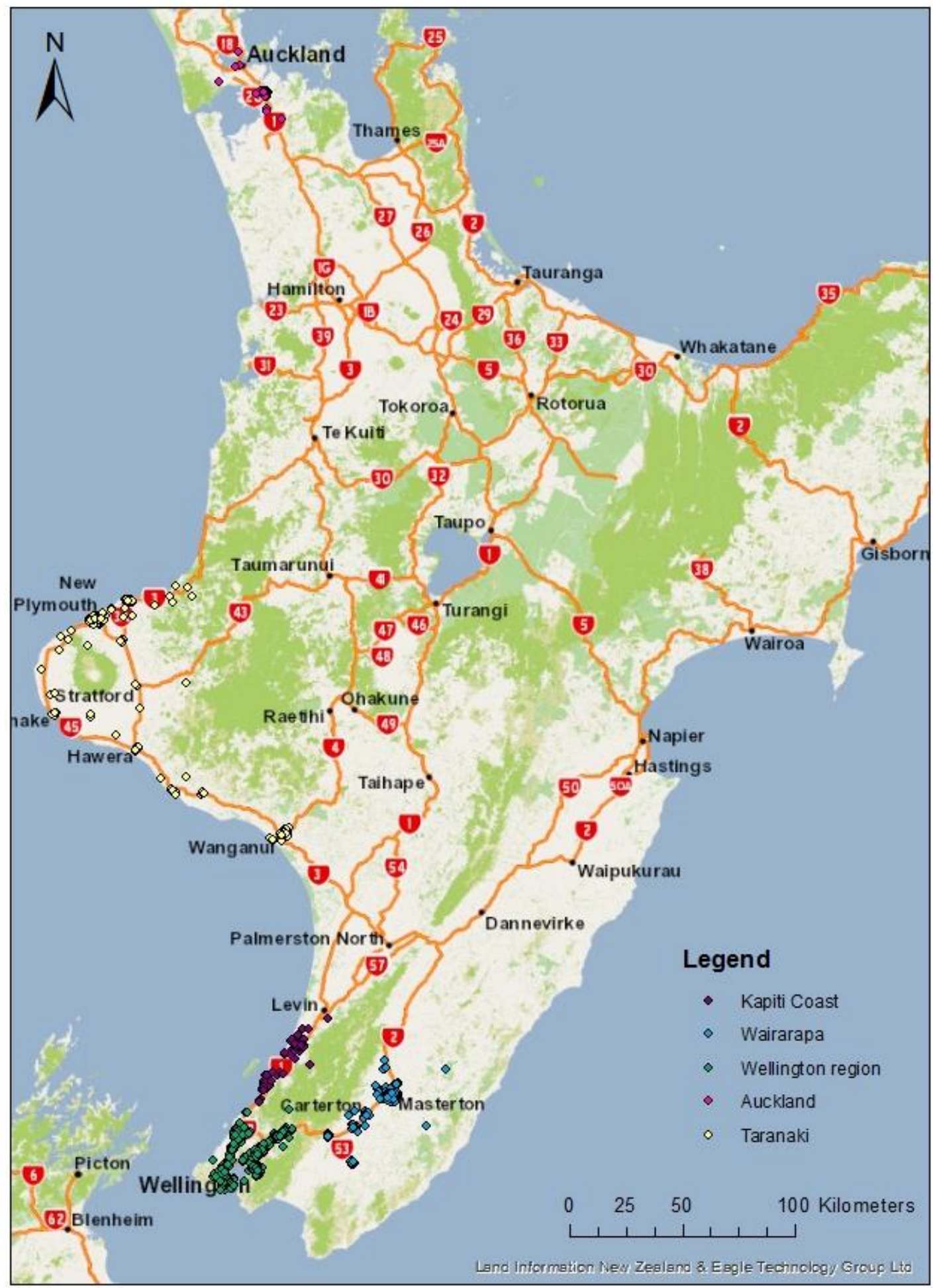

Source: YCP (2006) 


\subsubsection{City of Wellington}

The distribution of addresses in Figure 6.1 above are too broadly discussed to be useful. I have therefore selected five regions to analyse separately, beginning with the City of Wellington. Figure 6.2 shows the frequency of loneliness of youth in the City of Wellington. The majority of youth reported being lonely less than one day (441), followed by one to two days (123), and then by three to four and five to seven days (both 45). The average level of loneliness reported by youth in Wellington (not shown here) is 1.5 days of the week.

\section{Figure 6.2: Distribution of loneliness of youth in the Wellington Region, YCP} (2006)

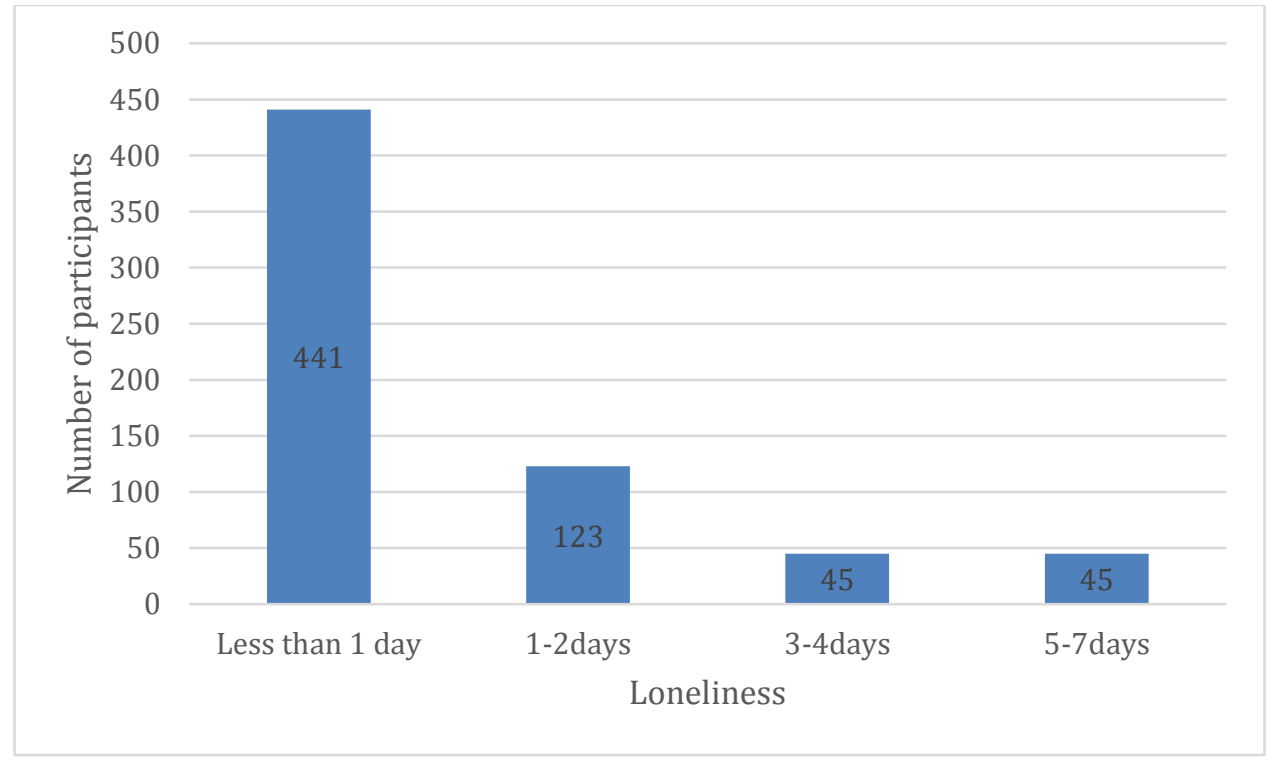

Source: YCP (2006)

\subsubsection{Spatial clustering effects in Wellington}

I have measured the spatial autocorrelation (the degree to which similar loneliness levels tend to be clustered or dispersed in space) based on feature locations and attribute values, using the Global Moran's I statistic. This spatial autocorrelation statistic indicates whether the distribution of points are spatially dispersed, random, or clustered. The Moran's I statistic for spatial autocorrelation is given as: 


$$
I=\frac{n}{S_{0}} \frac{\sum_{i=1}^{n} \sum_{j=1}^{n} w_{i, j} z_{i} z_{j}}{\sum_{i=1}^{n} z_{i}^{2}}
$$

where I is the Moran's score, $\mathrm{z}_{\mathrm{i}}$ is the deviation of the loneliness response (in each region) $i$ from its regional mean $\left(x_{i}-X\right), \mathrm{w}_{\mathrm{i}, \mathrm{j}}$ is the spatial weight between the level of loneliness of student $i$ and student $j, n$ is equal to the total number of students in the region, and $S_{0}$ is the aggregate of all the spatial weights. The Moran's I score outputs values between -1 (highly dispersed), 0 (random), and +1 (highly clustered).

I first tested the spatial autocorrelation of loneliness levels for youth in the Wellington Region (Wellington, Upper Hutt, Lower Hutt, Wainuiomata and Porirua). I found that the loneliness variable has a z-score of -2.26 and a Moran's index score of -0.195 . In general, a Moran's Index value near +1.0 indicates clustering, while an index value near -1.0 indicates dispersion. This result means that loneliness displays a significant but small dispersed geographic pattern (see Figure 6.3). A z-score of 2.26 suggests that there is a less than five percent likelihood that this dispersed pattern could be the result of random chance. 
Figure 6.3: How spatially correlated youth loneliness levels are, New Zealand 2006

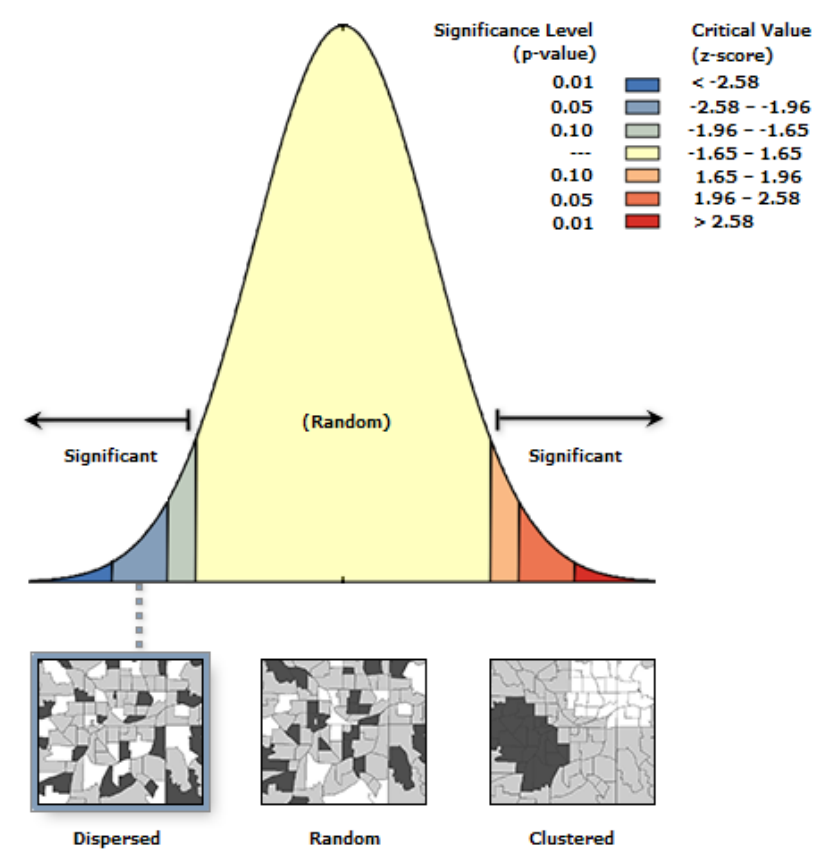

Source: YCP (2006)

The dispersed nature of loneliness is also reflected in Figure 6.4, where we can see that there is minimal clustering effect (as shown by the lack of High-High clusters, or the black dots). Most of the results are not clustered (as shown by the grey dots). 
Figure 6.4: Dispersed nature of the distribution of loneliness, YCP (2006).

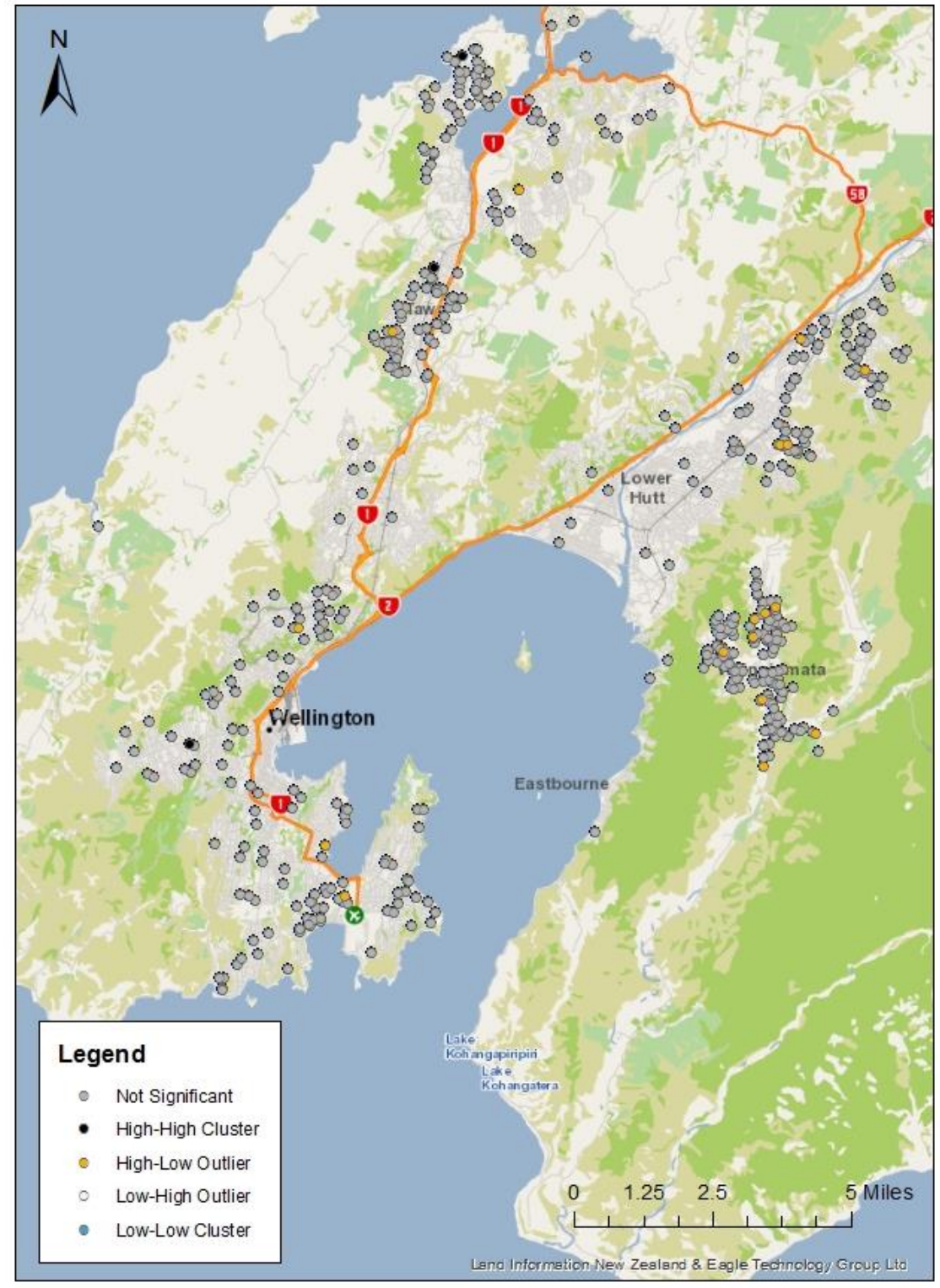

Source: YCP (2006)

The dispersed nature of loneliness could be explained by a young person's need for social contact. If there was a clustering effect of loneliness, there would be pockets of lonely people, who would most likely be searching for social contact with friends, or trying to find a partner. As a result, it is likely that these people would then, in turn, create networks with one another (provided that they meet each other's social desires). The dispersed patterning of loneliness is therefore more intuitive as a 
lonely young person is surrounded by non-lonely youth. It is unlikely that lonely youth repel each other, given how young people do not have the agency to decide where to live, but more likely that these lonely youth live amongst a community full of non-lonely people who are not actively searching for new social networks. As a result, it may be harder to fit into this group of socially satisfied people, and therefore feelings of loneliness may persist.

\subsubsection{Kapiti Coast}

Figure 6.5 shows the frequency of loneliness of youth on the Kapiti Coast. The majority of youth reported being lonely less than one day (59), followed by one to two days (16), three to four (11) and five to seven days (7). The average level of loneliness reported by youth on the Kapiti Coast (not shown here) is 1.58 days of the week.

\section{Figure 6.5: The distribution of loneliness of youth on the Kapiti Coast, YCP} (2006)

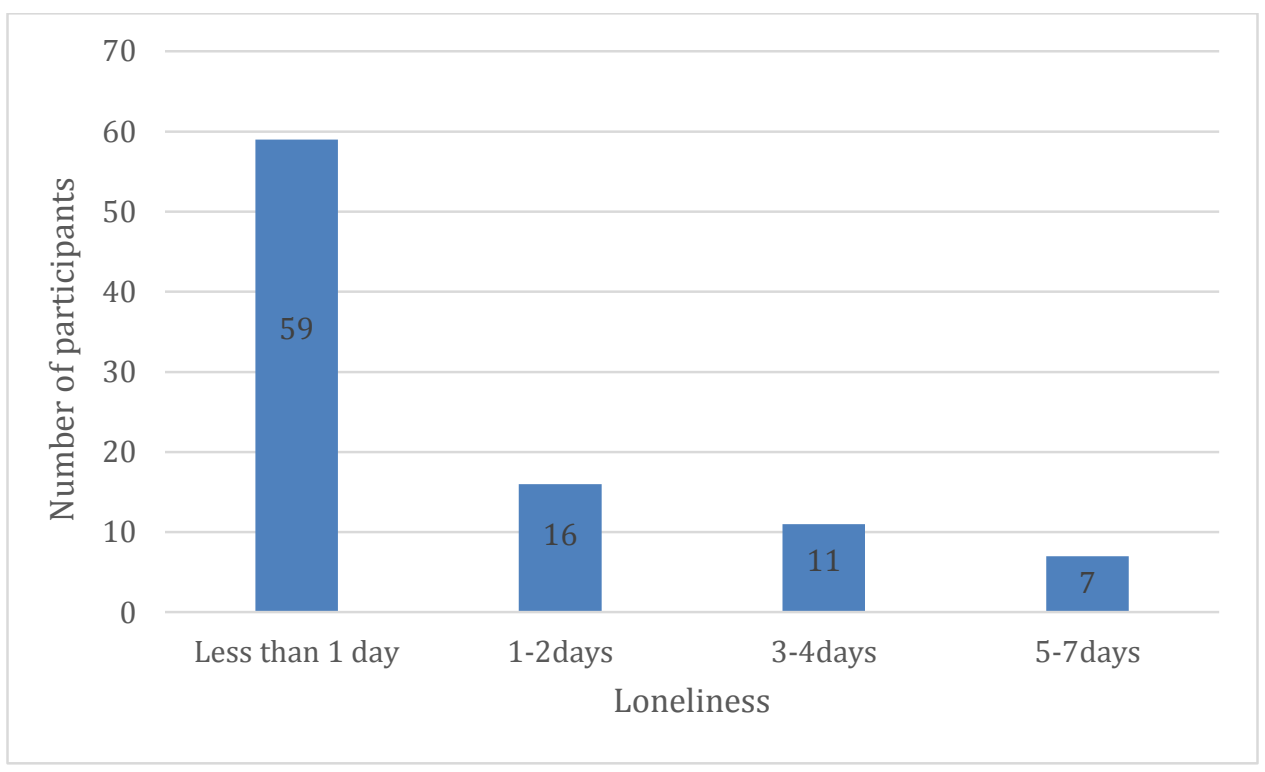

Source: YCP (2006)

The spatial autocorrelation of loneliness levels for the Kapiti Coast showed that loneliness is randomly distributed, and there is no clustering or dispersing effect. 


\subsubsection{Wairarapa}

Figure 6.6 shows the frequency of loneliness of youth in the Wairarapa. The majority of youth reported being lonely less than one day (207), followed by one to two days (69), three to four (30) and five to seven days (22). The average level of loneliness reported by youth in the Wairarapa (not shown here) is 1.53 days of the week.

Figure 6.6: The distribution of loneliness of youth in the Wairarapa, YCP (2006)

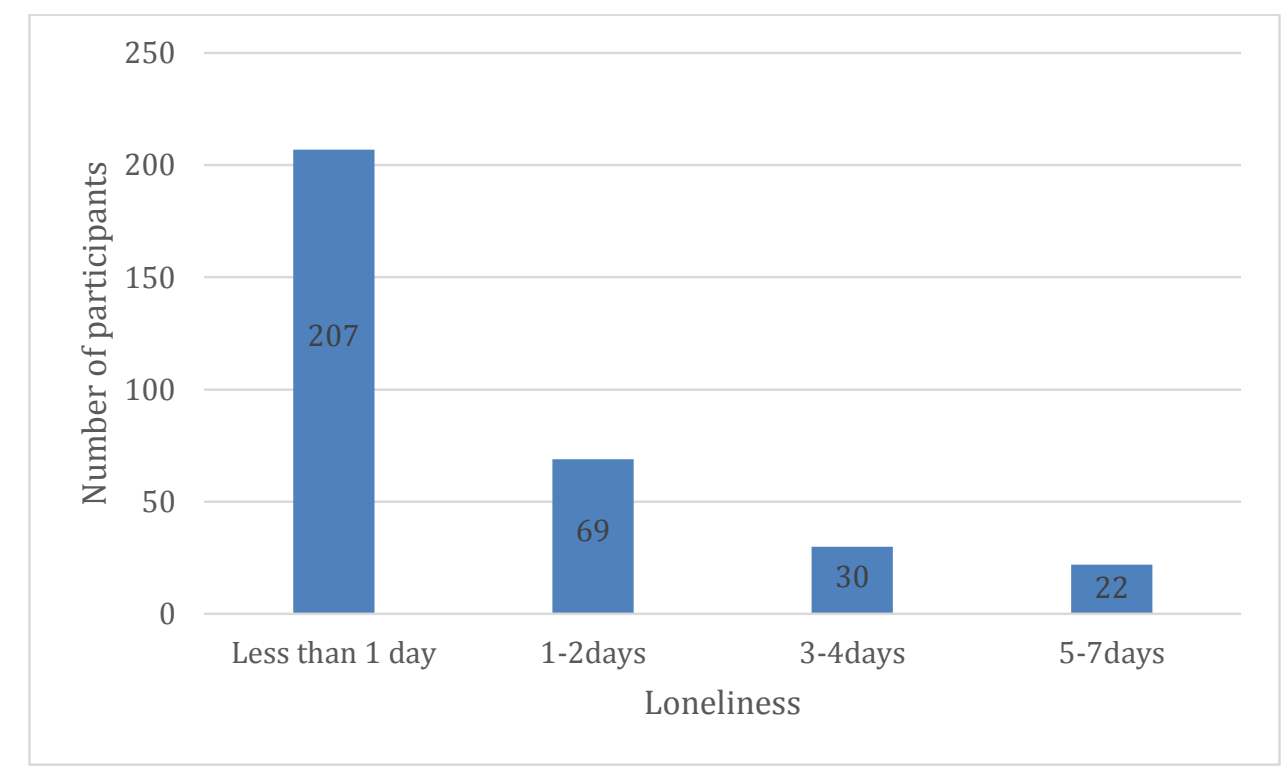

Source: YCP (2006)

The spatial autocorrelation of loneliness levels for the Wairarapa showed that loneliness is randomly distributed, and there is no clustering or dispersing effect.

\subsubsection{Auckland}

Figure 6.7 shows the frequency of loneliness of youth in Auckland. The majority of youth reported being lonely less than one day (40), followed by one to two days (17), five to seven days (7), and then by three to four days (6). The average level of 
loneliness reported by youth in Auckland (not shown here) is 1.48 days of the week, which is a lower average than in the Wellington region (taking into consideration differences in sample sizes).

Figure 6.7: The distribution of loneliness of youth in Auckland, YCP (2006)

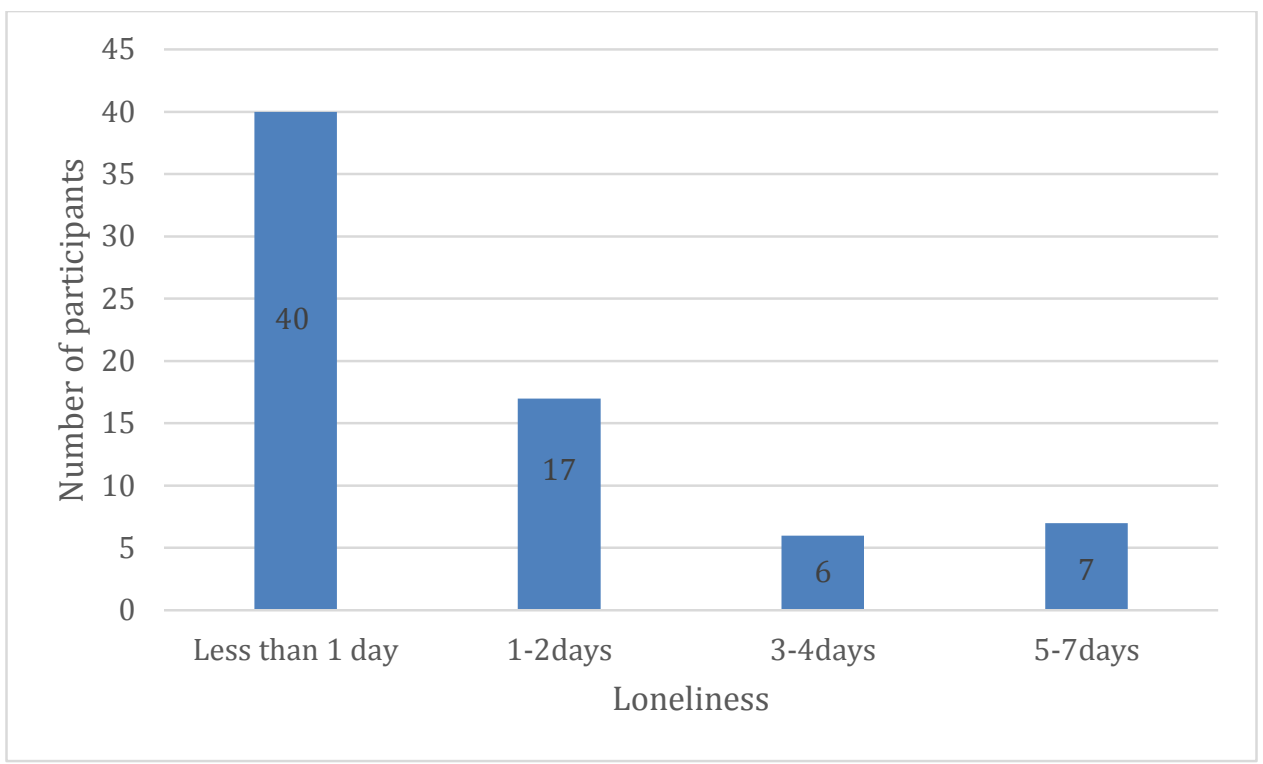

Source: YCP (2006)

The spatial autocorrelation of loneliness levels for Auckland showed that loneliness is randomly distributed, and there is no clustering or dispersing effect.

\subsubsection{Taranaki}

Figure 6.8 shows the frequency of loneliness of youth in Taranaki. The majority of youth reported being lonely less than one day (123), followed by one to two days (36), five to seven days (18), and then by three to four days (14). The average level of loneliness reported by youth in Auckland (not shown here) is 1.54 days of the week, which is a slightly higher average than in the Wellington and Auckland regions (taking into consideration differences in sample sizes). 
Figure 6.8: The distribution of loneliness of youth in Taranaki, YCP (2006)

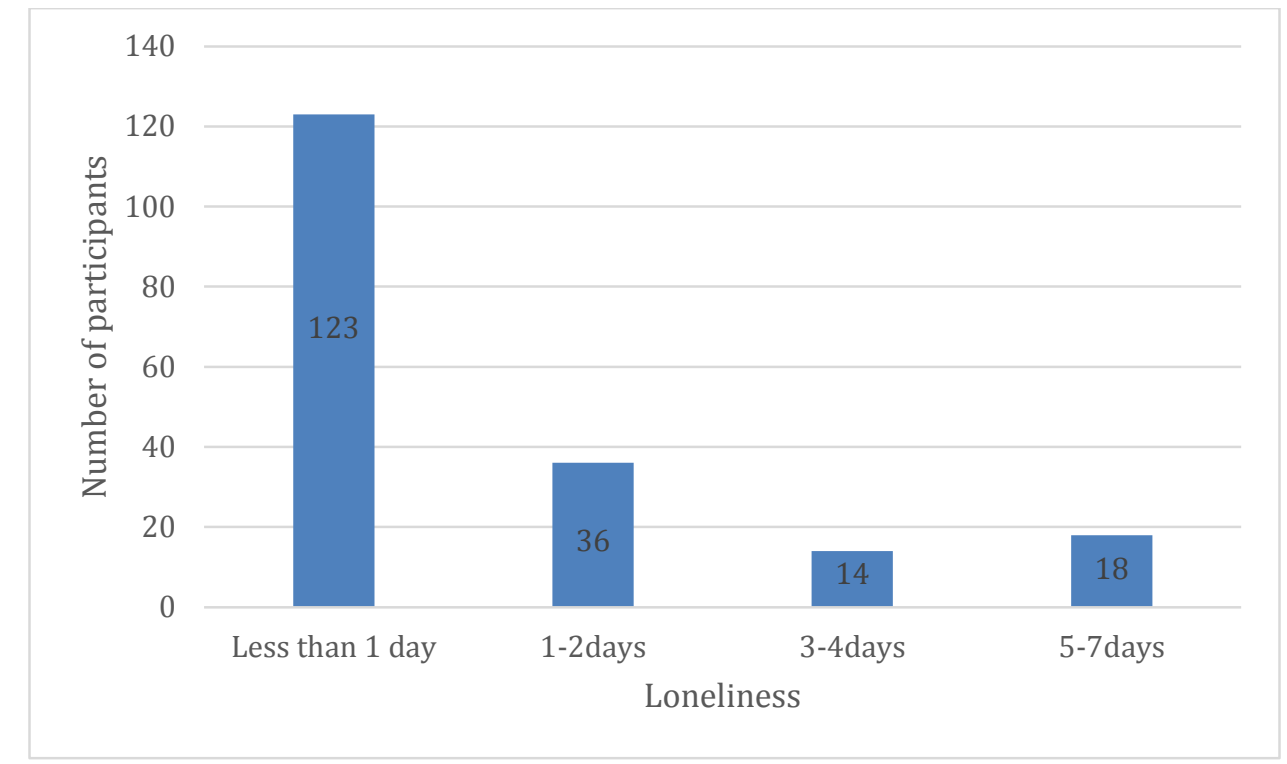

Source: YCP (2006)

The spatial autocorrelation of loneliness levels for Taranaki showed that loneliness is randomly distributed, and there is no clustering or dispersing effect.

\subsubsection{What of other variables?}

A number of other variables were tested for spatial clustering effects including the five types of connectedness discussed in Chapter 5 and also a number of covariates, including youth's psychological conditions. However, they were all found to be randomly distributed.

There are a number of factors that need to be considered when interpreting the spatial autocorrelation results. The comparatively small sample size of our dataset (1866 youth) may have an effect, as it may be that there are not enough respondents to find many dispersed/clustering effects of psychological wellbeing conditions. Rentfrow et al (2008) found, in their study of over half a million American's, that there are patterns of geographic variation in personality across the US. These large sample sizes provided the researchers with a much larger representative sample of the population, in comparison to our analysis of youth who mainly reside in 
Wellington, some in the Taranaki and very few in Auckland.

Additionally, given their age, youth do not have the agency to decide whether or not to live in a certain area, whereas their parents decide for the family. As a result, we may not find the geographic clustering of wellbeing, as demonstrated by Jokela et al (2014). It may be that if we tested geographic patterning of loneliness for the NZGSS sample of adults we would find more significant clustering effects, since most of the sample (being adults) would be able to make the decision to move to a certain area.

\subsubsection{Summary}

The above figures show the frequency of the experience of loneliness in the five regions - on average youth are less likely to be lonely in Auckland, followed by Wellington, the Wairarapa, the Taranaki, and finally the Kapiti Coast where youth are most likely to be lonely. These results suggest that youth in the main urban areas (Auckland and Wellington) are less likely to be lonely, whereas those young people who show a higher likelihood of loneliness are located in less dense areas.

The dispersed nature of loneliness in Wellington is also observed, indicating that lonely youth are not located near other lonely youth. This finding is a departure from existing loneliness research, and to the best of my knowledge spatial statistics have not been utilised in loneliness research before. The dispersed patterning of loneliness is intuitive as a lonely young person is surrounded by non-lonely youth. It is unlikely that lonely youth repel each other, given how young people do not have the agency to decide where to live, but more likely that these lonely youth live amongst a community full of non-lonely people who are not actively searching for new social networks. As a result, it may be harder to fit into this group of socially satisfied people, and therefore feelings of loneliness may persist. 


\subsection{New Zealand Deprivation Index}

My analysis of the NZGSS in Chapter 4 shows that there is a clean tendency for loneliness to rise in neighbourhoods with high levels of deprivation, even when controlling for other attributes of respondents. The issue here is whether this also applies to youth. Figure 6.9 is a visual representation of the levels of deprivation in Wellington, New Zealand, in relation to the location of participants and their associated loneliness level.

New Zealand Deprivation Index data was not available in the YCP 2006 dataset, however a spatial join (joining attributes from one feature to another based on the spatial relationship) in GIS enabled the matching of a person's loneliness level to the associated NZdep (2006) score of their neighbourhood. 
Figure 6.9: Visual representation of the New Zealand Deprivation Index, in relation to participant's loneliness levels, New Zealand 2006

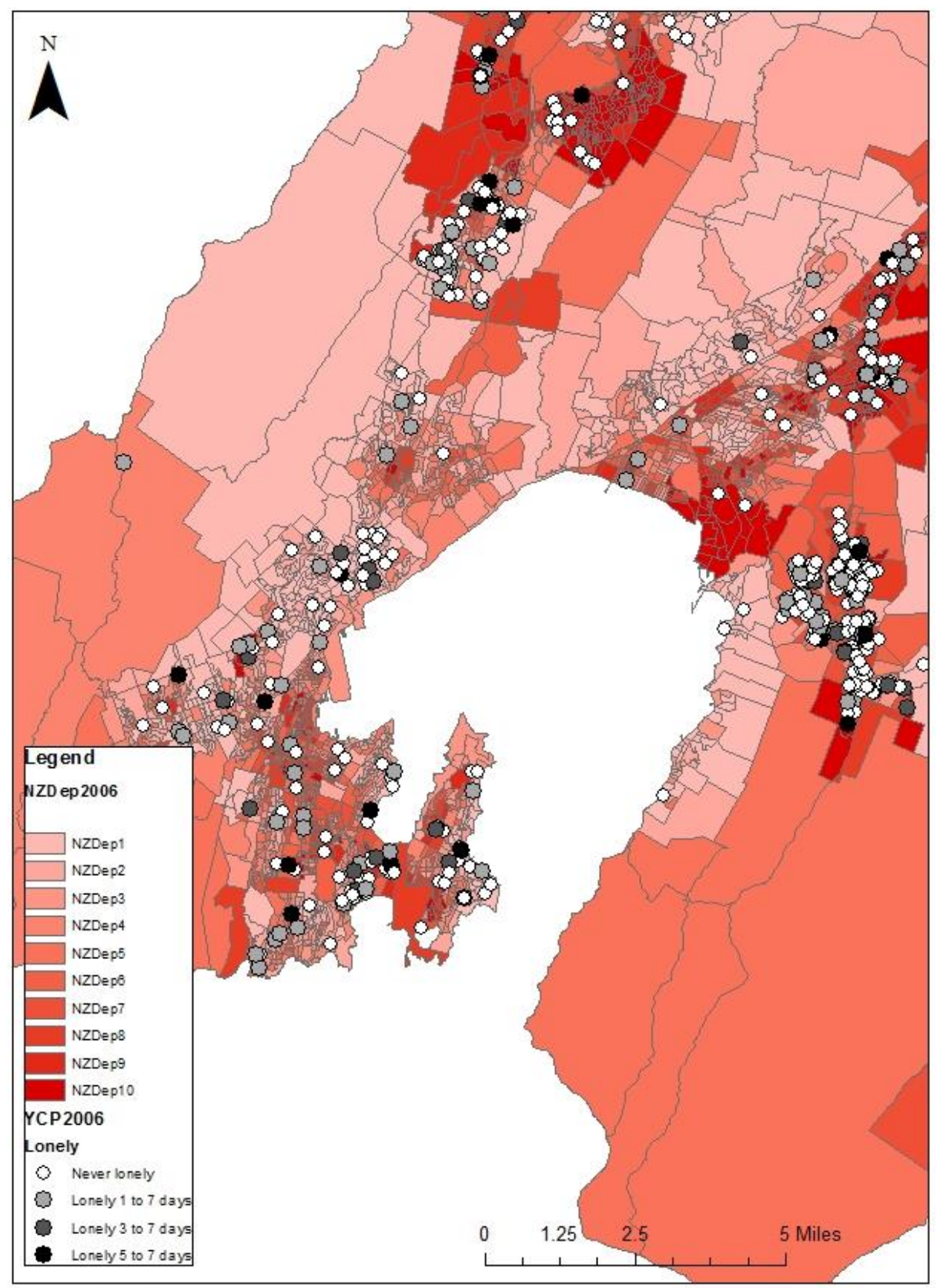

Source: YCP (2006)

The association between loneliness and neighbourhood deprivation is presented in Table 6.1, which shows that the odds of loneliness rises successively as the level of neighbourhood deprivation increases. 


\section{Table 6.1: Loneliness levels by levels of deprivation for youth, New Zealand 2006}

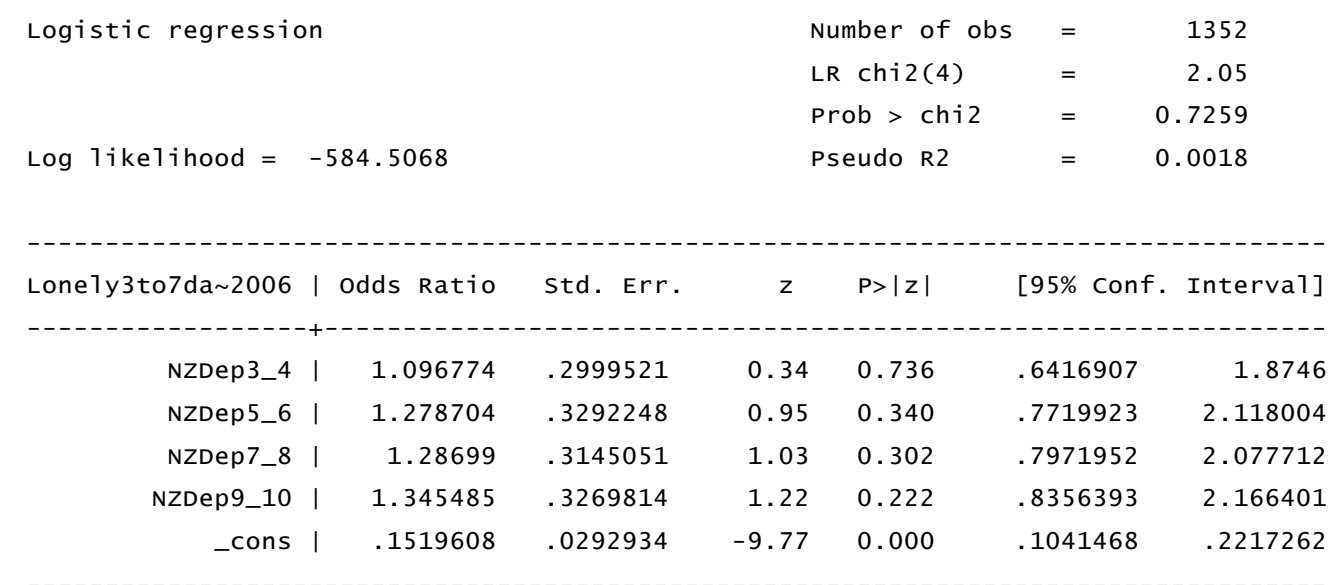

Source: YCP (2006)

These coefficients compare to the base of NZDep1_2 (areas with the lowest deprivation scores). It shows that youth who live in less deprived areas show a lower likelihood of reporting loneliness, compared to youth from all other areas. Those youth from areas of high deprivation (NZDep9_10) show the highest odds of reporting loneliness. These results are consistent with findings from Chapter 4 , which suggest that loneliness levels rise as level of deprivation increases for the adult population of New Zealand. However, the results from Table 6.1 are not statistically significant, which means that there is a chance that these findings are a result of random chance. The insignificance can, once again, be attributed to the sample size of the YCP. It may be that if the sample size was tripled (to be similar to that of the NZGSS), more results would be significant.

\subsection{Summary of Chapter 6}

This chapter was an attempt to extend previous work on the geographical variations in well-being for New Zealanders. Past research has examined these differences predominately through statistical analysis, whereas this chapter has also employed spatial analysis. This chapter has showed statistically significant dispersed patterns 
of loneliness for youth in Wellington; more specifically lonely youth from Wellington are 'isolated' from other lonely youth, amongst areas of not-lonely youth. Young lonely people, who are surrounded by others who are socially satisfied, would therefore find it difficult to fit into established social networks, or into the lives of people who are not searching, or needing, more social contact. As a result, their loneliness may persist. Further geographical analysis into the relationship between loneliness and level of neighbourhood deprivation is not statistically significant.

These results indicate that geographical context of where a young person lives can play a role in loneliness levels. This is further testament to the findings in the analysis of the NZGSS (2012) in Chapter 4 where I determined that people who live in Wellington, in main urban areas, and in lower socio-economic areas show a stronger propensity to report higher feelings of loneliness. 


\title{
Chapter 7 Conclusion
}

\author{
"Why do people have to be this lonely? \\ What's the point of it all? Millions of people \\ in this world, all of them yearning, looking \\ to others to satisfy them, yet isolating \\ themselves. Why? Was the earth put here \\ just to nourish human loneliness?"
}

- Haruki Murakami, Sputnik Sweetheart

This thesis is about loneliness, what it is, why it occurs and the role of place. The topic is important because loneliness can have serious implications, both for the individual (heart disease, depression, suicide, and premature death), and for society in which they live (overall levels of connectedness, community functioning and social exclusion). Loneliness may well be New Zealand's next big public health issue. An Australian study has pointed out that this "trend has important social costs and policy significance, since loneliness has been linked to corrosive impacts on physical and mental health, the functionality of communities and city life, and overall feelings of happiness and satisfaction" (Franklin, 2012, p. 12). From the above follow a number of policy challenges. In order to avoid higher levels of marginalisation and social exclusion in our communities, we need to put more emphasis on creating and maintaining meaningful contacts with other people, and make changes to our communities so that they foster connectivity and social inclusion. Loneliness has become widespread in modern day society.

I have asked three key questions in this thesis: why are people lonely in $21^{\text {st }}$ Century New Zealand, who are the most prone to higher levels of loneliness, and where do these people live? 
A recent magazine article by Blundell (2015) points to a decline in intergenerational living (and in fact more people living alone), and to what he argues as a culture of individualism. The associated higher levels of loneliness have been attributed to an increase in the number of couples getting divorced (on both partners and their children), longer working days, and the greater influence of online communication. My thesis presents evidence that supports this argument, by showing a 'displacement' effect of youth having net friends, on the way young people benefit from only having close friends, and the way having net friends lowers the reducing effect on loneliness because it takes time away from face-to-face connections.

At the same time, I also show how the geography of modern day society is exacerbating loneliness levels, by disrupting on-going proximity to friends and family (by being able to move places more easily), as it can make it harder to maintain frequent and meaningful contact. I have observed how individual and selected communities are becoming more exclusive because affluence allows greater privatisation, which often means high fences, fewer public parks and playgrounds, closed community centres, and the demise of the corner dairy and the local post office (Blundell, 2015). As Burholt and Naylor point out, "communities are not merely settings - they play a significant role in self-identity and are a vital source of emotional and experiential meaning for the inhabitant" (2005, p. 109). I have been able to show in this thesis how loneliness seems to be more prolific in urban areas than rural communities and much higher in lower socioeconomic areas, where our "roots are not deep enough, our support systems are too shallow" (Twenge, 2006, p. 115). This is particularly the case for youth in Wellington who show the highest odds of being lonely, whereas those who are older in Wellington are less likely to be lonely. This suggests that more needs to be done to help create strong social networks for young people in Wellington in particular. 
This thesis also shows that New Zealand youth exhibit higher rates of loneliness than older age groups, a result which is consistent with recent findings in loneliness research. Outside of academic research, however, the focus still remains primarily on the experience of loneliness among the elderly. As an example, this month's issue of the Listener magazine (April, 2015) featured an eight page spread on the loneliness 'epidemic' facing older people, and this is despite mentioning that the 2010 General Social Survey found that the most vulnerable people to social isolation are the young! There needs to be widespread acknowledgement about how loneliness affects not only the elderly, but also is common in younger populations. Public recognition could enable youth to recognise and confront their own feelings of loneliness, and will allow those close to them to notice symptoms and solutions that may not have been recognisable without this information, for example spending less time with friends online. Only then will there be a reduction in loneliness among the young.

In both surveys (the 2012 NZGSS and the 2006 YCP), all forms of contact (excluding net friendship and partnerships for youth) remain negatively associated with loneliness, even after controlling for a person's geographical context, demographics, achieved characteristics, and psychological wellbeing. Throughout this thesis a range of different types of social connections have been examined in relation to loneliness levels. The analysis of the NZGSS (2012) shows that being in contact with friends through non-face-to-face mediums remained negatively correlated with loneliness. Online friendships (never met face-to-face) for youth, identified in the 2006 YCP, were found to be associated with higher levels of loneliness. This finding is in line with other research, in which some believe that the 'new social frontier' (online communication) is in fact lowering youth wellbeing and taking away the quality of human connectedness, and time able to be spend with friends in-person. It is also important to note here that the study was taken in 2006, at the beginning of the social networking era. The results of the study could be different if the same 
questions were asked today as social networking has become more commonplace in today's society.

The analysis of the NZGSS (2012) in Chapter Four showed that being in a relationship is associated with lower levels of loneliness, however for youth the opposite is the case. This suggests that there is a change in the importance of emotional connections as we age. As detailed in the literature review, Weiss (1973) argued that there are two types of loneliness: emotional and social. Social loneliness, or disatisfaction with social networks, may be more important to consider for younger people, while emotional loneliness, or a lack of an emotional relationship with one other person, may be more prevalent in older people. This has important policy implications as it is useful to understand the types of contact that are most effective in reducing loneliness for different groups of people, including people of different ages.

The cumulative effect of connectedness on loneliness was also identified. The more types of contact a person has, the less likely they are to be lonely. This was especially evident in the 2012 NZGSS, as a combination of partnership, contact with family, friends, and community connectedness was associated with the lowest levels of loneliness over and above having only one or two of these types of contact. In the 2006 YCP the combination of contact with classmates, family, close friends and the neighbourhood was the most effective in reducing loneliness.

It is important to draw attention to a few limitations of this research, in order to provide future research suggestions. As outlined in the methodology section, loneliness can be measured in a number of different ways. Although loneliness scales are commonly used, I am critical of adopting one because they do not often differentiate loneliness and connectedness as separate entities. Hughes et al. state that "feelings of loneliness are not synonymous with being alone, but instead involve feelings of isolation, feelings of disconnectedness, and feelings of not belonging" 
(2004, p. 657). Accordingly, they studied the difference between subjective (loneliness) and objective social isolation (social contact), and found that the two are related, but are individual concepts and should be treated as such. Thus, this thesis treated loneliness and social contact as separate concepts, in individual item measures, and results remained consistent with what was found in the literature.

As mentioned in chapters 4 and 5, my analysis centres around different types of contact, rather than the number, frequency, or quality of these contacts. A more comprehensive analysis of loneliness and connectedness could be provided with all four of forms of contact considered, given the well documented effects of each on loneliness. Moreover, further research with a larger, more representative sample of New Zealand youth, with no selection bias, may result in more substantive findings about why youth are reporting higher levels of loneliness than any other age group. Additionally, information on the location of participants across both datasets would have been helpful in conducting further spatial analysis through GIS, as the use of spatial statistics is something that could be developed further in New Zealand mental health and wellbeing research.

It is common in published research based on unit record data to only account for a very small proportion of the overall variance. This has also been my experience with respect to two data sets used here. In such cases it is the sign, magnitude, and statistical significance of the estimated parameters associated with particular variables which is the primary focus.

Overall, it has become increasingly clear that prioritising creating and maintaining meaningful contacts with others will considerably reduce the extent to which loneliness levels have become a widespread concern in modern day society. If social connection is a large part of the answer to loneliness, then we must face again: why are millions of people who are yearning for contact isolating themselves, and experiencing loneliness as a result (Murakami, 1999)? 
Investing in social opportunities for people of all ages cannot be dismissed as a 'nicety'. What this thesis shows is that services and policies to ameliorate issues around loneliness, especially for the young, are critical to keep communities functioning, to prevent social exclusion, and to also keep people out of hospital and prevent premature death. There is a need to re-visit online communication, and how it may benefit people, as although this new social frontier can help people keep in touch with distant loved ones, there is a danger that we are replacing real-life relationships with superficial social networks. 


\section{Appendices}

\section{Appendix 1.}

\begin{tabular}{|c|c|c|c|c|c|c|c|c|c|c|c|c|}
\hline & Author & Title & Journal & Date & Sample of.. & $\begin{array}{l}\text { Sample } \\
\text { size }\end{array}$ & Location & Method & Loneliness measures & $\begin{array}{l}\text { Connectivity } \\
\text { measures }\end{array}$ & $\begin{array}{l}\text { Forms of social } \\
\text { contact }\end{array}$ & Relevant findings \\
\hline 1 & \begin{tabular}{|l|} 
Access \\
Research \\
Knowledge
\end{tabular} & $\begin{array}{l}\text { Loneliness in Northern Ireland } \\
\text { Adolescents }\end{array}$ & \begin{tabular}{|l|}
. (report by \\
Northern \\
Ireland Access \\
Research \\
Knowledge)
\end{tabular} & 2012 & 16 yos & 1434 & Ireland & \begin{tabular}{|l|} 
basic \\
tabulations
\end{tabular} & UCLA & \begin{tabular}{|l|} 
Connectivity \\
within loneliness \\
measure
\end{tabular} & & $\begin{array}{l}\text { No significant differences in gender, } \\
\text { household structure, urbanicity, More } \\
\text { lonely = ethnic minority, having a } \\
\text { disability, lower socioeconomic status, } \\
\text { not religious. }\end{array}$ \\
\hline 2 & Baker & All the Lonely People & \begin{tabular}{|l|}
. (report by the \\
Australia \\
Institute)
\end{tabular} & 2012 & HILDA & 5313 & Australia & $\begin{array}{l}\text { simple } \\
\text { tabulations }\end{array}$ & UCLA & $\begin{array}{l}\text { contact with } \\
\text { friends, family, } \\
\text { community, and } \\
\text { non-face-to-face } \\
\text { contact }\end{array}$ & $\begin{array}{l}\text { facebook friends, } \\
\text { community } \\
\text { involvment }\end{array}$ & $\begin{array}{l}\text { People living alone or in lone person } \\
\text { households, men (esp high levels <60) } \\
\text { whereas women highish levels when } \\
\text { they're young, higher levels of } \\
\text { loneliness are linked to lower levels of } \\
\text { loneliness, those who are disconnected } \\
\text { from their community }\end{array}$ \\
\hline 3 & \begin{tabular}{|l} 
Bastos and \\
Costa
\end{tabular} & $\begin{array}{l}\text { Loneliness and attachment } \\
\text { representations in adolescents } \\
\text { and young adults in the context } \\
\text { of peer relationships }\end{array}$ & Book & 2005 & $\begin{array}{l}\text { university } \\
\text { students }\end{array}$ & & Portugal & \begin{tabular}{|l|} 
multivariate \\
analysis
\end{tabular} & $\begin{array}{l}\text { Loneliness and } \\
\text { Aloneness Scale for } \\
\text { Children and } \\
\text { Adolescents, and the } \\
\text { Social and Emotional } \\
\text { Loneliness Scale for } \\
\text { Adults }\end{array}$ & In loneliness scale & & $\begin{array}{l}\text { Securly attached individuals } \\
\text { experienced lower levels of peer-related } \\
\text { loneliness than the insecure ones. }\end{array}$ \\
\hline 4 & $\begin{array}{l}\text { Borys and } \\
\text { Perlman }\end{array}$ & $\begin{array}{l}\text { Gender Differences in } \\
\text { Loneliness }\end{array}$ & $\begin{array}{l}\text { Personality and } \\
\text { Social } \\
\text { Psychology } \\
\text { Bulletin }\end{array}$ & 1985 & $\begin{array}{l}\text { University } \\
\text { students }\end{array}$ & 117 & UK & $\begin{array}{l}2 \mathrm{X} 2 \\
\text { analysis of } \\
\text { variance }\end{array}$ & UCLA & \begin{tabular}{|l|} 
Connectivity \\
within loneliness \\
measure
\end{tabular} & & Females apt to reporting more lonely \\
\hline 5 & $\begin{array}{l}\text { Cacioppo, } \\
\text { Hughes, } \\
\text { Waite, } \\
\text { Hawkley \& } \\
\text { Thisted }\end{array}$ & $\begin{array}{l}\text { A Short Scale for Measuring } \\
\text { Loneliness in Large Surveys: } \\
\text { Results From Two Population- } \\
\text { Based Studies }\end{array}$ & $\begin{array}{l}\text { Research on } \\
\text { Aging }\end{array}$ & 2006 & \begin{tabular}{|l|} 
persons \\
born 1947 \\
or earlier
\end{tabular} & 22,000 & US & \begin{tabular}{|l|} 
bivariate \\
ordinary \\
least \\
squares \\
regressions \\
\end{tabular} & $\begin{array}{l}\text { UCLA + Health } \\
\text { and Retirement Study }\end{array}$ & $\begin{array}{l}\text { UCLA + Health } \\
\text { and Retirement } \\
\text { Study }\end{array}$ & \begin{tabular}{|l|} 
UCLA measures + \\
marital status, \\
living arrangments, \\
volunteering,
\end{tabular} & \\
\hline
\end{tabular}




\begin{tabular}{|c|c|c|c|c|c|c|c|c|c|c|c|c|}
\hline & Author & Title & Journal & Date & Sample of.. & $\begin{array}{l}\text { Sample } \\
\text { size }\end{array}$ & Location & Method & Loneliness measures & $\begin{array}{l}\text { Connectivity } \\
\text { measures }\end{array}$ & $\begin{array}{l}\text { Forms of social } \\
\text { contact }\end{array}$ & Relevant findings \\
\hline 6 & Chipuer & $\begin{array}{l}\text { Dyadic attachments and } \\
\text { community } \\
\text { connectedness: links with } \\
\text { youths loneliness } \\
\text { experiences }\end{array}$ & $\begin{array}{l}\text { Journal of } \\
\text { Community } \\
\text { Psychology }\end{array}$ & 2001 & $\begin{array}{l}\text { Fifth and } \\
\text { sixth graders }\end{array}$ & 187 & Brisbane & \begin{tabular}{|l|} 
hierarchical \\
regression \\
analysis
\end{tabular} & $\begin{array}{l}\text { Loneliness and Social } \\
\text { Dissatisfaction } \\
\text { Questionnaire }\end{array}$ & $\begin{array}{l}\text { Loneliness and } \\
\text { Social } \\
\text { Dissatisfaction } \\
\text { Questionnaire }\end{array}$ & $\begin{array}{l}\text { Connectedness } \\
\text { with family, } \\
\text { friends, } \\
\text { community, school }\end{array}$ & $\begin{array}{l}\text { Youths' dyadic attachment } \\
\text { to their best friends was } \\
\text { more significant in } \\
\text { accounting for their } \\
\text { loneliness experiences than } \\
\text { their attachments to either } \\
\text { parent. }\end{array}$ \\
\hline 7 & $\begin{array}{l}\text { Cole and } \\
\text { Page }\end{array}$ & $\begin{array}{l}\text { Demographic predictors of } \\
\text { self-reported loneliness in } \\
\text { adults }\end{array}$ & $\begin{array}{l}\text { Psychological } \\
\text { Reports }\end{array}$ & 1991 & $\begin{array}{l}\text { random } \\
\text { sample }\end{array}$ & 8634 & US & \begin{tabular}{|l} 
logistic \\
regression
\end{tabular} & Lonely in the past year & $\begin{array}{l}\text {. (None L vs } \\
\text { Demographics) }\end{array}$ & & $\begin{array}{l}\text { Ethnicity is not a predictor } \\
\text { of loneliness }\end{array}$ \\
\hline 8 & $\begin{array}{l}\text { Cramer and } \\
\text { Neyedly }\end{array}$ & $\begin{array}{l}\text { Sex differences in } \\
\text { loneliness: The role of } \\
\text { masculinity and } \\
\text { femininity. }\end{array}$ & Sex Roles & 1998 & $\begin{array}{l}\text { University } \\
\text { students }\end{array}$ & 256 & Canada & $\begin{array}{l}\text { intercorrelat } \\
\text { ion matrix }\end{array}$ & UCLA & $\begin{array}{l}\text { Connectivity } \\
\text { within loneliness } \\
\text { measure }\end{array}$ & & Females more lonely \\
\hline 9 & $\begin{array}{l}\text { Creed and } \\
\text { Reynolds }\end{array}$ & $\begin{array}{l}\text { Economic deprivation, } \\
\text { experiential deprivation } \\
\text { and social loneliness in } \\
\text { unemployed and } \\
\text { employed youth }\end{array}$ & $\begin{array}{l}\text { Journal of } \\
\text { Community \& } \\
\text { Applied Social } \\
\text { Psychology }\end{array}$ & 2001 & youth & 148 & Brisbane & \begin{tabular}{|l|} 
hierarchical \\
multiple \\
regression \\
analyses
\end{tabular} & $\begin{array}{l}\text { Social and Emotional } \\
\text { Loneliness Scale for } \\
\text { Adults - 1-5 scale. }\end{array}$ & $\begin{array}{l}\text { Connectivity } \\
\text { within loneliness } \\
\text { measure }\end{array}$ & & $\begin{array}{l}\text { The unem- ployed with } \\
\text { access to regular paid work } \\
\text { experienced the least } \\
\text { Social Loneliness; the } \\
\text { unemployed with no paid } \\
\text { work experienced the } \\
\text { most. }\end{array}$ \\
\hline 10 & $\begin{array}{l}\text { Demakakos, } \\
\text { Nunn and } \\
\text { Nazroo }\end{array}$ & $\begin{array}{l}\text { Loneliness, relative } \\
\text { deprivation and life } \\
\text { satisfaction }\end{array}$ & $\begin{array}{l}\text {. (report by } \\
\text { Institute of } \\
\text { Fiscal Studies) }\end{array}$ & 2006 & $50+$ & & UK & \begin{tabular}{|l|} 
basic \\
tabulations
\end{tabular} & ELSA & $\begin{array}{l}\text { Connectivity } \\
\text { within loneliness } \\
\text { measure }\end{array}$ & & $\begin{array}{l}80+, \text { women, low } \\
\text { socioeconomic, } \\
\text { unpartnered, without } \\
\text { friends and family }\end{array}$ \\
\hline 11 & Flood & $\begin{array}{l}\text { Mapping Loneliness in } \\
\text { Australia }\end{array}$ & $\begin{array}{l}\text { (report by the } \\
\text { Australia } \\
\text { Institute) }\end{array}$ & 2005 & HILDA & 13000 & Australia & \begin{tabular}{|l|} 
simple \\
tabulations \\
and graphs
\end{tabular} & index of social support & $\begin{array}{l}\text { The Index of } \\
\text { Social Support }\end{array}$ & $\begin{array}{l}\text { support, quality of } \\
\text { relationships }\end{array}$ & $\begin{array}{l}\text { Men,men living alone, } \\
\text { single fathers, recent } \\
\text { seperation or divorce, } \\
\text { without work, do not } \\
\text { belong to clubs, }\end{array}$ \\
\hline
\end{tabular}




\begin{tabular}{|c|c|c|c|c|c|c|c|c|c|c|c|c|}
\hline & Author & Title & Journal & Date & Sample of.. & $\begin{array}{l}\text { Sample } \\
\text { size }\end{array}$ & Location & Method & Loneliness measures & $\begin{array}{l}\text { Connectivity } \\
\text { measures }\end{array}$ & Forms of social contact & Relevant findings \\
\hline 12 & $\begin{array}{l}\text { Fokkema, De } \\
\text { Jong } \\
\text { Gierveld, } \\
\text { Dykstra }\end{array}$ & $\begin{array}{l}\text { Cross-National } \\
\text { Differences in Older Adult } \\
\text { Loneliness }\end{array}$ & Journal of Psychology & 2012 & $50+$ & 12,248 & Europe & $\begin{array}{l}\text { multivariate } \\
\text { logistic } \\
\text { regression } \\
\text { analysis }\end{array}$ & single item on last week & Three variables & $\begin{array}{l}\text { Contact with children, } \\
\text { parents, social } \\
\text { participation }\end{array}$ & $\begin{array}{l}\text { Frequent contacts with parents and adult } \\
\text { children, social participation, and providing } \\
\text { support to family members were important in } \\
\text { preventing and alleviating loneliness in } \\
\text { almost all countries. }\end{array}$ \\
\hline 13 & Franklin & On Loneliness & $\begin{array}{l}\text { Geografiska Annaler. } \\
\text { Series B, Human } \\
\text { Geography }\end{array}$ & 2009 & & & & & & & & . \\
\hline 14 & Goosby et al & $\begin{array}{l}\text { Adolescent Loneliness } \\
\text { and Health in Early } \\
\text { Adulthood }\end{array}$ & Sociological Inquiry & 2013 & Adolescents & $\begin{array}{l}132 \\
\text { schools }\end{array}$ & US & \begin{tabular}{|l} 
logistic \\
regression
\end{tabular} & 4 point scale & 5 point scale & $\begin{array}{l}\text { parent support, school } \\
\text { attachment }\end{array}$ & $\begin{array}{l}\text { lonely adolescent females are more } \\
\text { vulnerable to reporting pooradult self-rated } \\
\text { health and being overweight or obese in } \\
\text { adulthood. }\end{array}$ \\
\hline 15 & $\begin{array}{l}\text { Hawkley, } \\
\text { Burleson, } \\
\text { Berntson } \\
\text { and } \\
\text { Cacioppo }\end{array}$ & $\begin{array}{l}\text { Loneliness in everyday } \\
\text { life: Cardiovascular } \\
\text { activity, psychosocial } \\
\text { context, and health } \\
\text { behaviors. }\end{array}$ & \begin{tabular}{|l} 
Journal of Personality \\
and Social \\
Psychology
\end{tabular} & 2003 & $\begin{array}{l}\text { Undergradu } \\
\text { ates }\end{array}$ & 135 & US & $\begin{array}{l}\text { Multilevel } \\
\text { regression } \\
\text { analyses }\end{array}$ & UCLA & $\begin{array}{l}\text { 12-item - } \\
\text { Appraisal Support } \\
\text { subscale of the } \\
\text { Interpersonal } \\
\text { Support } \\
\text { Evaluation List }\end{array}$ & social support & $\begin{array}{l}\text { Loneliness affects the cardio-vascular } \\
\text { system. Loneliness predicted higher total } \\
\text { peripheral resistance and lower cardiac } \\
\text { output }\end{array}$ \\
\hline 16 & Heylen & $\begin{array}{l}\text { The older, the lonelier? } \\
\text { Risk factors for social } \\
\text { loneliness in old age }\end{array}$ & Aging and Society & 2010 & $55+$ years & 1414 & Belgium & $\begin{array}{l}\text { multivariate } \\
\text { regression }\end{array}$ & $\begin{array}{l}\text { de Jong Gierveld } \\
\text { loneliness scale }\end{array}$ & $\begin{array}{l}\text { Panel Study of } \\
\text { Belgian } \\
\text { Households }\end{array}$ & $\begin{array}{l}\text { Quantity - frequency } \\
\text { and number, Quality - } \\
\text { satisfaction }\end{array}$ & Higher level of social loneliness for men, \\
\hline 17 & $\begin{array}{l}\text { Jaremka, } \\
\text { Fagundes, } \\
\text { Glaser, } \\
\text { Bennett, } \\
\text { Malaarkey } \\
\text { and Kiecolt- } \\
\text { Glaser }\end{array}$ & $\begin{array}{l}\text { Loneliness predicts pain, } \\
\text { depression, and fatigue: } \\
\text { understanding the role of } \\
\text { immune dysregulation. }\end{array}$ & $\begin{array}{l}\text { Psychoneuroendocrin } \\
\text { ology }\end{array}$ & 2012 & $\begin{array}{l}\text { cancer } \\
\text { survivors }\end{array}$ & 200 & US & $\begin{array}{l}\text { hierarchical } \\
\text { regression } \\
\text { analysis }\end{array}$ & UCLA & \begin{tabular}{|l}
. (None L vs \\
health)
\end{tabular} & & $\begin{array}{l}\text { Cancer survivors: Lonelier participant } \\
\text { experienced more pain, depression, and } \\
\text { fatigue than those who felt more socially } \\
\text { connected }\end{array}$ \\
\hline 18 & $\begin{array}{l}\text { Kearns, } \\
\text { Whitley, } \\
\text { Tannahill } \\
\text { and Ellaway }\end{array}$ & $\begin{array}{l}\text { Loneliness, social } \\
\text { relations and health and } \\
\text { well-being in deprived } \\
\text { communities }\end{array}$ & $\begin{array}{l}\text { Psychology, Health \& } \\
\text { Medicine }\end{array}$ & 2013 & adults & 4302 & Glasgow & \begin{tabular}{|l|} 
multinomial \\
(polytomous) \\
logistic \\
regression
\end{tabular} & single item measure & $\begin{array}{l}\text { social contacts } \\
\text { and support } \\
\text { measures }\end{array}$ & $\begin{array}{l}\text { how often they met up } \\
\text { with relatives and } \\
\text { friends, and how often } \\
\text { they spoke to their } \\
\text { neighbours }\end{array}$ & $\begin{array}{l}\text { social contact lowered loneliness, mental } \\
\text { health highly correlated with loneliness, no } \\
\text { qualifications predicted loneliness. Men } \\
\text { more lonely, }\end{array}$ \\
\hline
\end{tabular}




\begin{tabular}{|c|c|c|c|c|c|c|c|c|c|c|c|c|}
\hline & Author & Title & Journal & Date & Sample of.. & $\begin{array}{l}\text { Sample } \\
\text { size }\end{array}$ & Location & Method & Loneliness measures & $\begin{array}{l}\text { Connectivity } \\
\text { measures }\end{array}$ & Forms of social contact & Relevant findings \\
\hline 19 & $\begin{array}{l}\text { Knoke, } \\
\text { Burau and } \\
\text { Roehrle }\end{array}$ & $\begin{array}{l}\text { Attachment Styles, } \\
\text { Loneliness, Quality, and } \\
\text { Stability of Marital } \\
\text { Relationships }\end{array}$ & $\begin{array}{l}\text { Journal of Divorce \& } \\
\text { Remarriage }\end{array}$ & 2010 & Couple & 126 & Germany & \begin{tabular}{|l|} 
Pearsons \\
correlation, and \\
stepwise multiple \\
regression \\
analysis
\end{tabular} & \begin{tabular}{|l} 
Multidimensional \\
Loneliness \\
Questionnaire (social, \\
emotional, competence \\
in being alone)
\end{tabular} & \begin{tabular}{|l|} 
Partnership \\
Questionnaire, \\
Attachment Style \\
Questionnaire
\end{tabular} & $\begin{array}{l}\text { Length of relationship, } \\
\text { relationship quality, }\end{array}$ & $\begin{array}{l}\text { emotional forms of loneliness as well } \\
\text { as attachment styles are crucial for the } \\
\text { quality of marital relationships }\end{array}$ \\
\hline 20 & \begin{tabular}{|l|} 
Mullins, \\
Elston and \\
Gutkowski
\end{tabular} & $\begin{array}{l}\text { Social Determinants of } \\
\text { Loneliness Among Older } \\
\text { Americans }\end{array}$ & \begin{tabular}{|l} 
Genetic, Social \& \\
General Psychology \\
Monographs
\end{tabular} & 1996 & $65+$ & 1071 & \begin{tabular}{|l|} 
Florida, \\
US
\end{tabular} & \begin{tabular}{|l} 
stepwise \\
regression \\
analyses
\end{tabular} & De jong gierveld & $\begin{array}{l}\text { Six social support } \\
\text { variables }\end{array}$ & \begin{tabular}{|l|} 
existence of children \\
and friends, marital \\
status, closeness with \\
children, friends, spouse
\end{tabular} & $\begin{array}{l}\text { loneliness was greater among men, } \\
\text { those with no children, those with no } \\
\text { friends, those more physically } \\
\text { disabled, those who subjectively felt } \\
\text { that their health was poorer, and those } \\
\text { who subjectively felt that their } \\
\text { economic condition was inadequate. } \\
\text { Not related directly to loneliness but } \\
\text { with indirect influence were age, race, } \\
\text { education, marital status, and poverty } \\
\text { status. }\end{array}$ \\
\hline 21 & $\begin{array}{l}\text { Neto and } \\
\text { Barros }\end{array}$ & $\begin{array}{l}\text { Predictors of loneliness } \\
\text { among adolescents from } \\
\text { Portuguese immigrant } \\
\text { families in Switzerland }\end{array}$ & $\begin{array}{l}\text { Social Behaviour and } \\
\text { Personality }\end{array}$ & 2006 & adolescents & \begin{tabular}{|l|}
95 (swiss \\
and \\
a63(port \\
uguese)
\end{tabular} & Portugal & \begin{tabular}{|l|} 
stepwise multiple \\
regression \\
analysis
\end{tabular} & UCLA & \begin{tabular}{|l|} 
Connectivity \\
within loneliness \\
measure
\end{tabular} & & $\begin{array}{l}\text { low ethnic identity had higher rates of } \\
\text { loneliness }\end{array}$ \\
\hline 22 & \begin{tabular}{|l|} 
Olenik \\
Shemesh and \\
Zeidner
\end{tabular} & $\begin{array}{l}\text { Personality Predictors of } \\
\text { School Loneliness in } \\
\text { Adolescent Students }\end{array}$ & Psychology Research & 2013 & $\begin{array}{l}\text { high school } \\
\text { students }\end{array}$ & 203 & Israel & \begin{tabular}{|l|} 
ordinary least \\
square regression \\
analysis
\end{tabular} & $\begin{array}{l}24 \text { item - Illinois } \\
\text { loneliness and social } \\
\text { dissatisfaction scale }\end{array}$ & $\begin{array}{l}24 \text { item - Illinois } \\
\text { loneliness and } \\
\text { social } \\
\text { dissatisfaction } \\
\text { scale }\end{array}$ & $\begin{array}{l}\text { social dissatisfaction } \\
\text { with respect to the } \\
\text { school context }\end{array}$ & $\begin{array}{l}\text { personality variables are meaningfully } \\
\text { related to school-related loneliness in } \\
\text { adolescents. adolescents higher on } \\
\text { extraversion and agreeableness were } \\
\text { also lower on loneliness, whereas } \\
\text { those higher on neuroticism were also } \\
\text { higher on loneliness. Adolescent boys } \\
\text { and girls were not found to be reliably } \\
\text { differentiated on mean loneliness } \\
\text { scores. }\end{array}$ \\
\hline 23 & Ouellette & $\begin{array}{l}\text { The Social Network and } \\
\text { Attachment Bases of } \\
\text { Loneliness }\end{array}$ & . (thesis) & 2001 & $\begin{array}{l}\text { Undergradu } \\
\text { ates }\end{array}$ & 69 & $\begin{array}{l}\text { Virginia, } \\
\text { US }\end{array}$ & $\begin{array}{l}\text { Hierarchical } \\
\text { Multiple } \\
\text { Regression }\end{array}$ & $\begin{array}{l}\text { UCLA + Social and } \\
\text { Emotional Loneliness } \\
\text { Scale }\end{array}$ & $\begin{array}{l}\text { Experiences in } \\
\text { Close } \\
\text { Relationships, }\end{array}$ & $\begin{array}{l}\text { close relationships, } \\
\text { personal network }\end{array}$ & $\begin{array}{l}\text { A portion of loneliness is derived from } \\
\text { one's internal attachment security and } \\
\text { a separate portion is derived from the } \\
\text { external features of one's social } \\
\text { network integration }\end{array}$ \\
\hline
\end{tabular}




\begin{tabular}{|c|c|c|c|c|c|c|c|c|c|c|c|c|}
\hline & Author & Title & Journal & Date & Sample of.. & $\begin{array}{l}\text { Sample } \\
\text { size }\end{array}$ & Location & Method & Loneliness measures & $\begin{array}{l}\text { Connectivity } \\
\text { measures }\end{array}$ & Forms of social contact & Relevant findings \\
\hline 24 & $\begin{array}{l}\text { Parker and } \\
\text { Seal }\end{array}$ & $\begin{array}{l}\text { Forming, losing, renewing, } \\
\text { and replacing friendships: } \\
\text { Applying temporal } \\
\text { parameters to the } \\
\text { assessment of children's } \\
\text { friendship experiences. }\end{array}$ & $\begin{array}{l}\text { Child } \\
\text { Development }\end{array}$ & 1996 & \begin{tabular}{|l|} 
Children $8-$ \\
15 years
\end{tabular} & 216 & \begin{tabular}{|l|} 
Michigan \\
, US
\end{tabular} & ANOVA & 4 weeks & $\begin{array}{l}\text { A range of scales } \\
\text { on friendships }\end{array}$ & $\begin{array}{l}\text { tracking of friendships, } \\
\text { social acceptance }\end{array}$ & $\begin{array}{l}\text { the formation of new friendships at } \\
\text { camp will incrementally reduce } \\
\text { children's loneli- ness, this proved true } \\
\text { only when friendships tended to last }\end{array}$ \\
\hline 25 & \begin{tabular}{|l} 
Perlman, \\
Gerson and \\
Spiunner
\end{tabular} & $\begin{array}{l}\text { Loneliness among senior } \\
\text { citizens: An empirical } \\
\text { report. }\end{array}$ & Essence & 1978 & $\begin{array}{l}\text { average age } \\
70 \mathrm{yrs}\end{array}$ & 158 & Canada & & & $\begin{array}{l}\text { self-administered } \\
\text { questionnaire }\end{array}$ & $\begin{array}{l}\text { friend contact, number } \\
\text { of friends, social } \\
\text { anxiety, marital } \\
\text { satisfaction }\end{array}$ & $\begin{array}{l}\text { Greater loneliness = low marital } \\
\text { satisfaction. }\end{array}$ \\
\hline 26 & $\begin{array}{l}\text { Priyadarshini } \\
\text { and Mishra }\end{array}$ & $\begin{array}{l}\text { Adolescents' loneliness: } \\
\text { effect of gender and } \\
\text { internet use }\end{array}$ & \begin{tabular}{|l|} 
Asian Journal of \\
Research in \\
Social Sciences \\
and Humanities
\end{tabular} & 2013 & $\begin{array}{l}\text { Young } \\
\text { adults }\end{array}$ & 1008 & India & $2 \mathrm{X} 2$ anova & UCLA & \begin{tabular}{|l|} 
Internet \\
Addiction Scale
\end{tabular} & $\begin{array}{l}\text { level of internet } \\
\text { addiction }\end{array}$ & Males more lonely \\
\hline 27 & \begin{tabular}{|l|} 
Rubenstein, \\
Shaver and \\
Peplau
\end{tabular} & Loneliness & Human Nature & 1979 & all ages & 25,000 & US & \begin{tabular}{|l} 
simple \\
tabulations and \\
graphs
\end{tabular} & UCLA & \begin{tabular}{|l|} 
Connectivity \\
within loneliness \\
measure
\end{tabular} & & $\begin{array}{l}\text { Young more lonely, esp the single } \\
\text { because they are longing for that } \\
\text { special person. }\end{array}$ \\
\hline 28 & \begin{tabular}{|l|} 
Saklofske, \\
Yackulic and \\
Kelly
\end{tabular} & Personality and loneliness & $\begin{array}{l}\text { Personality and } \\
\text { Individual } \\
\text { Differences }\end{array}$ & 1985 & $17-25$ years & 101 & Canada & $\begin{array}{l}\text { pearsons } \\
\text { correlation }\end{array}$ & UCLA & \begin{tabular}{|l|} 
Connectivity \\
within loneliness \\
measure
\end{tabular} & & $\begin{array}{l}\text { Extraversion was related to loneliness } \\
\text { for both males and females;females } \\
\text { shows moderately high correlation } \\
\text { between neuroticism and loneliness }\end{array}$ \\
\hline 29 & $\begin{array}{l}\text { Salimi and } \\
\text { Jowkar }\end{array}$ & $\begin{array}{l}\text { Personality } \\
\text { Predispositions and } \\
\text { Loneliness and } \\
\text { Adolescence }\end{array}$ & \begin{tabular}{|l|} 
Procedia - Social \\
and Behavioral \\
Sciences
\end{tabular} & 2011 & mean age 17 & 426 & Iran & $\begin{array}{l}\text { Pearson } \\
\text { correlation } \\
\text { coefficient }\end{array}$ & $\begin{array}{l}\text { Social and Emotional } \\
\text { Loneliness Scale for } \\
\text { adults }\end{array}$ & \begin{tabular}{|l|} 
Connectivity \\
within loneliness \\
measure
\end{tabular} & & $\begin{array}{l}\text { People's negative thoughts about } \\
\text { themselves lead to less socialising, and } \\
\text { will decrease the likelihood of forming } \\
\text { satisfying relationships }\end{array}$ \\
\hline 30 & \begin{tabular}{|l|} 
Schultz and \\
Moore
\end{tabular} & $\begin{array}{l}\text { Loneliness: Differences } \\
\text { Across Three Age Levels }\end{array}$ & \begin{tabular}{|l|} 
Journal of Social \\
and Personal \\
Relationships
\end{tabular} & 1988 & $\begin{array}{l}\text { high school, } \\
\text { university } \\
\text { and retirees }\end{array}$ & 264 & \begin{tabular}{|l|} 
South \\
Carolina
\end{tabular} & $\begin{array}{l}3 \times 2 \text { analysis, } \\
\text { hierarchical } \\
\text { regression } \\
\text { analysis }\end{array}$ & UCLA & \begin{tabular}{|l|} 
Connectivity \\
within loneliness \\
measure
\end{tabular} & & $\begin{array}{l}\text { Loneliness was greatest for high } \\
\text { school students, at an intermediate } \\
\text { level for college students, and non } \\
\text { significant for retirees. }\end{array}$ \\
\hline
\end{tabular}




\begin{tabular}{|c|c|c|c|c|c|c|c|c|c|c|c|c|}
\hline & Author & Title & Journal & Date & Sample of.. & $\begin{array}{l}\text { Sample } \\
\text { size }\end{array}$ & Location & Method & Loneliness measures & $\begin{array}{l}\text { Connectivity } \\
\text { measures }\end{array}$ & Forms of social contact & Relevant findings \\
\hline 31 & $\begin{array}{l}\text { Van Tilburg } \\
\text { et al }\end{array}$ & $\begin{array}{l}\text { Loneliness among older } \\
\text { adults in the Netherlands, } \\
\text { Italy and Canada: a } \\
\text { multifaceted comparison. }\end{array}$ & $\begin{array}{l}\text { Canadian Journal } \\
\text { on Aging }\end{array}$ & 2004 & $\begin{array}{l}\text { Married and } \\
\text { widowed } \\
\text { older adults }\end{array}$ & 3543 & $\begin{array}{l}\text { Netherla } \\
\text { nds, } \\
\text { Tuscany, } \\
\text { Canada }\end{array}$ & \begin{tabular}{|l} 
multinomial \\
regression \\
analyses
\end{tabular} & 11- item scale & \begin{tabular}{|l|} 
Connectivity \\
within loneliness \\
measure
\end{tabular} & & $\begin{array}{l}\text { emotional loneliness: high probability } \\
\text { of being lonely in Tuscany, with a } \\
\text { lower probability in the Netherlands, } \\
\text { and a lower still in Canada. But social } \\
\text { loneliness the opposite. }\end{array}$ \\
\hline 32 & \begin{tabular}{|l|} 
Victor, \\
Burholt and \\
Martin
\end{tabular} & $\begin{array}{l}\text { Loneliness and ethnic } \\
\text { minority elders in Britain: } \\
\text { an exploratory study }\end{array}$ & $\begin{array}{l}\text { J Cross Cult } \\
\text { Gerontol }\end{array}$ & 2012 & $65+$ & \begin{tabular}{|l|}
300 \\
minority \\
elders, \\
and 169 \\
south \\
asian \\
elders
\end{tabular} & UK & basic tabulations & $\begin{array}{l}4 \text { scale current feeling } \\
\text { against } 10 \text { years ago }\end{array}$ & $\begin{array}{l}\text {. (None L vs } \\
\text { Ethnicity) }\end{array}$ & & $\begin{array}{l}\text { levels of loneliness are, with the } \\
\text { exception of the Indian population, } \\
\text { very much higher than for the general } \\
\text { population but are broadly } \\
\text { comparable with rates of loneliness } \\
\text { reported for older people in their } \\
\text { countries of origin }\end{array}$ \\
\hline 33 & $\begin{array}{l}\text { Wang, Fink } \\
\text { and Cai }\end{array}$ & $\begin{array}{l}\text { Loneliness, Gender and } \\
\text { Parasocial Interaction: A } \\
\text { Uses and Gratifications } \\
\text { Approach }\end{array}$ & $\begin{array}{l}\text { Communication } \\
\text { Quarterly }\end{array}$ & 2008 & $\begin{array}{l}\text { undergradua } \\
\text { te students }\end{array}$ & 514 & US & $\begin{array}{l}\text { regression } \\
\text { analysis }\end{array}$ & UCLA & \begin{tabular}{|l|} 
Social and \\
Emotional \\
Loneliness Scale
\end{tabular} & $\begin{array}{l}\text { Family, romantic, social } \\
\text { loneliness }\end{array}$ & $\begin{array}{l}\text { Gender interacted with family, } \\
\text { romantic, and chronic loneliness in } \\
\text { predicting parasocial interaction. For } \\
\text { women, greater family loneliness } \\
\text { predicted greater parasocial } \\
\text { interaction, whereas for men the effect } \\
\text { was negative. }\end{array}$ \\
\hline 34 & Weeks & \begin{tabular}{|l} 
Gender, Loneliness, and \\
Friendship Satisfaction in \\
Early Adulthood: The \\
Role of Friendship \\
Features and Friendship \\
Expectations
\end{tabular} & $\begin{array}{l}\text { (thesis at Duke } \\
\text { University) }\end{array}$ & 2013 & $18-29$ & \begin{tabular}{|l} 
Study $1=7$ \\
61 \\
study $2=1$ \\
008
\end{tabular} & US & $\begin{array}{l}\text { regression } \\
\text { analysis }\end{array}$ & $\begin{array}{l}\text { ten item measure about } \\
\text { L over a day. }\end{array}$ & $\begin{array}{l}\text { Friendship } \\
\text { Quality } \\
\text { Questionnaire }\end{array}$ & $\begin{array}{l}40 \text { items assessing six } \\
\text { different friendship } \\
\text { features }\end{array}$ & $\begin{array}{l}\text { STUDY1: Females overall lonelier } \\
\text { once controls were added. STUDY2: } \\
\text { females reported higher friendship } \\
\text { satisfaction, but not when statistically } \\
\text { controlled for. }\end{array}$ \\
\hline 35 & $\begin{array}{l}\text { Wiseman, } \\
\text { Guttfreund } \\
\text { and Lurie }\end{array}$ & $\begin{array}{l}\text { Gender differences in } \\
\text { loneliness and depression } \\
\text { of university students } \\
\text { seeking counselling }\end{array}$ & $\begin{array}{l}\text { British Journal of } \\
\text { Guidance \& } \\
\text { Counselling }\end{array}$ & 1995 & $\begin{array}{l}\text { University } \\
\text { students }\end{array}$ & 325 & Israel & $\begin{array}{l}\text { pearsons and } \\
2 \text { way anova }\end{array}$ & $\begin{array}{l}\text { UCLA and Beck } \\
\text { Depression Inventory }\end{array}$ & \begin{tabular}{|l|} 
Connectivity \\
within loneliness \\
measure
\end{tabular} & & Males more lonely \\
\hline 36 & $\begin{array}{l}\text { Yang and } \\
\text { Victor }\end{array}$ & $\begin{array}{l}\text { Age and loneliness in } 25 \\
\text { European nations }\end{array}$ & $\begin{array}{l}\text { Ageing and } \\
\text { Society }\end{array}$ & 2011 & \begin{tabular}{|l} 
European \\
Social \\
Survey - all \\
ages
\end{tabular} & 47,099 & Europe & \begin{tabular}{|l} 
gamma \\
correlation
\end{tabular} & $\begin{array}{l}\text { self-rating loneliness } \\
\text { scale }\end{array}$ & $\begin{array}{l}\text {. (just looked at L } \\
\text { vs Age }\end{array}$ & & $\begin{array}{l}\text { Loneliness exhibits a non-linear U- } \\
\text { shaped distrbution across the age } \\
\text { range, Russia and Eastern European } \\
\text { countries have highest rates of } \\
\text { loneliness, whereas Northern Europe } \\
\text { the lowest (mostly below 6\%). }\end{array}$ \\
\hline
\end{tabular}




\section{References}

Access Research Knowledge. (2012). Loneliness in Northern Ireland Adolescents (Vol. 81). Northern Ireland Access Research Knowledge.

Age UK. (2010). Loneliness and Isolation Evidence Review. UK: Age UK.

Amichai-Hamburger, Y., \& Ben-Artzi, E. (2003). Loneliness and internet use. Computers in Human Behavior, 19(1), 71-80.

Anderson, H. (1998). The Family Handbook. Westminster: Westminster John Knox Press.

Aristotle. (n.d.). Aristotle Quotes. Retrieved 16th December, 2014, from http://www.goodreads.com/quotes/183896-man-is-by-nature-a-social-animal-anindividual-who

Badoo. (2012). Generation Lonely? 39 Percent of Americans Spend More Time Socializing Online Than Face-to-Face. Retrieved March 5th, 2015

Baker, D. (2012). All the Lonely people: loneliness in Australia, 2001-2009 Institute Paper 9. Canberra: The Australia Institute

Barber, B. K., \& Schluterman, J.M. (2008). Connectedness in the lives of children and adolescents: A call for greater conceptual clarity. Journal of Adolescent Health, 43(3), 209-216.

Barford, V. (2013). Is modern life making us lonely? Retrieved March 5th, 2015

Bastos, M., \& Costa, M.E. (2006). Loneliness and attachment representations in adolescents and young adults in the context of peer relationships.

Bauman, Z. (2003). Liquid Love: On the Frailty of Human Bonds. Cambridge: Polity.

Baumeister, R. F., \& Leary, M.R. (1995). The Need to Belong: Desire for Interpersonal Attachments as a Fundamental Human Motivation. Psychological Bulletin, 117(3), 497-529.

Berguno, G., Leroux, Penny., McAinsh, K., and Sahikh, S. (2004). Children's Experience of Loneliness at School and its Relation to Bullying and the Quality of Teacher Interventions. The Qualitative Report 9(3), 483-499.

Berkman, L. F., Glass, T., Brissette, L., and Seeman, T.E. (2000). From social integration to health: Durkheim in the new millennium. Social Science and Medicine, 51, 843-857.

Bettmann, J. E. (2006). Using the attachment theory to understand the treatment of adult depression. Clinical Social Work Journal, 34(4).

Bingham, J. (2014). Britain the loneliness capital of Europe. Retrieved December 9th, 2014, from http://www.telegraph.co.uk/lifestyle/wellbeing/10909524/Britain-theloneliness-capital-of-Europe.html

Blundell, S. (2015, April 4-10). All the lonely people. The Listener, pp. 18-25. 
Borys, S., \& Perlman, D. (1985). Gender Differences in Loneliness. Personality and Social Psychology Bulletin, 11(1), 63-74.

Bowlby, J. (1951). Maternal care and mental health. World Health Organization Monograph.

Brennan, T., \& Auslander, N. (1979). Adolescent Loneliness: An Exploratory Study of Social and Psychological Pre-disposition and Theory. Boulder: Behavioral Research Institute.

Brennan, T. (1982). Loneliness in adolescence. In L. A. Peplau, \& Perlman, D. (Ed.), Loneliness: A sourcebook of current theory, research and therapy (pp. 269-290). New York: Wiley.

Bretherton, I. (1992). The Origins of attachment theory: John Bowlby and Mary Ainsworth. Developmental Psychology, 28, 759-775.

Broom, A., \& Willis, E. (2007). Competing Paradigms and Health Research. In M. Saks, \& Allsop, J. (Ed.), Researching Health: Qualitative, Quantitative and Mixed Methods. London: SAGE Publications Ltd.

Brown, J. S. (2013). Emerging applications of Geographic Information Systems (GIS) in community and local mental health research. Journal of Local and Global Health Perspectives.

Bunnell, T., Yea, S., Peake, L., Skelton, T., and Smith, M. (2012). Geographies of friendships. Progress in Human Geography, 36(4), 490-507.

Burholt, V., and Naylor, D. (2005). The relationship between rural community type and attachment to place for older people living in North Wales, UK. European Journal of Aging, 2, 109-119.

Burholt, V. (2011). Loneliness of older men and women in rural areas of the UK Safeguarding the convoy (pp. 35-29). Oxford: Age UK Oxfordshire

Burholt, V., and Scharf, T. (2014). Poor health and loneliness in later life: the role of depressive symptoms, social resources, and rural environments. The Journals of Gerontology Series B: Psychological Sciences and Social Sciences, 69(2), 311-324.

Burke, T. J., Woszidlo, A., and Segrin, C. (2012). Social Skills, Family Conflict, and Loneliness in Families. Communication Reports, 25(2), 75-87.

Cacioppo, J. T., \& Hawkley, L.C. (2000). Loneliness. Chicago: Chicago Center for Cognitive \& Social Neuroscience, University of Chicago.

Carden, R., \& Rettew, S. (2006). Internet chat room use, satisfaction with life, and loneliness. Psychological Reports, 98(1), 121-122.

Carstairs, V., and Morris, R. (1991). Deprivation and Health in Scotland. Aberdeen Aberdeen University Press.

Castree, N. (2003). Environmental issues: relational ontologies and hybrid politics. Progress in Human Geography, 27, 203-211.

Chen, W. C. (2003). Adolescent Interpersonal Relationship Quantity and Quality, Belongingness, and Loneliness. Austin: University of Austin. 
Chlipala, L. (2008). Longitudinal study of loneliness and depression as predictors of health in mid-to later life. (Masters of Science), University of North Texas.

Commission for Rural Communities. (2005). Rural Disadvantage: Our First Thematic Study. Cheltenham: Commission for Rural Communities.

Cramer, K. M., \& Neyedley, K.A. (1998). Sex differences in loneliness: The role of masculinity and femininity. Sex roles, 38(7/8), 654-653.

Creed, P. A., and Reynolds, J. (2001). Economic deprivation, experiential deprivation and social loneliness in unemployed and employed youth. Journal of Community \& Applied Social Psychology, 11(3), 167-178.

Crosnoe, R. (2000). Friendships in Childhood and Adolescence: The Life Course and New Directions. Social Psychology Quarterly, 63, 377-391.

De Botton, A. (2006). Essays in Love. England: Picador.

Demakakos, P., Nunn, S., and Nazroo, J. (2006). Loneliness, relative deprivation and life satisfaction. In J. Banks, Breeze, E., Lessof, C (Ed.), Retirement, Health and Relationships of the Older Population in England: The 2004 English Longitudinal Study of Ageing (Wave 2): Institute of Fiscal Studies

Demir, A., \& Tarhan, N. (2001). Loneliness and social dissatisfaction in Turkish adolescents. Journal of Psychology, 135(1), 113-124.

Diesing, J. (2013). Social Media: A solution to declining youth engagement in politics? , University of Otago, Otago.

Dorling, D., Vickers, D., Thomas, B., Pritchard, J., and Ballas, D. (2008). Changing UK: the way we live now. Sheffield: University of Sheffield

Duarte, G., and Rafanello, D. (2001). The migrant child: A special place in the field. Young Children, 56(2), 26-34.

Durkheim, E. (1897/1951). Suicide: a study in sociology. New York: Free Press.

Eisemann, M. (1984). Contact difficulties and experience of loneliness in depressed patients and non-psychiatric controls. Acta Psychiatrica Scandinavica, 70(2), 160-165.

Ernst, J. M., \& Cacioppo, J.T. (1999). Lonely Hearts: Psychological perspectives on loneliness. Journal of Applied Psychology, 8, 1-22.

Fischer, C. S., \& Phillips, S.L. (1982). Who is alone? Social characteristics of people with small networks. In L. A. Peplau, \& Perlman, D. (Ed.), Loneliness: A sourcebook of current theory, research, and therapy (pp. 269-290). New York: Wiley.

Flood, M. (2005). Mapping Loneliness in Australia. Canberra: The Australia Institute.

Franklin, A., and Tranter, B. (2008). Loneliness in Australia. Hobart: Housing and Community Research Unit, University of Tasmania.

Franklin, A. (2012). A lonely society? Loneliness and liquid modernity in Australia. Australian Journal of Social Issues, 47(1). 
Fromm-Reichmann, F. (1959). Loneliness. Psychiatry: Journal for the Study of Interpersonal Processes, 22, 1-15.

Gil, N. (2014). Loneliness: a silent plague that is hurting young people most. Retrieved March 2nd, 2015, from http://www.theguardian.com/lifeandstyle/2014/jul/20/loneliness-britains-silentplague-hurts-young-people-most

Google Books Ngram Viewer. (2015). Loneliness. Retrieved 28th March, 2015, from https://books.google.com/ngrams/graph?content=Loneliness\&year_start=1800\&ye ar_end $=2000 \&$ corpus $=15 \&$ smoothing $=3 \&$ share $=\&$ direct_url $=t 1 \% 3 \mathrm{~B} \% 2$ CLoneliness $\% 3 \mathrm{~B} \% 2 \mathrm{Cc} 0$

Goosby, B. J., Bellatorre, A., Walsemann, K.M., \& Cheadle, J.E. (2013). Adolescent Loneliness and Health in Early Adulthood. Sociological Inquiry, 83(4), 505-536.

Gray, M., Lobao, L., \& Martin, R. (2012). Making Space for Well-Being. Cambridge Journal of Regions, Economy and Society, 5, 3-13.

Griffin, J. (2010). The Lonely Society. London: The Mental Health Foundation.

Hagerstrand, T. (1975). Survival and arena: on the life-history of indivduals in relation to their geographical environment. The Monadnock, 49(9-29).

Hassan, R. (1995). Suicide Explained: The Australian Experience. Melbourne: Melbourne University Press.

Havens, B., Hall, M., Sylvestre, G., and Jivan, T. (2004). Social Isolation and Lonliness: Differences between Older Rural and Urban Manitobans. Canadian Journal on Aging, 23(2), 129-140.

Hawkley, L. C., Burleson, M.H., Berntson, G.G., \& Cacioppo, J.T. (2003). Loneliness in everyday life: Cardiovascular activity, psychosocial context, and health behaviors. Journal of Personality \& Social Psychology, 85, 105-120.

Hawkley, L. C., Hughes, M.E., Waite, L.J., Masi, C.M., Thisted, R.A., and Cacioppo, J.T. (2008). From Social Structural Factors to Perceptions of Relationship Quality and Loneliness: The Chicago Health, Aging, and Social Relations Study. J Gerontol B Psychol Sci Soc Sci, 63(6), 375-384.

Heinrich, L. M., \& Gullone, E. (2006). The clinical significance of loneliness: A literature review. Clinical Psychology Review, 26, 695-718.

Holley, H. L. (1998). Geography and mental health: a review. Social Psychiatry and Psychiatric Epidemiology, 33, 535-542.

Hughes, M. E., Waite, L.J., Hawkley, L.C. and Cacioppo, J.T. (2004). A Short Scale for Measuring Loneliness in Large Surveys: Results From Two Population-Based Studies. Journal of Aging Research, 26(6), 655-672.

Hunt, J. (2013). Loneliness. Torrance: Aspire Press. 
Hymel, S., Tarulli, D., Hayden Thomson, L., Terrell-Deutsch, B. (1999). Loneliness through the eyes of children. In K. J. Rotenberg, \& Hymel, S. (Ed.), Loneliness in childhood and adolescence (pp. 80-106). New York: Cambridge University Press

Institute for Social and Economic Research. (2005). Unilever family report 2005: home alone? UK: Institute for Social and Economic Research.

Jones, J. (2001). The geography of mental health. Epidemiologia e Psichiatria Sociale, 10(4), 219-224.

Jong Gierveld, J., and Kamphuis, F. (1985). The development of a Rasch-type loneliness scale. Appl Psychol Meas, 9, 289-299.

Jong Gierveld, J., and Tilburg, T.G. (1999). Manual of the loneliness scale. Amsterdam: VU University.

Jong Gierveld, J., and Tilburg, T.G. . (2006). A six-item scale for overall, emotional and social loneliness: confirmative tests on new survey data. Journal of Aging Research, 28, 582-598.

Joppe, M. (2000). The Research Process. Retrieved January 28, 2015, from http://www.ryerson.ca/ mjoppe/rp.htm

Jose, P.E., \& Lim, B.T. (2014). Social Connectedness Predicts Lower Loneliness and Depressive Symptoms over Time in Adolescents. Open Journal of Depression, 3, 154163.

Jose, P. E., \& Pryor, J. (2010). Does social connectedness lead to great sense of well-being in New Zealand adolescents? Findings from The Youth Connectedness Project. Psychology Aotearoa, 2(2), 94-97.

Katsirikou, A., and Skiadas, C.H. (2010). Qualitative and Quantitative Methods in Libraries: Theory and Applications. Singapore: World Scientific.

Katz, J. E., \& Rice, R.E. (2002). Project Syntopia: Social Consequences of Internet Use. IT \& Society, 1(1), 166-179.

Kearns A., W. E., Tannahill C., and Ellaway, A.,. (2014). Loneliness, social relations and health and well-being in deprived communities. Psychology, Health and Medicine, 24, $1-13$.

Kerns, K. A. (1994). A developmental model of the relations between mother-child attachment and friendship. In R. Erber, and Gilmour, R. (Ed.), Theoretical frameworks for personal relationships (pp. 129-156). New Jersey: Lawrence Erlbaum Associates

Kraut, R., Patterson, M., Lundmark, V., Kiesler, S., Mukopadhyay, T., \& Scherlis, W. (1998). Internet paradox. A social technology that reduces social involvement and psychological well-being? The American Psychologist, 53(9), 1017-1031.

La Grow, S., Neville, S., Alpass, F., and Rodgers, V. (2012). Loneliness and self-reported health among older persons in New Zealand. Australasian Journal on Ageing, 31(2), 121-123. 
Laursen, B., and Hartl, A.C. (2013). Understanding loneliness during adolescence:

Developmental changes that increase the risk of perceived social isolation. Journal of Adolescence, 1-8.

Lester, L. J. (2012). Bullying and the transition from primary to secondary school. Edith Cowan University, Joondalup.

Liebau, E., and Chisholm, L. (1993). Youth, social change and education: issues and problems. Journal of Education Policy, 8(1), 3-8.

Livingston, M., Bailey, N., and Kearns, A. (2010). Neighbourhood attachment in deprived areas: evidence from the north of England. Journal of Housing and the Built Environment, 25(4), 409-427.

London's Local Government Association. (2012). Campaign to end Loneliness. London: Local Government Association.

Longley, P. A., Goodchild, M.F., Maguire, D.J., Rhind, D.W. (2005). Geographic Information Systems and Science (2nd ed.). New York: Wiley.

Macintyre, C. (2012). Bullying and Young Children: Understanding the issues and tackling the problem. Oxon: Routledge.

Marcoen, A., and Brumagne, M. (1985). Loneliness Among Children and Young Adolescents. Developmental Psychology, 21(6), 1025-1031.

Margalit, M. (2010). Lonely Children and Adolescents: Self-Perceptions, Social Exclusion, and Hope London: Springer Science \& Business Media.

Marshall, A. (2006). A critique of the development of quantitative methodologies in human geography RADSTATS Journal.

Mazalin, D., \& Moore, S. (2004). Internet Use, Identity Development and Social Anxiety Among Young Adults. Behaviour Change, 21(2), 90-102.

McWhirter, B. T. (1990). Loneliness: A Review of Current Literature, With Implications for Counseling and Research. Journal of Counseling \& Development, 69(4), 417-422.

Medora, N., \& Woodward, J.C. (1986). Loneliness among adolescent college students at a midwestern university. Adolescence, 21(82), 391-402.

Middleton, N., Whitley, E., Frankel, S., Dorling, D., Sterne, J., and Gunnell, D. (2004). Suicide risk in small areas in England and Wales, 1991-1993. Social Psychiatry and Psychiatric Epidemiology 39(1), 45-52.

Miller, P. H. (1993). Theories of developmental psychology. US: Worth Publishers.

Monbiot, G. (2014). The age of loneliness is killing us. Retrieved March 3rd, 2015, from http://www.theguardian.com/commentisfree/2014/oct/14/age-of-lonelinesskilling-us

Moody, E. J. (2001). Internet use and its relationship to loneliness. CyberPsychology and Behavior, 4(3), 393-401. 
Morrell, S., Taylor, R., and Slaytor, E. (1999). Urban and rural suicide differentials in migrants and the Australian-born, New South Wales, Australia 1985-1994. Social Science and Medicine, 49, 81-91.

Morrison, P. (2013). The Measurement of Regional Growth and Well-Being. Berlin: Springer Verlag.

Moustakas, C. (1961). Loneliness. New Jersey: Prentice-Hall.

Mukherji, P., \& Albon, D. (2009). Positivist Research Research Methods in Early Childhood: An Introductory Guide. London: SAGE Publications Ltd

Mullins, L. C., Elston, C.H., Gutkowski, S.M. (1996). Social Determinants of Loneliness Among Older Americans. Genetic, Social, \& General Psychology Monographs, 122, 453-473.

National Geographic. (2015). Location. Retrieved 19th Feburary, 2015, from http://education.nationalgeographic.com/education/encyclopedia/location/?ar_a= 1

Neto, F., \& Barros, J. (2000). Predictors of loneliness among adolescents from Portuguese immigrant families in Switzerland. Social Behavior and Personality and Social Psychology Bulletin, 28(2), 193-206.

Newman, K.S. (1988). Falling from Grace: Downward Mobility in the Age of Affluence. California: University of California Press.

Nie, N. H. (2001). Sociability, interpersonal relations and the Internet: Reconciling conflicting findings. American Behavioral Scientist, 45(3), 420-435.

Nie, N. H., Hillygus, D.S., \& Erbring, L. (2008). Chapter 7. Internet Use, Interpersonal Relations, and Sociability: A Time Diary Study. Oxford: Blackwell Publishers Ltd.

Office of the Prime Minister's Science Advisory Committee. (2011). Improving the Transition: Reducing Social and Psychological Morbidity During Adolescence. Auckland: Office of the Prime Minister's Science Advisory Committee.

Ouellette, M. (2001). The Social Network and Attachment Bases of Loneliness (Bachelor of Arts in Psychology ), University of Virginia, Virginia.

Packard, V. (1972). A nation of strangers. Philadelphia: McKay.

Page, R. M., \& Cole, G.E. (1991). Demographic predictors of self-reported loneliness in adults. Psychological Reports, 68, 939-945.

Parker, J. G., \& Seal, J. (1996). Forming, losing, renewing, and replacing friendships: Applying temporal parameters to the assessment of children's friendship experiences. Child Development, 67, 2248-2268.

Parks, M. R., \& Floyd, K. (1995). Making friends in cyberspace. Journal of Communication, 46, 80-97.

Peplau, L. A., and Perlman, D. (1982). Loneliness: A sourcebook of current theory research and therapy. New York: Wiley-Interscience. 
Perlman, D., Gerson, A.C., \& Spinner, B. (1978). Loneliness among senior citizens: An empirical report. Essence, 2(4), 239-248.

Perlman, D., \& Peplau, L.A. (1998). Loneliness. In H. S. Friedman (Ed.), Encyclopedia of mental health, Vol 2 (pp. 571-581). San Diego: Academic Press

Perlman, D., and Landolt, M.A. (Ed.). (1999). Examination of loneliness in childrenadolescents and in adults: Two solitudes or unified enterprise? Cambridge: Cambridge University Press.

Pierce, C. M. (1975). Poverty and racism as they affect children. In I. Berlin (Ed.), Advocacy for child mental health (pp. 92-109). New York: Brunner/Mazel

Pinquart, M., and Sorensen, S. (2001). Influences on loneliness in older adults: a metaanalysis. Basic and Applied Social Psychology, 23, 245-266.

Ponizovsky, A. M., and Ritsner, M.S. (2004). Patterns of loneliness in an immigrant population. Comprehensive Psychiatry, 45(5), 408-414.

Priyadarshini Das, P. P., \& Mishra, C. (2013). Adolescents' loneliness: effect of gender and internet use. Asian Journal of Research in Social Sciences and Humanities, 3(9), 233242.

Pro Bono Australia. (2013). New Technology to Map Areas of Mental Health Challenges. Retrieved 1st August, 2014, from http://www.probonoaustralia.com.au/news/2013/08/new-technology-map-areasmental-health-challenges\#sthash.1D48jqRt.dpuf

Putnam, R. D. (2001). Bowling Alone: The Collapse and Revival of American Community. New York: Simon and Schuster.

Rashid, R. (2004). “Loneliness Is Killing Me": Life Stories And Resilience Of Canadian Immigrant Women. University of Lethbridge.

Rogers, C. (1961). A Way of Being. New York: Houghton Mifflin Company.

Rokach, A. (2013). Loneliness Updated: Recent Research on Loneliness and how it Affects Our Lives. Oxon: Routledge.

Roscoe, B., and Skomski, G. G. (1989). Loneliness among late adolescents. Adolesence, 24(96), 947-955.

Rubenstein, C., Shaver, P., \& Peplau, L.A. (1979). Loneliness. Human Nature, 2, 58-65.

Rubenstein, C., and Shaver, P.R. (Ed.). (1982). The experience of loneliness. New York: WileyInterscience.

Russell, D., Peplau L., \& Cutrona, C.E. (1980). The Revised UCLA Loneliness Scale: Concurrent and Discriminant Validity Evidence. Journal of Personality and Social Psychology, 39, 472-480.

Russell, D. (1982). The measurement of loneliness. In L. A. Peplau, \& Perlman, D. (Ed.), Loneliness: A sourcebook of current theory, research and therapy. (pp. 81-104). New York: Wiley-Interscience 
Saks, M., and Allsop, J. (2012). Researching Health: Qualitative, Quantitative and Mixed Methods: SAGE.

Scharf, T., and De Jong Gierveld, J. (2008). Loneliness in Urban Neighbourhoods: An AngloDutch Comparison. European Journal of Ageing, 5(103-115).

Schmitz, C. L., Jacobus, C. S., Stakeman, C., Valenzuela, G. A., and Sprankel, J. (2003). Immigrant and refugee communities: Resiliency, trauma, policy, and practice. Journal of Religion \& Spirituality in Social Work: Social Thought, 22(2/3), 135-158.

Seepersad, S. S. (2010). Understanding loneliness using attachment and systems theories and developing an applied intervention. www.webofloneliness.com.

Shaver, P. R., and Mikulincer, M. (2002). Attachment-related psychodynamics. Attachment \& Human Development, 4(2), 133-161.

Shik, A. W. Y. (2003). Battling solitude: The experience of loneliness among Hong Kong Chinese immigrant youth., University of Toronto.

Smith, C. (2010). The New Zealand General Social Survey: Statistics New Zealand.

Spitz, R. A., \& Wolf, K. (1946). Anaclitic depression. Psychoanalytic Studies of the Child, 3(4), 85-120.

Statistics New Zealand. (2013). Loneliness in New Zealand: Findings from the 2010 NZ General Social Survey

Stoddard, T. L. (1932). Lonely America. New York: Charles Scribner's Sons.

The Auckland Council. (2012). Aucklanders 50 and over: A health, social, economic and demographic summary analysis of the life experiences of older Aucklanders. Auckland: The Auckland Council.

The Hindu. (2012). Man as a social animal. The Hindu.

The Social Report. (2010). Social Connectedness. In The Ministry of Social Development. (Ed.).

Thurlow, C., Lengel, L., \& Tomic, A. (2004). Computer Mediated Communication. London: SAGE Publications Ltd.

Tuli, F. (2010). The Basis of Distinction Between Qualitative and Quantitative Research in Social Science: Reflection on Ontological, Epistemological and Methodological Perspectives. Ethiopian Journal of Education and Sciences, 6(1), 97-108.

Twenge, J. M. (2006). Generation Me. New York: Simon and Schuster.

Twisk, J. W. R. (2013). Applied Longitudinal Data Analysis for Epidemiology: A Practical Guide. Cambridge: Cambridge University Press.

Valkenburg, P. M., and Peter, J. (2007). Online Communication and Adolescent Well-Being: Testing the Stimulation Versus the Displacement Hypothesis. Journal of ComputerMediated Communication, 12(4), 1169-1182. 
Van Tilburg, T. G., Havens, B., De Jong Gierveld, J. (2004). Loneliness among older adults in the Netherlands, Italy and Canada: a multifaceted comparison. Can J Aging, 23, 169180.

Victor, C., Burholt, V., \& Martin, W. (2012). Loneliness and ethnic minority elders in Britain: an exploratory study. Journal of Cross Cultural Gerontology, 27(1).

Victor, C., \& Bowling, A. (2012). A longitudinal analysis of loneliness among older people in Great Britain. The Journal of Psychology: Interdisciplinary and Applied, 146(3), 313331.

Victor, C. R., Scambler, S.J., Shah, S., Cook, D.G., Harris, T., Rink, E., and de Wilde, S. (2002). Has loneliness amongst older people increased? An investigation into variations between cohorts. Ageing and Society, 22, 585-597.

Victor, C. R., Scambler, S.J., Bowling, A., and Bond, J. (2005). The prevalance of, and risk factors for, loneliness later in life: a survey of older people in Great Britain. Ageing Soc, 25, 357-375.

Weeks, M. K. S. (2013). Gender, Loneliness, and Friendship Satisfaction in Early Adulthood: The Role of Friendship Features and Friendship Expectations. (Doctor of Philosophy), Duke University.

Weiss, R. (1973). Loneliness: The Experience of Emotional and Social Isolation. Cambridge: The MIT Press.

Wenz, F. V. (1977). Effects of seasons and sociological variables on suicidal behavior. Public Health Reports, 92, 233-239.

West, D. A., Kellner, R., \& Moore-West, M. (1986). The Effects of Loneliness: A Review of the Literature. Comprehensive Psychiatry, 27(4), 351-363.

Willgerodt, M. A., Miller, A.M. and McElmurry, B.J. (2002). Becoming bicultural: Chinese American women and their development. Health Care for Women International, 23(467-480).

Wiseman, H., Guttfreund, D.G., \& Lurie, I. (1995). Gender differences in loneliness and depression of university students seeking counselling. British Journal of Guidance \& Counselling, 23(2).

Wiseman, H., Mayseless, O., and Sharabany, R. (2004). Why are they lonely? Perceived quality of early relationships with parents, attachment, personality predispositions and loneliness in first-year university students. Personality and Individual Differences, 40, 237-248.

Wolak, J., Mitchell, K.J., and Finkelhor, D. (2003). Escaping or connecting? Characteristics of youth who form close online relationships. Journal of Adolescence Health, 26(1), 105119.

Wood, R. (1978). Fitting the Rasch model: A heady tale. British Journal of Mathematical and Statistical Psychology, 31, 27-32.

Zilboorg, G. (1938). Loneliness. The Atlantic Monthly, 161, 45-54. 